\author{
UNIVERSIDADE DE SÃO PAULO \\ ESCOLA DE ENGENHARIA DE SÃO CARLOS
}

GABRIEL COUTO MANTESE

Proposta de framework para a validação de indicadores de simbiose industrial empregando a modelagem baseada em agentes

Proposal of framework for the validation of industrial symbiosis indicators using agent-based modeling

São Carlos

2018 



\section{Proposta de framework para a validação de indicadores de simbiose industrial empregando a modelagem baseada em agentes}

Proposal of framework for the validation of industrial symbiosis indicators using agent-based modeling

Tese apresentada à Escola de Engenharia de São Carlos da Universidade de São Paulo, como requisito para a obtenção do título de Doutor em Engenharia de Produção.

Área de concentração: Processos e Gestão de Operações.

Orientador: Prof. Dr. Daniel Capaldo Amaral

Thesis presented to the Engineering School of São Carlos of the University of São Paulo, as a requisite to obtaining the title of Doctor in Production Engineering.

Concentration area: Process and Operation Management

Supervisor: Prof. Dr. Daniel Capaldo Amaral

São Carlos 


\begin{abstract}
AUTORIZO A REPRODUÇÃO TOTAL OU PARCIAL DESTE TRABALHO, POR QUALQUER MEIO CONVENCIONAL OU ELETRÔNICO, PARA FINS DE ESTUDO E PESQUISA, DESDE QUE CITADA A FONTE.
\end{abstract}

Ficha catalográfica elaborada pela Biblioteca Prof. Dr. Sérgio Rodrigues Fontes da EESC/USP com os dados inseridos pelo(a) autor(a).

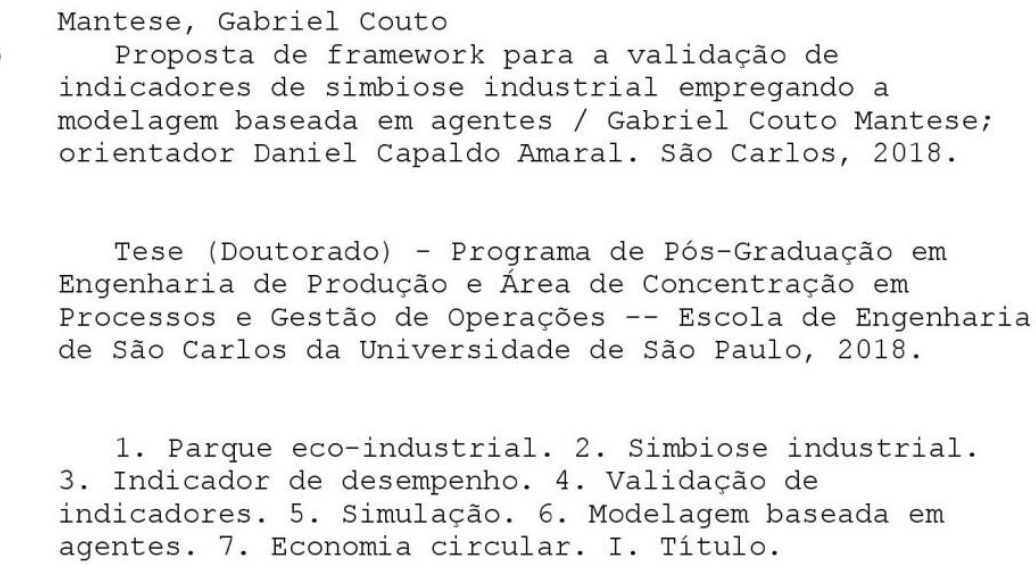

Eduardo Graziosi Silva - CRB - 8/8907 


\section{FOLHA DE JULGAMENTO}

Candidato: GABRIEL. COUTO MANTESE

Título da tese: Proposta de framework para a validação de indicadores de simbiose industrial empregando a modelagem baseada em agentes"

Data da defesa: 06/02/2018

\section{Comissão Julgadora:}

Resulfado:

Prof. Associado Daniel Capaldo Amaral (Orienłador)

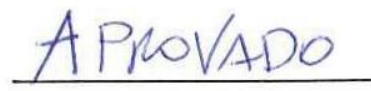

(Escola de Engenharia de São Carlos/EESC)

Prof. Associado Aldo Roberto Ometto

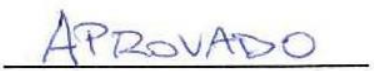

(Escola de Engenharia de São Carlos/EESC)

Prof. Dr. Sergio Luiz da Silva

(Universidade Federal de São Carlos/UFSCar - São Carlos)

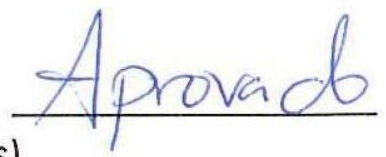

Prof. Dr. Luis Antonio de Santa Eulalia

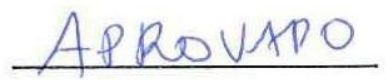

(Université de Sherbrooke/US - Canadá)

Prof. Dr. Frederico Yuri Hanai

XPROVADO

(Universidade Federal de São Carlos/UFSCar - São Carlos)

Coordenador do Programa de Pós-Graduação em Engenharia de Produção:

Prof. Associado Aldo Roberto Ometto

Presidente da Comissão de Pós-Graduação:

Prof. Associado Luis Fernando Costa Alberto 



\section{ACKNOWLEDGMENTS}

The author thanks São Paulo Research Foundation (FAPESP), through the grant \#2015/17192-5, for the funding support. The opinions, assumptions, and conclusions or recommendations expressed in this material are the responsibility of the author and do not necessarily reflect the view of FAPESP. 



\begin{abstract}
MANTESE, G. C. Proposal of framework for the validation of industrial symbiosis indicators using agent-based modeling. 2018. 243p. Tese (Doutorado) - Escola de Engenharia de São Carlos, Universidade de São Paulo, São Carlos, 2018.

Industrial symbiosis is crucial to the formation of the eco-industrial parks. Several performance indicators have been proposed for measuring and monitoring the industrial symbiosis. The current focus of researches is on the proposal of these indicators, while it is still necessary to validate them, so they can become more robust and reliable. However, there is no specific validation methodology for this type of indicator. The central objective of this research was to develop a methodology specific for the analysis of industrial symbiosis indicators. The work resulted in a framework for the validation of industrial symbiosis indicators with the differential of combining the conceptual validation, based on the technical and theoretical information on the indicator, and the empirical validation, based on the analysis of the indicated behavior. The framework is composed of a set of activities and artifacts that support all validation steps, which includes a set of specific validation criteria for industrial symbiosis indicators, and a simulation model developed through the agentbased modeling technique, which is able to simulate all the industrial symbiosis indicators available in the literature, allowing the comparison between them. The specific validation criteria were verified through the judgment of experts in the validation of an indicator, the Industrial Symbiosis Indicator; and the simulation model was proposed and used for the comparison between all the indicators, being possible to identify their characteristics in different scenarios. By combining the two strategies, a validation instrument with significant progress in relation to the state of the art is reached; it can support researches in the proposal of new indicators.
\end{abstract}

Keywords: Eco-industrial park, Industrial symbiosis, Performance indicator, Validation of indicators, Simulation, Agent-based modeling. 



\section{RESUMO}

MANTESE, G. C. Proposta de framework para a validação de indicadores de simbiose industrial empregando a modelagem baseada em agentes. 2018. 243p. Tese (Doutorado) - Escola de Engenharia de São Carlos, Universidade de São Paulo, São Carlos, 2018.

A simbiose industrial é fundamental para a formação dos parques eco-industriais. Vários indicadores de desempenho têm sido propostos para sua medição e acompanhamento. $O$ foco atual das pesquisas está na proposição desses indicadores e para que se tornem mais robustos e confiáveis faz-se necessário validá-los. Entretanto, não existe metodologia de validação específica para o caso desse tipo de indicador. O objetivo central dessa pesquisa foi desenvolver uma metodologia específica para analisar os indicadores de simbiose industrial. $O$ trabalho resultou em um framework para a validação de indicadores de simbiose industrial cujo diferencial é a combinação da validação conceitual, baseada nas informações técnicas e teóricas sobre o indicador, com a validação empírica, baseada na análise do comportamento do indicador. O framework é composto por um conjunto de atividades e artefatos que apoiam as etapas de validação. Destacam-se um conjunto de critérios de validação específicos para indicadores de simbiose industrial e um modelo de simulação desenvolvido através da técnica de modelagem baseada em agentes, que é capaz de simular todos os indicadores de simbiose industrial disponíveis na literatura, permitindo a comparação entre eles. Os critérios de validação específicos foram verificados por meio do julgamento de especialistas na validação de um indicador, o Indicador de Simbiose Industrial; e o modelo de simulação foi proposto e utilizado para a realização de uma comparação entre todos os indicadores, sendo possível identificar as características deles em diferentes cenários. Combinando as duas estratégias tem-se, portanto, um instrumento para validação com significativo avanço frente ao estado da arte e que poderá apoiar pesquisas na proposição de novos indicadores.

Palavras-chave: Parque eco-industrial, Simbiose industrial, Indicador de desempenho, Validação de indicadores, Simulação, Modelagem baseada em agentes. 



\section{TABLE OF CONTENTS}

CHAPTER I - GENERAL CONSIDERATIONS AND BACKGROUND .17

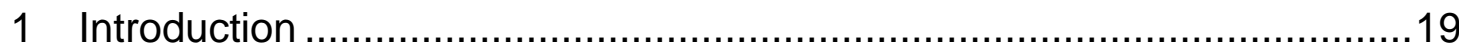

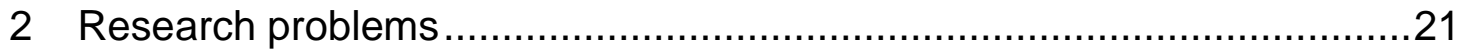

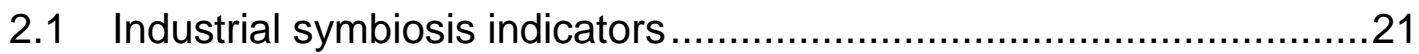

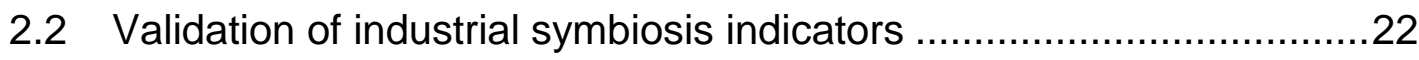

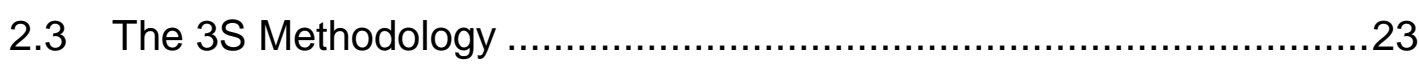

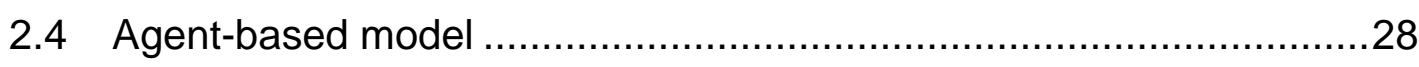

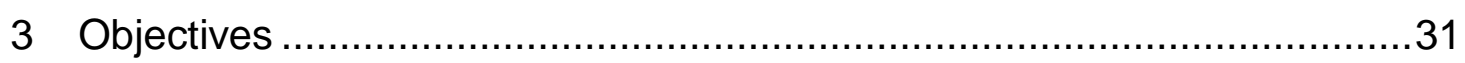

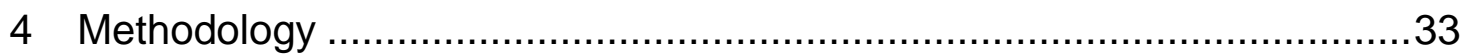

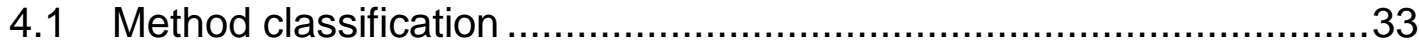

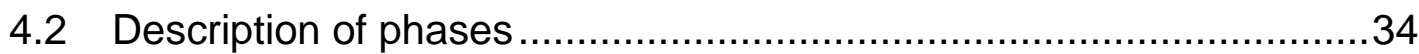

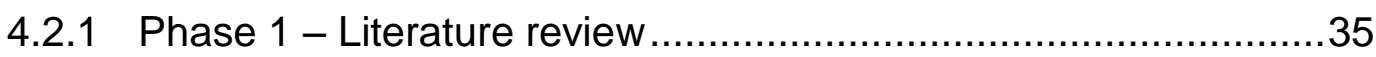

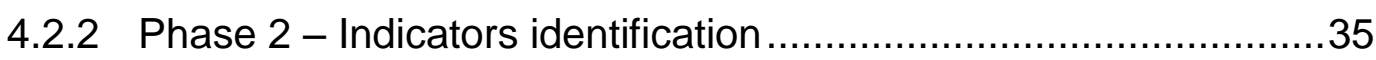

4.2.3 Phase 3 - Development of the specific validation criteria..............35

4.2.4 Phase 4 - Development of the simulation model .........................36

4.2.5 Phase 5 - Framework proposition ..............................................36

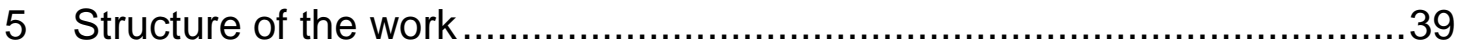

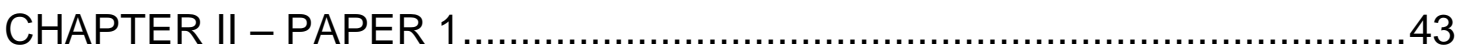

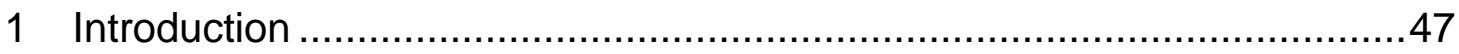

2 Eco-industrial parks and the industrial symbiosis.................................49

3 Evaluating industrial symbiosis indicators ...........................................51

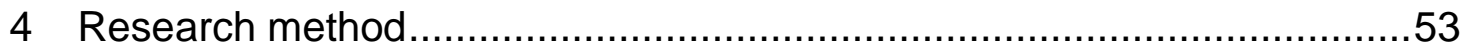

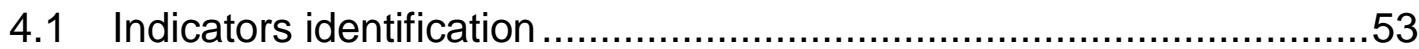

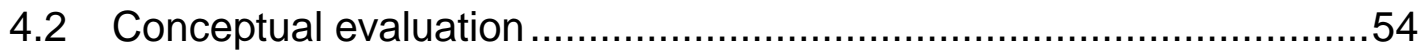

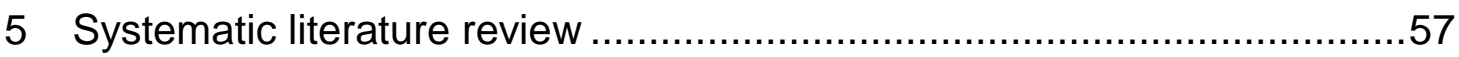

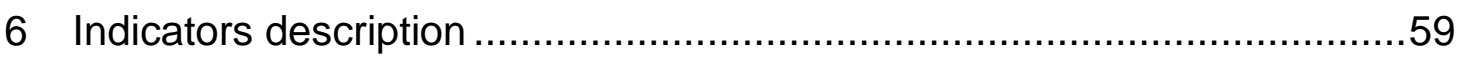

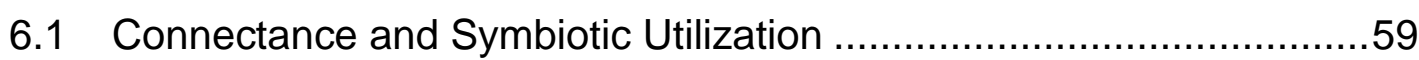

6.2 Eco-Connectance and By-product And Waste Recycling Rate ..........59

6.3 Industrial Symbiosis Index and Link Density ....................................60

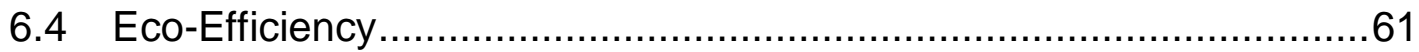

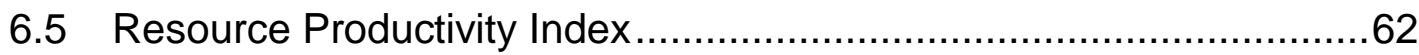

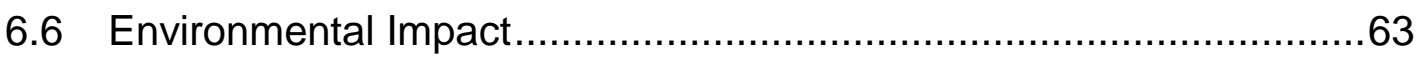




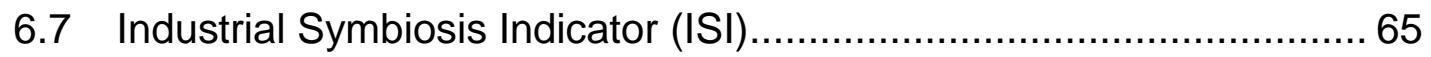

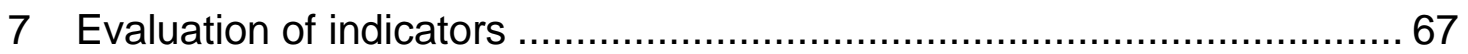

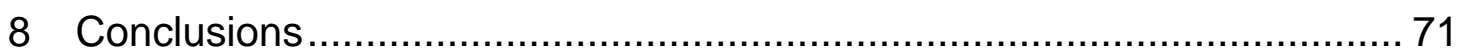

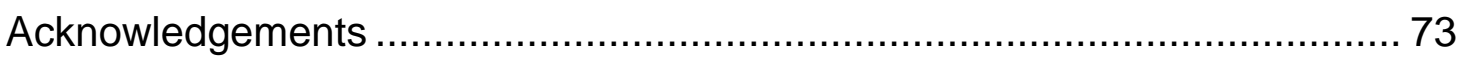

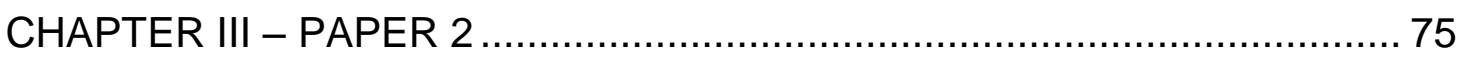

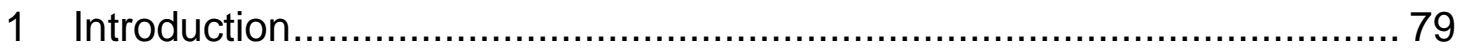

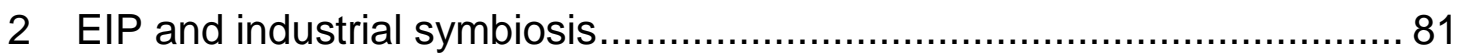

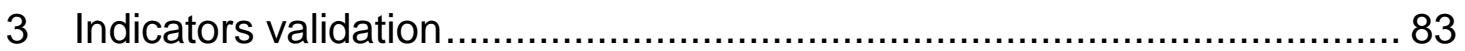

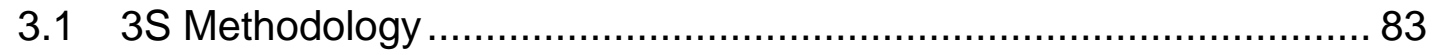

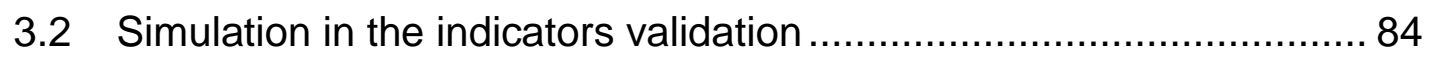

4 Proposal of a procedure to validate industrial symbiosis indicators combining simulation and the 3S Methodology .................................... 87

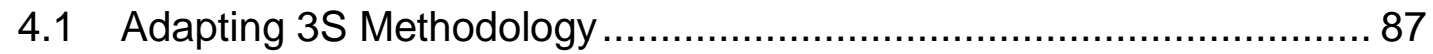

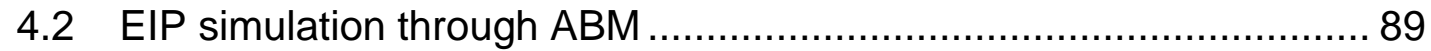

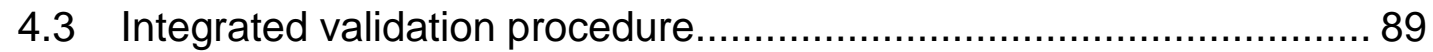

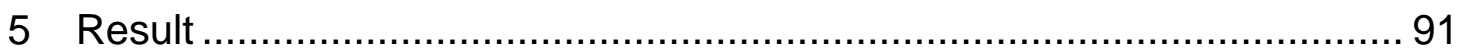

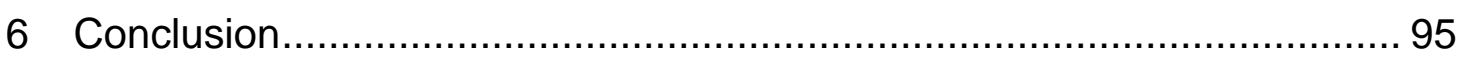

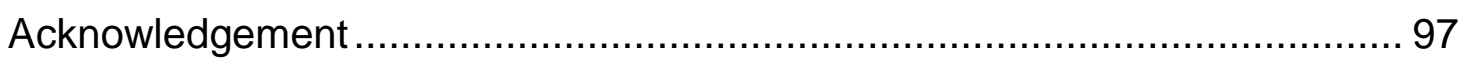

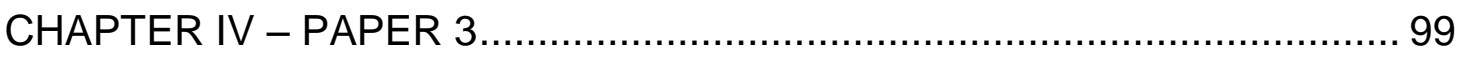

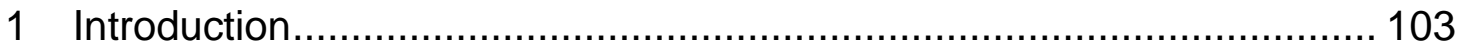

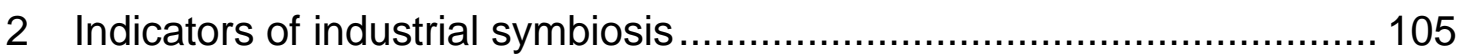

2.1 Industrial Symbiosis Indicator (ISI)............................................ 106

2.2 Eco-Connectance and By-Product And Waste Recycling Rate ....... 108

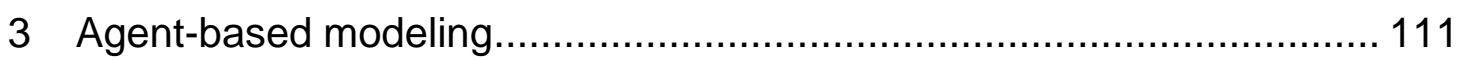

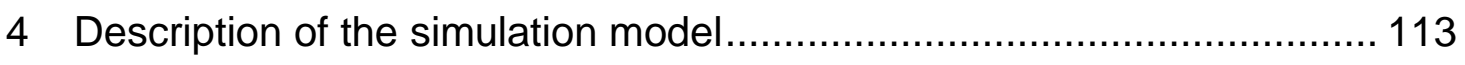

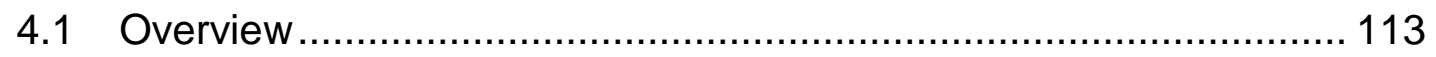

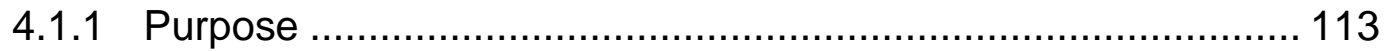

4.1.2 State variables and scales ................................................ 113

4.1.3 Process overview and scheduling .......................................... 115

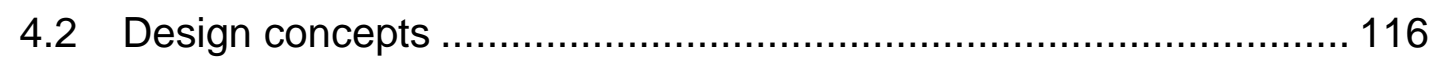

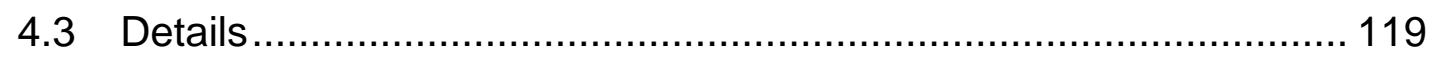

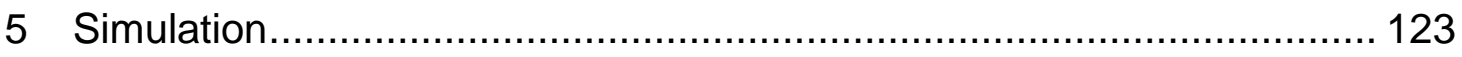

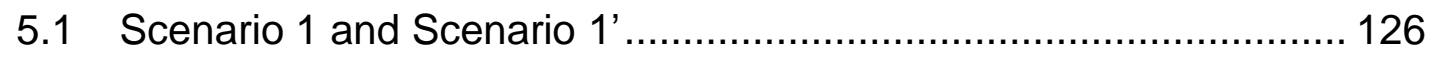

5.2 Scenario 2 and Scenario 2' ...................................................... 128 
5.3 Scenario 3 and Scenario 4 130

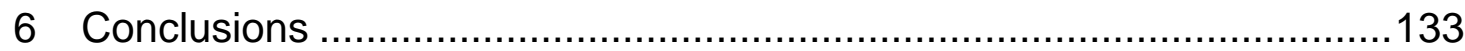

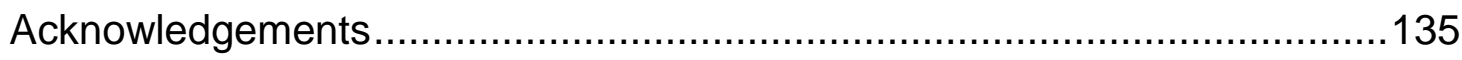

Appendix A - Submodels flowcharts ...................................................137

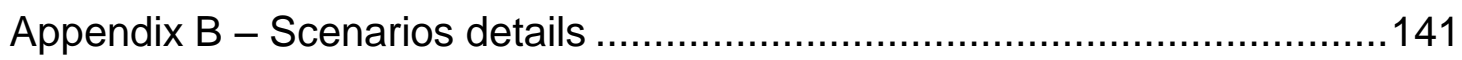

Appendix C - Downloading and using the EIPSymb ................................155

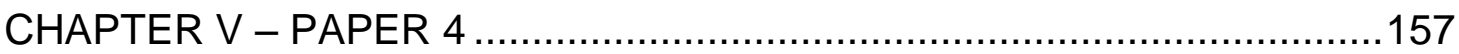

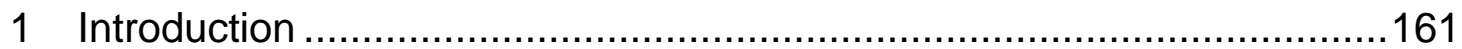

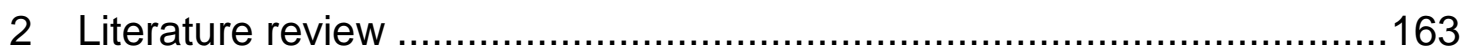

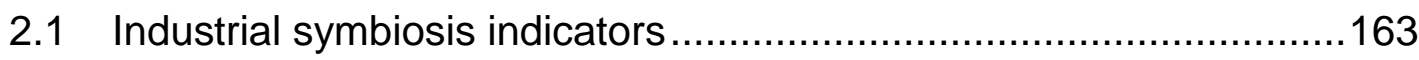

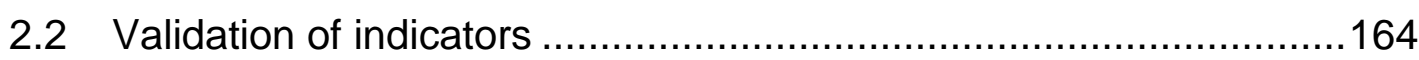

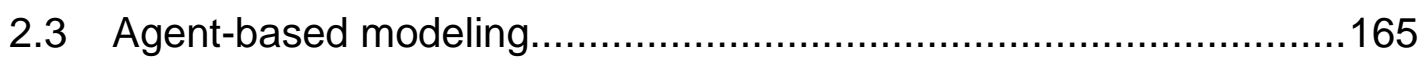

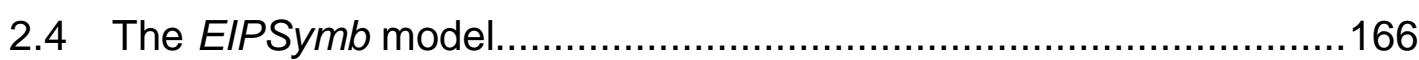

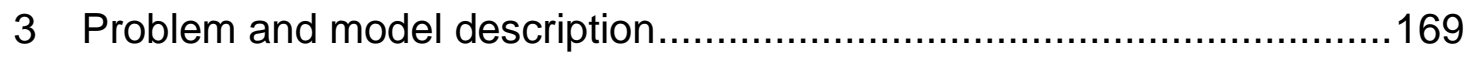

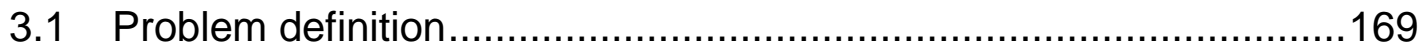

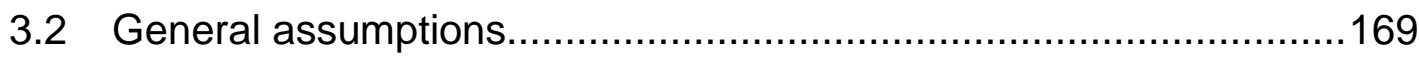

3.3 Assumptions for the calculation of the indicators...........................171

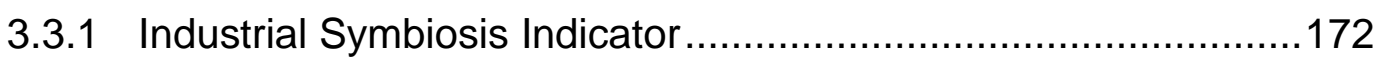

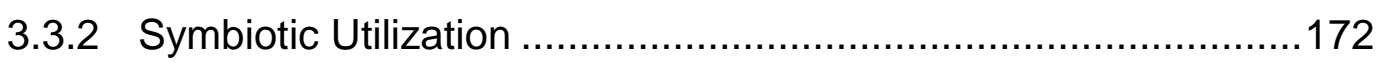

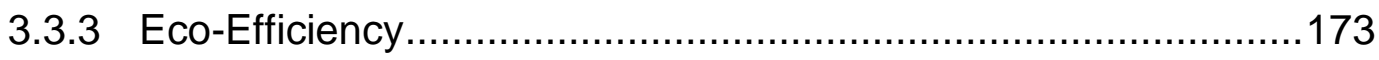

3.3.4 Resource Productivity Index ...................................................173

3.3.5 Environmental Impact.......................................................173

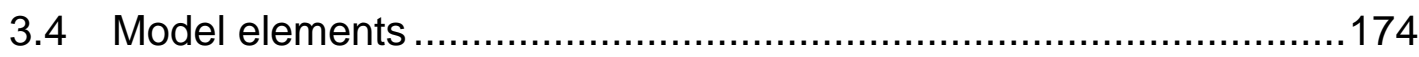

3.4.1 State variables and scales.................................................... 174

3.4.2 Process overview and scheduling .........................................174

3.4.3 Interaction and initialization .................................................. 175

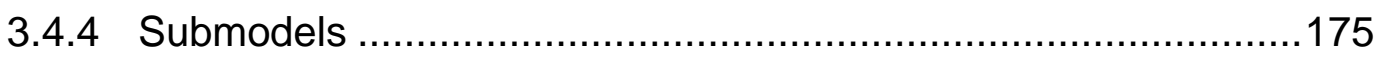

4 Scenarios for the industrial symbiosis indicators simulation...................177

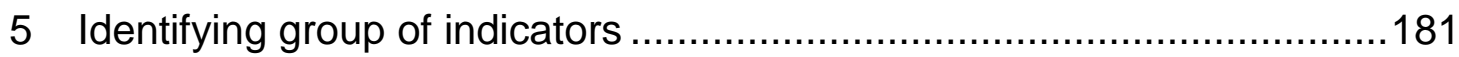

5.1 Amount of reused by-products indicators ....................................... 183

5.2 Percentage of reused by-products indicators .................................185

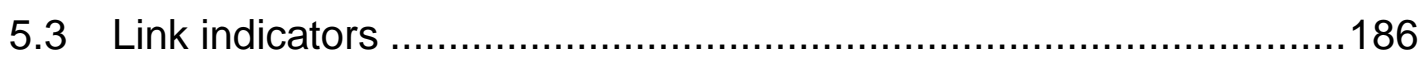

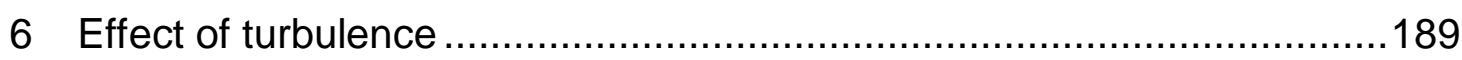

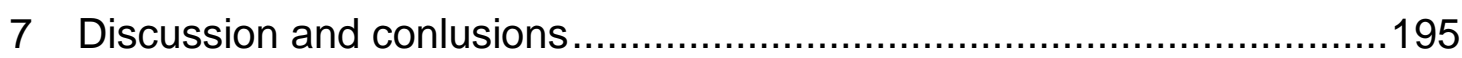


Acknowledgments

Appendix A - Downloading and using the EIPSymb\#2 ............................... 201

Appendix B - Mathematical description of the model parameters................ 203

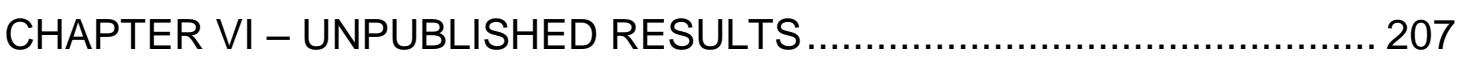

1 Application of the 3S Methodology using the specific criteria ................ 209

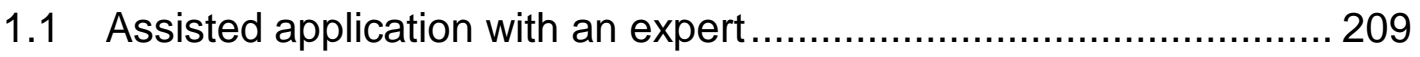

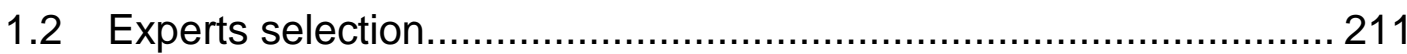

1.3 Application of the $3 S$ Methodology for the validation of the Industrial

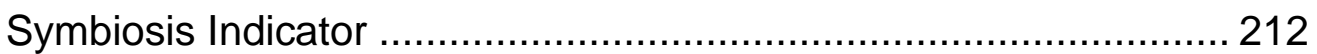

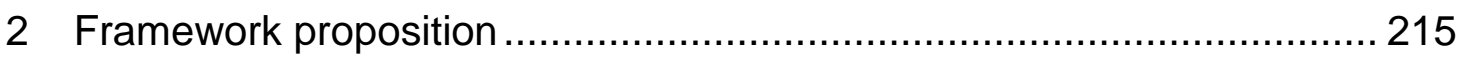

2.1 Development of the artifacts for operationalization ......................... 215

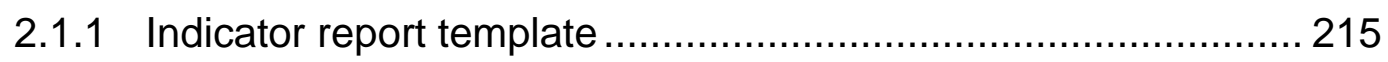

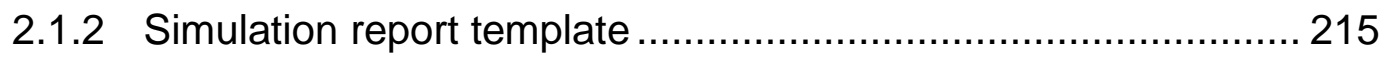

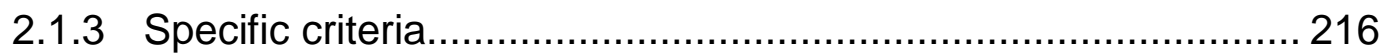

2.2 Development of the Framework concept .................................... 218

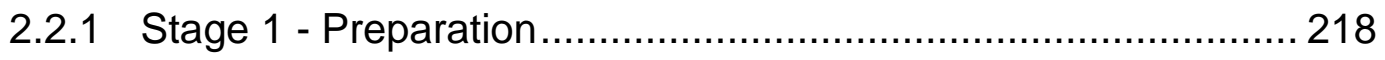

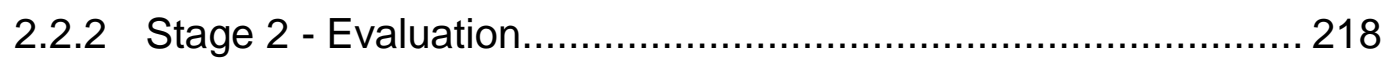

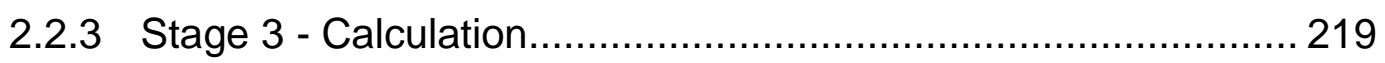

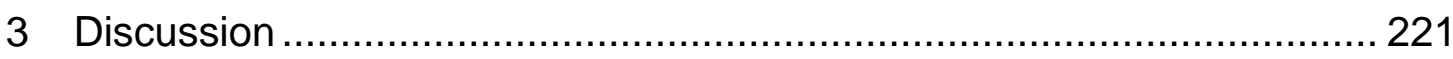

3.1 Industrial Symbiosis Indicator validation ........................................ 221

3.2 Application of the 3S Methodology using the specific criteria ......... 223

3.3 Framework for the validation of industrial symbiosis indicators ....... 224

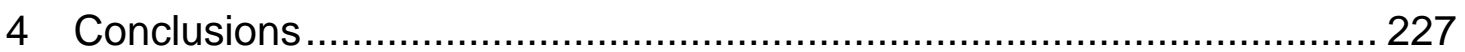

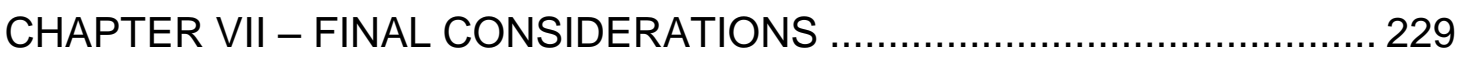

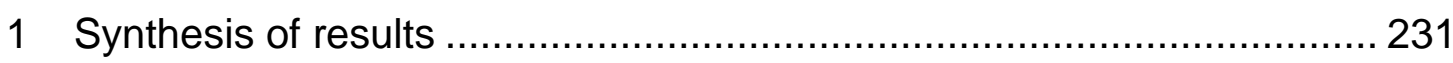

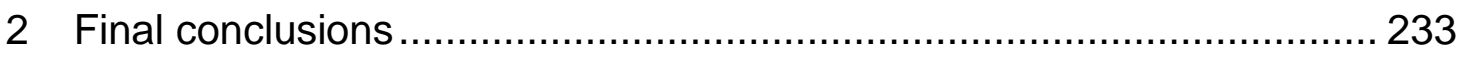

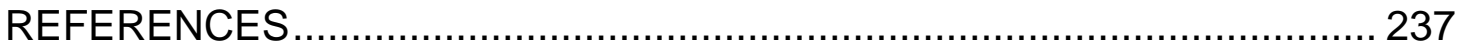


This work is presented through a collection of papers, so it was separated into chapters. This first chapter presents the initial considerations of the research, as the research problems and objectives. The results are then presented through four published papers, each presented in a chapter (from Chapter II to Chapter V). Chapter VI presents results not published and, finally, the Chapter VII presents the final considerations of the work, summarizing the results achieved with the four published papers and the unpublished results. 


\section{INTRODUCTION}

The concept of Eco-Industrial Park (EIP) originated in the early 1990s through the Indigo Development Institute (INDIGO DEVELOPMENT, 2006; LOWE, 2001). Since then, the interest in this type of industrial arrangement is increasing (VEIGA; MAGRINI, 2009; LOWE, 2001).

The industrial symbiosis is characterized by a better use of by-products and waste treatment and has a fundamental part for the EIPs formation. (CHERTOW, 1998; AGARWAL; STRACHAN, 2006; FELICIO et al., 2016). Encouraging the growth of industrial symbiosis in this type of industrial park is, therefore, of great importance to characterize it as an EIP. The researchers and professionals should find the means for the monitoring and measurement of its evolution so precisely as necessary.

Studies have been published using methods already known for the evaluation of industrial symbiosis networks in agglomerates of companies, as for example, Sokka et al. (2008), Bain et al. (2010), Wang et al. (2013), Wang et al. (2014) and Geng et al. (2014). Most of them use analyzes based on the Life Cycle Assessment and the Material Flow Analysis techniques to describe the interactions, which does not necessarily characterize the industrial symbiosis in the network.

In other works, such as Hardy and Graedel (2002), Tiejun (2010), Zhou et al. (2012), Gao et al. (2013), Park and Behera (2014) and Felicio et al. (2016), performance indicators to measure industrial symbiosis are proposed. However, according Park and Behera (2014), there is no universally accepted method or indicator. One of the problems in these approaches is the lack of instruments to analyze, compare and validate these indicators.

One way to ensure reliability to performance indicators is through their validation. According Bockstaller and Girardin (2003), the validation process has the purpose to verify if an indicator is scientifically designed, provides relevant information and is useful to its users. Still according the same authors, the validation can be conceptual, where information about the construction and use of the indicator are analyzed; or it may be empirical, where the indicator is analyzed through visual or statistical techniques and, in this case, needs to be applied (BOCKSTALLER; GIRARDIN, 2003). Finally, indicators can be validated in different ways: (i) through expert judgment; (ii) by comparing indicators that have the same purpose, but were 
constructed through different ways; (iii) through the application with real or simulated data (BOCKSTALLER; GIRARDIN, 2003).

It is available in the literature a methodology for the validation of environmental indicators in general, the $3 S$ Methodology of Cloquell-Ballester et al. (2006). It is a conceptual validation methodology based on the judgment of experts who analyze the indicator through established criteria.

This methodology has some limitations that hinder its application in industrial symbiosis indicators. The main one is about the validation criteria, which, because they are general, are not sufficient for the validation of this type of indicators. Another limitation is because it is just a conceptual validation, whereas an important aspect, the behavior of the indicator in different situations, is not verified.

The solution for this last aspect is the empirical validation. In practice, otherwise, this validation it would be required data from an EIP over a period of time to calculate the indicator and then be able to analyze its behavior. As access to actual data from an EIP was not possible for this research, a good solution is the generation of data through simulations of a fictitious EIP. In Bichraoui et al. (2013) and Romero and Ruiz (2014), the Agent-Based Modeling (ABM) technique is used to propose simulation models of an EIP, showing that simulation of an EIP is possible. In addition, Romero and Ruiz (2014) compared the ABM technique with System Dynamics, suggesting $A B M$ as the most appropriate technique for this purpose. However, the models proposed in these two studies did not include the calculation of performance indicators.

There are no tools capable of validating industrial symbiosis indicators, and then its development is necessary so it would be possible to provide recommendations on this type of indicators to the professionals in the area. The main research problem is how to create tools capable of supporting the validation of industrial symbiosis indicators, considering the complexity of testing the indicators in actual conditions and also promoting a wide validation.

Based on the main research problem, the central objective of this research program is to propose a Framework for the validation of industrial symbiosis indicators that considers aspects of both conceptual and empirical validations. 


\section{RESEARCH PROBLEMS}

This section shows the specific gap in each research area covered by this thesis. All these gaps contributed to the definition of the main problem.

\subsection{Industrial symbiosis indicators}

The definition of eco-industrial park used in this work is provided by the Indigo Development Institute:

(...) a community of manufacturing and service businesses located together on a common property. Member businesses seek enhanced environmental, economic, and social performance through collaboration in managing environmental and resource issues. By working together, the community of businesses seeks a collective benefit that is greater than the sum of individual benefits each company would realize by only optimizing its individual performance (INDIGO DEVELOPMENT, 2006).

As evidenced by Chertow (1998), Agarwal and Strachan (2006) and Felicio et al. (2016), industrial symbiosis is of extreme importance for the formation of an EIP. The concept of industrial symbiosis used is that presented by Lombardi and Laybourn (2012, pp. 31-32):

Industrial Symbiosis engages diverse organizations in a network to foster eco-innovation and long-term culture change. Creating and sharing knowledge through the network yields mutually profitable transactions for novel sourcing of required inputs, value-added destinations for non-product outputs, and improved business and technical processes.

Complementing the definition of industrial symbiosis, Chertow et al. (2008) stated that the symbiotic transactions can occur through 3 ways: (i) sharing of utilities and infrastructure; (ii) use of common services; (iii) exchange of by-products, where one company uses waste from another company as raw material.

According Chertow and Ehrenfeld (2012), an EIP should be considered as a dynamic system, where the park is a complex and adaptive environment, that is influenced by external factors (e.g. market conditions) and by internal factors (e.g. company strategies), and the system has the ability to self-organize. Industrial symbiosis is one of the ways by which an EIP can self-organize and reach a state of equilibrium even with the influences of external and internal factors (CHERTOW; EHRENFELD, 2012).

It is evident the importance of measuring and monitoring the evolution of industrial symbiosis in EIPs. The use of performance indicators is, according to 
Ramos and Caeiro (2010), one of the main approaches to sustainable development. Industrial symbiosis indicator is defined as the measure capable of quantifying, in an EIP, the industrial symbiosis resulting from the exchange of by-products and waste among the companies of the park. That is, the indicator should quantify the third type of symbiotic transaction presented by Chertow et al. (2008).

The effort to solve this problem produces a set of performance indicators that are already present in the literature for the measurement of industrial symbiosis. These indicators were searched and presented at Chapter II. However, there are no studies comparing these indicators, for example, showing their differences, advantages and disadvantages. The choice of which indicator to use and in what situation to use it becomes a difficult task.

Furthermore, these indicators require a careful evaluation, since it could result in damage to the environment. As stated by Rigby et al. (2001), while there is great interest in developing new performance indicators, little effort has been employed to validate them, can also be applied to the industrial symbiosis indicators.

\subsection{Validation of industrial symbiosis indicators}

The validation of a performance indicator aims to verify whether it was scientifically designed, whether the information provided is relevant and whether it is useful to its end users (BOCKSTALLER; GIRARDIN, 2003). More recent works have used this definition of Bockstaller and Girardin (2003) of validation of performance indicators (CLOQUELL-BALLESTER et al., 2006; BOCKSTALLER et al., 2009; AVELINE et al., 2009; HAK et al., 2012).

Still according Bockstaller and Girardin (2003) the validation of a performance indicator is divided into two stages, conceptual validation and empirical validation. While the former is based on data on the construction and use of the indicator, the empirical validation uses visual or statistical procedures to evaluate the behavior of the indicator (BOCKSTALLER; GIRARDIN, 2003).

Both kind of validation require a comparison standard or reference. The validation of indicators through the expert judgment is an always possible way (BOCKSTALLER; GIRARDIN, 2003). Bockstaller and Girardin (2003) also commented that validation can be done by comparing the indicator with indicators that have the same purpose, but were constructed through different ways, or even 
through the application of the indicator with real or simulated data (BOCKSTALLER, GIRARDIN, 2003).

However, there is no methodology that can be used for the specific validation of industrial symbiosis indicators. In the literature, the closest is the work of CloquellBallester et al. (2006), which proposes a methodology for the validation of environmental indicators in general, through the judgment of experts: the $3 \mathrm{~S}$ Methodology.

\subsection{The 3S Methodology}

The objective of the 3S Methodology is to guarantee quality, reliability and objectivity to indicators. It is based on expert judgment, consisting of 3 stages (CLOQUELL-BALLESTER et al., 2006):

- Self-validation - Performed by the work team that developed the indicator. Its main objective is to promote reflection on the indicator and avoid conceptual or operational inconsistencies;

- Scientific validation - Performed through the independent judgment of experts, that aim to grant accuracy and objectivity to the indicator;

- Social validation - Includes public participation. This stage is crucial in order to achieve consensus on the assessment of the environmental and social impacts.

The 3 stages are complementary, the credibility of the indicator submitted to the $3 S$ Methodology increases with its passage through the different stages of validation (CLOQUELL-BALLESTER et al., 2006). Figure 1 shows the steps to be performed for the validation of indicators through the $3 S$ Methodology. 


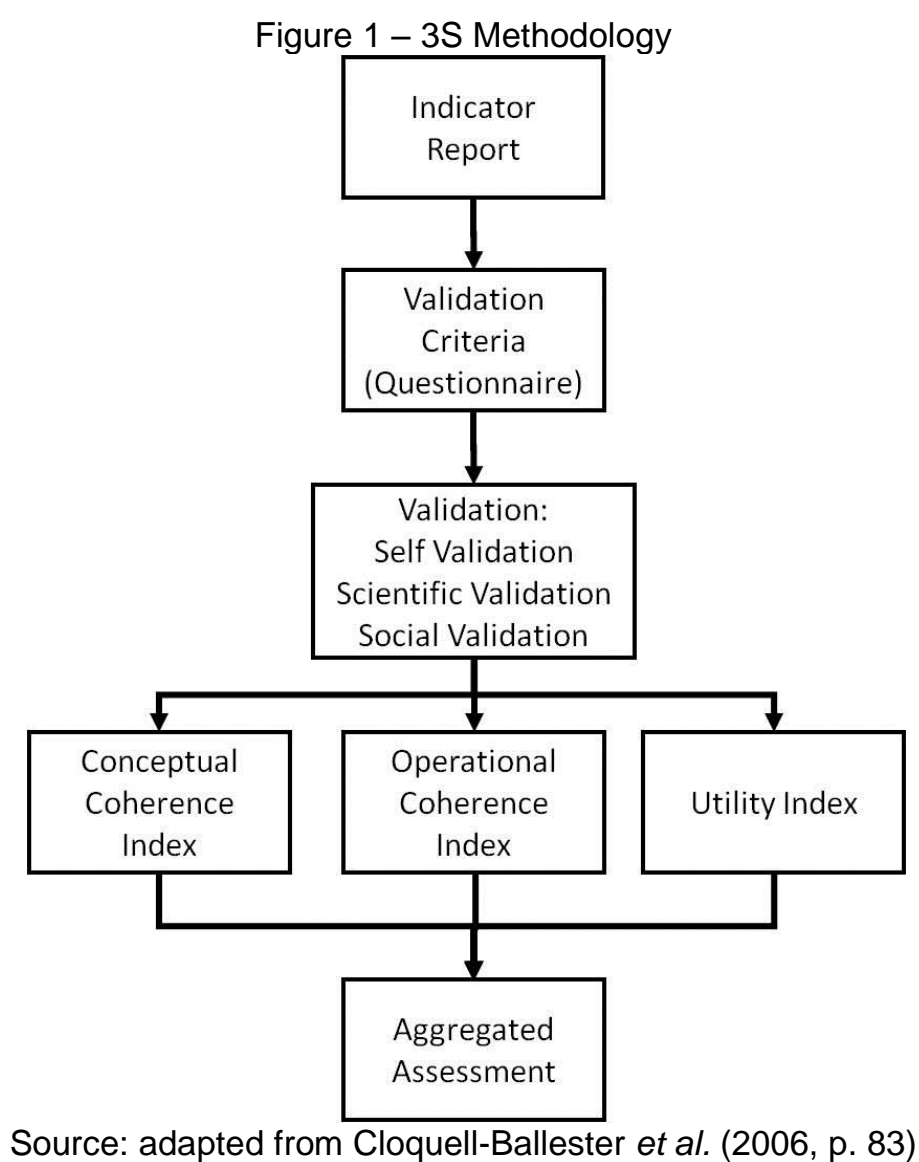

The Indicator Report should be prepared by the work team that developed the indicator and it will serve as a reference document, facilitating the assessment of the indicator (CLOQUELL-BALLESTER et al., 2006). Table 1 shows the minimum content that the indicator report should provide. 
Table 1 - Indicator Report

\begin{tabular}{ll}
\hline Guide for indicator report \\
\hline 1. Indicator & Name of the proposed indicator \\
\hline & $\begin{array}{l}\text { 2.1. Name of the environmental or social aspect (system } \\
\text { component) to be quantified through the indicator } \\
\text { 2.2. Description: description of the environmental or social } \\
\text { characteristic that represents the aspect }\end{array}$ \\
\hline
\end{tabular}

3.1. Conceptual definition: definition of the indicator and of the concepts and characteristics that it is made up of

3.2. Description of data and units: description of the data and units used to quantify the environmental aspect

3. Description 3.3. Operational definition: definition of the mathematical expression used to quantify the environmental aspect

3.4. Measuring method: details about sampling and/or measuring procedures followed by the indicator to be obtained. Possibility to reproduce and compare the measurement

4.1. Interpretation/meaning: Description of its interpretation and meaning through explanation of its operation

4. Justification

4.2. Accuracy: explanation of the indicator's accuracy and sensitivity to changes in the factor and security of both information and data

4.3. Relevancy: explanation of the indicator's relevancy to represent the characteristic that is to be quantified (aspect)

$\begin{array}{ll}\text { 5. Sources } & \text { Availability of data sources. Name of the documents and/or files } \\ \text { where the data comes from }\end{array}$

Source: adapted from Cloquell-Ballester et al. (2006)

Cloquell-Ballester et al. (2006) propose a hierarchy of criteria for the evaluation of the indicator, where each criterion may have different relative weights.

Table 2 shows the criteria proposed by the authors. 
Table 2 - Criteria for the indicators validation

\begin{tabular}{|c|c|c|c|}
\hline Criterion class & \multicolumn{2}{|l|}{ Criterion } & Question \\
\hline \multirow{3}{*}{$\begin{array}{l}\text { Conceptual } \\
\text { Coherence }\end{array}$} & \multicolumn{2}{|l|}{ Definition } & $\begin{array}{l}\text { The definition of the indicator and the } \\
\text { concepts that comprise it up is suitable }\end{array}$ \\
\hline & \multicolumn{2}{|l|}{ Relevance } & $\begin{array}{l}\text { There is a biunivocal correspondence } \\
\text { between the indicator and the factor to be } \\
\text { quantified }\end{array}$ \\
\hline & \multicolumn{2}{|c|}{ Interpretation/Meaning } & $\begin{array}{l}\text { The interpretation and meaning of the } \\
\text { indicator are suitable }\end{array}$ \\
\hline \multirow{4}{*}{$\begin{array}{l}\text { Operational } \\
\text { Coherence }\end{array}$} & \multicolumn{2}{|l|}{ Formulation } & $\begin{array}{l}\text { The mathematical formulation of the } \\
\text { indicator is suitable with regard to the } \\
\text { concept which is to be quantified }\end{array}$ \\
\hline & \multicolumn{2}{|c|}{ Data and Units } & $\begin{array}{l}\text { The data used to establish the indicator } \\
\text { and its units are suitable }\end{array}$ \\
\hline & \multicolumn{2}{|c|}{ Measuring Method } & $\begin{array}{l}\text { The proposed measurement procedures to } \\
\text { obtain the indicator are suitable, allowing } \\
\text { for its reproduction and comparison }\end{array}$ \\
\hline & \multicolumn{2}{|c|}{ Accuracy/Sensitivity } & $\begin{array}{l}\text { The indicator accuracy is suitable to } \\
\text { quantify the factor and it is sensitive to } \\
\text { changes in the latter }\end{array}$ \\
\hline \multirow{5}{*}{ Utility } & \multirow[b]{2}{*}{ Reliability } & Indicator & The indicator reliability is suitable \\
\hline & & Sources & $\begin{array}{l}\text { The reliability of the source of data which } \\
\text { the indicator is made up of is suitable }\end{array}$ \\
\hline & \multicolumn{2}{|c|}{ Availability/Applicability } & $\begin{array}{l}\text { The accessibility to the data and the } \\
\text { applicability of the indicator are suitable }\end{array}$ \\
\hline & \multirow{2}{*}{ Information } & Security & $\begin{array}{l}\text { The information provided by the indicator } \\
\text { may be catalogued as reliable }\end{array}$ \\
\hline & & Cost & $\begin{array}{l}\text { The cost of the information offered by the } \\
\text { indicator can be considered acceptable }\end{array}$ \\
\hline
\end{tabular}

The validation process itself, step three, is performed so that each expert assigns a grade for each question representing each criterion. These grades are assigned using the Likert scale of 5 levels (CLOQUELL-BALLESTER et al., 2006). The standard deviation of the scores for each criterion assigned by the different experts must be less than 1; if the standard deviation is greater than 1 it will be necessary to perform iterations through the Delphi technique until consensus is reached and the standard deviation is smaller than the unit (CLOQUELLBALLESTER et al., 2006). The experts should also provide weights for each criterion, where the AHP (Analytic Hierarchy Process) technique can be used (CLOQUELLBALLESTER et al., 2006).

Then, through the weights and grades assigned to each criterion, it is possible to obtain the value of the three indexes (Conceptual Coherence, Operational 
Coherence, Utility) and then aggregate them to obtain the final grade of the indicator (CLOQUELL-BALLESTER et al., 2006). This aggregation, according CloquellBallester et al. (2006), should satisfy the three requirements: (i) allow the classification of the indicator in different groups; (ii) avoid the value compensation; (iii) solve the exact boundary problem. The Electre TRI technique, by Mousseau (1999), according to Cloquell-Ballester et al. (2006), is the most indicated, however, different techniques can be used, including the weighted sum.

Conceptual Coherence determines the relationship between the indicator and the object of measurement; Operational Coherence determines whether the internal operations of the indicator are correct; and Utility determines the applicability of the indicator (CLOQUELL-BALLESTER et al., 2006). These indexes are in accordance with the conditions necessary for an indicator to be validated according Bockstaller and Girardin (2003) (CLOQUELL-BALLESTER et al., 2006).

Cloquell-Ballester et al. (2006) propose the following classification for the Aggregated Assessment:

- More than 4.5: Validated;

- Between 3.5 and 4.5: A brief review is required;

- Between 2.5 and 3.5: A thorough review is required;

- Less than 2.5: Unacceptable, redefine.

Although 3S Methodology is a validation methodology for environmental indicators in general, it is insufficient to be applied specifically in industrial symbiosis indicators, due to two main reasons.

The first reason is in relation to the evaluation criteria. The authors' proposal have general criteria that were elaborated for any environmental indicator. As, for example: "The definition of the indicator and the concepts that comprise it up is suitable". It is a type of questioning that could work for specific and one-dimensional indicators such as the amount of oxygen in the water. The industrial symbiosis phenomenon, however, is more abstract and its measurement can lead to different interpretations among the experts, which brings error to the analysis if this criterion is presented to the experts. Therefore, according to the analysis described in Chapter IV, the criteria were considered superficial, too much embracing and even repetitive.

The second reason is related to the complexity and novelty of the industrial symbiosis indicators, which require different types of data, from different sources, and 
arranged in a time series. This aspect hinders the use of data from real industrial plants, being a barrier to empirical validation. Observing the formula or value of the indicators over a period of time also becomes insufficient and the experts would need to give their opinion on data series rather than specific values or examples.

Moreover, because they are relatively new indicators and no cases of applications in real EIPs have been reported, little is known about their behavior in different conditions, and it is necessary to incorporate aspects of the empirical validation in the evaluation of this type of indicators, besides only using the judgment of experts about the technical information on the indicator, as does 35 Methodology.

The analysis of the $3 \mathrm{~S}$ Methodology is presented in Chapter III.

\subsection{Agent-based model}

An alternative identified during this research program is to simulate the industrial symbiosis indicators. Simulation allows to analyze the behavior of these indicators through different scenarios, subjecting them to different situations, where they can be stressed in distinguished ways so it is possible to verify their behaviors. This option becomes stronger when compared to the alternative of applying the indicators in situations of real industrial parks, because actual data are difficult to access and, even if accessed, would not satisfy all conditions faced by indicators. The use of real data would difficult researchers from observing the responses of the indicators in extreme conditions.

Romero and Ruiz (2014) have identified System Dynamics and Agent-Based Modeling techniques as the most likely options for modeling an EIP. After a comparison between the two different approaches they chose ABM as the most appropriate technique. In addition, some authors have discussed the applicability of ABM in the field of ecology (WILENSKY; RAND, 2015; GRIMM; RAILSBACK, 2013) and in the field of organizational systems (WILENSKY; RAND, 2015).

The ABM makes it possible to represent an EIP (complex system) through the modeling of the companies that constitute it (agents), verifying the behavior resulting from the interactions between the companies (industrial symbiosis) and the companies with the external environment.

The ABM technique is defined by Gilbert (2008) as a method that allows the creation, analysis and experimentation through models composed by agents that 
interact within an environment. It is useful for the understanding of complex systems of diverse areas, including the areas of social sciences, natural sciences and engineering (WILENSKY; RAND, 2015). One of the main advantages of the ABM is that it is not necessary to represent the entire system, but only its individual agents, so, it is possible to understand the dynamics that result from the interaction of the agents with each other and with the environment (RAILSBACK, GRIMM, 2011).

There are studies that have already used ABM for modeling an EIP, such as Bichraoui et al. (2013), where the EIP model was created with the focus on understanding the conditions of cooperation and learning. And the work of Romero and Ruiz (2014), where an EIP model was proposed to assess the potential of symbiotic relationships between companies and evaluate the overall EIP operation in different scenarios. However, these studies do not apply the proposed simulation models for the simulation of the industrial symbiosis indicators, so it is necessary to develop a new model for this purpose.

The reasons for choosing the agent-based modeling technique are described in more detail in Chapter IV. 


\section{OBJECTIVES}

The central objective of this research is to propose a Framework for the validation of industrial symbiosis indicators that considers aspects of both conceptual and empirical validations through agent-based simulation. This objective is deployed in specific objectives:

- Identify the industrial symbiosis indicators available in the literature;

- Analyze the limitations and positive aspects of 3S Methodology, identifying possible contributions in order to promote the conceptual validation of industrial symbiosis indicators;

- Propose a simulation model of EIPs that considers the calculation of industrial symbiosis indicators;

- Evaluate and analyze the industrial symbiosis indicators, comparing them to each other. 


\section{METHODOLOGY}

This section describes the classification of the research method according to the objectives. Then it presents the phases, with the respective scientific procedures adopted, to reach these objectives.

\subsection{Method classification}

The classification of the method used in this research is hypotheticaldeductive. The hypothetical-deductive method, according Marconi and Lakatos (2003) is understood through the scheme presented in Figure 2

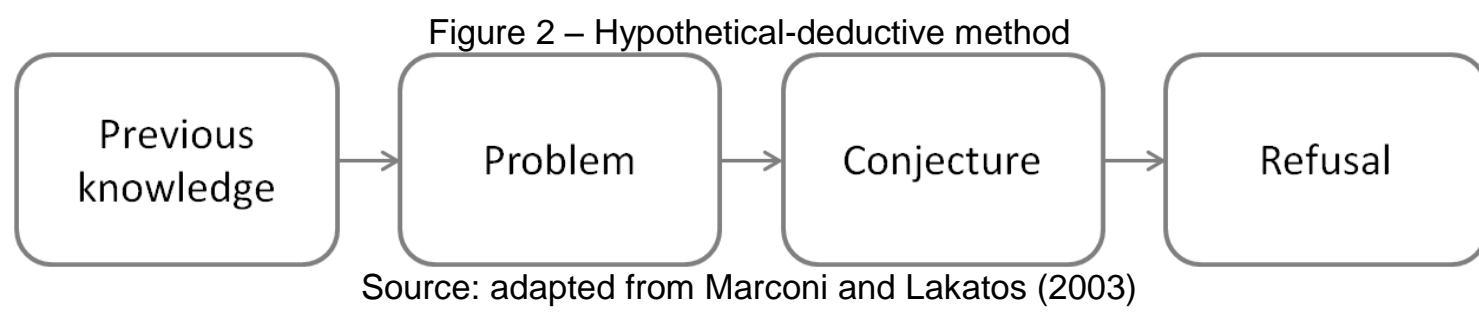

In the case of this research the "Previous knowledge" is mainly the theory about the validation of indicators. The "Problem" identified is that with the "Previous knowledge" it is not possible to validate the industrial symbiosis indicators. Therefore, as "Conjecture", it is proposed the Framework for the validation of industrial symbiosis indicators. Finally, the "Refusal", which according Marconi and Lakatos (2003) aims to refute the "Conjecture", is not carried out in this research, since the proposed Framework has not been refuted yet; on the contrary, the structures that compose the Framework are utilized to prove its usefulness.

Regarding the approach, it is a qualitative research, since it considers qualitative data (DALFOVO et al., 2008), has focus on interpretation and not on quantification, emphasis on subjectivity, flexibility in the research process, process orientation, concern with the context and recognition of the impact of the research process on the research (CASSEL; SYMON ${ }^{1}, 1994$ apud DALFOVO et al., 2008).

The nature of this research is applied, since it aims to generate knowledge for the solution of specific problems (GERHARDT; SILVEIRA, 2009), in the case of this research, the Framework for the validation of industrial symbiosis indicators.

${ }^{1}$ CASSELL, C.; SYMON, G. Qualitative methods in organizational research. London: Sage Publications, 1994. 
With respect to the objectives, this research is partly exploratory and partly prescriptive. It is exploratory, because in the first moment it aims to be more familiar with the research problem (GIL 2007 apud GERHARDT; SILVEIRA, 2009), which in the case of this work is the lack of tools for the validation of industrial symbiosis indicators, thus the concepts and tools related to the validation of indicators in general are explored, as well as the existing industrial symbiosis indicators. It is also prescriptive, since its central objective is proposing a solution (BONAT, 2009): the Framework for the validation of industrial symbiosis indicators.

Finally, this work is not conducted through the application of a single research procedure, but rather by a combination that configure a Research Program. The following section details what procedures and tools were used in each phase of the research.

\subsection{Description of phases}

The phases for the development of the research are directly related to the specific objectives. Figure 3 shows the phases and then each one is detailed. The workflow through the phases is almost entirely linear, with the exception of Phase 3 and Phase 4, held simultaneously.

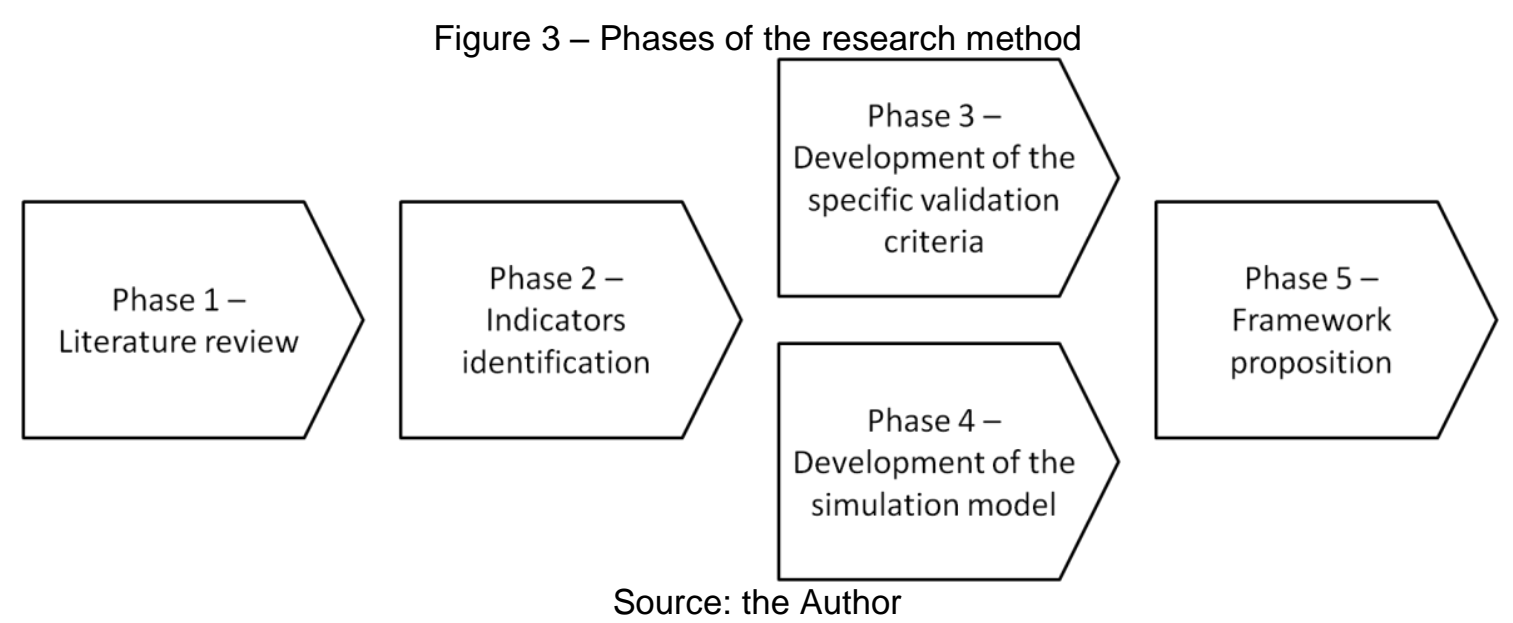

${ }^{2}$ GIL, A. C. Como elaborar projetos de pesquisa. 4. ed. São Paulo: Atlas, 2007. 


\subsubsection{Phase 1 - Literature review}

The literature review, according Fonseca (2002), aims to raise the theoretical references on the topic of study, allowing the researcher to know what has already been studied in this area.

The themes inherent to the research are studied, such as EIP, industrial symbiosis, performance indicators, validation of indicators, and agent-based modeling. It was at this stage that the 3S Methodology, by Cloquell-Ballester et al. (2006) was identified. The following areas of knowledge were studied:

- Industrial symbiosis indicators. A literature review on indicators was carried out, which allowed identifying the fundamental concepts on the theme. This is mainly presented in Chapter II (Paper 1)

- Validation of environmental indicators. The methods and papers published on validation of environmental indicators in general, as well as the validation of industrial symbiosis indicators were reviewed. This theme is mainly explored in the Chapter II (Paper 1) and in the Chapter III (Paper 2).

- Agent-based modeling applied to industrial symbiosis indicators. The applications of $A B M$ in the area of industrial symbiosis were studied and analyzed. Chapter IV (Paper 3) and Chapter V (Paper 4) presents details about this area.

\subsubsection{Phase 2 - Indicators identification}

In this phase the industrial symbiosis indicators available in the literature are identified. The indicators are also qualitatively compared.

It is performed a Systematic Literature Review, which consists of a literature review conducted in a systemic manner, where objective, systematic method of searching and the analysis of results are predefined (CONFORTO et al., 2011). It was used the procedure proposed by Conforto et al. (2011), called RBS Roadmap. The search parameters and results are described in Chapter II (Paper 1).

\subsubsection{Phase 3 - Development of the specific validation criteria}

Specific validation criteria for industrial symbiosis indicators are proposed. The criteria of the $3 S$ Methodology are used as a base, in addition to the knowledge on 
performance indicators and on industrial symbiosis acquired in Phase 1. The criteria developed were presented in Chapter III (Paper 2) and were improved at the end of the research, becoming the criteria obtained and described in Chapter VI (Unpublished results). In this final stage, these criteria were verified by experts and incorporated into the validation framework proposed.

\subsubsection{Phase 4-Development of the simulation model}

It is proposed a simulation model capable of representing a fictitious EIP and its symbiotic interactions, where the industrial symbiosis indicators are calculated within different scenarios. The simulation model is used to perform a benchmarking between the indicators identified in Phase 2.

Simulation is defined by Leal (2003) as the activity of imitating a real procedure, allowing the study of what could happen; it is possible to obtain results more easily than through an analytical method (STRACK, 1984), and to verify the effects in the studied system with different variations in the environment (MOREIRA, 2001).

It is used the ABM technique and the NetLogo platform to create this model. ABM allows the creation, analysis and experimentation through models composed of agents that interact within an environment (GILBERT, 2008). And the NetLogo platform is a free tool that consists of a programming environment that uses the $A B M$ technique for the simulation of complex natural and social phenomena (NETLOGO, 2017).

Chapter IV (Paper 3) presents the conceptual foundation for the application of $A B M$ in the validation of indicators and describes the functioning of the simulation model. Chapter V (Paper 4) describes the results of applying the model in the comparison of industrial symbiosis indicators identified in the literature.

\subsubsection{Phase 5 - Framework proposition}

In the last phase the Framework for the validation of industrial symbiosis indicators is proposed. The framework is the result of the combination of the specific criteria proposed in Phase 3, with the simulation model developed in Phase 4. 
The knowledge accumulated in the previous phases was used to elaborate this framework composed by 3 stages and that includes specific artifacts for the professionals who wish to carry out the evaluation. The artifacts are:

- Templates. The framework contains document templates, such as the Indicator report and the Simulation report.

- The model for the simulation of industrial symbiosis indicators, proposed in Chapter IV (Paper 3) and used in Chapter V (Paper 4).

- The set of criteria for the evaluation of the indicators by the experts.

These results are presented in Chapter VI (Unpublished results). 


\section{STRUCTURE OF THE WORK}

This work was developed through a collection of papers. Four published papers plus a chapter with unpublished results are used to describe the development of the method and the achievement of the central objective and the specific objectives. The papers and the unpublished results are presented as different chapters in this document.

The first paper, Paper 1 , is present in Chapter II. The paper is entitled "Identification and qualitative comparison of performance indicators of industrial symbiosis". It addresses the identification of industrial symbiosis indicators available in the literature through a systematic literature review. It is also performed a qualitative comparison between the indicators in order to verify their differences and similarities.

Paper 2, available in Chapter III, is entitled "A procedure to validate industrial symbiosis indicators combining conceptual and empirical validation methods". Two main results are presented: (i) the proposal of specific criteria for the validation of industrial symbiosis indicators; and (ii) the proposal of an idea of procedure for the validation of industrial symbiosis indicators combining aspects of conceptual validation and empirical validation. Both contributions are only proposals; no applied work was conducted.

The next paper, the Paper 3, is entitled "Comparison of industrial symbiosis indicators through agent-based modeling", and it is available in Chapter IV. It is presented the development, through the ABM technique, of a simulation model for the representation of an EIP. As a way of demonstrating the use of the model, three indicators, the Industrial Symbiosis Indicator, by Felicio et al. (2016), and the indicators proposed by Tiejun (2010), are simulated in different scenarios.

Paper 4 is presented in Chapter V and is entitled "Agent-based simulation to evaluate and categorize industrial symbiosis indicators". The simulation model proposed in Paper 3 (Chapter IV) is used as a tool for the comparison between the industrial symbiosis indicators. For that, the simulation model was advanced in order to consider more complex scenarios and to consider all the industrial symbiosis indicators available in the literature that was identified in Paper 1 (Chapter II).

Finally, the unpublished results are presented in Chapter VI. This chapter presents the final result of the research, that is the Framework for the validation of 
industrial symbiosis indicators. Before presenting the framework, the specific criteria, proposed in Paper 2 (Chapter III), are updated and applied in the validation of the Industrial Symbiosis Indicator as a way of demonstrating its usefulness. The Framework is composed of the combination of the simulation model proposed in Paper 3 (Chapter IV) and that was improved in Paper 4 (Chapter V) and the specific validation criteria. Furthermore, the framework is based on the idea of validation procedure presented in Paper 2 (Chapter III).

Figure 4 shows the relationship between each paper, and the unpublished results, and the objectives and method phases.

The papers contain contributions to the literature review, the Section 2 of this chapter presented only a synthesis of the most important terms. Figure 5 summarizes the contribution of each paper in relation to the literature review inherent to the research. 
Figure 4 - Relationship between papers, objectives and phases

Objective of the paper (or unpublished results)

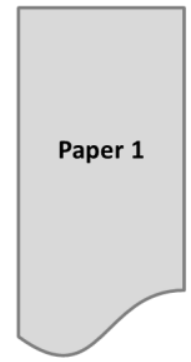

Identify and list the industrial

symbiosis indicators available in the literature.

Compare the indicators and qualitatively evaluate them.

Select the best industrial symbiosis indicator.

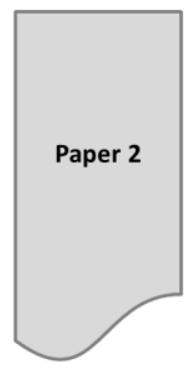

Adapt the validation criteria from the 3S Methodology to be applied in industrial symbiosis indicators.

Propose a validation procedure of industrial symbiosis indicators that combines aspects of conceptual validation and empirical validation.

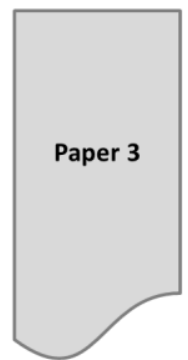

Propose the use of the ABM for the empirical validation of industrial symbiosis indicators, constructing a simulation model.

Use the model to compare three industrial symbiosis indicators in order to demonstrate the model use and to identify improvements in the indicators.

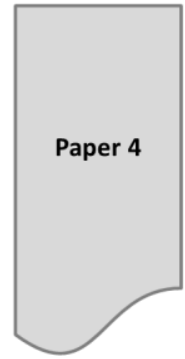

Propose advances in the mode developed in Paper 3 so that it is able to simulate all industrial symbiosis indicators.

Perform a benchmarking between the industrial symbiosis indicators using the simulation model, demonstrating the strengths and weaknesses of each indicator.

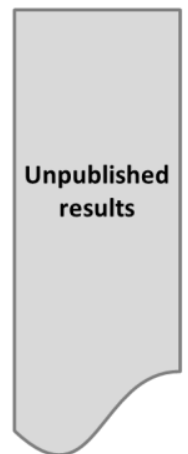

Apply the 3S Methodology in the Industrial Symbiosis Indicator (ISI) of Felicio et al. (2016), but using the specific validation criteria proposed in Paper 2.

Propose a Framework for the validation of industrial symbiosis indicators.
Objetcive of the research

Phases of the method

Identify the industrial symbiosis indicators available in the literature.

Evaluate and analyze the industrial symbiosis indicators, comparing them to each other.

Analyze the limitations and positive aspects of 3S Methodology, identifying possible contributions in order to promote the conceptual validation of industrial symbiosis indicators.

Propose a Framework for the validation of industrial symbiosis indicators that considers aspects of both conceptual and empirical validations through agent-based simulation.

Propose a simulation model of EIPs that considers the calculation of industrial symbiosis indicators.

Evaluate and analyze the industrial symbiosis indicators, comparing them to each other.

Propose a simulation model of EIPs that considers the calculation of industrial symbiosis indicators.

Evaluate and analyze the industrial symbiosis indicators, comparing them to each other.

Analyze the limitations and positive aspects of 3S Methodology, identifying possible contributions in order to promote the conceptual validation of industrial symbiosis indicators.

Evaluate and analyze the industrial symbiosis indicators, comparing them to each other.

Propose a Framework for the validation of industrial symbiosis indicators that considers aspects of both conceptual and empirical validations through agent-based simulation.
Phase 1 - Literature review.

Phase 2 - Indicators identification.

Phase 1 - Literature review.

Phase 3 - Development of the specific validation criteria.

Phase 5-Framework proposition.

Phase 1 - Literature review.

Phase 4-Development of the simulation model.

Phase 1 - Literature review.

Phase 4-Development of the simulation model.

Phase 1 - Literature review.

Phase 3-Development of the specific validation criteria.

Phase 5-Framework proposition. 
Figure 5 - Contribution of each paper in relation to the literature review

\section{Contribution to the literature review}
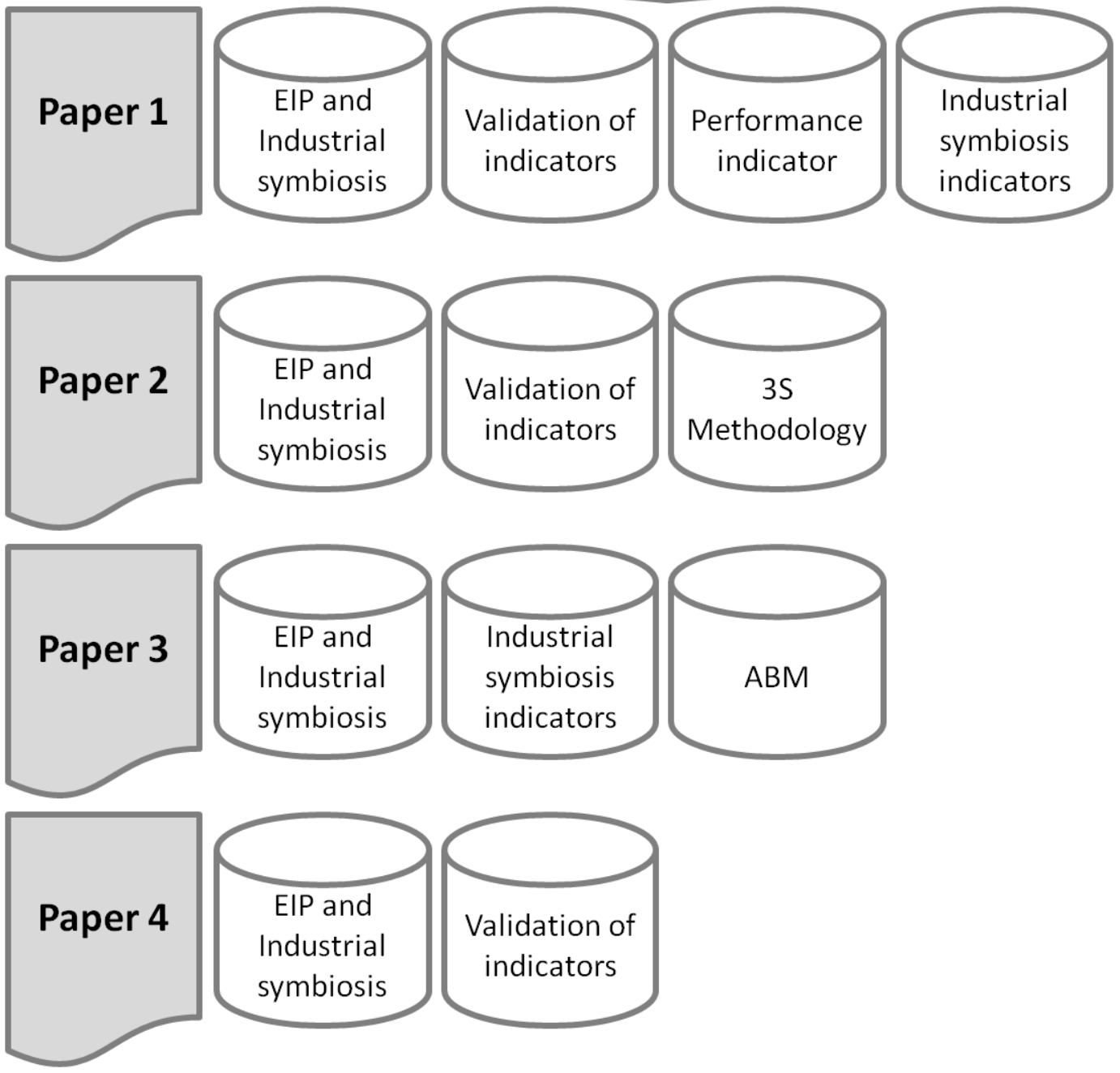

Source: the Author 
This chapter presents the first published paper that composes this thesis. Its reference, for correct quotation, is:

MANTESE, G. C.; AMARAL, D. C. Identification and qualitative comparison of performance indicators of industrial symbiosis. Revista Produção Online, v. 16, n. 4, p. 1329-1348, 2016.

The journal Revista de Produção Online is the original source, please use DOI (Digital Object Identifier) to access it: https://doi.org/10.14488/1676-1901.v16i4.2349. 


\title{
IDENTIFICATION AND QUALITATIVE COMPARISON OF PERFORMANCE INDICATORS OF INDUSTRIAL SYMBIOSIS
}

\author{
Gabriel Couto Mantese* E-mail: gabriel mantese@outlook.com \\ Daniel Capaldo Amaral Email: amaral@sc.usp.br \\ *Department of Production Engineering, University of São Paulo (USP), São \\ Carlos,SP, Brazil
}

\begin{abstract}
Industrial symbiosis is the exchange of by-products, energy and water between industries, centered on a collective approach, and in order to achieve competitive advantages. It is central to the concept of eco-industrial park and requires continuous monitoring by the professionals involved. Indicators have been proposed and the objective of this work is to identify and describe the indicators present in the literature, and then make a conceptual comparison. In a total of seven indicators, the ISI (Industrial Symbiosis Indicator), from Felicio et al. (2016), stands out due to the amount of its positive features, bigger than the others, and for facilitating the indication of trends. The Environmental Impact indicator, from Trokanas et al. (2015), also stands out, but for considering the financial and energy consumption aspects, inherent in the industrial symbiosis networks. The others indicators have serious problems, including superficiality and difficulty of application. A combination of both would be the best alternative, but further research is recommended with more robust assessments, based on cases or simulations.
\end{abstract}

Keywords: Industrial Symbiosis, Eco-Industrial Park, Performance Indicator, Indicators Evaluation, Comparison between Indicators. 


\section{INTRODUCTION}

The Eco-industrial Park (EIP) concept was created by Indigo Development Institute in late 1992 and presented to US-EPA (United State Environmental Protection Agency) in 1993 (INDIGO DEVELOPMENT, 2006; LOWE, 2001).

The interest in this type of industrial community is growing, which can be confirmed by Veiga and Magrini (2009) that show how the EIP concept has been spread to several countries as a new industrial arrangement model. Furthermore, Lowe (2001), at the beginning of 2001, identified that at least 100 eco-industrial projects had been initiated around the world and, since then, it is published regularly about the outcomes of these experiences or about the research methods and tools to support the EIPs establishment and development.

The EIP subject brings up the Industrial Symbiosis term, because, as noted by Chertow (1998), using data from 13 projects over two years, the industrial symbiosis is a key element for the EIP characterization. Agarwal and Strachan (2006) agree that an EIP is the grouping of industrial symbiosis networks. Therefore, the process of industrial symbiosis is essential to the EIP formation, and need to be measured, monitored and evaluated.

According to Agarwal and Strachan (2006), the industrial symbiosis development is limited because of the lack of comprehensive evaluation methods. Park and Behera (2014) reinforce this argument, the authors found that there is no method universally accepted to evaluate the performance of industrial symbiosis networks. One challenge is to improve the symbiosis networks evaluation and the first step is to ensure its maintenance and promotion.

There are papers dedicated to evaluate industrial symbiosis networks in industrial clusters, for example, Sokka et al. (2008), Bain et al. (2010), Wang et al. (2013; 2014) and Geng et al. (2014). Most of them use analysis based on the Life Cycle Assessment and Material Flow Analysis techniques to describe the networks, which does not necessarily characterize the symbiosis network.

Following the trend of the environmental and sustainable areas, where the sustainable development analysis and measurement are pursued through the proposition and utilization of performance indicators, as can be seen in Tachizawa (2009), Vianna et al. (2010), Rodrigues et al. (2015) and Rollano et al. (2015), 
recently emerged authors interested in creating performance indicators that measure specifically the industrial symbiosis.

Authors like Hardy and Graedel (2002), Tiejun (2010) and Felicio et al. (2016) use a performance indicator, or a set of indicators, to measure the industrial symbiosis in industrial parks. However, through a search in Web of Science databases, it was not found any paper compiling these indicators and comparing them with each other.

This paper has three objectives. The first is to list and present the performance indicators, or set of indicators, identified in the literature that have the aim to measure the industrial symbiosis. The second objective is to compare the indicators and evaluate them qualitatively. Finally, the third objective is to select the best indicator, or set of indicators, for measuring the industrial symbiosis in EIPs. 


\section{ECO-INDUSTRIAL PARKS AND THE INDUSTRIAL SYMBIOSIS}

An EIP is an industrial community, where its members pursue the environmental, social and economic performance improvement through cooperation, obtaining a collective benefit greater than the sum of individual benefits that would be obtained without cooperation (INDIGO DEVELOPMENT, 2006).

The industrial symbiosis is an analogy to the term already known from biology, but inserted into business reality. According to Chertow et al. (2008), there are three types of symbiotic transactions that may occur: (i) infrastructure and utilities sharing;

(ii) provision of common services; (iii) by-product exchanges, where a company uses the disposal/waste from another company as raw material.

The industrial symbiosis process, by improving the environmental issues, can also achieve social and economic advantages within an industrial cluster of companies that cooperate with each other synergistically.

In this context, the definition of instruments that contribute to the management of the professionals responsible for the EIP, known as brokers, becomes essential, as their role is stimulate the expansion of industrial symbiosis. 


\section{EVALUATING INDUSTRIAL SYMBIOSIS INDICATORS}

According to Neely et al. (1995), the performance measurement is the process of quantifying the effectiveness and/or the efficiency of an action. A performance indicator, or a set of indicators, is able to play this role. For Ramos and Caeiro (2010), the performance indicators are the mostly widely used approach for the evaluation of sustainable performance.

A performance indicator, or set of indicators, to measure industrial symbiosis and its evolution is a necessary tool for the EIP's brokers.

Neely et al. (1997) is one of the research groups that more developed and systematized the indicators literature. The authors presented a form of performance indicators description, The Performance Measure Record Sheet, and general criteria that serve to indicators in the Operations Management area. Franceschini et al. (2006) updated these general criteria.

In addition to the general criteria, it was also identified a set of specific works for the evaluation of environmental and sustainability indicators. They are the works of Bockstaller and Girardin (2003), Cloquell-Ballester et al. (2006) and Kurtz et al. (2001).

The most complete is the Bockstaller and Girardin (2003), which proposed a classification and a procedure, based on a decision tree, indicating how to proceed the validation of environmental performance indicators. This structure was used by Cloquell-Ballester et al. (2006) to create a specific methodology of indicators validation, based on expert judgment.

An indicator validation can be divided into two stages, the conceptual validation and the empirical validation (BOCKSTALLER; GIRARDIN, 2003). The first is based on the indicator data, information and description, as well on the perception of experts. The second stage is the evaluation with visual or statistical procedures, involving simulated or real data. This paper deals with the evaluation of indicators through the conceptual validation recommendations proposed by these authors. 


\section{RESEARCH METHOD}

The research method involves two stages: (i) Indicators identification; (ii) Conceptual evaluation.

\subsection{Indicators identification}

The first stage is the identification of the industrial symbiosis indicators that are available in the literature. A systematic literature review was conducted. The RBS Roadmap guide, by Conforto et al. (2011), was selected, because it is a systematic procedure of systematic literature review and can be used to conduct literature researches with greater scientific rigor (CONFORTO et al., 2011).

The guide was proposed with a primary focus on researches in the operations management field, specifically in product development and project management (CONFORTO et al., 2011). However, it can be applied in other areas, and was identified as a useful method for this research in particular.

The RBS Roadmap guide consists of three phases, containing a set of steps within each of them, as can be seen in Figure 1.

Figure 1 - Phases of RBS Roadmap

\begin{tabular}{|l|}
\hline \multicolumn{1}{|c|}{1 Input } \\
\hline 1.1 Problem \\
\hline 1.2 Objectives \\
\hline 1.3 Primary sources \\
\hline 1.4 Search string \\
\hline 1.5 Inclusion criteria \\
\hline 1.6 Qualification criteria \\
\hline 1.7 Method and tools \\
\hline 1.8 Schedule \\
\hline
\end{tabular}

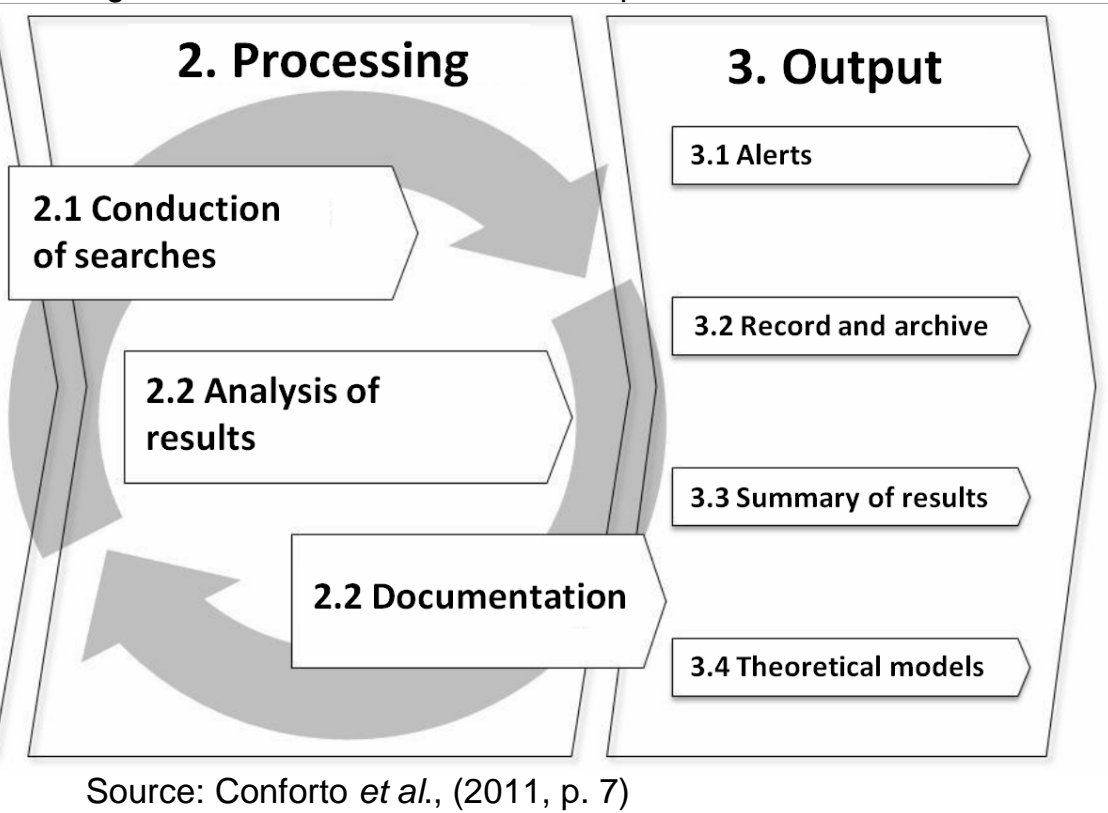

In Phase 1 (Input) the guidelines are defined, i.e., the systematic literature review is planned. In Phase 2 (Processing) is where the systematic literature review is performed, as the search string is conducted and the filters, for the papers 
inclusion, are applied. Finally, the Phase 3 (Output) is where the selected items are included in the research repository and the results are synthesized.

There are 3 filters to be applied at the papers founded by the search. In the first filter only the title, the keywords and the abstract are read. The second filter consists of reading the introduction and the conclusion of the papers. And in the last filter the remaining papers are read completely (CONFORTO et al., 2011).

\subsection{Conceptual evaluation}

In the second stage, the conceptual evaluation of the selected indicators is performed. This evaluation is made through a comparison of the indicators, highlighting their qualities and weaknesses.

In order to find a common language for this comparison it was applied a set of criteria and elements to describe each indicator. The source was the theory about "good indicators", i. e., the general and specific criteria to describe the performance indicators. These criteria were identified on performance indicator theory cited in Section 3 and are summarized in Table 1. 
Table 1 - Set of criteria identified

\begin{tabular}{|c|c|}
\hline Reference & Criteria \\
\hline Neely et al. (1997) & $\begin{array}{l}\text { Derived from strategy; } \\
\text { Simple to understand; } \\
\text { Accurate; } \\
\text { Relevant; } \\
\text { Clearly defined; } \\
\text { Visual impact; } \\
\text { Consistent; } \\
\text { Fast feedback; } \\
\text { Explicit purpose; } \\
\text { Explicitly defined formula and source of data; } \\
\text { Simple consistent format; } \\
\text { Based on trends; } \\
\text { Precise; } \\
\text { Objective. }\end{array}$ \\
\hline Franceschini et al. (2006) & $\begin{array}{l}\text { Properly operationalise the representation-target; } \\
\text { Should not provide more than the required information; } \\
\text { Should be defined considering the expenses to collect the needed } \\
\text { information; } \\
\text { Be easy to be understood and to be used. }\end{array}$ \\
\hline Bockstaller and Girardin (2003) & $\begin{array}{l}\text { Well founded; } \\
\text { Supplying reliable information; } \\
\text { Useful. }\end{array}$ \\
\hline Cloquell-Ballester et al. (2006) & $\begin{array}{l}\text { Conceptual coherence; } \\
\text { Operational coherence; } \\
\text { Utility. }\end{array}$ \\
\hline Kurtz et al. (2001) & $\begin{array}{l}\text { Conceptual relevance; } \\
\text { Feasibility of implementation; } \\
\text { Response variability; } \\
\text { Interpretation and utility. }\end{array}$ \\
\hline $\begin{array}{l}\text { It can be seen that } \\
\text { similar, which reinforce thes }\end{array}$ & $\begin{array}{l}\text { Source: the Authors } \\
\text { some criteria from different authors are equal or very } \\
\text { se findings. }\end{array}$ \\
\hline $\begin{array}{l}\text { The comparative eve } \\
\text { indicators have adherence } \\
\text { with more criteria than othe } \\
\text { of some of the principal } \\
\text { validation areas, serving as } \\
\text { accomplished through a col }\end{array}$ & $\begin{array}{l}\text { aluation between indicators is not intended to check if the } \\
\text { to the criteria, or if a particular indicator has adherence } \\
\text { ers. Table } 1 \text { was built only to systematize the contribution } \\
\text { authors in the performance indicators and indicators } \\
\text { a theoretical basis for the qualitative evaluation, which is } \\
\text { mparison. }\end{array}$ \\
\hline
\end{tabular}




\section{SYSTEMATIC LITERATURE REVIEW}

To conduct the systematic literature review, the first step was the definition of the Input Phase of RBS Roadmap:

a) Problem. There are performance indicators for measuring industrial symbiosis? If so, which are?

b) Objective. Identify performance indicators for measuring industrial symbiosis in eco-industrial parks that are available in the literature.

c) Primary sources. Initially, the works of Felicio et al. (2016), Hardy and Graedel (2002) and Tiejun (2010) had already been identified through previous studies about industrial symbiosis and eco-industrial parks. From these works, which propose indicators for measuring industrial symbiosis, the keywords for the search were identified.

d) Search string. All the databases from Web of Science (THOMSON REUTERS, 2015) were used and the search was applied in Topic (Title, Abstract and Keywords). The search was conducted in January 2016 and includes papers published up to 2015. It was used the search string: ts=("industrial symbiosis" OR "industrial ecology") AND ts=(indicator* OR index OR indice* OR connectance).

e) Inclusion criteria. Only works that present one or more indicators for measuring the industrial symbiosis were included. Works that present methods as, for example, the work of Bain et al. (2010), which proposes the use of the Material Flow Analysis method for checking the industrial symbiosis, were excluded.

f) Qualification criteria. The selected works were classified in three ways: (i) Presents only a specific indicator for measuring the industrial symbiosis in EIPs; (ii) Presents a specific indicator composed of sub-indicators for measuring the industrial symbiosis in EIPs; (iii) Presents a set of indicators that together measure the industrial symbiosis in EIPs.

g) Method and tools. For the application of the search, as stated above, it was used the Web of Science (THOMSON REUTERS, 2015) databases.

The second phase of RBS Roadmap was initiated by the search string application in the selected database. The result yielded a total of 200 papers. After 
applying the first filter, i.e., reading of title, abstract and keywords, 34 papers were selected. With the second filter, reading of introduction and conclusion, 14 papers were selected. Finally, with the application of the third filter, where the paper is read completely, 7 papers were selected. Although the work of Felicio et al. (2016) still being in the in press condition, and out of range of the systematic literature review (after 2015), it was included because it is one of the primary sources and is adherent to the research problem.

The result of systematic literature review, i.e., the 8 works identified, is presented in Table 2.

Table 2 - Selected works

\begin{tabular}{|c|c|c|c|}
\hline Reference & Work Title & Periodical or Event & $\begin{array}{l}\text { Qualification } \\
\text { criterion }\end{array}$ \\
\hline $\begin{array}{l}\text { Hardy and } \\
\text { Graedel } \\
(2002)\end{array}$ & $\begin{array}{l}\text { Industrial ecosystems as food } \\
\text { webs }\end{array}$ & $\begin{array}{l}\text { Journal of Industrial } \\
\text { Ecology }\end{array}$ & Set of indicators \\
\hline Tiejun (2010) & $\begin{array}{l}\text { Two quantitative indices for the } \\
\text { planning and evaluation of eco- } \\
\text { industrial parks }\end{array}$ & $\begin{array}{l}\text { Resources, Conservation } \\
\text { and Recycling }\end{array}$ & Set of indicators \\
\hline $\begin{array}{l}\text { Zhou et al. } \\
\text { (2012) }\end{array}$ & $\begin{array}{l}\text { Modeling and Optimization of a } \\
\text { Coal-Chemical Eco-industrial } \\
\text { System in China }\end{array}$ & $\begin{array}{l}\text { Journal of Industrial } \\
\text { Ecology }\end{array}$ & Set of indicators \\
\hline $\begin{array}{l}\text { Gao et al. } \\
(2013)\end{array}$ & $\begin{array}{l}\text { Study on Byproducts Recycling in } \\
\text { Eco-industrial Parks }\end{array}$ & $\begin{array}{l}\text { Advanced Research on } \\
\text { Material Engineering, } \\
\text { Chemistry and } \\
\text { Environment }\end{array}$ & Set of indicators \\
\hline $\begin{array}{l}\text { Park and } \\
\text { Behera (2014) }\end{array}$ & $\begin{array}{l}\text { Methodological aspects of } \\
\text { applying eco-efficiency indicators } \\
\text { to industrial symbiosis networks }\end{array}$ & $\begin{array}{l}\text { Journal of Cleaner } \\
\text { Production }\end{array}$ & $\begin{array}{l}\text { Specific indicator } \\
\text { composed by sub- } \\
\text { indicators }\end{array}$ \\
\hline $\begin{array}{l}\text { Wen and } \\
\text { Meng (2015) }\end{array}$ & $\begin{array}{l}\text { Quantitative assessment of } \\
\text { industrial symbiosis for the } \\
\text { promotion of circular economy: a } \\
\text { case study of the printed circuit } \\
\text { boards industry in China's Suzhou } \\
\text { New District }\end{array}$ & $\begin{array}{l}\text { Journal of Cleaner } \\
\text { Production }\end{array}$ & Specific indicator \\
\hline $\begin{array}{l}\text { Trokanas et } \\
\text { al. (2015) }\end{array}$ & $\begin{array}{l}\text { Semantic approach for pre- } \\
\text { assessment of environmental } \\
\text { indicators in Industrial Symbiosis }\end{array}$ & $\begin{array}{l}\text { Journal of Cleaner } \\
\text { Production }\end{array}$ & $\begin{array}{l}\text { Specific indicator } \\
\text { composed by sub- } \\
\text { indicators }\end{array}$ \\
\hline $\begin{array}{l}\text { Felicio et al. } \\
(2016)\end{array}$ & $\begin{array}{l}\text { Industrial symbiosis indicators to } \\
\text { manage eco-industrial parks as } \\
\text { dynamic systems }\end{array}$ & $\begin{array}{l}\text { Journal of Cleaner } \\
\text { Production }\end{array}$ & Specific indicator \\
\hline
\end{tabular}

Source: the Authors

The third phase of the RBS Roadmap consists only of the summary of results, where the identified indicators are described in detail. 


\section{INDICATORS DESCRIPTION}

The indicators description is made through an adaptation of The Performance Measure Record Sheet, by Neely et al. (1997). This method provides a summary and a simple report from each indicator, and highlights the main aspects for comparisons (NEELY et al., 1997).

\subsection{Connectance and Symbiotic Utilization}

Hardy and Graedel (2002), based on the Food Webs theory, proposed the use of two indicators simultaneously. Both are described in Table 3.

Table 3 - Connectance and Symbiotic Utilization

\begin{tabular}{ll}
\hline Indicator title & $\begin{array}{l}\text { a. Connectance } \\
\text { b. Symbiotic Utilization }\end{array}$ \\
\hline Purpose & $\begin{array}{l}\text { a. Define the degree of association between the EIP companies } \\
\text { b. Measure the magnitude and hazardousness of symbiotic relations }\end{array}$ \\
\hline $\begin{array}{l}\text { Related to which } \\
\text { business goal? }\end{array}$ & $\begin{array}{l}\text { a. Cooperation between companies } \\
\text { b. By-products exchange incentive. Greater incentive to exchange of } \\
\text { hazardous by-products }\end{array}$ \\
\hline $\begin{array}{l}\text { Minimum and } \\
\text { maximum value }\end{array}$ & $\begin{array}{l}\text { a. Ranges from } 0 \text { to } 1 . \text { The higher the better } \\
\text { b. Ranges from } 0 \text { to infinity. The higher the better }\end{array}$ \\
\hline
\end{tabular}

a. $\quad C=\frac{2 L}{S(S-1)}$

Where,

L: number of links

S: number of companies in the EIP

Formula

b. $U=\sum_{i=1}^{n} M_{i} H_{i}$

Where,

M: mass flow

$\mathrm{H}$ : potential hazard for each material stream

$\mathrm{n}$ : number of links

Source of data

Wastes/by-products flows of each company.

Hazard level of each waste/by-product.

Source: structure adapted from Neely et al. (1997) and content adapted from Hardy and Graedel (2002)

\subsection{Eco-Connectance and By-product And Waste Recycling Rate}

These two indicators were proposed by Tiejun (2010) to be used together. The indicators can be seen in Table 4. 
Table 4 - Eco-Connectance and By-product and Waste Recycling Rate

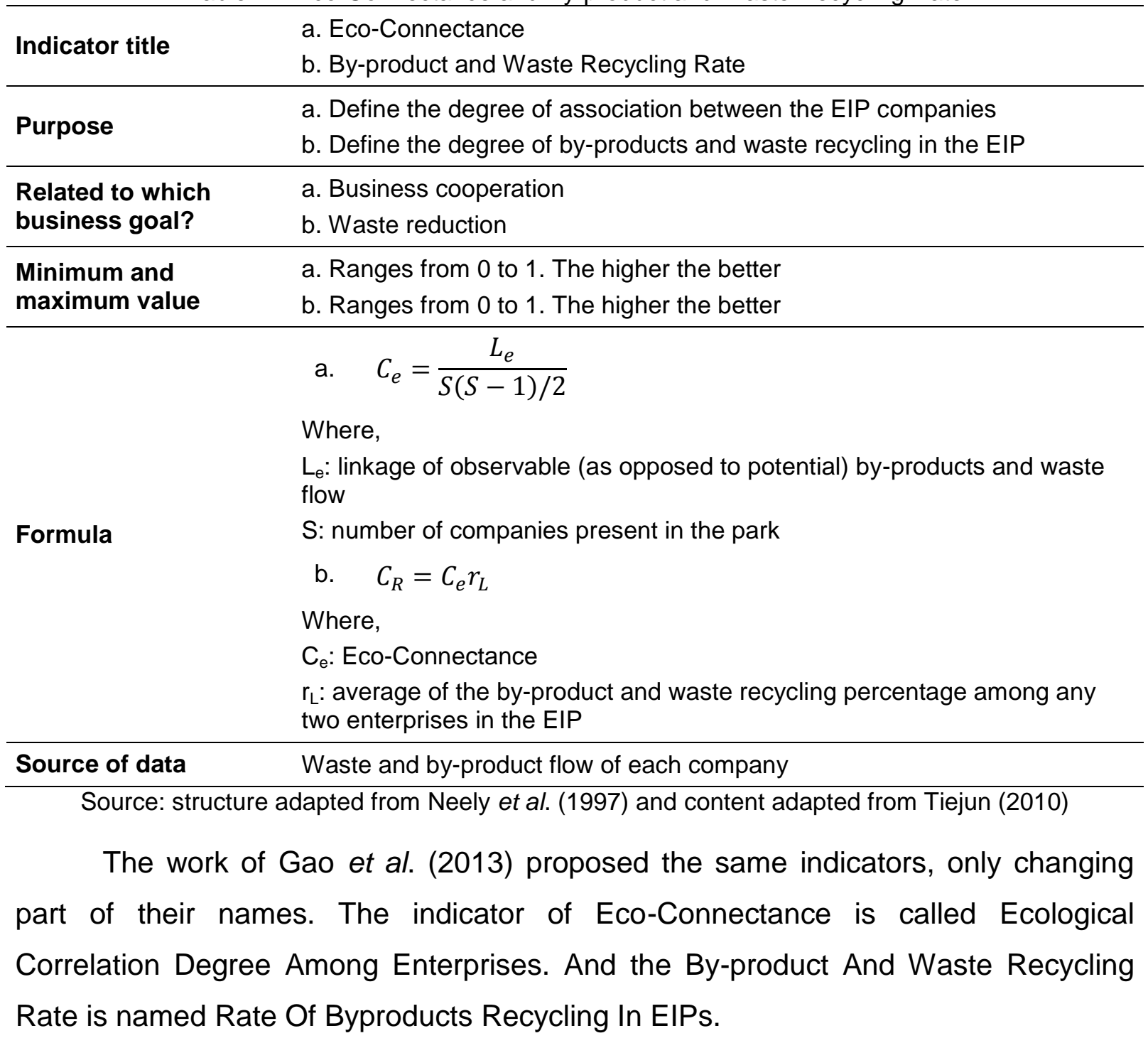

\subsection{Industrial Symbiosis Index and Link Density}

These indicators are presented by Zhou et al. (2012). Table 5 shows the two indicators. 
Table 5 - Industrial Symbiosis Index and Link Density

\begin{tabular}{ll}
\hline Indicator title & $\begin{array}{l}\text { a. Industrial Symbiosis Index } \\
\text { b. Link Density }\end{array}$ \\
\hline Purpose & $\begin{array}{l}\text { a. Check the intensity of resource utilization in the industrial symbiosis } \\
\text { system } \\
\text { b. Check the association density between the EIP companies }\end{array}$ \\
\hline $\begin{array}{l}\text { Related to which } \\
\text { business goal? }\end{array}$ & $\begin{array}{l}\text { a. Increase the waste/by-product exchange between EIP companies } \\
\text { b. Cooperation between the park companies }\end{array}$ \\
\hline $\begin{array}{l}\text { Minimum and } \\
\text { maximum value }\end{array}$ & $\begin{array}{l}\text { a. Ranges from } 0 \text { to } 1 . \text { The higher the better } \\
\text { b. Ranges from } 0 \text { to }(\mathrm{n}-1) / 2, \text { where } \mathrm{n} \text { is the number of companies. The } \\
\text { higher the better }\end{array}$ \\
\hline
\end{tabular}

a. Industrial Symbiosis Index $=\frac{\text { Symbiosis links }}{\text { Total links }}$

Formula

b.

$$
\text { Link Density }=\frac{\text { Total links }}{\text { Number of companies }}
$$

Where,

Total links: Symbiotic links added to the final products flow links between EIP companies

Source of data Local of origin and destination of waste/by-products and of products of each company

Source: structure adapted from Neely et al. (1997) and content adapted from Zhou et al. (2012)

\subsection{Eco-Efficiency}

Park and Behera (2014) proposed an Eco-efficiency indicator to evaluate the performance of symbiotic networks in an EIP. This indicator is composed by other four indicators, an economic indicator and three environmental indicators. Table 6 shows a summary of the indicators. 
Table 6 - Eco-Efficiency

\begin{tabular}{|c|c|}
\hline Indicator title & Eco-efficiency \\
\hline Sub-indicators & $\begin{array}{l}\text { a. Net Economic Benefit } \\
\text { b. Raw Material Consumption } \\
\text { c. Energy Consumption } \\
\text { d. } \mathrm{CO}_{2} \text { Emission }\end{array}$ \\
\hline Purpose & Evaluate the eco-efficiency of symbiotic transactions \\
\hline $\begin{array}{l}\text { Related to which } \\
\text { business goal? }\end{array}$ & $\begin{array}{l}\text { Encouraging the expansion of symbiotic relationships and increasing eco- } \\
\text { efficiency } \\
\text { a. Reduce costs } \\
\text { b. Consuming wastes/by-products from other EIP companies } \\
\text { c. Reduce energy consumption } \\
\text { d. Reduce emission of greenhouse gases }\end{array}$ \\
\hline $\begin{array}{l}\text { Minimum and } \\
\text { maximum value }\end{array}$ & Assumes any real value. The higher the better \\
\hline Formula & $\begin{array}{l}\qquad E c o-e f f i c i e n c y=\frac{E I}{E N} \\
\text { Where, } \\
\text { EI: Net economic benefit achieved through the exchange of by-products } \\
\text { EN: Representation of environmental influence, represented by the formula: } \\
E N=\sum_{i=1}^{3} \propto S_{i} \\
\text { Where, } \\
\mathrm{S}_{i} \text { : impact due to each environmental indicator } \\
\text { a: Weight of each environmental indicator (sum of weights must be equal to } \\
\text { 1) }\end{array}$ \\
\hline Source of data & $\begin{array}{l}\text { a. Monetary amount saved due to industrial symbiosis links } \\
\text { b. Quantity of raw material consumed by each company } \\
\text { c. Amount of energy consumed by each company } \\
\text { d. Amount of } \mathrm{CO}_{2} \text { emission of each company }\end{array}$ \\
\hline
\end{tabular}

Source: structure adapted from Neely et al. (1997) and content adapted from Park and Behera (2014)

\subsection{Resource Productivity Index}

The Resource Productivity Index emerged from the combination between the Substance Flow Analysis (SFA) approach and the Resource Productivity (RP) indicator. It was proposed by Wen and Meng (2015). Table 7 summarizes this indicator. 
Table 7 - Resource Productivity Index

\begin{tabular}{|c|c|}
\hline Indicator title & Resource Productivity Index \\
\hline Purpose & $\begin{array}{l}\text { Evaluate the contribution of industrial symbiosis in the development of circular } \\
\text { economy }\end{array}$ \\
\hline $\begin{array}{l}\text { Related to which } \\
\text { business goal? }\end{array}$ & $\begin{array}{l}\text { Productivity enhancement } \\
\text { Use of wastes/by-products as raw material }\end{array}$ \\
\hline $\begin{array}{l}\text { Minimum and } \\
\text { maximum value }\end{array}$ & Assumes any real value. The higher the better \\
\hline \multirow{4}{*}{ Formula } & $\begin{array}{l}R P=\frac{\sum I A V}{\sum D M I} \\
\text { Where, } \\
\text { RP: Resource Productivity } \\
\sum \text { IAV: Industrial added value } \\
\sum \text { DMI: Direct material input in the system (amount) }\end{array}$ \\
\hline & $\begin{array}{l}\text { The variable } \sum D M I \text { is only about the direct material used, i.e., only the virgin raw } \\
\text { material. The indirect material is the reused raw material, i.e., wastes/by-products } \\
\text { that are reused as raw materials. Thus the indicator increases with the substitution } \\
\text { of direct material by indirect material. }\end{array}$ \\
\hline & $\begin{array}{l}\text { Due to the use of the SFA approach, the Resource Productivity Index considers } \\
\text { only one type of substance in its calculation. This means that for every production } \\
\text { chain, a new value of the indicator must be calculated. }\end{array}$ \\
\hline & $\begin{array}{l}\text { On the other hand, the substance may be energy or water, and thus, the indicator } \\
\text { value for the use of water and energy can be calculated. }\end{array}$ \\
\hline Source of data & $\begin{array}{l}\text { Amount of direct material used } \\
\text { Industrial value added by company }\end{array}$ \\
\hline
\end{tabular}

Source: structure adapted from Neely et al. (1997) and content adapted from Wen and Meng (2015)

\subsection{Environmental Impact}

The Environmental Impact indicator was proposed by Trokanas et al. (2015). It consists of five sub-indicators. Table 8 shows them all. 
Table 8 - Environmental Impact (continue)

\begin{tabular}{|c|c|}
\hline $\begin{array}{l}\text { Indicator } \\
\text { title }\end{array}$ & Environmental Impact (ENVI) \\
\hline \multirow{5}{*}{$\begin{array}{l}\text { Sub- } \\
\text { indicators }\end{array}$} & a. Embodied Carbon Cost (ECC) \\
\hline & b. Virgin Materials Financial Saving (VMFS) \\
\hline & c. Landfill Diversion Financial Saving (LDFS) \\
\hline & d. Transportation Financial Impact (TFI) \\
\hline & e. Energy Consumption Financial Impact (ECFI) \\
\hline
\end{tabular}

Assess the financial impact due to the environmental impact of symbiotic transactions

a. Assess the embodied carbon cost of materials exchanged between the companies

b. Assess the financial savings achieved through the replacing of virgin materials by by-

Purpose products

c. Assess the financial savings achieved by not sending the reused by-products to landfill

d. Assess the financial impact of the reused by-products transportation between companies

e. Assess the energy cost consumed in the processing of reused by-products

Related

to which

business Reduction of environmental impact

goal?

Minimum

and

maximum Assumes any real value. The lower the better.

value

Source: structure adapted from Neely et al. (1997) and content adapted from Trokanas et al. (2015) 
Table 8 - Environmental Impact (continuation)

$$
E N V I=\sum_{i=0}^{\text {pairs }} \frac{\left(w_{E C C} * E C C\right)-\left(w_{V M F S} * V M F S\right)-\left(w_{L D F S} * L D F S\right)+\left(w_{T F I} * T F I\right)+\left(w_{E C F I} * E C F I\right)}{\sum w_{i}}
$$

Where,

pairs: amount of symbiotic transactions

w: weight of sub-indicators

The sub-indicators are calculated according to the formulas:
a. $E C C=\left(\sum_{i j}^{n_{r e s}} Q_{i j} * E C_{R(i j)}\right) * C O_{2}^{P}$
b. $V M F S=\sum_{i j}^{n_{i n}} C_{i j} *\left(F P_{i j}-R P_{i j}\right)$
c. $L D F S=\sum_{i j}^{n_{r e s}} Q_{i j} *\left(D C_{i j}+R P_{i j}+L T\right)$
d. $T I F=\left(\sum_{i j}^{n_{s y m}} T F_{i j} * l_{i j} * Q_{i j}\right) * C O_{2}^{P}$
e. $E C F I=\left(\sum_{i j}^{n_{e n}} Q_{i j} * C C_{i j}\right) * C O_{2}^{P}$

Where,

$\mathrm{Q}_{\mathrm{ij}}$ : Quantity of by-product exchanged between industries i and j

Formula $\quad E C_{R(i i)}$ : Embodied carbon of by-product exchanged between industries $i$ and $j$

$\mathrm{CO}_{2}{ }^{\mathrm{P}}$ : Price of $\mathrm{CO}_{2}$ as formed in the boundaries of carbon exchange scheme

$\mathrm{C}_{\mathrm{ij}}$ : Capacity of industry $\mathrm{j}$ satisfied by industry $\mathrm{i}$

$F P_{\mathrm{ij}}$ : Price of the feedstock that is replaced by a by-product between industries $\mathrm{i}$ and $\mathrm{j}$

$\mathrm{RP}_{\mathrm{ij}}$ : Price of by-product exchanged between industries $\mathrm{i}$ and $\mathrm{j}$

$\mathrm{DC}_{\mathrm{ij}}$ : Disposal cost for by-product exchanged between industries $\mathrm{i}$ and $\mathrm{j}$

LT: Landfill tax for region

$\mathrm{TF}_{\mathrm{ij}}$ : Transportation factor between industries $\mathrm{i}$ and $\mathrm{j}$

$\mathrm{I}_{\mathrm{ij}}$ : The physical distance between industries $\mathrm{i}$ and $\mathrm{j}$

CCij: Carbon content of energy type

$\mathrm{n}_{\text {res }}$ : Number of by-products exchanged in the symbiotic network

$\mathrm{n}_{\mathrm{in}}$ : Number of inputs involved in the symbiotic network

$\mathrm{n}_{\text {syn }}$ : Number of pairwise exchanges in the symbiotic network

$\mathrm{n}_{\mathrm{en}}$ : number of different types of energy required in a symbiotic network

Amount of exchanged by-products

Source of Amount of energy used in processing by-products

data Geographical location of industries

Price of the replaced raw materials and by-products

Source: structure adapted from Neely et al. (1997) and content adapted from Trokanas et al. (2015)

\subsection{Industrial Symbiosis Indicator (ISI)}

The ISI was proposed by Felicio et al. (2016) and is described in Table 9.

Table 9 - Industrial Symbiosis Indicator (continue)

\begin{tabular}{ll}
\hline Indicator title & Industrial Symbiosis Indicator (ISI) \\
\hline Purpose & $\begin{array}{l}\text { Indicate the evolution of the performance of symbiotic relationships between } \\
\text { companies of an EIP }\end{array}$
\end{tabular}

\section{Related to which Encourage the expansion of symbiotic relationships
business goal?}

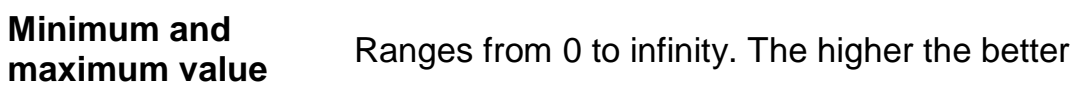

Source: Structure adapted from Neely et al. (1997) and content adapted from Felicio et al. (2016) 
Table 9 - Industrial Symbiosis Indicator (continuation)

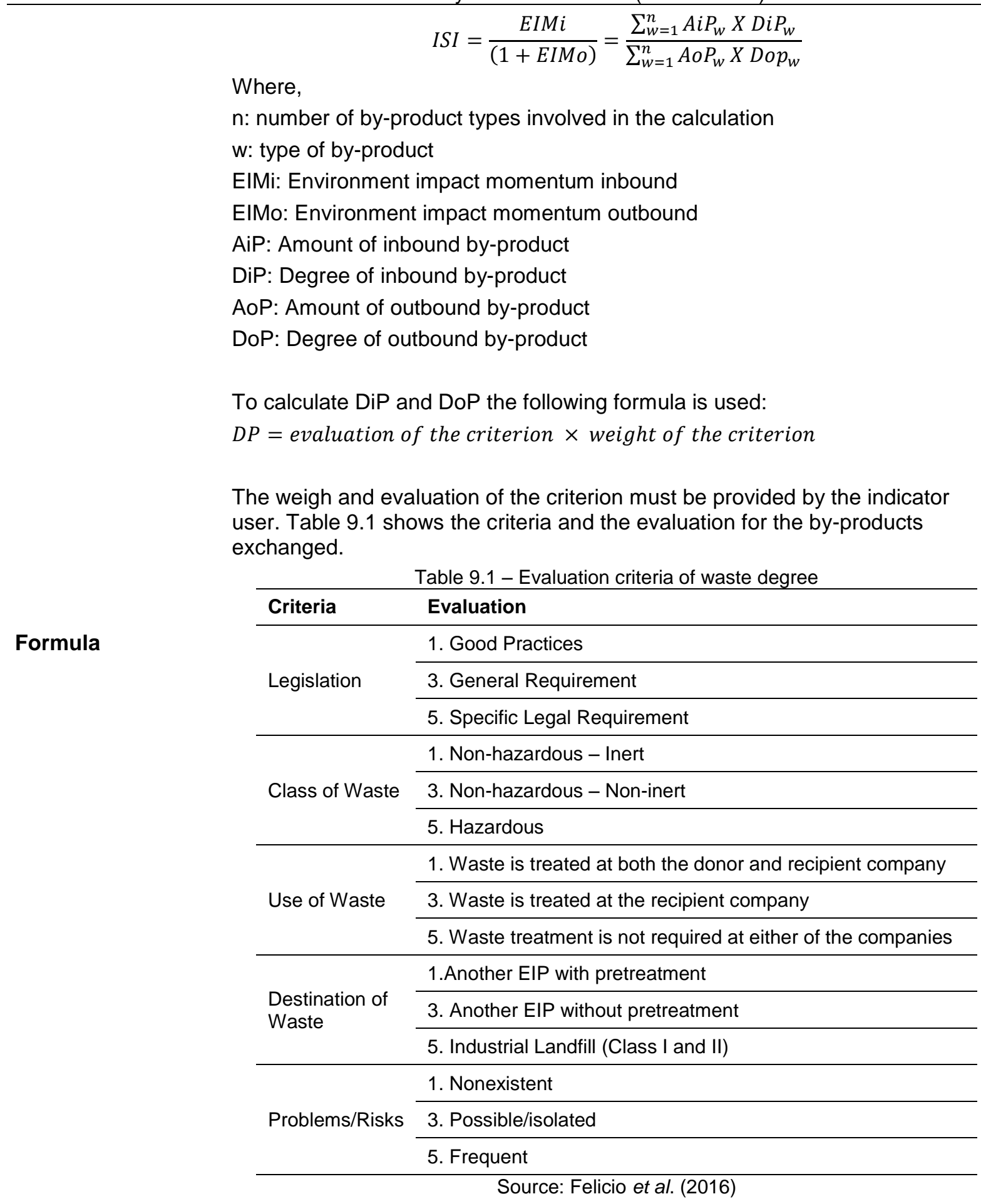

DiP does not consider the criterion "Destination of Waste", while DoP does not use the criterion "Use of Waste".

Wastes and by-products flows of each company.

Source of data

Waste legislation.

Class of waste.

Problems/risks with regard to waste.

Source: Structure adapted from Neely et al. (1997) and content adapted from Felicio et al. (2016) 


\section{EVALUATION OF INDICATORS}

Using the criteria presented in Section 4.2 and the formula and characteristics of each indicator, described in Section 6, the main aspects that an industrial symbiosis indicator should cover were identified: (i) Correct representation of industrial symbiosis; (ii) Waste/by-product classification; (iii) Quantification of reused and discarded wastes/by-products; (iv) Difficulty of data access and collection; (v) Indication of trend; (vi) Existence of a reference value (for comparison); (vii) Coverage value (minimum and maximum values).

The indicators evaluation is summarized in Table 10, which, due to its size, is divided into two parts (10.A and 10.B).

Table 10.A - Comparative evaluation of indicators (first part)

\begin{tabular}{|c|c|c|}
\hline Indicator(s) & Positive aspects and strengths & Negative aspects and weaknesses \\
\hline \multirow{4}{*}{$\begin{array}{l}\text { Connectance } \\
\text { and Symbiotic } \\
\text { Utilization } \\
\text { (HARDY; } \\
\text { GRAEDEL, } \\
\text { 2002) }\end{array}$} & $\begin{array}{l}\text { 1- Wastes receive different } \\
\text { classifications according to their } \\
\text { hazardousness }\end{array}$ & \multirow{2}{*}{$\begin{array}{l}\text { 1- The hazardousness classification of wastes } \\
\text { does not follow a rule }\end{array}$} \\
\hline & & \\
\hline & $\begin{array}{l}\text { waste } \\
\text { 3- Data of amount of waste are } \\
\text { not difficult to obtain }\end{array}$ & $\begin{array}{l}\text { 2- Values of different EIPs cannot be } \\
\text { compared because the hazardousness } \\
\text { classification may be different }\end{array}$ \\
\hline & $\begin{array}{l}\text { 4- Symbiotic Utilization do not } \\
\text { have maximum value, meaning } \\
\text { that the industrial symbiosis can } \\
\text { always be increased }\end{array}$ & $\begin{array}{l}\text { 3- Do not consider the amount of discarded } \\
\text { waste }\end{array}$ \\
\hline \multirow{4}{*}{$\begin{array}{l}\text { Eco- } \\
\text { Connectance } \\
\text { and By-product } \\
\text { and Waste } \\
\text { Recycling Rate } \\
\text { (TIEJUN, 2010; } \\
\text { GAO et al., } \\
\text { 2013) }\end{array}$} & & 1- Do not classify the different types of waste \\
\hline & $\begin{array}{l}\text { 1- Consider both quantity of used } \\
\text { and discarded waste }\end{array}$ & \multirow{2}{*}{$\begin{array}{l}\text { 2- The formula of the By-product and Waste } \\
\text { Recycling Rate indicator is inconsistent, } \\
\text { because a company can send } 50 \% \text { of the } \\
\text { generated waste to another company and the } \\
\text { remaining } 50 \% \text { to a third company. This results } \\
\text { in a rL equal to } 50 \% \text {. But in another scenario, } \\
\text { the same company is sending } 100 \% \text { of the } \\
\text { generated waste to only one company, which } \\
\text { would result in a rL equal to } 100 \%\end{array}$} \\
\hline & \multirow[t]{2}{*}{$\begin{array}{l}\text { 2- Data of amount of waste are } \\
\text { not difficult to obtain }\end{array}$} & \\
\hline & & $\begin{array}{l}\text { 3- Do not consider the absolute value of } \\
\text { amount of waste, only the percentage }\end{array}$ \\
\hline \multirow{2}{*}{$\begin{array}{l}\text { Industrial } \\
\text { Symbiosis } \\
\text { Index and Link } \\
\text { Density (ZHOU } \\
\text { et al., 2012) }\end{array}$} & \multirow{2}{*}{$\begin{array}{l}\text { 1- The data are very easy to be } \\
\text { obtained }\end{array}$} & $\begin{array}{l}\text { 1- Only verify if the companies have some kind } \\
\text { of connection, but do not consider the waste } \\
\text { amount or its classification }\end{array}$ \\
\hline & & $\begin{array}{l}\text { 2- These indicators do not represent the } \\
\text { industrial symbiosis as defined by Chertow et } \\
\text { al. (2008) }\end{array}$ \\
\hline
\end{tabular}


Table 10.B - Comparative evaluation of indicators (second part)

\begin{tabular}{ll}
\hline Indicator(s) & $\begin{array}{l}\text { Positive aspects and } \\
\text { strengths }\end{array}$ \\
\hline & \\
& 1- Considers financial aspects \\
Eco-efficiency & $\begin{array}{l}\text { 2- Considers energy } \\
\text { consumption }\end{array}$ \\
(PARK; & $\begin{array}{l}\text { 3- Data of amount of raw } \\
\text { material are not difficult to } \\
\text { obtain }\end{array}$ \\
\end{tabular}

\section{Negative aspects and weaknesses}

1- Financial data are difficult to obtain

2- Does not classify the different types of material

3- Values of different EIPs cannot be compared, because the weight of environmental subindicators may be different

4- Does not consider the amount of discarded waste

5- The data of amount of waste are not used directly, because data of amount of virgin raw material consumed are used. This suggests that the less virgin materials are being used, the more by-products and wastes are being used as raw material. That is an indirect measure of waste use as input

1- Financial data are difficult to obtain

1- Although the classification of materials is not considered, it is used the Substance Flow Analysis approach to quantify the materials in an equivalent way

\section{Productivity}

Resource Index (WEN; MENG, 2015)

2- It has no maximum value, meaning that the industrial symbiosis can always be increased

3- Considers financial aspects

2- Does not consider the amount of discarded waste

3- The data of amount of waste are not used directly, because data of amount of virgin raw material consumed are used. This suggests that the less virgin materials are being used, the more by-products and wastes are being used as raw material. That is an indirect measure of waste use as input

4- It is not calculated just one value for the whole EIP. It is necessary to calculate the indicator for each chain of each substance type

1- Considers the amount of reused waste

1- Financial data are difficult to obtain

2- Although the classification

Environmental Impact of waste is not considered, it (TROKANAS et al., 2015) is used the Embodied Carbon approach to quantify the waste in an equivalent way

3- Considers financial aspects

4- Considers energy consumption

2- Involves the use of many data for the indicator calculation, which difficult the use at the beginning of the application

3- Does not consider the amount of discarded waste

4- Values of different EIPs cannot be compared because the sub-indicators weights may be different

1- Classifies the wastes based on various criteria 2- Considers both quantity of used and discarded waste

Industrial 3- It has no maximum value, Symbiosis Indicator (ISI) (FELICIO et al., 2016)
1- In the formula was necessary to add 1 in the denominator. This causes different effects depending on the magnitude of exchanged waste amounts

2- It is necessary to be always aware to changes in the criteria classifications of each waste at each period. Can be hard-working

3- Values of different EIPs cannot be compared because the criteria weights may be different are not difficult to obtain 5- Indicates trend 
Table 10 indicates the set of positive and negative aspects of each indicator. Both indicators from Zhou et al. (2012) can be considered superficial compared to the others. They are reductionists in the scope of the industrial symbiosis information and dimensions.

The indicators from Felicio et al. (2016) and Hardy and Graedel (2002) stand out positively because they consider the waste classification. Hardy and Graedel (2002), however, only consider the hazardousness in the classification. Felicio et al. (2016) suggest five criteria and rules to classify each waste. In addition, the indicators from Hardy and Graedel (2002) do not consider the amount of discarded waste, which is considered by the indicator from Felicio et al. (2016).

Although the indicators proposed by Wen and Meng (2015) and by Trokanas et al. (2015) do not consider the waste classification, they stand out because this aspect is overcame through the use of Substance Flow Analysis and Embodied Carbon approaches respectively, being able to compare equivalently the different materials. However, the indicator from Wen and Meng (2015) does not consider the direct use of exchanged by-products and waste, it considers the amount of virgin raw material used. That also occurs with the indicator from Park and Behera (2014). In addition, the indicator from Wen and Meng (2015) should be calculated for each chain of each substance type, it does not provide a unique value for the park as a whole.

The indicators from Felicio et al. (2016) and Tiejun (2010) are the only ones to consider the amount of discarded waste. However, the indicators from Tiejun (2010) do not use absolute values, only percentages of the reused waste. Furthermore, the indicators from Tiejun (2010) do not consider the classification of waste.

The indicators proposed by Park and Behera (2014) and by Trokanas et al. (2015) are the only ones to consider the financial aspect and the energy consumption, while the indicator from Wen and Meng (2015) considers only the financial aspect. The disadvantage is that such data are difficult to be shared among EIP members, which can complicate the application. 


\section{CONCLUSIONS}

The main indicators are the ISI (FELICIO et al., 2016) and the Environmental Impact indicator (TROKANAS et al., 2015). The positive characteristics of both indicators stand out, but they also have negative aspects and weaknesses that must be considered.

For the researches and industrial engineering professionals interested in measuring the industrial symbiosis, it is suggested the combined use of the ISI and the Environmental Impact indicator, or some of its sub-indicators. This work also provides the basis for researchers interested in creating new indicators, because it shows advantages and disadvantages that can serve as an inspiration for proposing new indicators.

This work did a conceptual validation and, as a next step, is suggested an empirical validation. It was impossible to be made because these indicators are at an early stage of proposition. The most appropriate is to apply the ISI and the Environmental Impact indicator in a real situation, i.e., in a consolidated EIP.

However, the access to such parks is still difficult, and there are not many real cases that can be used for a test. 


\section{ACKNOWLEDGEMENTS}

The authors thank FAPESP (São Paulo Research Foundation) for funding support through grants No 2014/11464-0 and No 2015/17192-5. 
This chapter presents the second published paper that composes this thesis. Its reference, for correct quotation, is:

MANTESE, G. C.; DE PIERE, B. A.; AMARAL, D. C. A Procedure to Validate Industrial Symbiosis Indicators Combining Conceptual and Empirical Validation Methods. In: ISPE TE. 2016. p. 166-175.

The IOSPress is the original source, please use the DOI (Digital Object Identifier) to access it: https://doi.org/10.3233/978-1-61499-703-0-166. 


\title{
A PROCEDURE TO VALIDATE INDUSTRIAL SYMBIOSIS INDICATORS COMBINING CONCEPTUAL AND EMPIRICAL VALIDATION METHODS
}

\author{
Gabriel Couto Mantese* \\ Bruna Aparecida de Piere \\ Daniel Capaldo Amaral \\ University of São Paulo
}

*Corresponding Author, E-Mail: gabriel mantese@outlook.com

\begin{abstract}
Industrial symbiosis is the exchange of by-products, energy and water between industries, centered on a collective approach, and in order to achieve competitive advantages. It is central to the concept of Eco-Industrial Park (EIP) and requires continuous monitoring of the professionals involved. Performance indicators for the measurement and monitoring of industrial symbiosis have been proposed and identified in the literature, however there is no consolidate indicator that is widely used in practice. These indicators require validation in order to evaluate and choose which options are able to measure the industrial symbiosis. There are two types of indicators validation, the conceptual validation and the empirical validation. This study investigates the integration of the conceptual validation and the empirical validation in the evaluation of the industrial symbiosis indicators. It is proposed the combined use of an indicator validation methodology based on expert judgment, the $3 S$ Methodology, and a simulation technique, the Agent-Based Modeling (ABM). The proposed procedure aims to validate any indicator of industrial symbiosis, providing specific criteria to the evaluation.
\end{abstract}

Keywords: Industrial Symbiosis, Performance Indicator, Indicator Validation, Agent-Based Modeling. 


\section{INTRODUCTION}

Industrial Symbiosis is characterized by a better use of by-products and waste. It is an essential part for the formation of Eco-Industrial Parks (EIP) (CHERTOW, 1998; AGARWAL; STRACHAN, 2006).

EIP is a concept of industrial arrangement created in the early 90 's, where companies seek sustainable development through mutual cooperation (INDIGO DEVELOPMENT, 2006; LOWE, 2001). According to Lowe (2001) and Veiga and Magrini (2009), the concept has spread to several countries through applied projects and publications.

The industrial symbiosis monitoring and measurement in this type of park are imperative. Performance indicators have been proposed for this purpose. However, as noted by Rigby et al. (2001), while is employed great interest in developing new performance indicators, little effort is intended to their validation. This is also observed with regard to the indicators for industrial symbiosis measurement, because none of the identified articles (HARDY; GRAEDEL, 2002; TIEJUN, 2010; ZHOU et al., 2012; GAO et al., 2013; PARK; BEHERA, 2014; WEN; MENG, 2015; TROKANAS et al., 2015; FELICIO et al., 2016) deals with the validation, but with their proposition or use.

Performance indicator validation is important because, according to Bockstaller and Girardin (2003), it aims to verify if an indicator is scientifically designed, if it provides relevant information and if it is useful to its users. The validation provides greater accuracy to the indicator.

The indicator validation process can be dived into two stages: the conceptual validation and the empirical validation (BOCKSTALLER; GIRARDIN, 2003). The first is based on the indicator data, information and description, where the validation through expert judgment is always possible (BOCKSTALLER; GIRARDIN, 2003).

Empirical validation is the indicator evaluation through visual or statistical procedures (BOCKSTALLER; GIRARDIN, 2003). The indicator application is required, which can be accomplished through a real case or with simulated data (BOCKSTALLER; GIRARDIN, 2003).

The article proposes a procedure that incorporates aspects of both validation stages, comprising a validation methodology based on the expert judgment and a simulation through Agent-Based Modeling (ABM) technique. 


\section{EIP AND INDUSTRIAL SYMBIOSIS}

The Eco-Industrial Park concept was created in 1992 by the Indigo Development institute (LOWE, 2001):

(...) a community of manufacturing and service businesses located together on a common property. Member businesses seek enhanced environmental, economic, and social performance through collaboration in managing environmental and resource issues. By working together, the community of businesses seeks a collective benefit that is greater than the sum of individual benefits each company would realize by only optimizing its individual performance (INDIGO DEVELOPMENT, 2006).

According to Chertow and Ehrenfeld (2012), an EIP should be considered as a dynamic system, where the park is a complex and adaptive environment, being influenced by external factors (e.g. market conditions) and internal factors (e.g. business strategies), and the system has the self-organizing ability. The industrial symbiosis is one of the ways by which an EIP can self-organize and achieve an equilibrium state (CHERTOW; EHRENFELD, 2012).

The industrial symbiosis concept is presented by Chertow (2000) as a metaphor where the industrial ecosystem mimics a natural ecosystem. It is responsible for the cooperation between different companies through the exchange of material, energy, water and by-products, achieving competitive advantages (CHERTOW, 2000).

According to Chertow et al. (2008), there are three types of symbiotic transactions: (i) utilities and infrastructure sharing; (ii) use of common services; (iii) by-product exchanges, where a company uses waste from another company as raw material.

Chertow (2000) points out that geographical proximity is a key factor for the industrial symbiosis development, because it is through this proximity that the synergic cooperation possibilities arise. Finally, Felicio et al. (2016) comment that the perfect symbiosis is impossible to reach, it can always be increased. 


\section{INDICATORS VALIDATION}

As already defined in the Introduction, the purpose of a performance indicator validation is to verify if the indicator is scientifically designed, if it provides relevant information and if it is useful to its users (BOCKSTALLER; GIRARDIN, 2003).

\subsection{S Methodology}

The 3S Methodology, by Cloquell-Ballester et al. (2006), is an indicator conceptual validation methodology that aims to ensure quality, reliability and objectivity for indicators. It is based on expert judgment.

Criteria in the form of questions are used in the evaluation procedure. These criteria are separated into three classes (Conceptual coherence; Operational coherence; Utility) (CLOQUELL-BALLESTER et al., 2006). These criteria are presented in Table 1.

Table 1 - 3S Methodology evaluation criteria.

\section{Questionnaire to evaluate the indicators to be validated}

Conceptual coherence

1.The definition of the indicator and the concepts that comprise it up is suitable

2.There is a biunivocal correspondence between the indicator and the factor to be quantified

3. The interpretation and meaning of the indicator are suitable

Operational coherence

1.The mathematical formulation of the indicator is suitable with regard to the concept which is to be quantified

2. The data used to establish the indicator and its units are suitable

3.The proposed measurement procedures to obtain the indicator are suitable, allowing for its reproduction and comparison

4.The indicator accuracy is suitable to quantify the factor and it is sensitive to changes in the latter

Utility

1.The indicator reliability is suitable

2.The reliability of the source of data which the indicator is made up of is suitable

3.The accessibility to the data and the applicability of the indicator are suitable

4.The information provided by the indicator may be catalogued as reliable

5. The cost of the information offered by the indicator can be considered acceptable

Source: Cloquell-Ballester et al. (2006, p. 87)

The criteria classes are designed to satisfy the three conditions proposed by Bockstaller and Girardin (2003). The conceptual coherence aims to verify if the indicator is scientifically designed; while the operational coherence verifies whether 
the indicators provides relevant information; and the utility verifies whether the indicator is useful to users.

Experts are responsible for answering the questions, assigning scores 1 to 5 (Likert Scale), totally disagreeing or totally agreeing respectively (CLOQUELLBALLESTER et al., 2006). An Indicator Report must be prepared so that the evaluators can access more easily the indicator's information (CLOQUELLBALLESTER et al., 2006).

The final score of each criterion is the average of evaluators' scores for that criterion. The criteria's scores are aggregated to form the classes' scores, which are aggregated to obtain the final score for the indicator. According to Cloquell-Ballester et al. (2006), the indicator can be classified according to the Table 2.

Table 2 - Indicator Classification

\begin{tabular}{ll}
\hline Final sore & Classification \\
\hline More than 4.5 & Validated \\
\hline Between 3.5 and 4.5 & A brief review is required \\
\hline Between 2.5 and 3.5 & A thorough review is required \\
\hline Less than 2.5 & Unacceptable. Redefine \\
\hline Source: Adapted from Cloquell-Ballester et al. (2006)
\end{tabular}

The 3S Methodology consists of three stages, differentiated by the type of evaluator (CLOQUELL-BALLESTER et al., 2006): (i) Self-validation - Executed by the working team that developed the indicator; (ii) Scientific validation - Conducted through independent expert judgment; (iii) Social validation - Includes public participation.

\subsection{Simulation in the indicators validation}

According to Bockstaller and Girardin (2003), a way to proceed with the empirical validation of an indicator is evaluating its behavior through simulation.

Among the various techniques employed to produce a simulation, AgentBased Modeling emerges as the main option for an EIP. It has, as one of its main advantages, the no need to represent the system completely, but only its individual agents, so it is possible to understand the dynamics that results from the interaction of agents with each other and with the environment. This makes the modeling process simpler. 
Furthermore, there are studies that used the ABM to represent an EIP. The model proposed by Bichraoui et al. (2013) focuses on understand the cooperation and learning conditions that permeate the park. While the model proposed by Romero and Ruiz (2014) has the aim to evaluate the influence of the symbiotic relationships in the global operation of the EIP. 


\section{PROPOSAL OF A PROCEDURE TO VALIDATE INDUSTRIAL SYMBIOSIS INDICATORS COMBINING SIMULATION AND THE 3S METHODOLOGY}

The proposal of the new procedure to validate industrial symbiosis indicators is divided into three phases. At first, the $3 S$ Methodology is adapted with regard to the evaluation criteria in order to be applied in industrial symbiosis indicators. Second, a simulation model of an EIP, that considers its symbiotic relationships, is proposed. Finally the integration between the two previous phases is described, resulting in the new validation procedure of industrial symbiosis indicators.

\subsection{Adapting 3S Methodology}

There are no specific criteria for the evaluation of industrial symbiosis indicators in the literature. Furthermore, the criteria proposed by Cloquell-Ballester et al. (2006) were considered superficial, too much embracing, and even repetitive.

The first adaptation of $3 S$ Methodology identified as necessary is the adaptation of the criteria proposed by Cloquell-Ballester et al. (2006). Table 3 presents the new criteria, specifics for the application on industrial symbiosis indicators. 
Table 3 - Evaluation criteria adapted for the application on industrial symbiosis indicators

Questionnaire to evaluate the indicators of industrial symbiosis to be validated

Conceptual coherence

1. The indicator measures the exchange of water, energy and by-products between companies in an eco-industrial park eco industrial, correct representing the industrial symbiosis

2. The indicator classifies the different by-products in accordance with appropriate criteria

3. The indicator considers amounts of by-product reused. In a direct way ${ }^{*}$

4. The indicator considers amounts of by-product discarded

Operational coherence

1. The mathematical formulation is suitable for measuring industrial symbiosis, taking into account the aspects that must be quantified

2. The data needed to calculate the indicator are relevant, while there are no data that are relevant and are not considered

3. The measurement procedures for obtaining the data are adequate, allowing their reproduction and comparison

4. The indicator is able to indicate trends

5. The numerical result has no limit, meaning that the industrial symbiosis can always be improved

6. The indicator allows comparison with other parks

Utility

1. The indicator calculation and its procedures do not require excessive effort

2. Data sources are reliable

3. Data sources are easy to access

4. The indicator final result has meaning

5. The costs required for data collection and indicator application are acceptable

${ }^{*}$ The indicator is able to record directly the by-products that are reused, rather than, for example, quantify them by the decrease in the use of virgin raw material.

Source: the Authors

The criteria classes was not changed, because they are in accordance with the presented by Bockstaller and Girardin (2003) in the indicators validation theory. The criteria adaptations were based on the EIP and industrial symbiosis theory, presented in Section 2. In addition, the studies containing the symbiosis indicators (HARDY; GRAEDEL, 2002; TIEJUN, 2010; ZHOU et al., 2012; GAO et al., 2013; PARK; BEHERA, 2014; WEN; MENG, 2015; TROKANAS et al., 2015; FELICIO et al., 2016) were also studied. However, due to space limitation, details of these indicators are not presented.

Another adjustment made in 35 Methodology concerns the three stages differentiated by the type of evaluator. The 35 Methodology authors, Bockstaller and Girardin (2003), argue that, with this differentiation, the indicator credibility increases with the passage through the three stages. We do not disagree with the authors, 
however, we believe that this restricts the use of the 3S Methodology to the indicator creators. And the intention is that the procedure proposed here be used both by the indicator creator and by who wish to use the indicator or by who just wish to validate it. The proposed adaptation is to extinguish this differentiation of evaluators.

\subsection{EIP simulation through ABM}

There is no study that uses an agent-based model in the representation of an EIP that aims to apply performance indicators. So we developed a simulation model of an EIP through ABM technique, using the NetLogo (2016) platform, which has the purpose of representing the interactions between the companies that compose the EIP with regard to by-products flow, and allows the calculation of industrial symbiosis indicators.

In summary, the model allows:

- Entrance and exit of companies in the EIP;

- Creation of by-products exchange links between companies;

- Variation in the amounts of by-products traded between companies;

- Variation in the amounts of by-products generate by each company;

- Dispatch of by-products not used to the landfill.

The model behavior depends on input data provided by the user, which can calibrate the model in different scenarios. To consider the calculation of the indicators it is necessary to modify the source code of the model in order to include the calculation of the desired indicators. This requires additional effort, however, because it was used the ABM technique, this effort is not excessive. Furthermore, the most complex part of the source code is already written. However, due to space limitations, the model will not be described in detail.

\subsection{Integrated validation procedure}

3S Methodology, according to Section 3.1, proposes that an Indicator Record should be created, so the evaluators have access more easily to the information about the indicator to be validated. The integration between conceptual and empirical validations happens at this point. We propose that simulations complement the Indicator Report. More than theoretical information about the indicator and its 
construction, the report will also contain simulations of the indicator behavior, demonstrating its evolution in different scenarios.

The one interested in validating the indicator must establish the preconditions to guide the construction of scenarios. These conditions can be grounded by aspects that differentiate the indicator or by a set of typical events in an EIP. The one responsible for designing the Indicator Report is the right person to perform the simulations through the model and, eventually, by inserting the indicator calculation in the source code. 


\section{RESULT}

The result is the validation process of industrial symbiosis indicators, named "Integrated Validation Procedure for Industrial Symbiosis Indicators". Figure 1 presents the process of this new procedure.

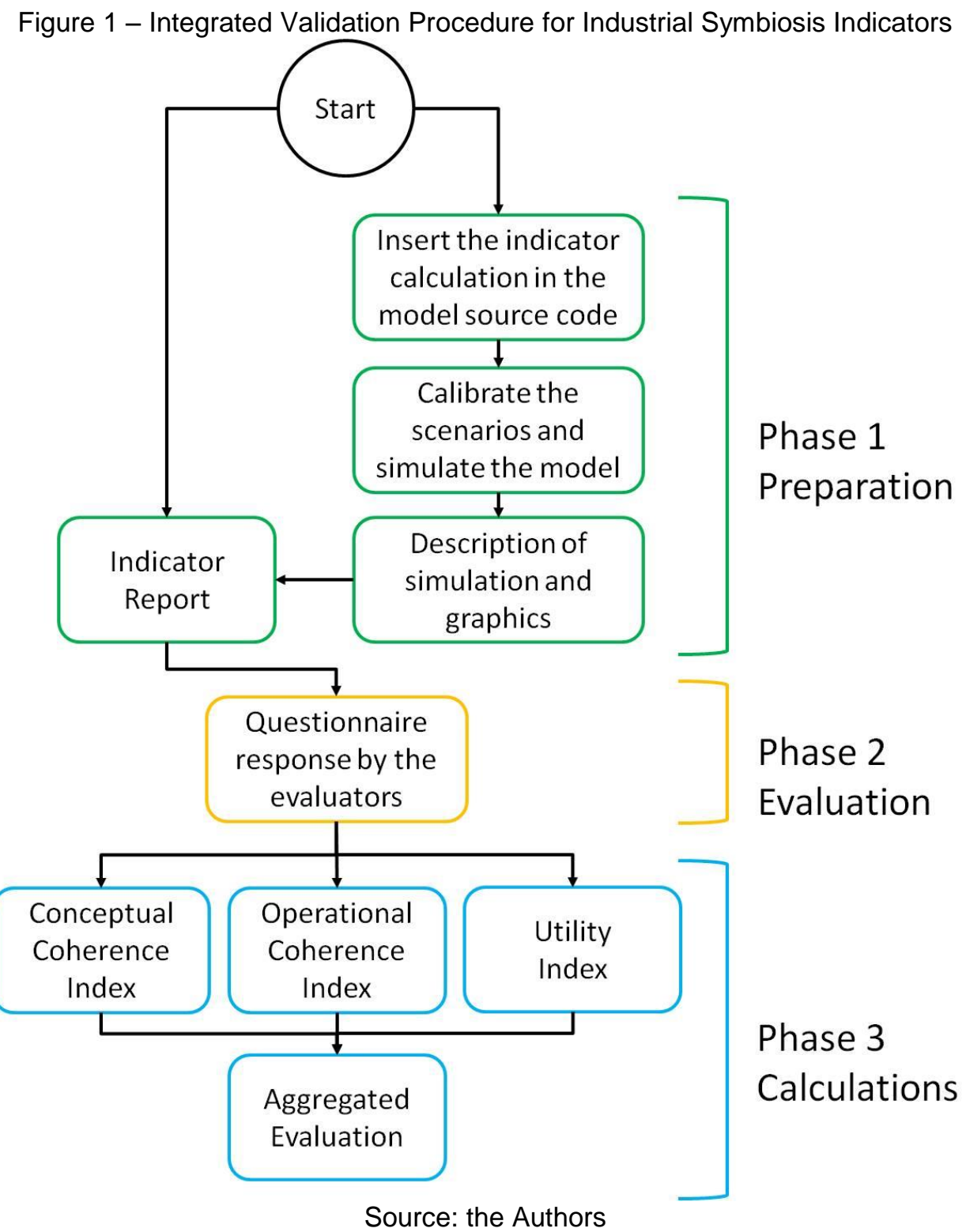

The process is divided into three phases: (i) Preparation; (ii) Evaluation; (iii) Calculations. Although the Evaluation phase is the "core", because it is in this phase that the experts assign scores to the criteria, the Preparation phase is the most laborious and has great importance, because it is in this phase the documents that will guide the whole evaluation are created. Any errors or omissions may jeopardize the entire process. 
The Evaluation phase comprises only the questionnaire response by the evaluators, the questionnaire is presented in Table 3. The last phase, Calculation, is where the evaluators' responses are compiled and the scores of each of the three indices (Conceptual coherence; Operational coherence; Utility) and the Aggregated Evaluation are obtained. For the final decision, whether the indicator is validated, we followed the recommendation of Cloquell-Ballester et al. (2006) presented in Table 2.

With regard to Indicator Report, we took the suggestion of minimum content, by Cloquell-Ballester et al. (2006), and added the description of the simulations. Table 4 shows what these information are.

Table 4 - Minimum content of Indicator Report

\begin{tabular}{ll}
\hline Guide for indicator report \\
\hline 1. Indicator & Name of the proposed indicator \\
\hline 2. Aspect & 2.1. Name of the environmental or social aspect (system component) to be \\
quantified through the indicator \\
2.2. Description: description of the environmental or social characteristic that \\
represents the aspect
\end{tabular}
Source: Adapted from Cloquell-Ballester et al. (2006)

Figure 2 presents an example on how the part that explains the simulations in the Indicator Report should be provided to the evaluators. We choose to present only this part because this is the innovative part of the report. It should be created as 
many scenarios as it deems necessary to represent the behavior of the indicator that is being validated.

Figure 2 The simulation part in the Indicator Report

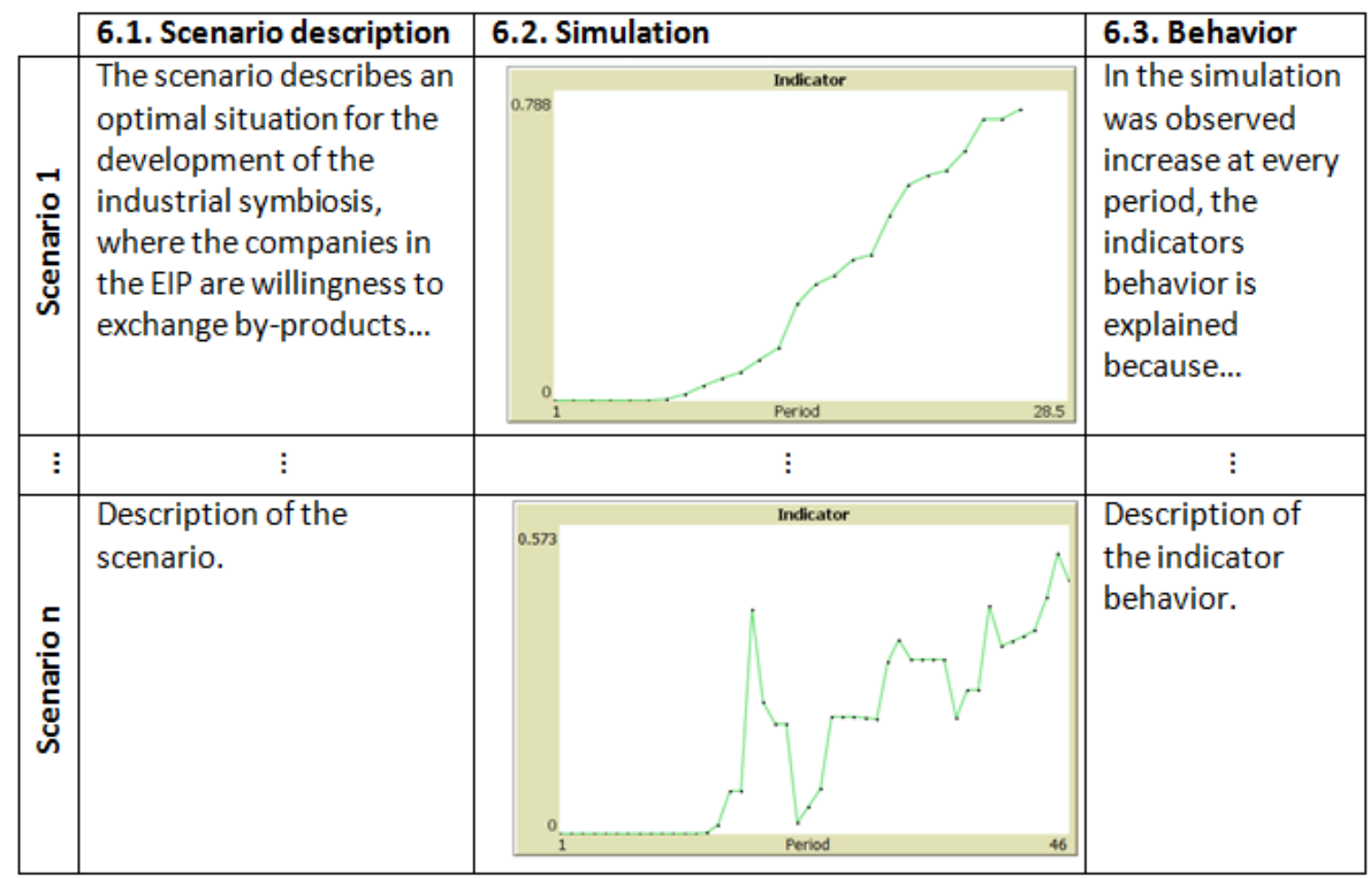

Source: the Authors 


\section{CONCLUSION}

The procedure proposed combines aspects of both conceptual and empirical validations to validate any indicators of industrial symbiosis. The gain in insert the simulation in a validation through the expert judgment is the provision of more information of different kinds to the evaluator, which will have more knowledge on the indicator.

The adaptation of the evaluation criteria for the specific application in industrial symbiosis indicators is another positive aspect of the procedure. Due to the possibility to simulate more than one indicator at the same time, this procedure also allows the evaluators to compare the indicators during the process of assigning scores to the evaluation criteria.

The need of great effort in the Preparation phase, particularly with regard to the simulation, is considered the main difficulty in applying the procedure.

This paper provides only the proposal of this new procedure, the practical application has not yet been held. As a next step, we will apply the procedure, verifying its applicability and possibly improving and proposing a final version. 


\section{ACKNOWLEDGEMENT}

The authors thank FAPESP (São Paulo Research Foundation) for funding support through grants No 2014/11464-0 and No 2015/17192-5. 
This chapter presents the third published paper that composes this thesis. Its reference, for correct quotation, is:

MANTESE, G. C.; AMARAL, D. C. Comparison of industrial symbiosis indicators through agent-based modeling. Journal of Cleaner Production, v. 140, p. 1652-1671, 2017.

The Journal of Cleaner Production is the original source, please use the DOI (Digital Object Identifier) to access it: https://doi.org/10.1016/i.jclepro.2016.09.142. 


\title{
COMPARISON OF INDUSTRIAL SYMBIOSIS INDICATORS THROUGH AGENT-BASED MODELING
}

\author{
Gabriel Couto Mantese* \\ Daniel Capaldo Amaral \\ Department of Production Engineering, University of São Paulo, São Carlos, SP, \\ Brazil \\ * Corresponding Author, E-mail: gabriel mantese@outlook.com
}

\begin{abstract}
The validation of environmental impact indicators is a prerequisite for professionals and brokers in charge of Eco-Industrial Parks (EIPs). In the specific case of industrial symbiosis indicators, this task is particularly challenging owing to the inherent difficulty in obtaining series of real data of consequence for the small number of EIPs and large number of organizations. Agent-Based Modeling (ABM) emerges as a technique to support EIP simulations. This work endorses the use of the $A B M$ technique to validate indicators of industrial symbiosis through the construction of a model that simulates an EIP, which is then evaluated by applying three indicators: the Industrial Symbiosis Indicator (ISI) of Felicio et al. (2016) and the Eco-Connectance and By-product and Waste Recycling Rate indicators of Tiejun (2010). The model was able to calculate the three indicators and identify conditions where their performances are equal or with misleading information regarding industrial symbiosis evolution. It supports the validation of industrial symbiosis indicators and demonstrates that the indicator by Felicio et al. (2016) is more robust for turbulent periods of industrial ecosystem environments.
\end{abstract}

Keywords: Eco-industrial park, Industrial symbiosis, Performance indicator Validation, Agent-based modeling, Simulation. 


\section{INTRODUCTION}

The use of performance indicators is one of the main approaches to support sustainable development (RAMOS; CAEIRO, 2010). Through this instrument, business professionals, representatives of regulatory protection agencies, and governments can diagnose, manage, and make decisions favoring the reduction of environmental impacts.

Industrial ecology has access to a new category of indicators: the so-called indicators of industrial symbiosis. Industrial symbiosis is a key concept for the development of an Eco-Industrial Park (EIP) (AGARWAL; STRACHAN, 2006; CHERTOW, 1998). Managers and business professionals participating in an EIP make decisions that have a direct impact on the level of symbiosis. A number of indicators are available in literature, such as those introduced in the works of Tiejun (2010), Felicio et al. (2016), Park and Behera (2014), and Zhou et al. (2012).

According to Meul et al. (2009), the validation of a performance indicator considers two aspects of the indicator: its accuracy and credibility. The accuracy is related to the consistency the indicator has to its application, while credibility expresses the confidence the user has in the indicator and in the information provided by it as well as the willingness to effectively use the indicator (MEUL et al., 2009). Accordingly, the validation process for an indicator can be separated into two stages: conceptual validation, which is based on data, information, and a description of the indicator, and empirical validation, the analysis of the behavior of the indicator outputs for which either visual or statistical procedures can be used.

According to Cloquell-Ballester et al. (2006), an ever possible way to proceed with the conceptual validation is through the expert judgment. The empirical validation of indicators for industrial symbiosis relies on data collected by various organizations and on the monitoring of a park for a significant period of time. This task is further impaired by the lack of real data owing to the scarceness of consolidated parks. A potential solution proposed by Bockstaller and Girardin (2003) is the use of simulated data.

The simulation technique known as Agent-Based Modeling (ABM) has been highlighted by Romero and Ruiz (2014) for the representation of an EIP, through which understanding the dynamics resulting from the interaction of the individuals of 
a system between themselves and the environment is possible (RAILSBACK; GRIMM, 2011).

The utilization of $A B M$ as an instrument for validating symbiosis indicators is investigated in this work. Three indicators were selected as a case study: the Industrial Symbiosis Indicator (ISI) of Felicio et al. (2016) and indicators of EcoConnectance and Byproduct and Waste Recycling Rate of Tiejun (2010). According to the bibliographical review performed by Felicio et al. (2016), the indicators of connectance are recommended for brokers and professionals involved with managing and controlling EIPs. And the ISI allows for consideration of the dynamic perspective of these parks as described by Chertow and Ehrenfeld (2012).

The indicators of Tiejun (2010) are the most widespread in literature. Other studies mention its use in the evaluation of industrial symbiosis networks. These studies include Gao et al. (2013) and Hardy and Graedel (2002). The ISI (FELICIO et al., 2016) is a recent indicator and needs to be evaluated before being made available to professionals. The comparison between them could reveal strengths and weaknesses for those interested in real applications. The challenge is performing both evaluation and comparison. Is the ABM simulation appropriate to answer these questions?

This study has two main objectives. The first one is to propose the application of the ABM technique for empirical validation of the cited industrial symbiosis indicators and constructing a simulation model. The second objective is to use the model to perform a comparison between three indicators to validate the model, demonstrate its use, and identify improvements in the indicators evaluated. 


\section{INDICATORS OF INDUSTRIAL SYMBIOSIS}

The EIP concept was created by the Indigo Development Institute in 1992 (LOWE, 2001) and has spread to several countries (VEIGA; MAGRINI, 2009). It is defined as a community of industries located within the same property that seeks to improve environmental, economic, and social performance through mutual cooperation, thus generating a greater collective benefit than the sum of the individual benefits companies would gain if they do not cooperate with each other (INDIGO DEVELOPMENT, 2006).

Industrial symbiosis is fundamental to the establishment of EIPs (AGARWAL; STRACHAN, 2006; CHERTOW, 1998). It has been defined by Chertow et al. (2008), who identified three types of symbiotic transactions: (i) sharing of infrastructure and utilities, (ii) provision of common resources, and (iii) by-product exchange between companies, where materials that would be discarded are used as raw materials.

The encouragement of this type of cooperation relies on the action of facilitators who can monitor and promote industrial symbiosis. Indicators of industrial symbiosis are among the tools available by these managers and Felicio et al. (2016) analyzed the relevant literature. They identified three approaches (FELICIO et al., 2016): eco-industrial indicators, material flow analysis (MFA) indicators, and life cycle assessment (LCA) indicators. The research identified papers that proposed a combination of these techniques and papers using network analysis. Felicio et al. (2016) concluded that the best indicators were those proposed by Hardy and Graedel (2002) and Tiejun (2010), because they consider an indicator of connectance.

Felicio et al. (2016) analyzed the indicators and proposed a new indicator entitled Industrial Symbiosis Indicator (ISI) that differs from that of Tiejun (2010) and was elaborated to capture the dynamic behavior of an EIP. According to Felicio et al. (2016), these indicators evaluate industrial symbiosis better according to the needs of managers and brokers interested in managing and controlling EIPs. The next sections describe each one separately.

Felicio et al. (2016) did not mention the paper of Park and Behera (2014) that proposes another approach to measure the industrial symbiosis, an indicator of EcoEfficiency. The indicator of Eco-Efficiency also seems to be a promising indicator, but we consider that a comparison between the ISI and the indicators proposed by Tiejun (2010) is yet a challenger process. 


\subsection{Industrial Symbiosis Indicator (ISI)}

The objective of ISI is to monitor the evolution of industrial symbiosis in an EIP. It can be used as a decision-making tool (FELICIO et al., 2016) and is useful in the management of EIPs as dynamic systems. The formula expressing ISI is shown as Equation (1) (FELICIO et al., 2016):

$$
I S I=\frac{E I M i}{1+E I M o}=\frac{\sum_{w=1}^{n}\left(A i P_{w} \times D i P_{w}\right)}{1+\sum_{w=1}^{n}\left(A o P_{w} \times D o P_{w}\right)}
$$

Where,

$\mathrm{n}$ : Number and type of by-products involved in the calculation

w: Type of by-product

EIMi: Environment impact momentum inbound

EIMo: Environment impact momentum outbound

AiP: Amount of inbound by-product

DiP: Degree of inbound by-product

AoP: Amount of outbound by-product

DoP: Degree of outbound by-product

The AiP variable represents the amount of by-products exchanged between EIP companies, while AoP represents the amount that leaves the park boundaries without being used. These quantities are measured in tons (FELICIO et al., 2016).

The DiP and DoP variables, however, classify the degree of each by-product. The degree is a qualitative evaluation of the environmental impact of the by-products (FELICIO et al., 2016). An example presented by the authors (FELICIO et al., 2016) explains the importance of classifying the by-products according to their environmental impact. For example, $100 \mathrm{~kg}$ of cardboard cannot be compared to 100 $\mathrm{kg}$ of batteries owing to their different level of toxicity to the environment. Therefore, an indicator for measuring industrial symbiosis must consider not only the quantities of the by-products but also their environmental impact. The DiP and DoP variables through the ISI accomplish that goal. For that purpose, a qualitative assessment of environmental impact within certain criteria is used. Table 1 presents the criteria used, as well as the possible evaluations for each criterion. 
Table 1 - By-product evaluation criteria.

\begin{tabular}{|c|c|}
\hline Criteria & Evaluation of the criteria \\
\hline \multirow[t]{3}{*}{ Legislation } & (1) Good Practices \\
\hline & (3) General Requirement \\
\hline & (5) Specific Legal Requirement \\
\hline \multirow[t]{3}{*}{ Class of by-product } & (1) Non-hazardous, inert \\
\hline & (3) Non-hazardous, non-inert \\
\hline & (5) Hazardous \\
\hline \multirow[t]{3}{*}{ Use of by-product } & (1) By-product is treated by both the donor and recipient company \\
\hline & (3) By-product is treated by the recipient company \\
\hline & (5) By-product treatment is not required by either of the companies \\
\hline \multirow{3}{*}{$\begin{array}{l}\text { Destination of by- } \\
\text { product }\end{array}$} & (1) Another EIP, with pretreatment \\
\hline & (3) Another EIP, without pretreatment \\
\hline & (5) Industrial Landfill (Class I and II) \\
\hline \multirow[t]{3}{*}{ Problems/risks } & (1) Nonexistent \\
\hline & (3) Possible/isolated \\
\hline & (5) Frequent \\
\hline
\end{tabular}

In the case of the inbound by-product, only the criterion "destination of byproduct" is not used, while for the outbound byproduct the criterion "use of byproduct" is not used (FELICIO et al., 2016).

Equation (2) is used to calculate the "degree of inbound byproduct" and "degree of outbound by-product" (DiP and DoP), for which the weight of the criterion is assigned by the indicator user.

$D P=$ evaluation of the criterion $\times$ weight of the criterion

Where,

DP: Degree of by-product (inbound and outbound)

Evaluation of the criterion: Can assume values of 1, 3, or 5

Weight of the criterion: Calculated through the Analytic Hierarchy Process

The ISI is composed of the relationship between the amount of by-product

The ISI is composed of the relationship between the amount of by-product reused as raw material and amount of by-product that leaves the EIP, while considering the potential environmental impact of each material. It increases with increase in the amount of by-product reused as raw material and decreases with increase in the amount of discarded by-product. Its value has no specific meaning; it 
is an index number that provides an indication of trend. Furthermore, it has no limit, which is consistent with the concept that perfect symbiosis cannot be achieved but can always be incremented (FELICIO et al., 2016).

The indicator can also be used in the decision regarding the entry of a new company into the park by verifying the extent to which this new company can help to increase the industrial symbiosis. In addition, through its calculation process, identifying the contribution of each company to the overall industrial symbiosis is also possible (FELICIO et al., 2016).

\subsection{Eco-Connectance and By-Product And Waste Recycling Rate}

The Eco-Connectance indicator establishes the degree of connectivity between the companies that constitute the EIP and is defined by Equation (3) (TIEJUN, 2010):

$$
C_{e}=\frac{L_{e}}{S(S-1) / 2}
$$

Where,

$\mathrm{C}_{e}$ : Eco-Connectance of the EIP

$\mathrm{L}_{e}$ : Observable (as opposed to potential) by-products and waste flow

$S$ : Number of factories or companies in an EIP

The indicator of the By-product and Waste Recycling Rate defines the degree to which the by-products and wastes of a company are used by other companies in the EIP (TIEJUN, 2010). It is defined by Equation (4) (TIEJUN, 2010):

$$
C_{R}=C_{e} \times r_{L}
$$

Where,

$\mathrm{C}_{\mathrm{R}}$ : By-product and Waste Recycling Rate

$\mathrm{C}_{\mathrm{e}}$ : Eco-Connectance of the EIP

$r_{L}$ : Average of by-product and waste recycling percentage between any two companies in an EIP, $0 \%<r_{L} \leq 100 \%$ 
Both indicators range from 0 to 1 , are interdependent and inseparable, and can be used either in the planning or construction of an EIP, or even in the quantitative assessment of an existing EIP (TIEJUN, 2010).

Comparing the ISI with the two indicators proposed by Tiejun (2010), the ISI has no finite value, while the indicators of Tiejun (2010) range from 0 to 1 . In addition, the ISI considers the quantity of reused and discarded by-products. Conversely, the indicators of Tiejun (2010), through the By-product and Waste Recycling Rate indicator, consider the percentages of by-products reused, and, through the EcoConnectance indicator, only the quantities of symbiotic links. Lastly, the greatest difference between the two sets of indicators is that the ISI considers the classification of the byproducts through some criteria, while the indicators of Tiejun (2010) neglect this aspect. 


\section{AGENT-BASED MODELING}

Romero and Ruiz (2014) identified the System Dynamics (SD) and ABM techniques as the most likely options for modeling an EIP. After comparing both approaches, as presented in Table 2, these authors chose ABM as the most appropriate technique.

Table 2. Comparison between System Dynamics and Agent-Based Modeling.

\begin{tabular}{|c|c|c|}
\hline $\begin{array}{l}\text { Comparative } \\
\text { Features }\end{array}$ & System Dynamics & Agent-Based Modeling \\
\hline $\begin{array}{l}\text { Modeling } \\
\text { Approach }\end{array}$ & $\begin{array}{l}\text { Deductive (top-down). Inference from } \\
\text { the structure to the system behavior. }\end{array}$ & $\begin{array}{l}\text { Inductive (bottom-up). Inference from the } \\
\text { agents' behavior to the system behavior. }\end{array}$ \\
\hline Unit of analysis & $\begin{array}{l}\text { System Structure. The behavior of } \\
\text { the system arises from its structure. }\end{array}$ & $\begin{array}{l}\text { Agents' rules. The behavior of the } \\
\text { system emerges from the agents' } \\
\text { behavior and their interactions. }\end{array}$ \\
\hline Building blocks & $\begin{array}{l}\text { Feedback loops. Representation of } \\
\text { cause-and-effect relationships. }\end{array}$ & $\begin{array}{l}\text { Agents. Individual entities that form the } \\
\text { system. }\end{array}$ \\
\hline Handling of time & $\begin{array}{l}\text { Continuous. Temporal variable is } \\
\text { continuous. }\end{array}$ & Discrete. Temporal variable is discrete. \\
\hline $\begin{array}{l}\text { Formal } \\
\text { expression }\end{array}$ & $\begin{array}{l}\text { Algebraic equations that define } \\
\text { variable relationships and feedback. }\end{array}$ & $\begin{array}{l}\text { Logic sentences that define behavioral } \\
\text { rules of the agents. }\end{array}$ \\
\hline $\begin{array}{l}\text { Model } \\
\text { representation }\end{array}$ & $\begin{array}{l}\text { Causal relationships that nonlinearly } \\
\text { link the observed variables, } \\
\text { parameters, and stock } \\
\text { accumulations, considering temporal } \\
\text { and spatial delays between cause } \\
\text { and effect. }\end{array}$ & $\begin{array}{l}\text { Agent population formed by autonomous, } \\
\text { heterogeneous, and independent entities } \\
\text { with their own objectives, properties, and } \\
\text { social ability to interact between them } \\
\text { and with their surroundings. }\end{array}$ \\
\hline $\begin{array}{l}\text { Model } \\
\text { representation }\end{array}$ & $\begin{array}{l}\text { Causal loop diagrams and stock and } \\
\text { flow structures. }\end{array}$ & $\begin{array}{l}\text { Individual representation of agents that } \\
\text { form the system. }\end{array}$ \\
\hline
\end{tabular}

Source: Adapted from Romero and Ruiz (2014, p. 396)

According to Gilbert (2008), ABM is "a computational method that enables a researcher to create, analyze, and experiment with models composed of agents that interact within an environment." The interactions, which follow certain rules, create emerging patterns in the system (PAGE, 2005).

An advantage is that it is not necessary to represent the overall state of the system, only the status of each individual agent (RAILSBACK; GRIMM, 2011). This simplifies the modeling, since to directly model the system as a whole, more complex and sophisticated mathematical models would be required instead of dealing with smaller parts of this system, i.e., their agents.

$A B M$ has been applied to different fields including ecology (GRIMM; RAILSBACK, 2013; WILENSKY; RAND, 2015) and organizational systems (WILENSKY; RAND, 2015). According to Wilensky and Rand (2015), ABM has been 
widely used in the past two decades by scientists conducting research. In fact, two recent papers apply ABM to the modeling of EIPs, namely Romero and Ruiz (2014) and Bichraoui et al. (2013).

The work by Romero and Ruiz (2014) aimed to allow the evaluation of the potential of the symbiotic relationships between companies that comprise the park and to evaluate the overall operation of the EIP in different scenarios. In the work by Bichraoui et al. (2013), the ABM technique is used to create a model that represents an EIP, with a focus on understanding the cooperation and learning conditions.

None of the researchers, however, used this technique as a validation procedure for indicators of industrial symbiosis. This is the goal of the model introduced in the current work. As the strategy to test this idea, we created a model and perform an evaluation of the industrial symbiosis indicators that are more useful for managers and brokers in EIPs, as evaluated by Felicio et al. (2016). These professionals need references for choosing and adapting indicators as decision tools to improve the industrial symbiosis levels. 


\section{DESCRIPTION OF THE SIMULATION MODEL}

The model was named EIPSymb, an allusion to EIP and Symbiosis terms. The ODD (Overview, Design Concepts, and Details) protocol proposed by Grimm et al. (2006) is used for its description. The ODD protocol was initially published with the purpose of standardizing the descriptions of ABM (GRIMM et al., 2010). It was designed so that $A B M$ publications would be more complete, quick and easy to understand, and organized in a manner that allows for presenting information in a consistent order (RAILSBACK; GRIMM, 2011). Its computational development was performed in the NetLogo platform, a programmable modeling environment that simulates natural and social phenomena through complex system models (NETLOGO, 2015).

\subsection{Overview}

\subsubsection{Purpose}

The purpose of EIPSymb is to represent the interactions between companies of an EIP in terms of the flow of by-products. EIPSymb was designed to allow the calculation of indicators of industrial symbiosis for every change in the system's state from the data of inbound and outbound by-products. The simulation includes three indicators for an initial evaluation of the model: Eco-Connectance and By-product and Waste Recycling Rate, by Tiejun (2010), and the ISI, proposed by Felicio et al. (2016).

\subsubsection{State variables and scales}

The global environment is divided into two local units. The first represents the EIP and contains the agents company, which may interact with each other through the exchange of by-products. The other unit represents the environment external to the EIP and contains the agent landfill, which is responsible for receiving the nonreused by-products. There is only one agent of the landfill type, which is associated with a single state variable, named who, which is the identification of each agent. The agents company are defined by the following variables:

- who: Identification of each agent. 
- type-product: Represents the type of product produced by the company. It may assume the values $0,1,2,3$, or 4 .

- type-residue-generated: Represents the type of by-product generated in the manufacture of the product. It is directly related to the variable type-product. Table 3 shows the relationship between the types of products and the byproducts generated.

- type-residue-used: Represents the type of by-product that can be used by the company as raw material. It is directly related to the variable type-product. Table 3 shows the relationship between the types of products and the byproducts used as raw materials.

- time-in-park: Number of complete periods in the EIP.

- residue-generated: Amount (in tons) of by-product generated.

- residue-absorption-capacity: Capacity (in tons) of by-product that the company is able to absorb as raw material.

- residue-absorbed: Amount (in tons) of by-product that the company is using as raw material.

Table 3 - Types of products and their relationships with the types of by-products generated and used as raw material

\begin{tabular}{lll}
\hline type-product & type-residue-generated & type-residue-used \\
\hline 0 & $\mathrm{~A}$ & $\mathrm{E}$ \\
\hline 1 & $\mathrm{~B}$ & $\mathrm{~A}$ \\
\hline 2 & $\mathrm{C}$ & $\mathrm{B}$ \\
\hline 3 & $\mathrm{D}$ & $\mathrm{C}$ \\
\hline 4 & $\mathrm{E}$ & $\mathrm{D}$ \\
\hline & & Source: The Authors
\end{tabular}

The concept used to define the types of products and the types of by-products generated or used as raw materials was inspired by the study of Bichraoui et al. (2013).

There is yet another type of entity, the link, which represents the by-products' flow between EIPSymb agents, whether company-company or company-landfill. This entity is represented by the state variables:

- end1 and end2: Identification of the link. end1 is associated with the number of the agent's who variable from where the byproduct is being released. end2 is 
related to the number of the agent's who variable to which the by-product is being sent.

- type-residue: Represents the type of by-product exchanged through the link.

- time-existence: Number of periods that the link exists.

- intensity: Amount (in tons) of by-products that are being sent by the link.

- color. Allows for visual differentiation between the industrial symbiosis links and the links of by-products sent out of the EIP. The link between two companies is green, while the link to the landfill is red.

\subsubsection{Process overview and scheduling}

The EIPSymb must be initiated through a Setup command button that clears the NetLogo world, visually differentiates local units, and creates the agent landfill. After this command, the EIPSymb is ready to be initiated. Figure 1 depicts a flowchart of the processes included in the model.

Figure 1 - Flowchart overview of EIPSymb processes.

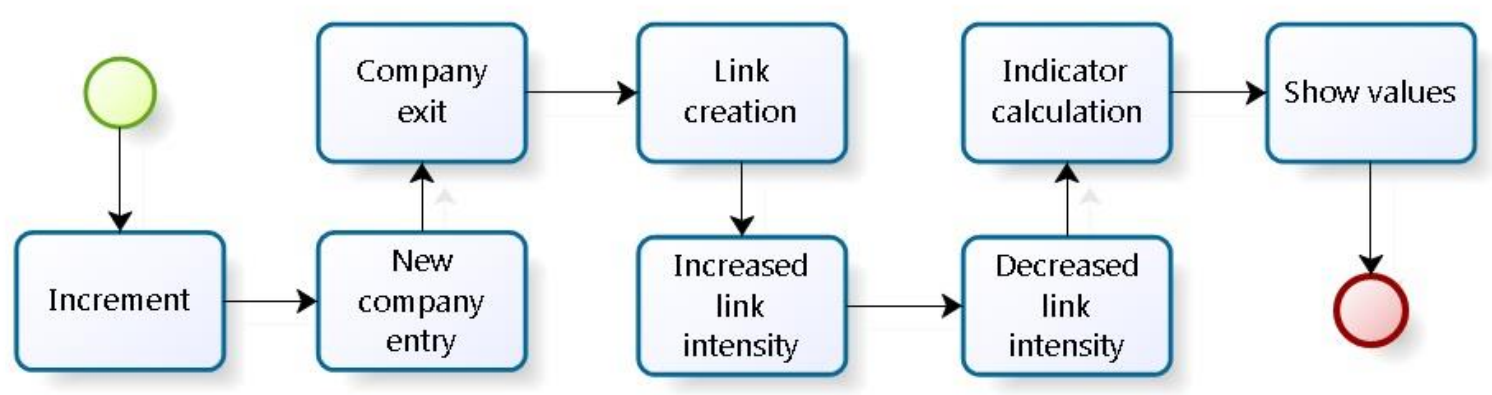

Source: The Authors

The Increment process varies the amount of by-product generated and each company's by-products absorption capacity with respect to the previous period. The process Indicator calculation, in addition to calculating the value of the three indicators, updates their graphs. The process Show values is responsible for listing the values of companies and links variables. Each process will be detailed further, in the subsection "Submodels". 


\subsection{Design concepts}

\section{a) Basic principles}

The concept of industrial symbiosis in EIPs is one of the basic principles used in EIPSymb. The others are the ISI, Eco-Connectance and By-product and Waste Recycling Rate indicators as well as their respective mathematical formulations.

\section{b) Emergence}

The numerical results of the ISI, Eco-Connectance and By-product and Waste Recycling Rate indicators represent the emerging EIPSymb phenomena.

\section{c) Sensing}

Companies are aware of the amount of their by-products that the other companies can still absorb. Thus, they do not send more by-products than the amount that companies with which they exchange by-products can absorb. Companies also realize when other companies with which they exchange byproducts had their by-product absorption capacities reduced, thus scale down the amount of by-products they send them. They also recognize the type of by-product that each company is able to absorb. Therefore, only compatible by-products are exchanged.

\section{d) Interaction}

The interactions between agents occur through two types of links:

- company-company: Dispatching of by-products from one company to another that uses the by-products as raw materials.

- company-landfill: By-products that are not exchanged with other companies in the EIP and are thus sent to the landfill.

\section{e) Stochasticity}

Various EIPSymb processes display random behaviors in which the uniform distribution is used:

- Increment: Each company's residue-generated and residue-absorptioncapacity variables may increase or decrease according to a rationale that involves randomness. 
- New company entry: Uses a randomness-based rationale to decide whether a new company enters.

- Once the company enters the EIP, another random process determines the type of product it will produce, therefore defining the type of by-product generated and the type of by-product used as raw material.

- Company exit: Uses a randomness-based logic to determine the exit of a company.

- Link creation: Considers a probability-based rationale to decide whether companies that do not yet exchange by-products will start this exchange.

- Increased links intensity: The intensity variable associated with the links of byproducts exchanged between companies depends on a randomness-based rationale to decide whether an increase will occur.

- Decreased links intensity: The intensity variable associated with the links of by-products exchanged between companies depends on a randomness-based rationale to decide whether a decrease will occur.

The processes described, except for the definition of the type of product produced in each company-and, consequently, the type of by-product generated and the type of by-product used as raw material-use input values provided by the EIPSymb user.

\section{f) Collectives}

The collective observed in EIPSymb is related to the fact that the assembly of companies forms an industrial park. However, when companies interact, they do not change their behavior, acting as a collective.

\section{g) Observation}

The communication of the results of the EIPSymb simulation includes the visualization of the following:

- NetLogo world in the current period.

- The current period, the number of companies, existing symbiosis links and possible symbiosis links in the current period.

- Values of the ISI, Eco-Connectance and By-product and Waste Recycling Rate indicators in the current period. 
- Graphic evolution of the ISI, Eco-Connectance and By-product and Waste Recycling Rate indicators over time.

- Values of each company's residue-generated, residue-absorption-capacity, residue-absorbed, type-residue-generated, and type-residue-used variables in the current period.

- Values of each link's intensity variable in the current period.

Figure 2 shows the EIPSymb output interface.

Figure 2 - Visualization of the EIPSymb outputs

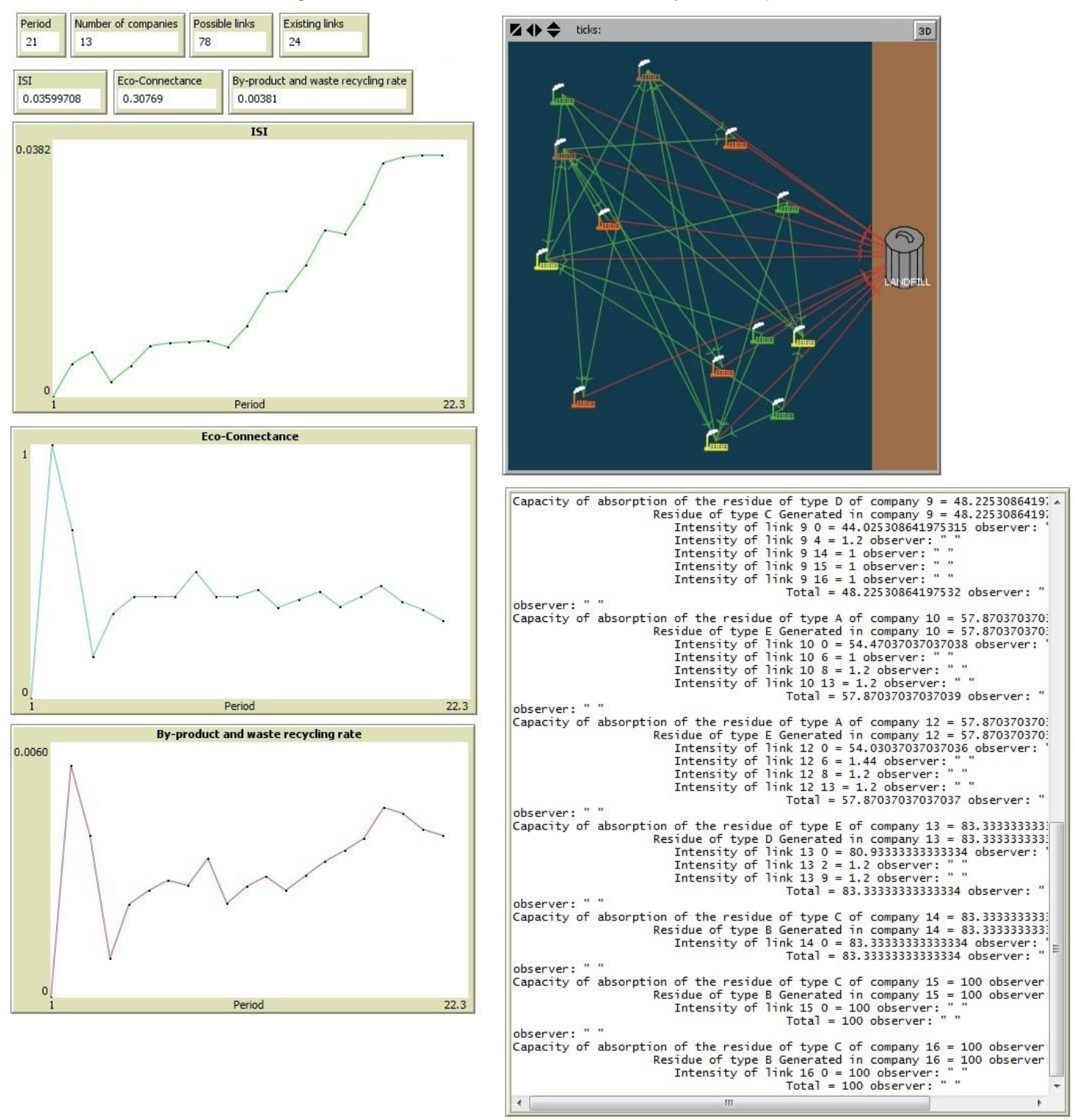

Source: The Authors 


\subsection{Details}

\section{a) Initialization}

The initialization of the EIPSymb is accomplished through the Setup command. The command differentiates local units and creates the agent landfill allocating it to a local unit external to the EIP. During the simulation, companies and links between those companies are created. When a company is created, the residue-generated and residue-absorption-capacity variables are given the same value, which is equal to $100 \mathrm{t}$. However, when a link between two companies is established, the intensity variable is given the value of $1 \mathrm{t}$.

\section{b) Input}

According to Grimm et al. (2010), this element is reserved to describe the utilization of external data and their sources. The EIPSymb does not use external data; however, the element "Input" was maintained to describe the input data used in the description of the simulation scenario. Such data must be supplied by the user at the start of the simulation and at any period interval considered desirable to change their values. Input data include:

- probability-of-entry-of-a-new-company: Value between $0 \%$ and $100 \%$ is used in the entry decision of a new company.

- probability-of-exit-of-a-company: Value between $0 \%$ and $100 \%$ is used in the exit decision of a company

- probability-of-creating-connection: Value between $0 \%$ and $100 \%$ is used in the decision to create new links between companies.

- probability-of-increasing-connection-intensity: Value between $0 \%$ and $100 \%$ is used in the decision to increase the amount of by-products exchanged between companies through existing links.

- probability-of-decreasing-connection-intensity: Value between $0 \%$ and $100 \%$ is used in the decision to decrease the amount of by-products exchanged between companies through existing links.

- probability-of-increasing-production: Value between $0 \%$ and $100 \%$ is used in the decision to increase the production of each company with a direct impact on the residue-generated and residue-absorption-capacity variables. 
- probability-of-decreasing-production: Value between $0 \%$ and $100 \%$ is used in the decision to decrease the production of each company with a direct impact on the residue-generated and residue-absorption-capacity variables.

- intensity-variation-step: This value must be greater than 1 and is used in processes that vary the link intensity between companies. This value represents the step in which link intensity is altered.

- increment-production. This value must be greater than 1 and is used in the Increment process that changes the values of each company's residuegenerated and residue-absorption-capacity variables. This value represents the step in which these variables are changed.

The evaluations of the criteria proposed by Felicio et al. (2016) for the classification of the generated by-products and for use in the calculation of the ISI are also input data. The possible classifications of each by-product are presented in Section 2.1, Table 1. Only the criterion "destination of by-product" is not classified since, in this simulation model, the only destination available when the by-products are not used is the landfill.

Figure 3 depicts the spaces intended for input data insertion.

Figure 3 - Input data

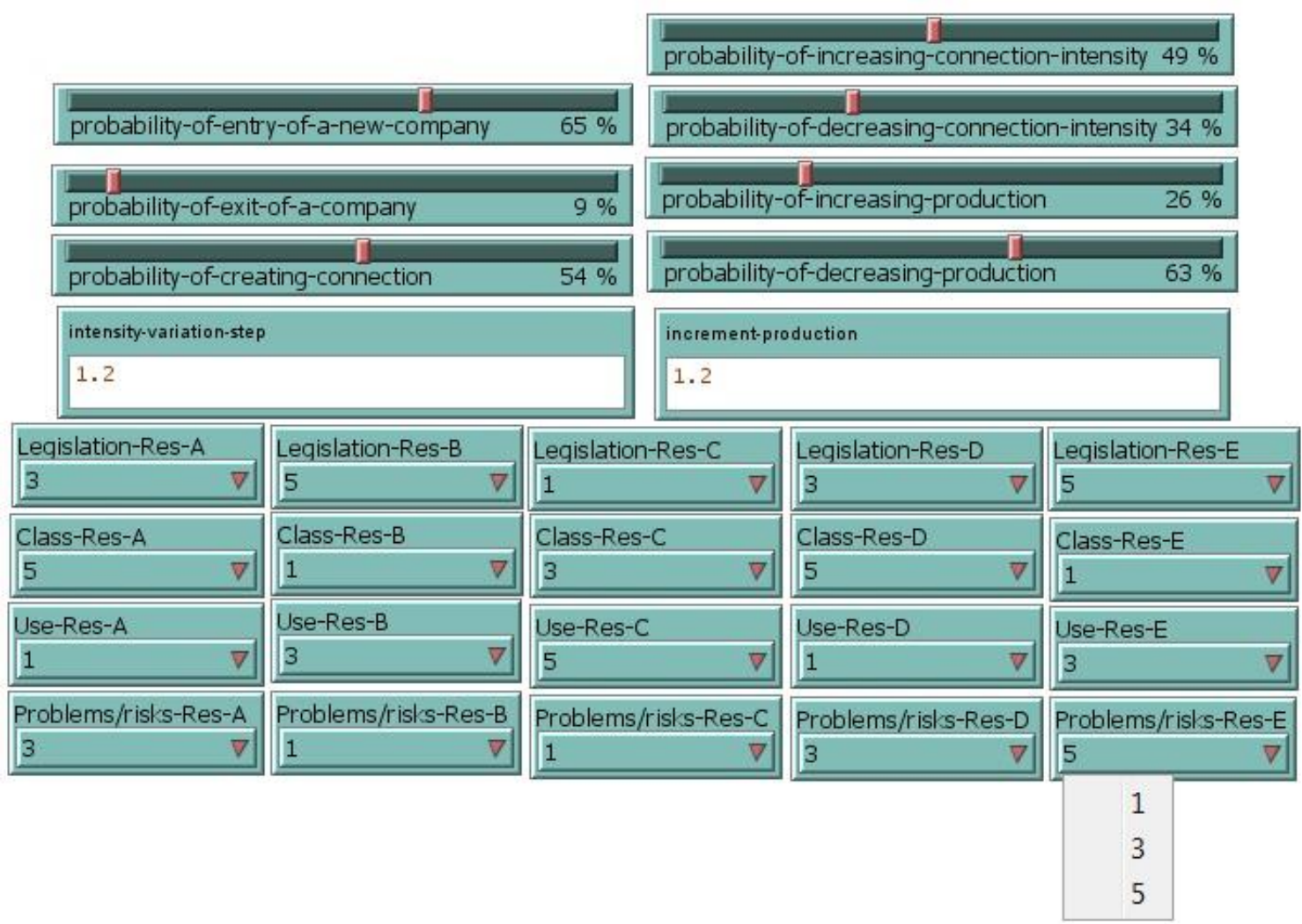

Source: The Authors 


\section{c) Submodels}

There are ten submodels in the EIPSymb, eight of them are shown in Figure 1:

- Setup: The Setup submodel is not depicted in the overview flowchart of the EIPSymb processes (Figure 1). It is already described in the subsection "Initialization". This submodel prepares the simulation environment.

- Increment. Responsible for changing each company's residue-generated and residue-absorption-capacity variables. It does so by using the incrementproduction input data to adjust the variation step.

- New Company Entry: Accounts for the entry of new companies into the EIP. It is also responsible for assigning values to each company's type-product, typeresidue-generated, and type-residue-used variables.

- Company Exit: Accounts for the exit of companies from the EIP.

- Link Creation: Responsible for creating new symbiotic links between EIP companies.

- Increased Links Intensity: This submodel aims to control the increase of the variable intensity of symbiotic links.

- Decreased Links Intensity: Controls the decrease of the variable intensity of symbiotic links.

- Indicator calculation: Accounts for the calculation of the numerical values of the three indicators used in the EIPSymb. It also updates their corresponding graphs. The values of the variable intensity of each link and the by-product classifications are used to calculate the ISI. The values of the number of companies, possible links, existing links, and link intensity variable are used to calculate the Eco-Connectance and the By-product and Waste Recycling Rate indicators.

- Show values: Lists the values of each company's residue-absorbed, residueabsorption-capacity, and residue-generated variables. It also lists the values of the link intensity variable.

- Residue absorption assistant: Responsible for updating the residue-absorbed variable. This submodel is not depicted in the overview flowchart of the EIPSymb processes (Figure 1). It is activated whenever the values of the intensity of one or more links change through the action of some submodel or activity. This occurs, for example, when a link's intensity decreases so that the 
receiving company will absorb fewer by-products. In that case, its residueabsorbed variable is updated through this submodel.

In order to better describe the EIPSymb, the flowcharts of some submodels are presented in the Appendix A. Furthermore, the Appendix C presents how to proceed to download and use the model. 


\section{SIMULATION}

In order to confirm the behavior of the indicators, the EIPSymb model was used to create different scenarios. These were conceived to represent potential situations occurring in a real EIP. Not all possible situations need to be represented, but only a subset that enables the evaluation of the indicators' behavior in different situations. There are four primary scenarios and two additional scenarios derived from two of these primary scenarios.

Scenario 1 represents an optimal situation for the development of industrial symbiosis. In this scenario, companies exchange by-products with all other companies that use those by-products as raw materials, as long as there is available by-product in the donor company and a need for it in the receiving company. The links intensity and the production of each company are always increased, but the rate at which links intensity grows is higher than the rate at which companies increase their production. It is initiated from zero, i.e., with no company in the EIP. In order to represent an expanding park, a new company enters the EIP at every period but none leave it. The classification of the by-products, performed in agreement with Felicio et al. (2016) for the calculation of the ISI (Table 1), aims to classify byproducts displaying the lowest possible environmental impact.

Scenario 1', in which only the classification of the by-products is different, was also created. These classifications are opposed to those in Scenario 1, since they aim to represent the by-products with the highest possible environmental impact. In both scenarios, 25 periods are simultaneously simulated.

Scenario 2 represents an unstable situation where it cannot be predicted what may happen in the coming periods. The entry rate for a company in the EIP is high; however, its exit rate is also high, thus generating a high turnover within the park. Input data are defined in such a way that increments of the links intensity and in each company's production are unpredictable, i.e., increasing, decreasing, or remaining stable for distinct instances. The classification of the by-products is performed in such a way to present three by-products classified as having a high environmental impact potential and two others with low environmental impact potential.

In order to establish a similar relation to the one existing between Scenarios 1 and 1', Scenario 2' is created by changing the classifications of the by-products in relation to Scenario 2. By-products classified as having a high impact potential in 
Scenario 2 are now classified as having a low impact potential, and the reverse also occurs. In both scenarios, 35 periods are simultaneously simulated.

Before starting the simulation of Scenario 3, a maturation period is performed. This maturation period is calibrated to only entry of a single company by period, no other process is accomplished. It is simulated during 15 periods, and in the final section of this maturation period, there are 15 companies in the park. These companies do not exchange any by-products with other companies, all are sent to the landfill, so the values of the indicators are null. Scenario 3 represents a conservative situation regarding the evolution of industrial symbiosis, i.e., a situation in which companies are hesitant to cooperate with each other, but when cooperation between two companies is initiated it tends to increase, although at a low rate. The companies' production also increases at a low rate. In this scenario, there are no companies entering or exiting the EIP. Therefore, the companies that were created at the maturation period are the ones that comprise this scenario. The classification of the by-products is made to have all types of classifications among the by-products. This scenario is initiated after the 15 periods of the maturation period and simulated for 25 periods.

Scenario 4 represents a completely adverse situation to the development of industrial symbiosis. In this scenario, companies barely create links for by-product exchange, and the existing links tend toward lower intensities until extinguished. The entry probability of a company is average, while its exit probability is low. Furthermore, the companies' production volumes tend to increase, thus aggravating the result of industrial symbiosis given the increase in the amount of by-products sent to the landfill. This scenario is initiated after 25 periods simulated in Scenario 3. The classification of by-products is made to have all types of classification among the byproducts. This scenario is simulated for 20 periods.

Table 4 shows the specific values of the input parameters used in each scenario. 
Table 4 - Values of input parameters used in the scenarios

\begin{tabular}{|c|c|c|c|c|c|c|}
\hline \multirow[b]{2}{*}{ Entry parameter } & \multicolumn{6}{|c|}{ Scenarios } \\
\hline & 1 & 1 ' & 2 & $2^{\prime}$ & 3 & 4 \\
\hline $\begin{array}{l}\text { Probability of entry of a new } \\
\text { company }\end{array}$ & $100 \%$ & $100 \%$ & $80 \%$ & $80 \%$ & $0 \%$ & $50 \%$ \\
\hline $\begin{array}{l}\text { Probability of exit of a } \\
\text { company }\end{array}$ & $0 \%$ & $0 \%$ & $2 \%$ & $2 \%$ & $0 \%$ & $1 \%$ \\
\hline $\begin{array}{l}\text { Probability of creating } \\
\text { connection }\end{array}$ & $100 \%$ & $100 \%$ & $40 \%$ & $40 \%$ & $15 \%$ & $5 \%$ \\
\hline $\begin{array}{l}\text { Probability of increasing } \\
\text { connection intensity }\end{array}$ & $100 \%$ & $100 \%$ & $50 \%$ & $50 \%$ & $50 \%$ & $5 \%$ \\
\hline $\begin{array}{l}\text { Probability of decreasing } \\
\text { connection intensity }\end{array}$ & $0 \%$ & $0 \%$ & $25 \%$ & $25 \%$ & $5 \%$ & $50 \%$ \\
\hline $\begin{array}{l}\text { Probability of increasing } \\
\text { production }\end{array}$ & $100 \%$ & $100 \%$ & $50 \%$ & $50 \%$ & $50 \%$ & $50 \%$ \\
\hline $\begin{array}{l}\text { Probability of decreasing } \\
\text { production }\end{array}$ & $0 \%$ & $0 \%$ & $50 \%$ & $50 \%$ & $5 \%$ & $5 \%$ \\
\hline Intensity variation step & 2.0 & 2.0 & 1.5 & 1.5 & 1.05 & 1.2 \\
\hline Production increment & 1.1 & 1.1 & 1.5 & 1.5 & 1.05 & 1.2 \\
\hline Legislation of by-product $A$ & 1 & 5 & 5 & 1 & 1 & 3 \\
\hline Class of by-product $A$ & 1 & 5 & 5 & 1 & 3 & 5 \\
\hline Use of by-product A & 5 & 1 & 1 & 5 & 5 & 1 \\
\hline Problem/risks of by-product $A$ & 1 & 5 & 5 & 1 & 1 & 3 \\
\hline Legislation of by-product B & 1 & 5 & 5 & 1 & 3 & 5 \\
\hline Class of by-product $B$ & 1 & 5 & 5 & 1 & 5 & 1 \\
\hline Use of by-product B & 5 & 1 & 1 & 5 & 1 & 3 \\
\hline Problem/risks of by-product B & 1 & 5 & 5 & 1 & 3 & 5 \\
\hline Legislation of by-product C & 1 & 5 & 1 & 5 & 5 & 1 \\
\hline Class of by-product $C$ & 1 & 5 & 1 & 5 & 1 & 3 \\
\hline Use of by-product $C$ & 5 & 1 & 5 & 1 & 3 & 5 \\
\hline Problem/risks of by-product $\mathrm{C}$ & 1 & 5 & 1 & 5 & 5 & 1 \\
\hline Legislation of by-product $D$ & 1 & 5 & 1 & 5 & 1 & 3 \\
\hline Class of by-product $D$ & 1 & 5 & 1 & 5 & 3 & 5 \\
\hline Use of by-product $D$ & 5 & 1 & 5 & 1 & 5 & 1 \\
\hline Problem/risks of by-product $D$ & 1 & 5 & 1 & 5 & 1 & 3 \\
\hline Legislation of by-product E & 1 & 5 & 1 & 5 & 3 & 5 \\
\hline Class of by-product $\mathrm{E}$ & 1 & 5 & 1 & 5 & 5 & 1 \\
\hline Use of by-product E & 5 & 1 & 5 & 1 & 1 & 3 \\
\hline Problem/risks of by-product $\mathrm{E}$ & 1 & 5 & 1 & 5 & 3 & 5 \\
\hline
\end{tabular}


There are two conditions that are constant in all scenarios:

- By-products not reused by the companies are sent to the landfill.

- The evaluation criteria proposed by Felicio et al. (2016) for the calculation of the ISI all have the same weight, i.e., 0.25.

\subsection{Scenario 1 and Scenario 1'}

Figure 4 shows the graphical evolution of the three indicators. The graphical evolution of the ISI is depicted by two curves. One curve represents Scenario 1 and is designated as ISI, while the other curve represents Scenario 1' and is named ISI'. The other two indicators (Eco-Connectance and By-product and Waste Recycling Rate) assume equal values in both scenarios since the classification of the byproducts has no influence over their values. To assist in the understanding and interpretation of the graphical evolution of the indicators, some outputs and details regarding the simulation is provided in the Appendix $B$. 
Figure 4-Graphical evolution of indicators in Scenarios 1 and 1'
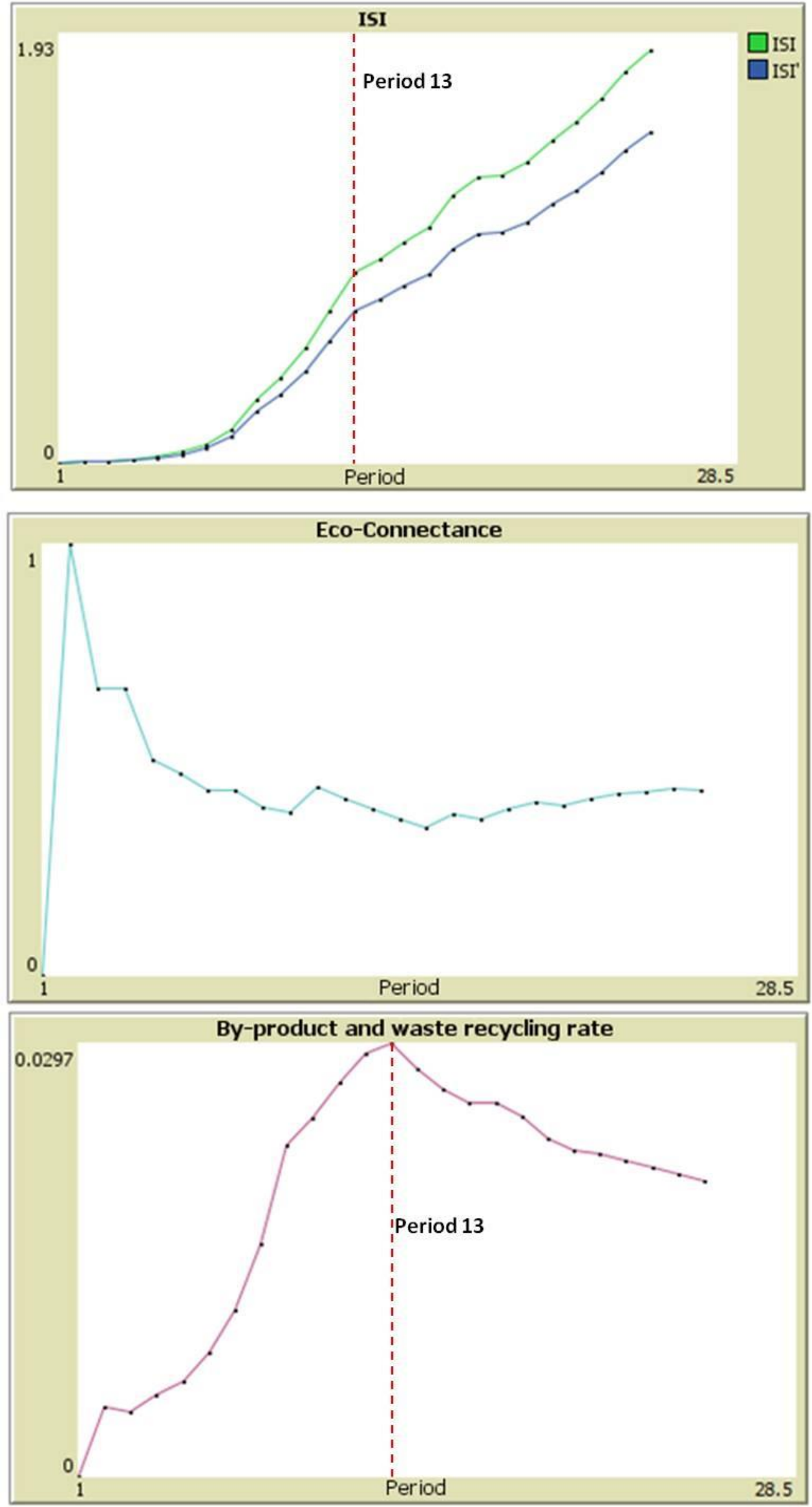

Source: The Authors 
The Eco-Connectance indicator has a very high variation in the beginning and then remains practically stable. This occurs because at the beginning there are only a few companies, and any change, however small, in the number of symbiotic links or number of companies in the park produces a large change in the value of the indicator. Following this turbulent period, the indicator value remains stable within the same level. This value represents the equilibrium level of the Eco-Connectance indicator for the established scenario.

When comparing the ISI with the By-product and Waste Recycling Rate indicator, the existence of two distinct phases can be observed. The first phase goes up to Period 13, in which the two indicators display a marked tendency to increase in value. The second phase, following Period 13 onward, is represented by the ISI continuing to increase (though at a less pronounced rate) while the By-product and Waste Recycling Rate indicator begins to drop. This happens after some companies that are in the EIP for more time have $100 \%$ of their by-products sent to other companies, thus the symbiotic links between these companies cannot increase the percentage of exchanged by-product. On the other hand, there are new companies entering in the EIP that are still sending little-to-none by-products to other companies. Over the evaluation periods, the combination of these two events intensifies causing a negative influence on the trend of both indicators. However, there is greater rigor in the By-product and Waste Recycling Rate since the indicator considers the percentage of exchanged by-products and not the absolute quantities, as does the ISI.

This result provides an indication that the Eco-Connectance and By-product and Waste Recycling Rate indicators are not robust to changes in the quality of exchanged wastes or to changes in the volume of discarded and reused by-products. Lastly, the difference between the ISI and ISI' values can be noted. This difference is exclusively rooted in the different classifications of the by-products, thus proving that this indicator is sensitive to changes in the type of waste exchanged.

\subsection{Scenario 2 and Scenario 2'}

Likewise, as with Scenarios 1 and 1', Scenarios 2 and 2' were simulated simultaneously. Figure 5 depicts the graphical evolution of the indicators. Appendix B also provides information on the simulation of these scenarios. 
Figure 5 - Graphical evolution of indicators in Scenarios 2 and 2'
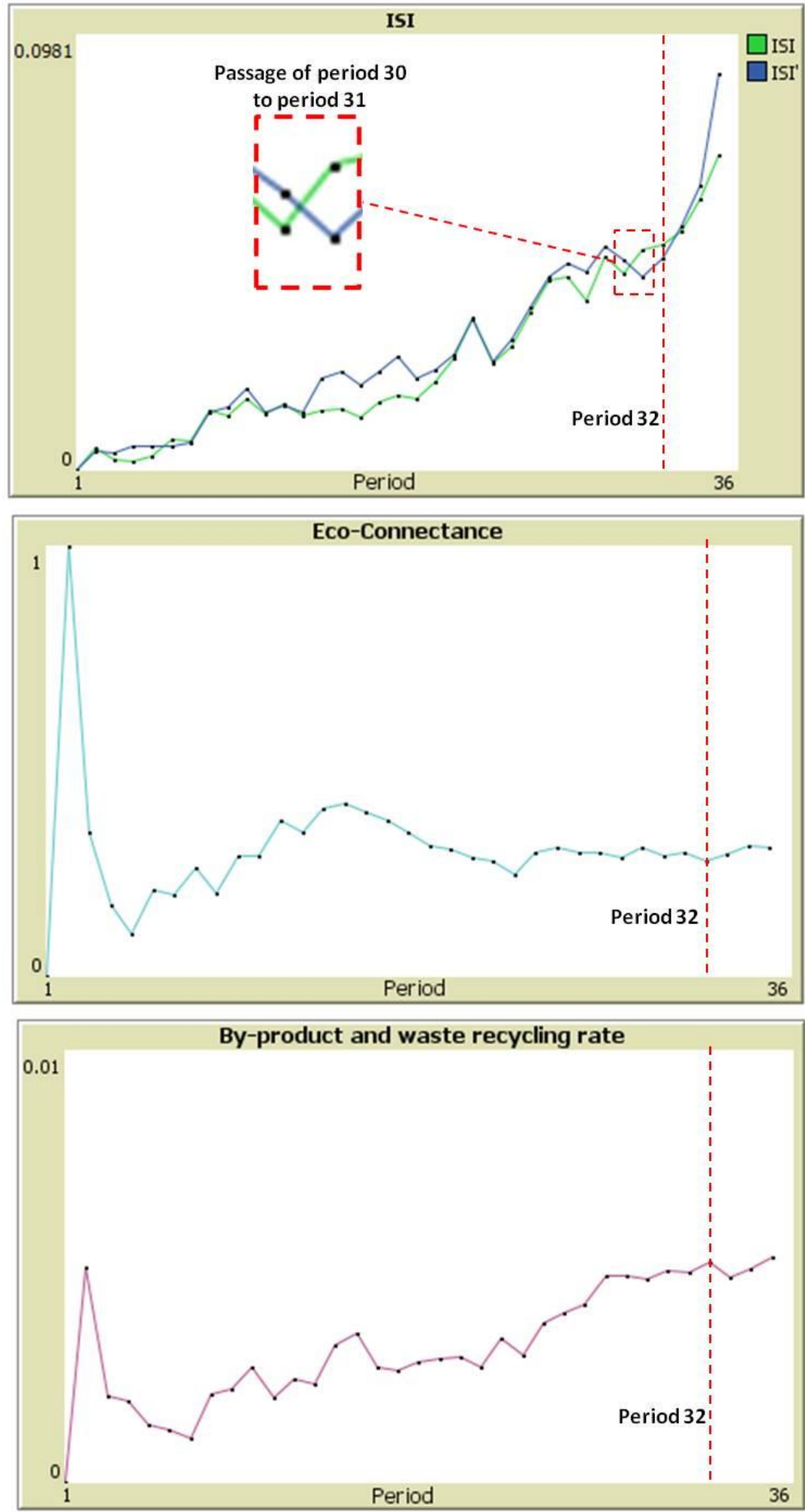

Source: The Authors 
There are moments where ISI increases while ISI' decreases. This behavior can be observed in Figure 5, which highlights the passage of Period 30 to Period 31. This occurs as a consequence of the differences in the classifications of the byproducts between Scenarios 2 and 2'. In fact, in Scenario 2, by-products A, B, and C are classified as displaying a high environmental impact, while by-products $D$ and $E$ are classified as displaying a low impact. In Scenario 2', however, the reverse is true, i.e., by-products $\mathrm{A}, \mathrm{B}$, and $\mathrm{C}$ are classified as displaying a low environmental impact, while by-products $D$ and $E$ are classified as displaying a high impact. From period 30 to period 31, the percentage of recycled by-products from set A, B, and C increases, while the percentage of recycled by-products of set $D$ and $E$ decreases. This has a positive impact on the ISI value and a negative impact on the ISI' value. The opposite also occurs; for example, there are times when the ISI' increases while the ISI decreases.

At other instances, the ISI, ISI' and indicator of Eco-Connectance increase, but the By-product and Waste Recycling Rate indicator decreases. This occurs when going from Period 32 to Period 33 and can also be observed in Figure 5, in which Period 32 is highlighted. The explanation for this phenomenon is the same as in Scenarios 1 and 1'. The ISI takes into account the amounts of by-products while the By-product and Waste Recycling Rate takes into consideration the percentage of each symbiotic link with respect to those produced by the transferring company. It is thus possible that the average percentage of by-products exchanged in the links may decrease. This decrease may occur despite the creation of new connections that produce an increase in the value of the Eco-Connectance indicator and despite the fact that the total percentage of by-products reused in the EIP increases thereby contributing to increased ISI and ISI' values. This potential situation results from the presence of new links which, although newer, still exchange few by-products, thus negatively affecting the value of the By-product and Waste Recycling Rate indicator.

\subsection{Scenario 3 and Scenario 4}

The graphical evolution of the three indicators in both scenarios is depicted in Figure 6. Likewise, as with the previous scenarios, some information on the simulation of both scenarios is provided in Appendix B. 
Figure 6 - Graphical evolution of indicators in Scenarios 3 and 4
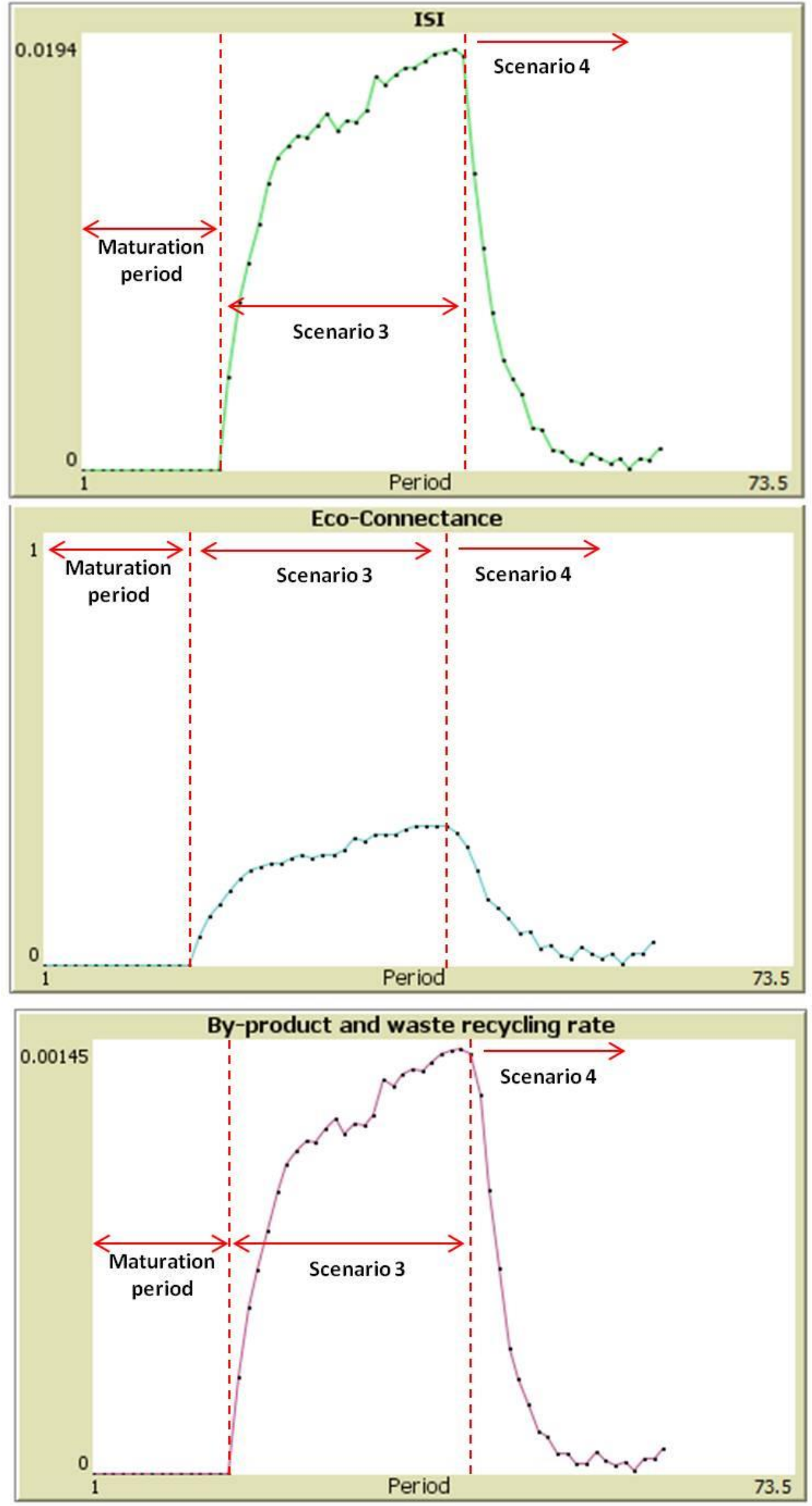

Source: The Authors 
As shown in Figure 6, in Scenario 3 the three indicators display a sharp increase at the beginning of the simulation and soon reach an equilibrium. Despite this, both the ISI and By-product and Waste Recycling Rate indicator display low values owing to the conservative approach used in the calibration of the scenario. The equilibrium level of the three indicators represents the moment at which all possible industrial symbiosis links established by the 15 companies in the EIP in the given scenario are reached. Afterward, the ISI and By-product and Waste Recycling Rate indicator do not increase, although the waste quantities exchanged by the symbiotic links increase. This occurs because the increasing rate at which the companies' production, and consequently the by-products generated, increases. Only small changes are detected.

Alternately, as might be expected, the values of the three indicators displayed a steep decrease in Scenario 4. Although the values of the indicators in this simulation did not reach zero at any time, and in some periods a small increase was observed, the values of the indicators were always very low. In fact, for the last period they reached the following values: (i) $I S I=0.00096$; (ii) Eco-Connectance $=$ 0.05667; and (iii) By-product and Waste Recycling Rate $=0.00009$. Furthermore, only $0.116 \%$ of the park's by-products were reused. 


\section{CONCLUSIONS}

The results demonstrated that the EIPSymb model allowed for the calculation of the indicators and described their behaviors in different situations, reproducing different symbiosis conditions and wastes with distinct impact levels.

The simulation showed an enhanced robustness of the ISI results. The ISI was able to correctly represent increasing and decreasing trends during symbiosis and under conditions in which the indicators proposed by Tiejun (2010) failed. In other conditions, both proved to be sufficient.

Regarding the pair of indicators proposed by Tiejun (2010), the EcoConnectance indicator always tended toward an equilibrium level, even when symbiosis was clearly being enhanced. The By-product and Waste Recycling Rate indicator presented misleading results in certain conditions, because its numerical value may have decreases even when the percentage of recycled by-products in the park increases, (see Scenarios 1 and 1').

Although these restrictions are hypothetically identifiable in the indicator formula, the simulation allowed a systematic identification of the conditions of use of the indicators. The EIPSymb model allowed the identification of condition segments under which the indicators may present misleading information about the evolution of industrial symbiosis in the EIP. This type of analysis allows a more precise assessment of the robustness of the indicator for the park conditions and waste impact levels. Therefore, this model performs beyond the limits of mere conceptual validation even though real data was not used as an input.

Another advantage of this type of simulation is the fact that owing to its systematic nature, this model can be applied to a larger number of indicators, as, for example, the Eco-Efficiency indicator, by Park and Behera (2014). Thus, it allows comparisons in which the outcome is more didactic to users, as it provides more precise and detailed recommendations for the use of certain indicators to professionals in the area. This is certainly an advantage as the validation procedure must also convince the end users of the quality of the indicators.

The simulation clearly demonstrated the effect of the type of waste and its level of impact on the evaluation of the symbiosis. Therefore, this aspect must be taken into consideration in any system of indicators used to assess industrial symbiosis. Indicators that do not take into account these aspects are only useful in 
extreme conditions of perfect symbiosis or unfavorable environments for symbiosis. In addition, their use is not recommended in the case of turbulent environments or when measurements are performed for longer periods of time.

This work identified several issues for improvement in the EIPSymb model, such as the possibility of shipping the by-products not redeemed within the park to other EIPs. Another issue raised is the possibility of initiating the residue-generated and residue-absorption-capacity variables of the agent company and the intensity variable, associated with the symbiosis links, with different values instead of the same default value. These improvements should contribute to refining and enhancing the simulation model.

By enhancing and refining the EIPSymb model, many research outlets become possible: (i) consideration of other industrial symbiosis indicators, (ii) studying the financial aspects inherent to symbiotic interactions, and (iii) the use of actual data representing the evolution of a real EIP to calibrate the input data, thus creating scenarios that more closely resemble reality. These are just some of the possibilities. 


\section{ACKNOWLEDGEMENTS}

The authors thank FAPESP (São Paulo Research Foundation) for funding support through grants No. 2014/11464-0 and No. 2015/17192-5. 


\section{APPENDIX A - SUBMODELS FLOWCHARTS}

The flowcharts of some submodels are presented in this appendix.

Figure A.1 - Flowchart of Increment submodel

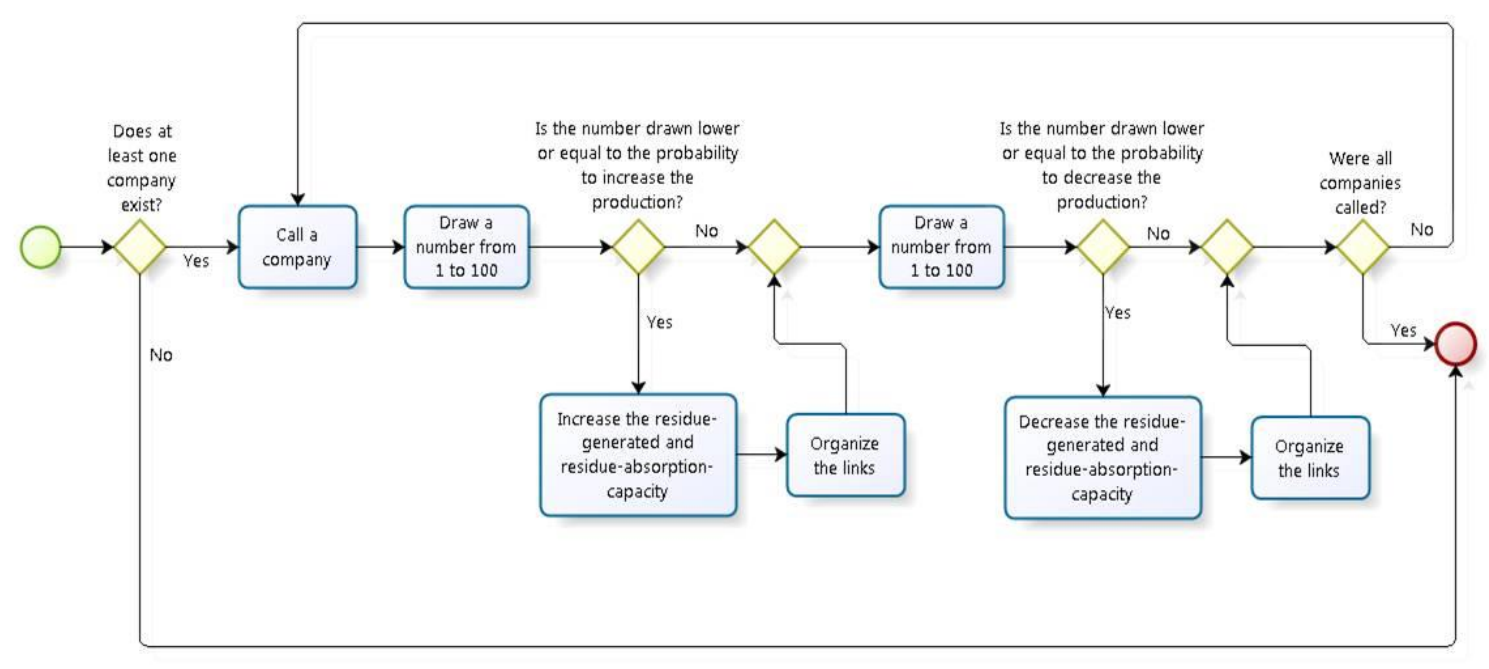

Source: The Authors

Figure A.2 - Flowchart of New Company Entry submodel

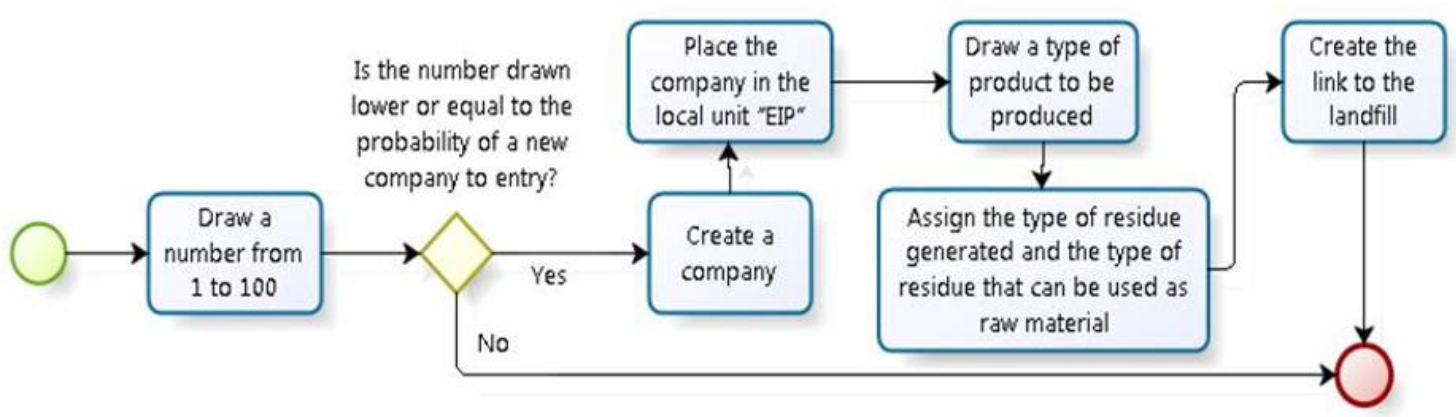

Source: The Authors 
Figure A.3 - Flowchart of Company Exit submodel

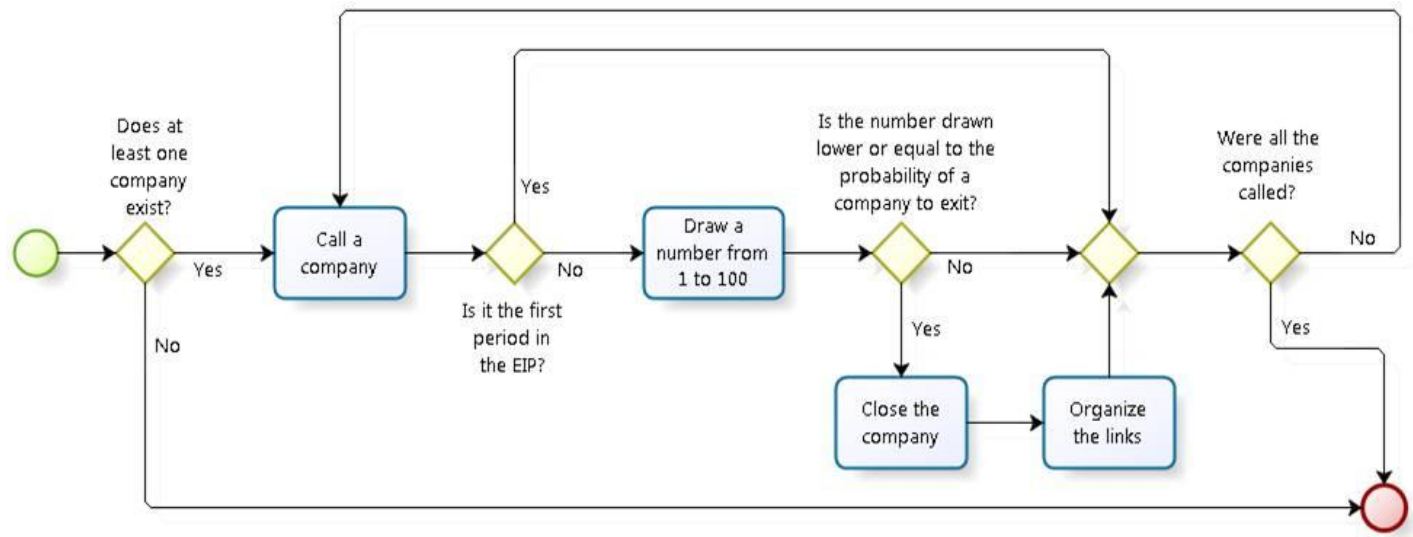

Source: The Authors

Figure A.4 - Flowchart of Link Creation submodel

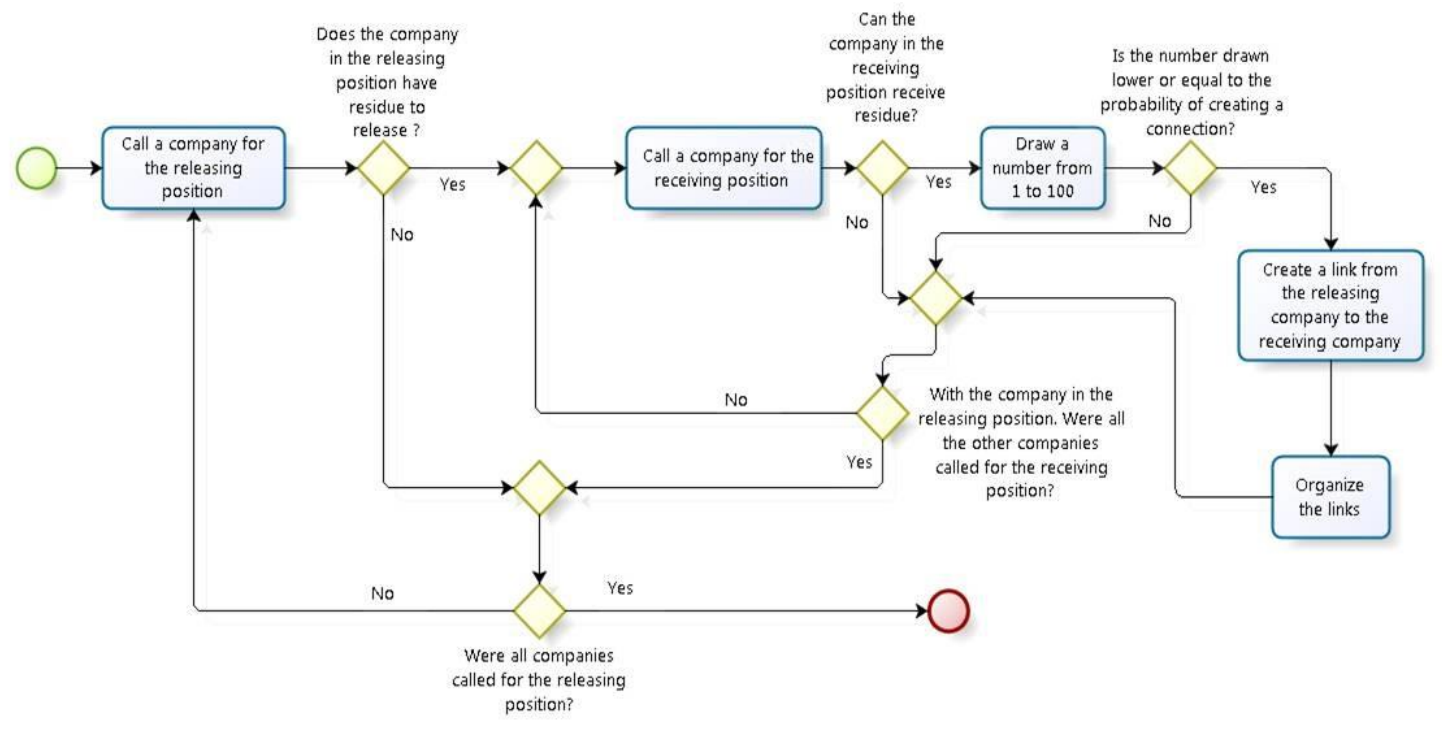

Source: The Authors 
Figure A.5 - Flowchart of Increased Links Intensity submodel

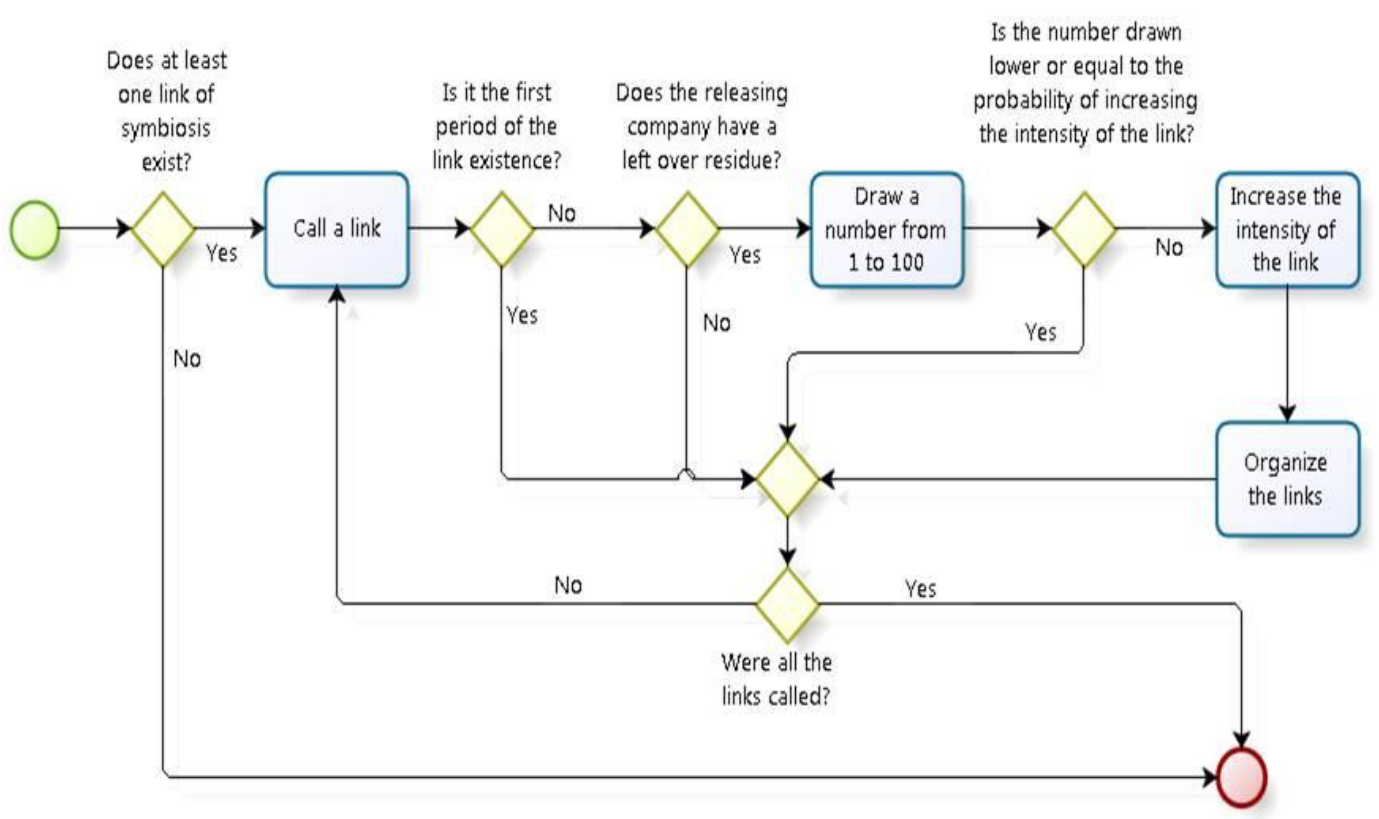

Source: The Authors

Figure A.6. Flowchart of Decreased Links Intensity submodel

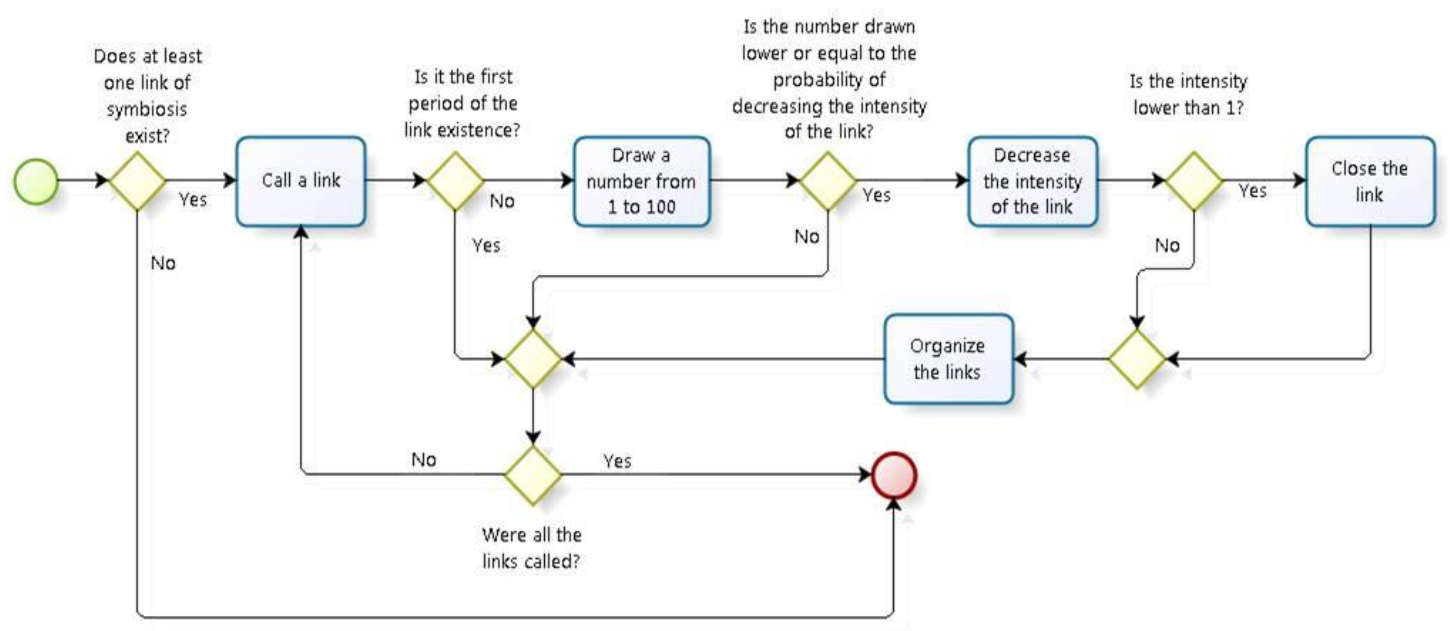

Source: The Authors

The Organize the links activity can be found in most submodels' flowcharts. This activity is responsible for adjusting the intensity variable of each link that is influenced by previous activities of the submodel. If necessary, this activity can also create links to the landfill. 


\section{APPENDIX B - SCENARIOS DETAILS}

In this appendix, we present the output values and some details about the simulation of the scenarios. The Tables B.5 and B.6 are initiated at period 16, since there is a maturation period of 15 periods before the simulation of Scenario 3 . The Tables B.7 and B. 8 are initiated at period 41, because Scenario 4 begins after Scenario 3.

Table B.1 - Values of the simulation of Scenarios 1 and 1" (continue)

\section{Scenarios 1 and 1}

\begin{tabular}{|c|c|c|c|c|c|c|c|c|c|}
\hline Period & ISI & ISI' & Eco-Connectance & $\begin{array}{c}\text { By-product and } \\
\text { Waste Recycling } \\
\text { Rate }\end{array}$ & $\begin{array}{l}\text { Number of } \\
\text { companies }\end{array}$ & $\begin{array}{l}\text { Existing } \\
\text { links }\end{array}$ & $\begin{array}{l}\text { Possible } \\
\text { links }\end{array}$ & $\begin{array}{c}\text { Amount of } \\
\text { generated by- } \\
\text { product }\end{array}$ & $\begin{array}{l}\% \text { of reused } \\
\text { by-product }\end{array}$ \\
\hline 1 & 0.00000 & 0.00000 & 0.00000 & 0.00000 & 1 & 0 & 0 & 100.000 & 0.000 \\
\hline 2 & 0.00477 & 0.00382 & 1.00000 & 0.00476 & 2 & 1 & 1 & 210.000 & 0.476 \\
\hline 3 & 0.00913 & 0.00731 & 0.66666 & 0.00447 & 3 & 2 & 3 & 331.000 & 0.906 \\
\hline 4 & 0.01752 & 0.01403 & 0.66666 & 0.00558 & 4 & 4 & 6 & 464.100 & 1.724 \\
\hline 5 & 0.02861 & 0.02290 & 0.50000 & 0.00656 & 5 & 5 & 10 & 610.510 & 2.785 \\
\hline 6 & 0.04891 & 0.03914 & 0.46666 & 0.00849 & 6 & 7 & 15 & 771.561 & 4.666 \\
\hline 7 & 0.08455 & 0.06766 & 0.42857 & 0.01139 & 7 & 9 & 21 & 948.717 & 7.800 \\
\hline 8 & 0.15205 & 0.12168 & 0.42857 & 0.01595 & 8 & 12 & 28 & 1143.589 & 13.204 \\
\hline 9 & 0.28830 & 0.23071 & 0.38889 & 0.02274 & 9 & 14 & 36 & 1357.948 & 22.387 \\
\hline 10 & 0.38283 & 0.30634 & 0.37778 & 0.02461 & 10 & 17 & 45 & 1593.743 & 27.693 \\
\hline 11 & 0.51942 & 0.41564 & 0.43636 & 0.02700 & 11 & 24 & 55 & 1853.116 & 34.195 \\
\hline 12 & 0.68518 & 0.54827 & 0.40909 & 0.02899 & 12 & 27 & 66 & 2138.429 & 40.669 \\
\hline 13 & 0.85339 & 0.68286 & 0.38462 & 0.02967 & 13 & 30 & 78 & 2452.270 & 46.054 \\
\hline 14 & 0.91606 & 0.73299 & 0.36264 & 0.02790 & 14 & 33 & 91 & 2797.499 & 47.818 \\
\hline
\end{tabular}


Table B. 1 - Values of the simulation of Scenarios 1 and 1" (continuation)

\section{Scenarios 1 and 1}

\begin{tabular}{|c|c|c|c|c|c|c|c|c|c|}
\hline Period & ISI & ISI' & Eco-Connectance & $\begin{array}{c}\text { By-product and } \\
\text { Waste Recycling } \\
\text { Rate }\end{array}$ & $\begin{array}{l}\text { Number of } \\
\text { companies }\end{array}$ & $\begin{array}{l}\text { Existing } \\
\text { links }\end{array}$ & $\begin{array}{l}\text { Possible } \\
\text { links }\end{array}$ & $\begin{array}{l}\text { Amount of } \\
\text { generated by- } \\
\text { product }\end{array}$ & $\begin{array}{l}\% \text { of reused } \\
\text { by-product }\end{array}$ \\
\hline 15 & 0.99282 & 0.79441 & 0.34286 & 0.02655 & 15 & 36 & 105 & 3177.248 & 49.828 \\
\hline 17 & 1.20022 & 0.96033 & 0.36029 & 0.02559 & 17 & 49 & 136 & 4054.470 & 54.557 \\
\hline 18 & 1.28119 & 1.02510 & 0.38562 & 0.02474 & 18 & 59 & 153 & 4559.917 & 56.169 \\
\hline 21 & 1.45189 & 1.16165 & 0.40952 & 0.02215 & 21 & 86 & 210 & 6400.250 & 59.220 \\
\hline 22 & 1.53225 & 1.22593 & 0.41991 & 0.02161 & 22 & 97 & 231 & 7140.275 & 60.514 \\
\hline 23 & 1.63612 & 1.30902 & 0.42688 & 0.02117 & 23 & 108 & 253 & 7954.302 & 62.069 \\
\hline 24 & 1.75534 & 1.40441 & 0.43116 & 0.02074 & 24 & 119 & 276 & 8849.732 & 63.711 \\
\hline
\end{tabular}

Source: The Authors 
Table B.2 - Details of the simulation of Scenarios 1 and 1" (continue) 
Table B.2 - Details of the simulation of Scenarios 1 and 1" (continuation)

\begin{tabular}{|c|c|c|c|c|c|c|c|c|c|c|}
\hline \multicolumn{11}{|c|}{ Scenarios 1 and 1 ' } \\
\hline Period & $\begin{array}{l}\text { Amount of } \\
\text { generated by- } \\
\text { product of } \\
\text { type A }\end{array}$ & $\begin{array}{l}\% \text { of } \\
\text { reused by- } \\
\text { product of } \\
\text { type } A\end{array}$ & $\begin{array}{l}\text { Amount of } \\
\text { generated by- } \\
\text { product of } \\
\text { type B }\end{array}$ & $\begin{array}{l}\quad \% \text { of } \\
\text { reused by- } \\
\text { product of } \\
\text { type B }\end{array}$ & $\begin{array}{l}\text { Amount of } \\
\text { generated by- } \\
\text { product of } \\
\text { type C }\end{array}$ & $\begin{array}{l}\text { \% of } \\
\text { reused by- } \\
\text { product of } \\
\text { type C }\end{array}$ & $\begin{array}{l}\text { Amount of } \\
\text { generated by- } \\
\text { product of } \\
\text { type D }\end{array}$ & $\begin{array}{l}\quad \% \text { of } \\
\text { reused by- } \\
\text { product of } \\
\text { type D }\end{array}$ & $\begin{array}{l}\text { Amount of } \\
\text { generated by- } \\
\text { product of } \\
\text { type } E\end{array}$ & $\begin{array}{l}\% \text { of } \\
\text { reused by- } \\
\text { product of } \\
\text { type } E\end{array}$ \\
\hline 20 & 1499.243 & 68.882 & 2155.303 & 66.247 & 231.000 & 19.048 & 809.240 & 2.224 & 1032.714 & 74.375 \\
\hline 21 & 1649.167 & 68.882 & 2370.833 & 68.713 & 354.100 & 27.111 & 890.164 & 4.381 & 1135.986 & 78.360 \\
\hline 22 & 1914.084 & 65.284 & 2607.916 & 69.867 & 389.510 & 49.293 & 979.180 & 7.966 & 1249.584 & 78.360 \\
\hline 23 & 2205.492 & 62.324 & 2868.708 & 70.293 & 428.461 & 73.064 & 1077.098 & 14.483 & 1374.543 & 78.360 \\
\hline 24 & 2426.041 & 62.324 & 3155.579 & 70.701 & 571.307 & 71.802 & 1184.808 & 25.334 & 1511.997 & 78.360 \\
\hline 25 & 2668.645 & 62.324 & 3571.137 & 69.517 & 628.438 & 82.431 & 1303.289 & 32.689 & 1663.196 & 78.360 \\
\hline
\end{tabular}


Table B. 3 - Values of the simulation of Scenarios 2 and 2" (continue)

\section{Scenarios 2 and 2}

\begin{tabular}{|c|c|c|c|c|c|c|c|c|c|}
\hline Period & ISI & ISI' & Eco-Connectance & $\begin{array}{c}\text { By-product and } \\
\text { Waste Recycling } \\
\text { Rate }\end{array}$ & $\begin{array}{l}\text { Number of } \\
\text { companies }\end{array}$ & $\begin{array}{l}\text { Existing } \\
\text { links }\end{array}$ & $\begin{array}{l}\text { Possible } \\
\text { links }\end{array}$ & $\begin{array}{l}\text { Amount of } \\
\text { generated by- } \\
\text { product }\end{array}$ & $\begin{array}{l}\% \text { of reused } \\
\text { by-product }\end{array}$ \\
\hline 1 & 0.00000 & 0.00000 & 0.00000 & 0.00000 & 1 & 0 & 0 & 100.000 & 0.000 \\
\hline 3 & 0.00240 & 0.00389 & 0.33333 & 0.00200 & 3 & 1 & 3 & 266.667 & 0.375 \\
\hline 4 & 0.00198 & 0.00517 & 0.16667 & 0.00188 & 4 & 1 & 6 & 383.333 & 0.391 \\
\hline 7 & 0.00658 & 0.00596 & 0.19048 & 0.00101 & 7 & 4 & 21 & 694.444 & 0.720 \\
\hline 8 & 0.01351 & 0.01295 & 0.25000 & 0.00205 & 8 & 7 & 28 & 644.444 & 1.513 \\
\hline 9 & 0.01209 & 0.01423 & 0.19444 & 0.00216 & 9 & 7 & 36 & 688.889 & 1.524 \\
\hline 10 & 0.01602 & 0.01826 & 0.27778 & 0.00267 & 9 & 10 & 36 & 811.111 & 1.973 \\
\hline 15 & 0.01385 & 0.02220 & 0.40000 & 0.00343 & 10 & 18 & 45 & 1536.111 & 2.026 \\
\hline 16 & 0.01180 & 0.01919 & 0.38182 & 0.00266 & 11 & 21 & 55 & 2112.500 & 1.749 \\
\hline 17 & 0.01544 & 0.02198 & 0.36364 & 0.00257 & 12 & 24 & 66 & 2279.167 & 2.125 \\
\hline 18 & 0.01681 & 0.02573 & 0.33333 & 0.00279 & 13 & 26 & 78 & 2648.958 & 2.389 \\
\hline
\end{tabular}


Table B. 3 - Values of the simulation of Scenarios 2 and 2" (continuation)

Scenarios 2 and 2

\begin{tabular}{|c|c|c|c|c|c|c|c|c|c|}
\hline Period & ISI & ISI' & Eco-Connectance & $\begin{array}{c}\text { By-product and } \\
\text { Waste Recycling } \\
\text { Rate }\end{array}$ & $\begin{array}{l}\text { Number of } \\
\text { companies }\end{array}$ & $\begin{array}{l}\text { Existing } \\
\text { links }\end{array}$ & $\begin{array}{l}\text { Possible } \\
\text { links }\end{array}$ & $\begin{array}{c}\text { Amount of } \\
\text { generated by- } \\
\text { product }\end{array}$ & $\begin{array}{l}\% \text { of reused } \\
\text { by-product }\end{array}$ \\
\hline 19 & 0.01600 & 0.02050 & 0.30303 & 0.00285 & 12 & 20 & 66 & 2740.625 & 2.075 \\
\hline 20 & 0.02002 & 0.02248 & 0.29487 & 0.00291 & 13 & 23 & 78 & 2747.569 & 2.416 \\
\hline 21 & 0.02509 & 0.02614 & 0.27473 & 0.00265 & 14 & 25 & 91 & 2331.713 & 2.902 \\
\hline 22 & 0.03450 & 0.03396 & 0.26667 & 0.00335 & 15 & 28 & 105 & 2249.306 & 3.840 \\
\hline 23 & 0.02400 & 0.02430 & 0.23810 & 0.00296 & 15 & 25 & 105 & 2485.764 & 2.743 \\
\hline 24 & 0.02791 & 0.02957 & 0.28571 & 0.00369 & 15 & 30 & 105 & 2825.347 & 3.257 \\
\hline 25 & 0.03543 & 0.03679 & 0.30000 & 0.00392 & 16 & 36 & 120 & 3034.144 & 4.054 \\
\hline 26 & 0.04292 & 0.04355 & 0.28676 & 0.00410 & 17 & 39 & 136 & 3063.310 & 4.808 \\
\hline 27 & 0.04333 & 0.04646 & 0.28758 & 0.00477 & 18 & 44 & 153 & 3071.644 & 4.994 \\
\hline 28 & 0.03816 & 0.04458 & 0.27485 & 0.00480 & 19 & 47 & 171 & 3791.030 & 4.617 \\
\hline 29 & 0.04807 & 0.05033 & 0.30000 & 0.00471 & 20 & 57 & 190 & 3912.172 & 5.433 \\
\hline 30 & 0.04440 & 0.04749 & 0.27895 & 0.00490 & 20 & 53 & 190 & 4284.761 & 5.106 \\
\hline 31 & 0.04963 & 0.04361 & 0.28571 & 0.00488 & 21 & 60 & 210 & 4946.492 & 5.098 \\
\hline 32 & 0.05067 & 0.04755 & 0.26840 & 0.00508 & 22 & 62 & 231 & 5540.982 & 5.395 \\
\hline 33 & 0.05401 & 0.05500 & 0.28458 & 0.00475 & 23 & 72 & 253 & 5737.587 & 5.983 \\
\hline 34 & 0.06106 & 0.06409 & 0.30435 & 0.00495 & 24 & 84 & 276 & 5801.939 & 6.814 \\
\hline 35 & 0.07099 & 0.08915 & 0.30072 & 0.00523 & 24 & 83 & 276 & 5183.941 & 8.518 \\
\hline
\end{tabular}

Source: The Authors 
Table B.4 - Details of the simulation of Scenarios 2 and 2" (continue) 
Table B.4 - Details of the simulation of Scenarios 2 and 2" (continuation)

\begin{tabular}{|c|c|c|c|c|c|c|c|c|c|c|}
\hline \multicolumn{11}{|c|}{ Scenarios 2 and 2' } \\
\hline Period & $\begin{array}{l}\text { Amount of } \\
\text { generated } \\
\text { by-product } \\
\text { of type A }\end{array}$ & $\begin{array}{l}\quad \% \text { of } \\
\text { reused by- } \\
\text { product of } \\
\text { type } A\end{array}$ & $\begin{array}{l}\text { Amount of } \\
\text { generated } \\
\text { by-product } \\
\text { of type B }\end{array}$ & $\begin{array}{l}\% \text { of } \\
\text { reused by- } \\
\text { product of } \\
\text { type B }\end{array}$ & $\begin{array}{l}\text { Amount of } \\
\text { generated } \\
\text { by-product } \\
\text { of type C }\end{array}$ & $\begin{array}{l}\% \text { of reused } \\
\text { by-product of } \\
\text { type } C\end{array}$ & $\begin{array}{l}\text { Amount of } \\
\text { generated } \\
\text { by-product } \\
\text { of type D }\end{array}$ & $\begin{array}{l}\quad \% \text { of } \\
\text { reused by- } \\
\text { product of } \\
\text { type D }\end{array}$ & $\begin{array}{l}\text { Amount of } \\
\text { generated by- } \\
\text { product of } \\
\text { type } E\end{array}$ & $\begin{array}{l}\% \text { of } \\
\text { reused by- } \\
\text { product of } \\
\text { type } E\end{array}$ \\
\hline 20 & 656.250 & 1.848 & 787.500 & 2.240 & 826.042 & 1.271 & 66.667 & 16.453 & 411.111 & 3.687 \\
\hline 21 & 487.500 & 2.731 & 675.000 & 2.725 & 606.250 & 1.588 & 166.667 & 5.063 & 396.296 & 4.518 \\
\hline 22 & 325.000 & 4.942 & 712.500 & 3.345 & 572.917 & 2.105 & 166.667 & 7.181 & 472.222 & 4.751 \\
\hline 23 & 437.500 & 3.529 & 425.000 & 1.118 & 826.042 & 1.721 & 144.444 & 7.853 & 652.778 & 3.437 \\
\hline 24 & 572.917 & 3.305 & 391.667 & 1.213 & 803.819 & 2.451 & 166.667 & 10.359 & 890.278 & 3.522 \\
\hline 25 & 606.250 & 3.557 & 336.111 & 2.120 & 803.819 & 2.840 & 200.000 & 12.699 & 1087.963 & 4.237 \\
\hline 26 & 606.250 & 4.113 & 336.111 & 3.366 & 803.819 & 3.758 & 166.667 & 16.214 & 1150.463 & 4.676 \\
\hline 27 & 859.375 & 3.705 & 313.889 & 4.610 & 550.694 & 4.282 & 211.111 & 11.376 & 1136.574 & 5.234 \\
\hline 28 & 1289.063 & 3.136 & 421.296 & 4.072 & 803.819 & 3.073 & 177.778 & 14.933 & 1099.074 & 6.024 \\
\hline 29 & 1389.063 & 4.189 & 369.753 & 7.501 & 803.819 & 4.307 & 211.111 & 12.086 & 1138.426 & 5.842 \\
\hline 30 & 1239.063 & 3.043 & 336.420 & 7.382 & 1168.692 & 3.824 & 294.444 & 8.915 & 1246.142 & 6.844 \\
\hline 31 & 959.375 & 5.296 & 411.420 & 6.401 & 1738.223 & 2.596 & 294.444 & 9.552 & 1543.030 & 6.598 \\
\hline 32 & 1355.729 & 4.991 & 444.753 & 6.427 & 1853.038 & 3.338 & 294.444 & 13.129 & 1593.017 & 6.414 \\
\hline 33 & 1903.038 & 4.549 & 471.296 & 9.204 & 1268.692 & 4.945 & 491.667 & 9.758 & 1602.894 & 6.402 \\
\hline 34 & 2003.038 & 4.026 & 454.630 & 14.491 & 1235.359 & 5.139 & 548.611 & 11.027 & 1560.301 & 8.000 \\
\hline 35 & 2003.038 & 3.637 & 698.611 & 13.226 & 855.671 & 8.369 & 425.000 & 17.535 & 1201.620 & 10.832 \\
\hline
\end{tabular}

Source: The Authors 
Table B.5 - Values of the simulation of Scenario 3 (continue)

Scenario 3

\begin{tabular}{|c|c|c|c|c|c|c|c|c|}
\hline Period & ISI & Eco-Connectance & $\begin{array}{c}\text { By-product and } \\
\text { Waste Recycling } \\
\text { Rate }\end{array}$ & $\begin{array}{l}\text { Number of } \\
\text { companies }\end{array}$ & $\begin{array}{l}\text { Existing } \\
\text { links }\end{array}$ & $\begin{array}{l}\text { Possible } \\
\text { links }\end{array}$ & $\begin{array}{c}\text { Amount of } \\
\text { generated by- } \\
\text { product }\end{array}$ & $\begin{array}{l}\% \text { of reused } \\
\text { by-product }\end{array}$ \\
\hline 16 & 0.00417 & 0.06667 & 0.00032 & 15 & 7 & 105 & 1535.238 & 0.456 \\
\hline 17 & 0.00750 & 0.11429 & 0.00056 & 15 & 12 & 105 & 1555.738 & 0.784 \\
\hline 18 & 0.00925 & 0.14286 & 0.00068 & 15 & 15 & 105 & 1587.025 & 0.971 \\
\hline 19 & 0.01094 & 0.17143 & 0.00082 & 15 & 18 & 105 & 1640.614 & 1.150 \\
\hline 20 & 0.01273 & 0.20000 & 0.00095 & 15 & 21 & 105 & 1667.939 & 1.326 \\
\hline 21 & 0.01390 & 0.21905 & 0.00104 & 15 & 23 & 105 & 1723.471 & 1.437 \\
\hline 22 & 0.01443 & 0.22857 & 0.00108 & 15 & 24 & 105 & 1770.177 & 1.486 \\
\hline 23 & 0.01487 & 0.23810 & 0.00112 & 15 & 25 & 105 & 1834.926 & 1.533 \\
\hline 24 & 0.01478 & 0.23810 & 0.00111 & 15 & 25 & 105 & 1889.466 & 1.523 \\
\hline 25 & 0.01534 & 0.24762 & 0.00115 & 15 & 26 & 105 & 1914.718 & 1.585 \\
\hline 26 & 0.01585 & 0.25714 & 0.00119 & 15 & 27 & 105 & 1958.566 & 1.631 \\
\hline 27 & 0.01513 & 0.24762 & 0.00114 & 15 & 26 & 105 & 2004.455 & 1.562 \\
\hline 28 & 0.01553 & 0.25714 & 0.00117 & 15 & 27 & 105 & 2056.269 & 1.610 \\
\hline 29 & 0.01548 & 0.25714 & 0.00116 & 15 & 27 & 105 & 2083.489 & 1.605 \\
\hline 30 & 0.01597 & 0.26667 & 0.00120 & 15 & 28 & 105 & 2126.203 & 1.658 \\
\hline 31 & 0.01753 & 0.29524 & 0.00132 & 15 & 31 & 105 & 2169.006 & 1.805 \\
\hline 32 & 0.01711 & 0.28571 & 0.00130 & 15 & 30 & 105 & 2214.901 & 1.761 \\
\hline 33 & 0.01761 & 0.30476 & 0.00134 & 15 & 32 & 105 & 2290.419 & 1.807 \\
\hline 34 & 0.01789 & 0.30476 & 0.00136 & 15 & 32 & 105 & 2315.240 & 1.836 \\
\hline 35 & 0.01791 & 0.30476 & 0.00135 & 15 & 32 & 105 & 2384.629 & 1.831 \\
\hline
\end{tabular}


Table B.5 - Values of the simulation of Scenario 3 (continuation)

Scenario 3

\begin{tabular}{|c|c|c|c|c|c|c|c|c|}
\hline Period & ISI & Eco-Connectance & $\begin{array}{c}\text { By-product and } \\
\text { Waste Recycling } \\
\text { Rate }\end{array}$ & $\begin{array}{l}\text { Number of } \\
\text { companies }\end{array}$ & $\begin{array}{c}\text { Existing } \\
\text { links }\end{array}$ & $\begin{array}{c}\text { Possible } \\
\text { links }\end{array}$ & $\begin{array}{c}\text { Amount of } \\
\text { generated by- } \\
\text { product }\end{array}$ & $\begin{array}{l}\% \text { of reused } \\
\text { by-product }\end{array}$ \\
\hline 36 & 0.01819 & 0.31429 & 0.00138 & 15 & 33 & 105 & 2449.244 & 1.862 \\
\hline 37 & 0.01851 & 0.32381 & 0.00140 & 15 & 34 & 105 & 2518.761 & 1.883 \\
\hline 38 & 0.01857 & 0.32381 & 0.00141 & 15 & 34 & 105 & 2569.336 & 1.890 \\
\hline 39 & 0.01869 & 0.32381 & 0.00142 & 15 & 34 & 105 & 2614.320 & 1.903 \\
\hline 40 & 0.01844 & 0.32381 & 0.00140 & 15 & 34 & 105 & 2701.046 & 1.877 \\
\hline
\end{tabular}

Source: The Authors

Table B.6 - Details of the simulation of Scenario 3 (continue)

\begin{tabular}{|c|c|c|c|c|c|c|c|c|c|c|}
\hline \multicolumn{11}{|c|}{ Scenario 3} \\
\hline Period & $\begin{array}{l}\text { Amount of } \\
\text { generated } \\
\text { by-product } \\
\text { of type A }\end{array}$ & $\begin{array}{l}\quad \% \text { of } \\
\text { reused by- } \\
\text { product of } \\
\text { type } A\end{array}$ & $\begin{array}{c}\text { Amount of } \\
\text { generated } \\
\text { by-product of } \\
\text { type B }\end{array}$ & $\begin{array}{l}\quad \% \text { of } \\
\text { reused by- } \\
\text { product of } \\
\text { type B }\end{array}$ & $\begin{array}{l}\text { Amount of } \\
\text { generated } \\
\text { by-product } \\
\text { of type C }\end{array}$ & $\begin{array}{l}\quad \% \text { of } \\
\text { reused by- } \\
\text { product of } \\
\text { type C }\end{array}$ & $\begin{array}{c}\text { Amount of } \\
\text { generated by- } \\
\text { product of type } \\
\text { D }\end{array}$ & $\begin{array}{l}\quad \% \text { of } \\
\text { reused by- } \\
\text { product of } \\
\text { type } D\end{array}$ & $\begin{array}{l}\text { Amount of } \\
\text { generated by- } \\
\text { product of } \\
\text { type } E\end{array}$ & $\begin{array}{l}\text { \% of } \\
\text { reused by- } \\
\text { product of } \\
\text { type } E\end{array}$ \\
\hline 16 & 710.238 & 0.563 & 100.000 & 1.000 & 105.000 & 0.000 & 410.000 & 0.244 & 210.000 & 0.476 \\
\hline 17 & 720.738 & 0.846 & 100.000 & 2.050 & 105.000 & 0.952 & 420.000 & 0.238 & 210.000 & 0.976 \\
\hline 18 & 741.525 & 1.106 & 100.000 & 2.050 & 105.000 & 0.952 & 425.250 & 0.247 & 215.250 & 1.441 \\
\hline 19 & 768.601 & 1.360 & 100.000 & 2.103 & 110.250 & 0.907 & 441.263 & 0.250 & 220.500 & 1.906 \\
\hline 20 & 773.601 & 1.372 & 100.000 & 2.103 & 115.763 & 0.907 & 458.076 & 0.459 & 220.500 & 2.837 \\
\hline 21 & 796.006 & 1.380 & 105.000 & 3.955 & 121.551 & 0.864 & 474.902 & 0.453 & 226.013 & 2.838 \\
\hline 22 & 819.794 & 1.374 & 110.250 & 4.769 & 127.628 & 0.784 & 486.492 & 0.454 & 226.013 & 2.909 \\
\hline
\end{tabular}


Table B.6 - Details of the simulation of Scenario 3 (continuation)

\begin{tabular}{|c|c|c|c|c|c|c|c|c|c|c|}
\hline \multicolumn{11}{|c|}{ Scenario 3} \\
\hline Period & $\begin{array}{l}\text { Amount of } \\
\text { generated } \\
\text { by-product } \\
\text { of type A }\end{array}$ & $\begin{array}{l}\% \text { of } \\
\text { reused by- } \\
\text { product of } \\
\text { type A }\end{array}$ & $\begin{array}{l}\text { Amount of } \\
\text { generated } \\
\text { by-product of } \\
\text { type B }\end{array}$ & $\begin{array}{l}\% \text { of } \\
\text { reused by- } \\
\text { product of } \\
\text { type B }\end{array}$ & $\begin{array}{l}\text { Amount of } \\
\text { generated } \\
\text { by-product } \\
\text { of type C }\end{array}$ & $\begin{array}{l}\quad \% \text { of } \\
\text { reused by- } \\
\text { product of } \\
\text { type C }\end{array}$ & $\begin{array}{c}\text { Amount of } \\
\text { generated by- } \\
\text { product of type } \\
\text { D }\end{array}$ & $\begin{array}{l}\quad \% \text { of } \\
\text { reused by- } \\
\text { product of } \\
\text { type D }\end{array}$ & $\begin{array}{l}\text { Amount of } \\
\text { generated by- } \\
\text { product of } \\
\text { type } E\end{array}$ & $\begin{array}{l}\text { \% of } \\
\text { reused by- } \\
\text { product of } \\
\text { type } E\end{array}$ \\
\hline 23 & 860.784 & 1.348 & 115.763 & 4.635 & 127.628 & 0.823 & 498.951 & 0.654 & 231.801 & 2.955 \\
\hline 24 & 878.786 & 1.348 & 115.763 & 4.733 & 127.628 & 0.823 & 523.898 & 0.633 & 243.391 & 2.908 \\
\hline 25 & 898.250 & 1.456 & 121.551 & 4.603 & 127.628 & 0.823 & 523.898 & 0.654 & 243.391 & 2.954 \\
\hline 26 & 916.526 & 1.447 & 127.628 & 4.427 & 134.010 & 0.784 & 537.011 & 0.650 & 243.391 & 3.487 \\
\hline 27 & 955.317 & 1.413 & 127.628 & 3.604 & 134.010 & 0.784 & 538.321 & 0.671 & 249.179 & 3.433 \\
\hline 28 & 975.832 & 1.529 & 134.010 & 3.474 & 134.010 & 0.823 & 550.780 & 0.679 & 261.638 & 3.322 \\
\hline 29 & 983.589 & 1.517 & 134.010 & 3.483 & 134.010 & 0.823 & 563.862 & 0.686 & 268.019 & 3.313 \\
\hline 30 & 1004.810 & 1.627 & 134.010 & 4.229 & 134.010 & 0.823 & 578.654 & 0.678 & 274.720 & 2.987 \\
\hline 31 & 1032.768 & 1.615 & 134.010 & 5.852 & 134.010 & 0.864 & 593.499 & 0.843 & 274.720 & 3.084 \\
\hline 32 & 1064.608 & 1.591 & 140.710 & 4.941 & 134.010 & 0.907 & 607.235 & 0.845 & 268.338 & 3.267 \\
\hline 33 & 1111.457 & 1.621 & 140.710 & 5.811 & 140.710 & 0.864 & 622.822 & 0.824 & 274.720 & 3.220 \\
\hline 34 & 1114.803 & 1.650 & 140.710 & 5.982 & 140.710 & 0.864 & 637.597 & 0.836 & 281.420 & 3.248 \\
\hline 35 & 1147.941 & 1.544 & 140.710 & 6.187 & 147.746 & 0.864 & 652.741 & 0.857 & 295.491 & 3.509 \\
\hline 36 & 1172.901 & 1.621 & 147.746 & 6.061 & 155.133 & 0.823 & 677.621 & 0.840 & 295.843 & 3.602 \\
\hline 37 & 1215.238 & 1.599 & 147.746 & 6.233 & 155.133 & 0.864 & 703.746 & 0.812 & 296.899 & 3.952 \\
\hline 38 & 1240.525 & 1.625 & 147.746 & 6.224 & 162.889 & 0.823 & 721.277 & 0.814 & 296.899 & 4.038 \\
\hline 39 & 1260.241 & 1.638 & 147.746 & 6.400 & 171.034 & 0.823 & 730.256 & 0.813 & 305.043 & 4.035 \\
\hline 40 & 1302.959 & 1.626 & 147.746 & 6.574 & 171.034 & 0.823 & 759.012 & 0.783 & 320.296 & 3.884 \\
\hline
\end{tabular}


Table B.7 - Values of the simulation of Scenario 4

\section{Scenario 4}

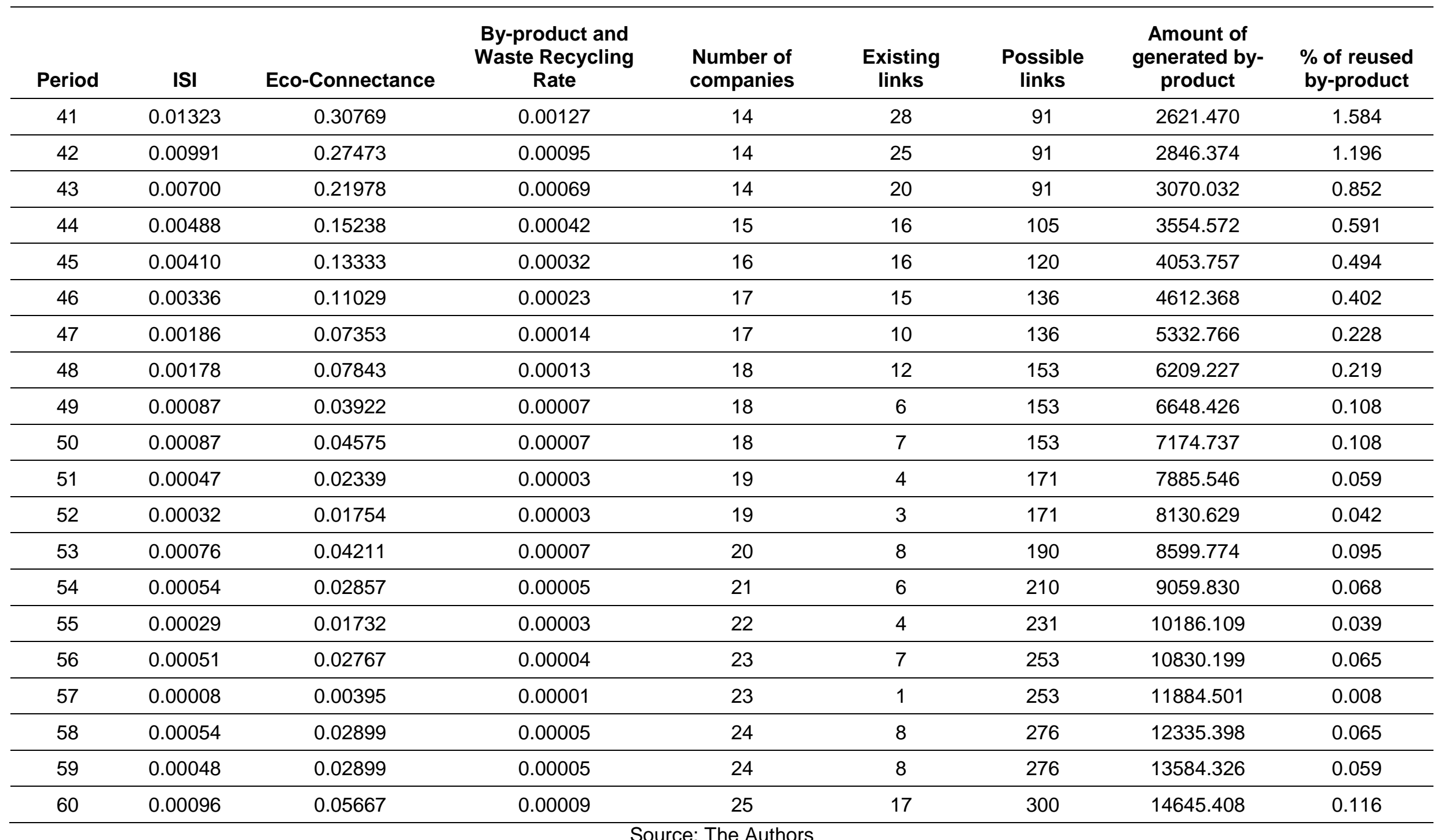


Table B.8 - Details of the simulation of Scenario 4 (continue) 
Table B. 8 - Details of the simulation of Scenario 4 (continuation)

\begin{tabular}{|c|c|c|c|c|c|c|c|c|c|c|}
\hline \multicolumn{11}{|c|}{ Scenario 4} \\
\hline Period & $\begin{array}{l}\text { Amount of } \\
\text { generated by- } \\
\text { product of } \\
\text { type } A\end{array}$ & $\begin{array}{l}\% \text { of } \\
\text { reused } \\
\text { by- } \\
\text { product } \\
\text { of type A }\end{array}$ & $\begin{array}{l}\text { Amount of } \\
\text { generated by- } \\
\text { product of } \\
\text { type B }\end{array}$ & $\begin{array}{l}\% \text { of } \\
\text { reused } \\
\text { by- } \\
\text { product } \\
\text { of type B }\end{array}$ & $\begin{array}{c}\text { Amount of } \\
\text { generated by- } \\
\text { product of type } \\
\text { C }\end{array}$ & $\begin{array}{l}\quad \% \text { of } \\
\text { reused by- } \\
\text { product of } \\
\text { type C }\end{array}$ & $\begin{array}{l}\text { Amount of } \\
\text { generated by- } \\
\text { product of } \\
\text { type D }\end{array}$ & $\begin{array}{c}\% \text { of } \\
\text { reused } \\
\text { by- } \\
\text { product of } \\
\text { type } D\end{array}$ & $\begin{array}{l}\text { Amount of } \\
\text { generated by- } \\
\text { product of } \\
\text { type } E\end{array}$ & $\begin{array}{c}\% \text { of } \\
\text { reused } \\
\text { by- } \\
\text { product of } \\
\text { type E }\end{array}$ \\
\hline 59 & 6409.839 & 0.031 & 248.832 & 0.000 & 869.023 & 0.115 & 4319.285 & 0.023 & 1737.347 & 0.230 \\
\hline 60 & 7120.457 & 0.098 & 298.598 & 0.670 & 869.023 & 0.000 & 4443.285 & 0.045 & 1914.045 & 0.313 \\
\hline
\end{tabular}

Source: The Authors 


\section{APPENDIX C - DOWNLOADING AND USING THE EIPSYMB}

The EIPSymb is available in an online community of agent-based models. This community is named "Modeling Commons" and is intended for the sharing and discussing of models developed in the NetLogo platform (MODELING COMMONS, 2016).

The link to access the EIPSymb in the "Modeling Commons" community is: http://modelingcommons.org/browse/one model/4780. There are details about the model function and how to use it. Anyone can download the model for free.

As the "Modeling Commons" is also an environment to collaborate on modeling projects (MODELING COMMONS, 2016), more than only download the model, it is also possible to upload other versions of the EIPSymb. As, for example, a version where others indicators for measuring the industrial symbiosis are automatically calculated. 
This chapter presents the fourth published paper that composes this thesis. Its reference, for correct quotation, is:

MANTESE, G. C.; AMARAL, D. C. Agent-based simulation to evaluate and categorize industrial symbiosis indicators. Journal of Cleaner Production, v. 186 p. 450-464, 2018.

The Journal of Cleaner Production is the original source, please use the DOI (Digital Object Identifier) to access it: https://doi.org/10.1016/j.jclepro.2018.03.142. 


\title{
AGENT-BASED SIMULATION TO EVALUATE AND CATEGORIZE INDUSTRIAL SYMBIOSIS INDICATORS
}

\author{
Gabriel Couto Mantese* \\ Daniel Capaldo Amaral
}

Department of Production Engineering, University of São Paulo, São Carlos, SP, Brazil

*Corresponding Author, E-mail: gabriel mantese@outlook.com

\begin{abstract}
There is a research effort towards the understanding of industrial symbiosis and part of it is directed to the development of performance indicators. The result is a variety of indicators, which hinders the evaluation, comparison, and decision by researchers and practitioners. This paper presents a comparative evaluation of the industrial symbiosis indicators available in the literature. The indicators were simulated through an agent-based model in two distinct scenarios, in a stable environment and in one with significant changes. The behaviors of the indicators were compared and the results allowed the classification of the indicators into three groups: (i) those related to the amount of by-products reused; (ii) those that behave according to the percentage of by-products reused; (iii) those influenced by the number of links. Considering the differences in performance and complexity, amount of information for calculation, it is concluded that the best alternative is to combine indicators from different groups. The indicators Connectance \& EcoConnectance (simplicity), Eco-Efficiency (overall park impact), and Industrial Symbiosis Indicator (flexibility) stood out. The simulation proved to be a platform that can be used for the study and development of these indicators.
\end{abstract}

Keywords: Industrial symbiosis, Agent-based modeling, Performance indicators, Validation of indicators. 


\section{INTRODUCTION}

Industrial symbiosis aims to draw together separate companies in a collective approach to the physical exchange of materials, water, energy and by-products, in an attempt to achieve competitive advantages (CHERTOW, 2000). The seminal example is the Kalundborg industrial complex, Denmark, where companies, in the 1970 's, started to exchange energy and materials in a self-organized way (CHERTOW, 2000; CHERTOW 2007; EHRENFELD; CHERTOW, 2002; JACOBSEN, 2006; VALENTINE, 2016).

After Kalundborg, great effort was employed in attempts to replicate the phenomenon in other localities and, as Chertow and Ehrenfeld (2012) observed, most of these attempts were unsuccessful because industrial ecosystems resemble complex adaptive systems, subjected to changes that discourage the maintenance of industrial symbiosis relationships among the actors.

The current challenge is to consider this complexity. One of the efforts has been the proposal of performance indicators for industrial symbiosis measurement and monitoring (HARDY; GRAEDEL, 2002; DAI, 2010; ZHOU et al., 2012; GAO et al., 2013; PARK; BEHERA, 2014; WEN; MENG, 2015; TROKANAS et al., 2015; FELICIO et al., 2016). It is understood that these indicators could be useful tools for managers to create initiatives for monitoring, evaluation, and an incentive to maintain the bonds of industrial symbiosis.

As identified by Mantese et al. (2016), these efforts are mainly devoted to proposals for new indicators, while the efforts towards evaluation and comparison of the proposed indicators are not in the same proportion. Especially regarding the direct comparison between the indicators in order to identify which one would be most suitable for each situation.

The authors who mostly considered this topic were Mantese and Amaral (2017), who presented a simulation model capable of representing an Eco-Industrial Park (EIP) and its symbiotic interactions to calculate the behavior of industrial symbiosis indicators. The indicators could be applied through different scenarios and without the need for actual data. The model was successfully tested, allowing the evaluation of the indicators proposed by Dai (2010) and Felicio et al. (2016).

The model proposed by Mantese and Amaral (2017) has certain limitations; it does not consider the amounts of final products produced and sold to other 
companies in the park, the energy consumption, the emissions of $\mathrm{CO}_{2}$ in the atmosphere, and the financial value of symbiotic and non-symbiotic transactions between the companies of the park. The model considers only the amount of byproducts, generated by the companies, that are reused by other companies or that are discarded.

Despite its limitations, this research showed that simulations allow the comparison between indicators. Would it be possible to improve the model proposed by the authors and then submit all the industrial symbiosis indicators to a comparison of their behavior in predefined scenarios? If so, could we identify similarities, differences, advantages, and disadvantages for each indicator in a comparative way and thus establish guidelines for the decisions of professionals and researchers?

This paper describes a comparative evaluation of the industrial symbiosis indicators. It presents the adaptations and advances introduced into the model proposed by Mantese and Amaral (2017), named EIPSymb, and the results of a comparison between the indicators proposed in eight studies, which were identified through a systematic literature review. This paper demonstrates their strengths, weaknesses and an indication for the combination of use and paths to make them more robust from a scientific point of view.

The method used in this paper was developed from the simulation model proposed by Mantese and Amaral (2017), the EIPSymb. It was necessary to make advances in the model to adapt it to the objective of a comparative evaluation and create a more sophisticated scenario, capable of challenging the limits of the indicators' behavior.

Section 2 presents the literature review. Section 3 describes the problem statement and the model that generated the simulations. Section 4 describes the requirements used to define the simulation scenarios and their parameterization. describe and discuss the results of the simulations, and Section 7 , the conclusions. 


\section{LITERATURE REVIEW}

\subsection{Industrial symbiosis indicators}

Lombardi and Laybourn (2012) updated the industrial symbiosis definition provided by Chertow (2000), defining it as:

Industrial Symbiosis engages diverse organizations in a network to foster eco innovation and long-term culture change. Creating and sharing knowledge through the network yields mutually profitable transactions for novel sourcing of required inputs, value-added destinations for non-product outputs, and improved business and technical processes (LOMBARDI; LAYBOURN 2012, p. 29).

Industrial symbiosis can be observed through the cooperation of different entities through three transaction types: utility sharing, services joint provision, and exchanges of by-products to be reused as inputs (CHERTOW et al., 2008; WU et al., 2006).

The definition of by-product is "something that is produced as a result of making something else" (CAMBRIDGE DICTIONARY, 2017). When we refer to a byproduct, we are considering any kind of material in any state, except $\mathrm{CO}_{2}$, energy and water, which were the result of the production process and are not the final product.

The evaluation of the industrial symbiosis level through indicators is one of the important challenges in the field. Mantese and Amaral (2016) performed a systematic literature review to identify the performance indicators for the measurement of industrial symbiosis in EIPs and identified eight papers, presented in Table 1. The indicators proposed by Gao et al. (2013) are identical to the indicators proposed by Dai (2010), with different names. 
Table 1 - Industrial symbiosis indicators.

\begin{tabular}{ll}
\hline Reference & Indicator(s) \\
\hline Hardy and Graedel (2002) & $\begin{array}{l}\text { a. Connectance } \\
\text { b. Symbiotic Utilization }\end{array}$ \\
\hline Dai (2010* & $\begin{array}{l}\text { a. Eco-Connectance } \\
\text { b. By-Product And Waste Recycling Rate }\end{array}$ \\
\hline Zhou et al. (2012) & $\begin{array}{l}\text { a. Industrial Symbiosis Index } \\
\text { b. Link Density }\end{array}$ \\
\hline Gao et al. (2013)* & $\begin{array}{l}\text { a. Ecological Correlation Degree Among Enterprises } \\
\text { b. Rate Of By-Products Recycling In EIPs }\end{array}$ \\
\hline Park and Behera (2014) & Eco-Efficiency \\
\hline Wen and Meng (2015) & Resource Productivity Index \\
\hline Trokanas et al. (2015) & Environmental Impact \\
\hline Felicio et al. (2016) & Industrial Symbiosis Indicator \\
\hline$\left(^{*}\right)$ identical indicators with different names \\
\hline \multicolumn{1}{c}{ Source: adapted from Mantese and Amaral (2016) }
\end{tabular}

In addition to identifying the indicators proposed in the literature, Mantese and Amaral (2016) presented a brief description and a qualitative comparison, discussing the indicators' properties and differences. Despite the progress, their effort was not an systematic evaluation.

\subsection{Validation of indicators}

In the field of environmental science, the validation of indicators is a fundamental process before their use for decision-making. According to Bockstaller and Girardin (2003), it consists of verifying whether the indicator was scientifically designed, if the information provided is relevant, and if it is useful to the users.

Furthermore, they considered that validation could be divided into two stages, conceptual validation and empirical validation (BOCKSTALLER; GIRARDIN, 2003). The first is based on the evaluation of the indicator's conceptual data, such as information about its construction, where an always possible way is through the judgment of experts (BOCKSTALLER; GIRARDIN, 2003). The empirical validation takes place through statistical or visual procedures, where the indicator must be applied in a real situation or within simulated data (BOCKSTALLER; GIRARDIN, 2003). 
Among the available methodologies for the validation of indicators, is the $3 S$ Methodology, by Cloquell-Ballester et al. (2006) based on expert judgment, which assigns grades to the indicator that is being validated based on established criteria.

Mantese et al. (2016) adapted the evaluation criteria of the 3S Methodology for the specific validation of industrial symbiosis indicators. Furthermore, they suggested the use of indicator simulations in order to provide experts not only information on the indicator's construction, but also on its behavior in different scenarios (MANTESE et al., 2016).

Another effort in this field was made by Mantese and Amaral (2017), who proposed a model, developed through the Agent-Based Modeling (ABM) technique, for the simulation of industrial symbiosis indicators. Initially the model was applied in the simulation of the indicators proposed by Dai (2010) and Felicio et al. (2016), with the potential to be extended to other indicators (MANTESE; AMARAL, 2017).

The number of proposals for indicators, however, is greater than the number of papers presenting applications or evaluations of these indicators. In the case of the evaluations, there are still no objective comparisons between the proposed indicators. Regarding the industrial symbiosis indicators identified in the literature by Mantese and Amaral (2016), and presented in Table 1, there are some arising questions:

- Are indicators different from each other?

- Which is the degree of similarity or differentiation between the indicators?

- In which environmental conditions are they advantageous?

- Which indicator to apply?

\subsection{Agent-based modeling}

The ABM is defined by Gilbert (2008) as a method for the creation of simulation models that are composed of agents that can interact with each other and with the environment. According Ghali et al. (2017), through ABM it is possible to verify the behavior of a complex system by modeling the individuals that compose it, that is, its agents. Similarly, Railsback and Grimm (2011) highlighted as an advantage of the ABM that it is only necessary to represent the state of the agents and not of the system as a whole. 
The possibility of representing complex models is an aspect that approximates this technique to the study of industrial symbiosis, a phenomenon that involves several actors, decisions and interactions. Romero and Ruiz (2014) compared ABM with System Dynamics as alternatives for the simulation of symbiotic networks in an EIP, suggesting ABM as the most appropriate.

Despite few works, there are expressive investigations in the area of industrial symbiosis using ABM. Romero and Ruiz (2014) evaluated the potential of cooperation between companies and the overall performance of EIP in different scenarios. Bichraoui et al. (2013) explored the companies' individual behavior aspects that can contribute to the development of industrial symbiosis. Ghali et al. (2017) investigated the impact of social factors in the development of symbiotic networks. Finally, Mantese et al. (2016) and Mantese and Amaral (2017) suggested the validation of industrial symbiosis indicators using a simulation model of an EIP developed through the ABM technique,

This work contributes to the knowledge advancement of the ABM application in the context of industrial symbiosis indicators. Therefore, the choice for this technique was inspired by the previous work of Mantese and Amaral (2017). The idea was to improve the model proposed by the authors in order to allow the evaluation of all industrial symbiosis indicators.

\subsection{The EIPSymb model}

As discussed in the introduction section, the model used in this work is an evolution of the model proposed by Mantese and Amaral (2017), named EIPSymb. This section presents an overview of the model, which is presented in detail by its authors, Mantese and Amaral (2017).

The model name is EIPSymb, an allusion to the terms EIP and Symbiosis (MANTESE; AMARAL, 2017). It was developed through the NetLogo platform and it was used the ODD (Overview, Design Concepts, and Details) protocol by Grimm et al. (2006) to describe it. Table 2 shows a brief description of the EIPSymb. 
Table 2 - EIPSymb description (continue)

\begin{tabular}{|c|c|c|c|c|c|}
\hline Block & Element & \multicolumn{4}{|c|}{ Description of the EIPSymb } \\
\hline \multirow{5}{*}{ Overview } & Purpose & \multicolumn{4}{|c|}{$\begin{array}{l}\text { To represent the interactions between companies of an EIP regarding } \\
\text { the flow of by-products, allowing the calculation of the indicators } \\
\text { proposed by Dai (2010) and by Felicio et al. (2016) }\end{array}$} \\
\hline & \multirow{2}{*}{$\begin{array}{l}\text { State } \\
\text { variables and } \\
\text { scales }\end{array}$} & \multicolumn{4}{|c|}{$\begin{array}{l}\text { There are two local units, one is external to the EIP and contains the } \\
\text { agent landfill; the other is the EIP and contains the agent company that } \\
\text { is defined by the variables: who, type-product, type-residue-generated, } \\
\text { type-residue-used, time-in-park, residue-generated, residue-absorption- } \\
\text { capacity, residue-absorbed. }\end{array}$} \\
\hline & & \multicolumn{4}{|c|}{$\begin{array}{l}\text { There is another type of entity, the link, that connect two agents, they } \\
\text { are defined by the variables: end1; end2, type-residue, time-existence, } \\
\text { intensity, color (for visual differentiation). }\end{array}$} \\
\hline & \multirow{2}{*}{$\begin{array}{l}\text { Process } \\
\text { overview and } \\
\text { scheduling }\end{array}$} & & & $\begin{array}{l}\text { Link } \\
\text { creation }\end{array}$ & $\begin{array}{c}\text { Indicator } \\
\text { calculation }\end{array} \longrightarrow$ Show values \\
\hline & & Increment & $\begin{array}{c}\text { New } \\
\text { company } \\
\text { entry }\end{array}$ & $\begin{array}{c}\text { Increased } \\
\text { link } \\
\text { intensity }\end{array}$ & $\begin{array}{c}\text { Decreased } \\
\text { link } \\
\text { intensity }\end{array}$ \\
\hline \multirow{7}{*}{$\begin{array}{l}\text { Design } \\
\text { concepts }\end{array}$} & $\begin{array}{l}\text { Basic } \\
\text { principles }\end{array}$ & \multicolumn{4}{|c|}{ Industrial symbiosis in EIPs, and the indicators that are calculated. } \\
\hline & Emergence & \multicolumn{4}{|c|}{ The numerical results of the indicators calculated. } \\
\hline & Sensing & \multicolumn{4}{|c|}{$\begin{array}{l}\text { Companies are aware of the amount and type of the by-products that } \\
\text { the other companies can absorb. }\end{array}$} \\
\hline & Interaction & \multicolumn{4}{|c|}{ There are two types of interaction: company-company; company-landfill. } \\
\hline & Stochasticity & \multicolumn{4}{|c|}{$\begin{array}{l}\text { Uniform distribution is used in the following processes: Increment, New } \\
\text { company entry, Company exit, Link creation, Increased links intensity, } \\
\text { Decreased links intensity. }\end{array}$} \\
\hline & Collectives & \multicolumn{4}{|c|}{ The assembly of companies forms an industrial park. } \\
\hline & Observation & \multicolumn{4}{|c|}{$\begin{array}{l}\text { The communication of the results of the EIPSymb simulation includes } \\
\text { the visualization of the following: NetLogo world; value of each indicator } \\
\text { in the each period; the indicators graphic evolution. }\end{array}$} \\
\hline
\end{tabular}

Source: adapted from Mantese and Amaral (2017) 
Table 2 - EIPSymb description (continuation)

\begin{tabular}{|c|c|c|}
\hline Block & Element & Description of the EIPSymb \\
\hline \multirow{4}{*}{ Details } & & $\begin{array}{l}\text { The initialization is accomplished through the Setup command that } \\
\text { prepares the NetLogo world. }\end{array}$ \\
\hline & Initialization & $\begin{array}{l}\text { When a company is created, the residue-generated and residue- } \\
\text { absorption-capacity variables are given the same value, } 100 \text { ton. When } \\
\text { a symbiotic link between two companies is established, the intensity } \\
\text { variable is given the value of } 1 \text { ton. }\end{array}$ \\
\hline & Input & $\begin{array}{l}\text { The input data are used to calibrate the scenarios, they are: probability- } \\
\text { of-entry-of-a-new-company, probability-of-exit-of-a-company, } \\
\text { probability-of-creating-connection, probability-of-increasing-connection- } \\
\text { intensity, probability-of-decreasing-connection-intensity, probability-of- } \\
\text { increasing-production, probability-of-decreasing-production, intensity- } \\
\text { variation-step, increment-production. }\end{array}$ \\
\hline & Submodels & $\begin{array}{l}\text { The submodels in the EIPSymb are: Setup - prepares the simulation } \\
\text { environment; Increment - changes each company's residue-generated } \\
\text { and residue-absorption-capacity variables; New Company Entry - } \\
\text { Controls the entry of new companies into the EIP; Company Exit - } \\
\text { Controls the exit of companies from the EIP; Link Creation - creates } \\
\text { new symbiotic links between companies; Increased Links Intensity - } \\
\text { controls the increase of the variable intensity of symbiotic links; } \\
\text { Decreased Links Intensity - controls the decrease of the variable } \\
\text { intensity of symbiotic links; Indicator calculation - Calculates the } \\
\text { numerical values of the indicators and updates their graphs; Show } \\
\text { values - Lists the values of each company's variables; Residue } \\
\text { absorption assistant - Responsible for updating the residue-absorbed } \\
\text { variable. }\end{array}$ \\
\hline
\end{tabular}

Source: adapted from Mantese and Amaral (2017) 


\section{PROBLEM AND MODEL DESCRIPTION}

\subsection{Problem definition}

This study proposes a comparative evaluation of the industrial symbiosis indicators through a simulation model. The starting point was the model proposed by Mantese and Amaral (2017), named EIPSymb. Since it was not developed specifically for a general comparison, the EIPSymb model has a set of limitations for this application.

The main limitations are that it does not consider the amounts of final products produced and sold to other companies in the park, the energy consumption, $\mathrm{CO}_{2}$ emissions, and the financial value of symbiotic and non-symbiotic transactions between the companies.

In the development of the model's new version, the algorithm's general logic was maintained because of the agent-based modeling strategy: the EIP is composed of a set of agents, each representing a company. The solution to the limitations demanded, however, a complete revision of the model proposed by Mantese and Amaral (2017) and further development such as the creation of new variables, new decision rules, new process and a new submodel. The result is a new version, named EIPSymb\#2. The new assumptions and submodel of the resulting model are presented in the following sections.

\subsection{General assumptions}

The fundamental logic employed in EIPSymb\#2 follows the proposal of Mantese and Amaral (2017). The EIP is a set of agents, each representing a company of the park. Each company is an individual agent that transforms inputs into outputs. However, the standard transformation process of the model has changed with the inclusion of new variables, Figure 1.

Figure 1 - Standard transformation process without using by-product

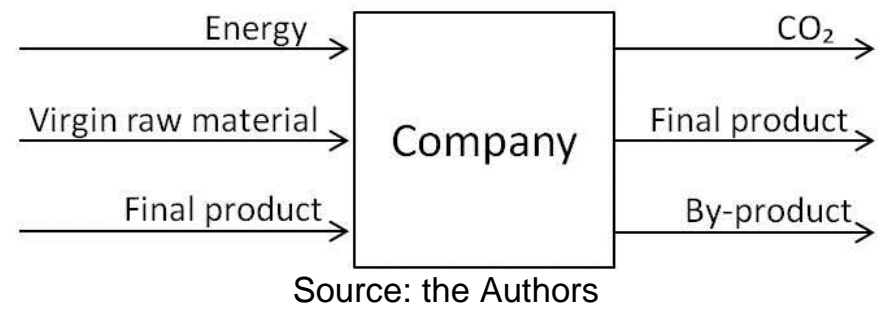


Unlike the previous version, this process considers a greater number of inputs and outputs, including energy, virgin raw material, $\mathrm{CO}_{2}$ emissions, and final product. Table 3 presents the mass balance of the process shown in Figure 1 for the manufacturing of 1 ton of final product.

Table 3 - Amounts of the standard transformation process flows without using by-product

\begin{tabular}{lll} 
& & Amount \\
\hline \multirow{3}{*}{ Input } & Energy & $15000 \mathrm{kWh}$ \\
\cline { 2 - 3 } & Virgin raw material & 2 ton \\
\cline { 2 - 3 } & Final product & 0.3 ton \\
\hline \multirow{3}{*}{ Output } & $\mathrm{CO}_{2}$ & 1.2 ton \\
\cline { 2 - 3 } & Final product $^{*}$ & 1 ton \\
\cline { 2 - 3 } & By-product & 0.1 ton \\
\hline
\end{tabular}

* The final products are of different types. This will be explained in more detail later.

Source: the Authors

However, since the simulation model aims to represent an EIP and its symbiotic interactions, it should also consider the production process that involves the use of by-product, Figure 2 .

Figure 2 - Standard transformation process using only by-product

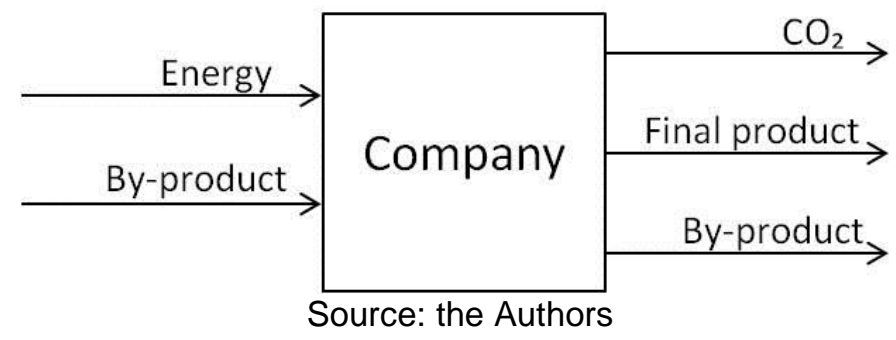

Table 4 shows the mass balance of the process presented in Figure 2 for the manufacturing of 1 ton of final product.

Table 4 - Amounts of the standard transformation process flows using only by-product

\begin{tabular}{lll} 
& & Amount \\
\hline \multirow{2}{*}{ Input } & Energy & $800 \mathrm{kWh}$ \\
\cline { 2 - 3 } & By-product* & 1.2 ton \\
\hline \multirow{3}{*}{ Output } & $\mathrm{CO}_{2}$ & 0.1 ton \\
\cline { 2 - 3 } & Final product & 1 ton \\
\cline { 2 - 3 } & By-product* $^{*}$ & 0.1 ton
\end{tabular}

* The by-products are of different types. This will be explained in more detail later. 
Figures 1 and 2 show the extremes of the process, without using by-product and using only by-product as input, respectively; the simulation model provides intermediate situations. Table 5 presents the monetary values for each flow.

\begin{tabular}{ll}
\multirow{2}{*}{ Table 5 - Monetary values for each flow } & \multicolumn{2}{c}{ Value } \\
\hline Energy & 0.05 dollar/ kWh \\
\hline Virgin raw material & 200 dollars/ton \\
\hline Final product & 2000 dollars/ton \\
\hline By-product & 1300 dollars/ton \\
\hline \multicolumn{3}{c}{ Source: the Authors }
\end{tabular}

The new variable 'final product' is present in both Figure 1 and Table 3 as input and output. The same applies for the variable 'by-product' in Figure 2 and Table 4. The final product and by-product are different for each process flow. Furthermore, EIPSymb\#2 has now different types of companies as well. There are five types of companies, each one having as input a type of product and a type by-product and as output different types of final product and by-product. In addition, a type of virgin raw material will also serve as input. Table 6 shows the relationship between the types of inputs and outputs for each type of company.

Table 6 - Types of inputs, outputs and the relationships between them

\begin{tabular}{lllll}
\hline $\begin{array}{l}\text { Final product } \\
\text { that is } \\
\text { produced }\end{array}$ & $\begin{array}{l}\text { By-product that } \\
\text { is generated }\end{array}$ & $\begin{array}{l}\text { Final product } \\
\text { that is used as } \\
\text { input }\end{array}$ & $\begin{array}{l}\text { Virgin raw } \\
\text { material that is } \\
\text { used as input }\end{array}$ & $\begin{array}{l}\text { By-product that } \\
\text { is used as input }\end{array}$ \\
\hline 1 & $\mathrm{~A}$ & 4 & $\mathrm{I}$ & $\mathrm{B}$ \\
\hline 2 & $\mathrm{~B}$ & 5 & $\mathrm{II}$ & $\mathrm{C}$ \\
\hline 3 & $\mathrm{C}$ & 1 & $\mathrm{III}$ & $\mathrm{D}$ \\
\hline 4 & $\mathrm{D}$ & 2 & $\mathrm{IV}$ & $\mathrm{E}$ \\
\hline 5 & $\mathrm{E}$ & 3 & $\mathrm{~V}$ & $\mathrm{~A}$ \\
\hline
\end{tabular}

\subsection{Assumptions for the calculation of the indicators}

Each indicator requires specific parameters that need to be calculated throughout the simulation. In the following sections, we present the specific assumptions embedded in the model for the indicators' calculation. 


\subsubsection{Industrial Symbiosis Indicator}

For the calculation of this indicator, it is necessary to evaluate the by-products according to their potential environmental impact, Table 7.

Table 7 - Evaluation criteria for by-products classification in the Industrial Symbiosis Indicator calculation

\begin{tabular}{|c|c|}
\hline Criteria & Evaluation \\
\hline \multirow{3}{*}{ Legislation } & 1. Good practices \\
\hline & 3. General requirement \\
\hline & 5. Specific legal requirement \\
\hline \multirow{3}{*}{ Class of waste } & 1. Non-hazardous - inert \\
\hline & 3. Non-hazardous - non-inert \\
\hline & 5. Hazardous \\
\hline \multirow{3}{*}{ Use of waste } & 1. Waste is treated at both the donor and recipient company \\
\hline & 3. Waste is treated at the recipient company \\
\hline & 5. Waste treatment is not required at either of the companies \\
\hline \multirow{3}{*}{$\begin{array}{l}\text { Destination of } \\
\text { waste }\end{array}$} & 1. Another EIP with pretreatment \\
\hline & 3. Another EIP without pretreatment \\
\hline & 5. Industrial landfill (class I and II) \\
\hline \multirow{3}{*}{ Problems/risks } & 1. Nonexistent \\
\hline & 3. Possible/isolated \\
\hline & 5. Frequent \\
\hline
\end{tabular}

The evaluation is performed by the EIPSymb\#2 user as input data. Furthermore, according to Felicio et al. (2016), different relative weights can be assigned to these criteria, but in EIPSymb\#2 the weights will be the same. Finally, when a by-product is not reused by any EIP company, it can be either sent to the landfill or reused by other companies outside the EIP. For simplification, when a byproduct is not reused by an EIP company, it will be sent to the landfill.

\subsubsection{Symbiotic Utilization}

In order to calculate this indicator, according to Hardy and Graedel (2002), the Potential Hazard $(\mathrm{H})$ of each by-product reused as input, must be considered. We assume that the Potential Hazard will be directly proportional to the by-product classification criteria according to the Industrial Symbiosis Indicator by Felicio et al. (2016). This approach was adopted because the authors did not suggest how to 
perform the classification of the Potential Hazard, leaving it to the indicator user. The Potential Hazard will then be calculated:

$\mathrm{H}=$ Legislation $\times$ Class of waste $\times$ Problems/risks

\subsubsection{Eco-Efficiency}

Park and Behera (2014) use the consumed energy as input for the indicator calculation. In an example shown in their paper, with the intention that the energy has compatible units with the amounts of materials consumed and $\mathrm{CO}_{2}$ emitted (both measured in ton), the energy is in the form of steam and has ton as its unit. In this study, for this indicator calculation, we assume that the unit of energy used is tons of oil equivalent (toe), which according to Aneel (2017): $1 \mathrm{kWh}=8.6 \times 10^{-5}$ toe.

\subsubsection{Resource Productivity Index}

This indicator uses the substance flow analysis so that by-products can be considered equated. In the model, we will assume that the amounts of the standard transformation process are the amounts of a substance. Thus, the indicator can be calculated for the whole EIP. In addition, the indicator can be calculated assuming that water and energy are substances. In EIPSymb\#2 we will also apply this assumption for energy. The unit of energy used is tons of oil equivalent (toe), which according to Aneel (2017): $1 \mathrm{kWh}=8.6 \times 10^{-5}$ toe.

\subsubsection{Environmental Impact}

According to Trokanas et al. (2015), this indicator is composed of five sub indicators, Embodied Carbon Cost (ECC), Virgin Materials Financial Saving (VMFS), Landfill Diversion Financial Saving (LDFS), Transportation Financial Impact (TFI) and Energy Consumption Financial Impact (ECFI):

- ECC: It is necessary to use the embodied carbon of the exchanged byproducts. We will use the embodied carbon of aluminum, which according to Hammond and Jones (2011) is about $8 \mathrm{kgCO}_{2} / \mathrm{kg}$. Furthermore, it is still necessary to define the $\mathrm{CO}_{2}$ credit price according to the carbon exchange scheme. The paper that proposed the indicator (TROKANAS et al., 2015) used the $\mathrm{CO}_{2}$ credit price value as 3.72 pounds $/ \mathrm{kg}$, which is equivalent to approximately 5 dollars $/ \mathrm{kg}$. 
- LDFS: Only the price of the by-products that are sent to the landfill will be considered, with no cost for disposal or landfill tax.

- TFI: We assume that the by-product's transportation cost, for reuse in other companies, is equal to the transportation cost of the same material to the landfill if it was not reused. Thus, this sub indicator is always null.

- ECFI: For the calculation of this sub indicator, it is necessary to know the energy $\mathrm{CO}_{2}$ content. In an example of the indicator's application, its value was around $0.5 \mathrm{kgCO}_{2} / \mathrm{kWh}$ for the electric energy (TROKANAS et al., 2015).

Finally, relative weights should be defined for each of the sub indicators (TROKANAS et al., 2015). In this study, the weights will be the same.

\subsection{Model elements}

\subsubsection{State variables and scales}

The following new variables were defined for the agent company:

- type-product-used: type of final product used as input;

- type-virgin-raw-material: type of virgin raw material used as input;

- product-produced: amount (tons) of final product produced;

- product-input: amount (tons) of final product used as input;

- virgin-raw-material: amount (tons) of virgin raw material used as input.

There is also a new type of link, which will be differentiated by a variable already existing in the first version of the model:

- color: allows for visual differentiation between the industrial symbiosis links, the links of by-products sent out of the EIP, and the links of final product. The symbiosis link between two companies is green, while the link to the landfill is red and the link that is sending the final product is blue.

\subsubsection{Process overview and scheduling}

The EIPSymb\#2 has an additional process, the sub process Exchange of final product among EIP companies. Figure 3 depicts a flowchart of the processes included in the model. 
Figure 3. Flowchart overview of EIPSymb\#2 processes

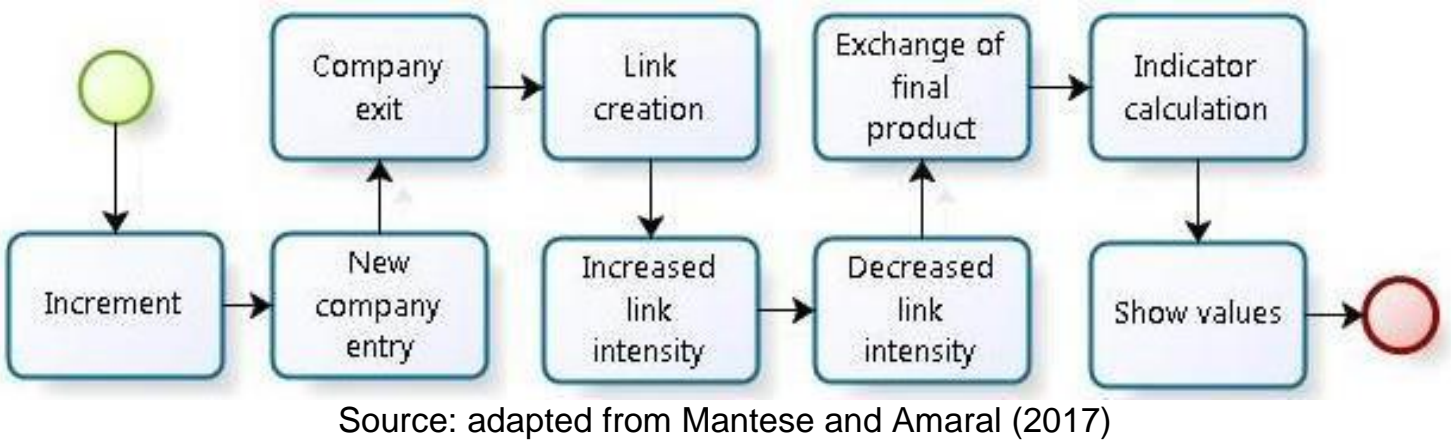

\subsubsection{Interaction and initialization}

There is a new type of interaction between the companies. The companycompany trading of final product, which represents the dispatching of final products from one company to another to be used as input.

The companies and the relationship between them (links) are created throughout the simulation. When a company enters the park, it receives the value 300 for the variable product-produced, which means that the company is producing 300 tons of final product. It directly influences the values of the residue-generated, product-input, virgin-raw-material, and residue-absorption-capacity variables according to the proportions presented in Tables 3 and 4 . When a symbiotic link is created, it receives the value 1 for the variable intensity, which means that companies are exchanging 1 ton of by-product through that link.

\subsubsection{Submodels}

The EIPSymb\#2 has a new submodel (Exchange of final product), which is responsible for the organization of the companies regarding the exchange of final product to be used as input in the production process, Figure 4. 
Figure 4 - Flowchart of Exchange of final product submodel

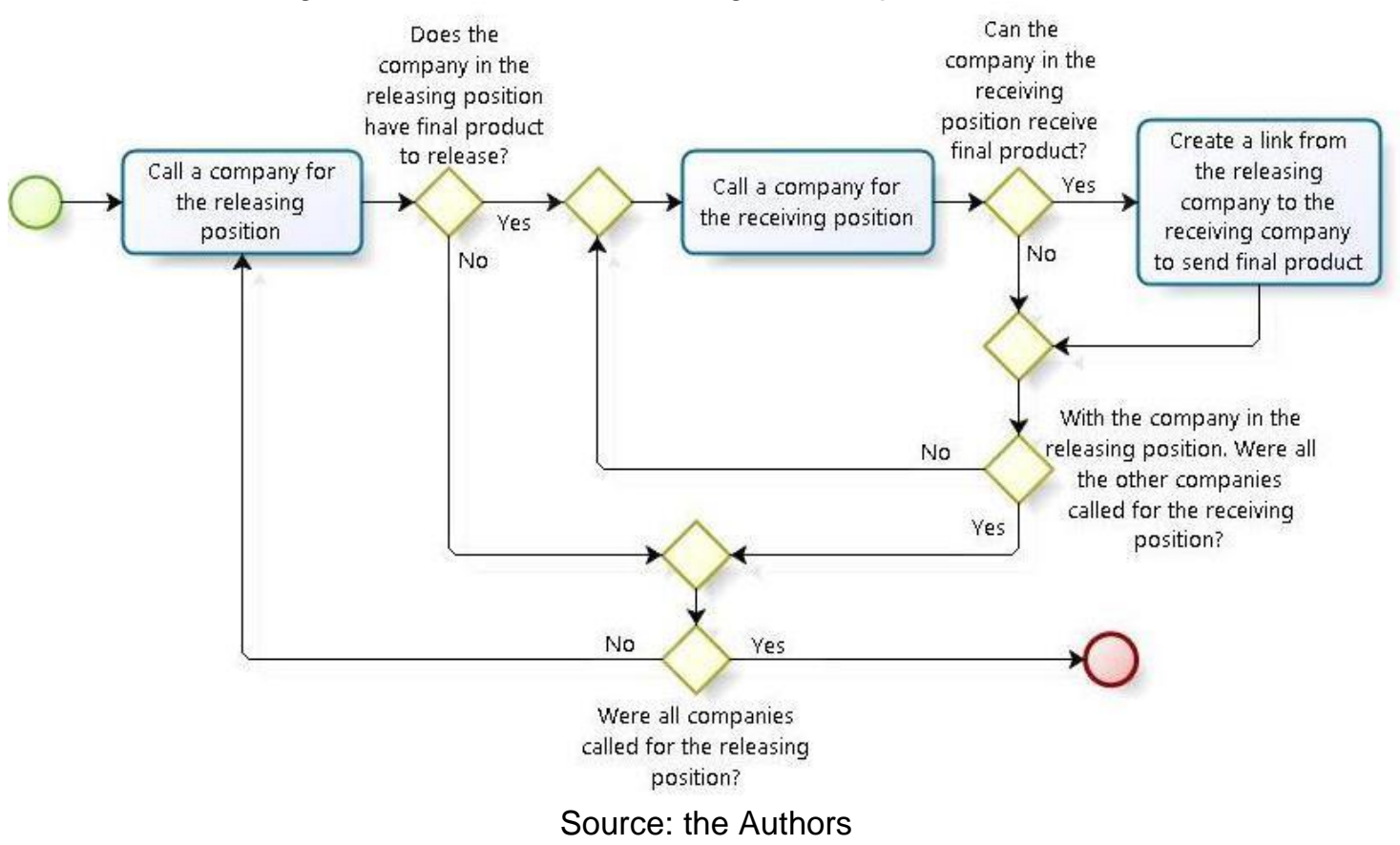

For simplicity, the rule of this submodel is that the priority destination of products produced by companies within the EIP is for companies within the EIP. Furthermore, the highest priority is given to the oldest company in the park, followed the second oldest company and so on. If there are still products produced, they will be sold to companies outside the EIP. In addition, if the demand is not fully met by the companies within the EIP, products from companies outside the EIP will be purchased.

Finally, for a more formal definition of the parameters that guide the simulation model, its agents and the decisions influenced by the input data, the Appendix B was created to provide a mathematical description of them. 


\section{SCENARIOS FOR THE INDUSTRIAL SYMBIOSIS INDICATORS SIMULATION}

In order to verify all situations, two scenarios were created, each one designed with a special variation, represented by the symbol line (').

Scenario 1 represents an optimal situation for the industrial symbiosis development, where all companies that are in the EIP exchange by-products with the other companies, respecting the by-products types. The amounts of by-product exchanged have always an increasing trend, respecting the limits that each company can absorb. This scenario represents an expanding park, where in each period a new company enters the EIP, without any company leaving, and where companies increase the amount of final product produced. This increase in production is slower than the increase of by-product exchanged at each period, improving the park's industrial symbiosis. Finally, all types of by-products are classified as being of low potential environmental impact according to the criteria proposed by Felicio et al. (2016).

In Scenario 1', the only difference is in the classification of the by-products types. The by-products were classified as being of high potential environmental impact. Both scenarios are simulated simultaneously for 20 periods.

Scenario 2 aims to represent an unstable situation, where the companies' turnover in the EIP is high, with companies entering and leaving the park constantly. The symbiotic links are not easily established, but when created they tend to increase, while production has high variation, increasing and decreasing in different periods. Regarding the classification of by-products, three types are classified as having low potential environmental impact, according to the criteria of Felicio et al. (2016), and two types are classified as having high potential environmental impact.

Similar to the relation between Scenarios 1 and 1', Scenario 2' was created, where classifications of by-product types regarding the environmental impact potential were changed, with three types being of high potential environmental impact and two being of low potential environmental impact. These scenarios are more challenging situations for the performance indicators. Both scenarios are simulated simultaneously for 25 periods. The Table 8 presents the input values for each scenario. 
Table 8 - Values of input parameters used in the scenarios

\begin{tabular}{|c|c|c|c|c|}
\hline \multirow[b]{2}{*}{ Entry parameter } & \multicolumn{4}{|c|}{ Scenario } \\
\hline & 1 & $1^{\prime}$ & 2 & 2' \\
\hline Probability of entry of a new company & $100 \%$ & $100 \%$ & $80 \%$ & $80 \%$ \\
\hline Probability of exit of a company & $0 \%$ & $0 \%$ & $2 \%$ & $2 \%$ \\
\hline Probability of creating connection & $100 \%$ & $100 \%$ & $40 \%$ & $40 \%$ \\
\hline Probability of increasing connection intensity & $100 \%$ & $100 \%$ & $50 \%$ & $50 \%$ \\
\hline Probability of decreasing connection intensity & $0 \%$ & $0 \%$ & $25 \%$ & $25 \%$ \\
\hline Probability of increasing production & $100 \%$ & $100 \%$ & $50 \%$ & $50 \%$ \\
\hline Probability of decreasing production & $0 \%$ & $0 \%$ & $50 \%$ & $50 \%$ \\
\hline Intensity variation step & 2.0 & 2.0 & 1.5 & 1.5 \\
\hline Production increment & 1.1 & 1.1 & 1.5 & 1.5 \\
\hline Legislation of by-product $A$ & 1 & 5 & 5 & 1 \\
\hline Class of by-product $A$ & 1 & 5 & 5 & 1 \\
\hline Use of by-product $A$ & 5 & 1 & 1 & 5 \\
\hline Problem/risks of by-product $A$ & 1 & 5 & 5 & 1 \\
\hline Legislation of by-product B & 1 & 5 & 5 & 1 \\
\hline Class of by-product $B$ & 1 & 5 & 5 & 1 \\
\hline Use of by-product B & 5 & 1 & 1 & 5 \\
\hline Problem/risks of by-product B & 1 & 5 & 5 & 1 \\
\hline Legislation of by-product $C$ & 1 & 5 & 1 & 5 \\
\hline Class of by-product $C$ & 1 & 5 & 1 & 5 \\
\hline Use of by-product $C$ & 5 & 1 & 5 & 1 \\
\hline Problem/risks of by-product $C$ & 1 & 5 & 1 & 5 \\
\hline Legislation of by-product $\mathrm{D}$ & 1 & 5 & 1 & 5 \\
\hline Class of by-product $D$ & 1 & 5 & 1 & 5 \\
\hline Use of by-product D & 5 & 1 & 5 & 1 \\
\hline Problem/risks of by-product $D$ & 1 & 5 & 1 & 5 \\
\hline Legislation of by-product $\mathrm{E}$ & 1 & 5 & 1 & 5 \\
\hline Class of by-product $E$ & 1 & 5 & 1 & 5 \\
\hline Use of by-product $E$ & 5 & 1 & 5 & 1 \\
\hline Problem/risks of by-product $\mathrm{E}$ & 1 & 5 & 1 & 5 \\
\hline
\end{tabular}

Source: the Authors

In Scenarios 2 and 2', two internal rules of EIPSymb\#2 were changed, making the situation even more unstable. In these scenarios, companies may use one or more types of by-products as input, Table 9 . 
Table 9 - New input and output rules for Scenarios 2 and 2'

\begin{tabular}{lllll}
\hline $\begin{array}{l}\text { Final product } \\
\text { that is } \\
\text { produced }\end{array}$ & $\begin{array}{l}\text { By-product that } \\
\text { is generated }\end{array}$ & $\begin{array}{l}\text { Final product } \\
\text { that is used as } \\
\text { input }\end{array}$ & $\begin{array}{l}\text { Virgin raw } \\
\text { material that is } \\
\text { used as input }\end{array}$ & $\begin{array}{l}\text { By-product that } \\
\text { is used as input }\end{array}$ \\
\hline 1 & $\mathrm{~A}$ & 4 & $\mathrm{I}$ & $\mathrm{B}$ \\
\hline 2 & $\mathrm{~B}$ & 5 & $\mathrm{II}$ & $\mathrm{C} ; \mathrm{A} ; \mathrm{E}$ \\
\hline 3 & $\mathrm{C}$ & 1 & $\mathrm{III}$ & $\mathrm{D} ; \mathrm{A}$ \\
\hline 4 & $\mathrm{D}$ & 2 & $\mathrm{IV}$ & $\mathrm{E} ; \mathrm{A}$ \\
\hline 5 & $\mathrm{E}$ & 3 & $\mathrm{~V}$ & \\
\hline
\end{tabular}

The second rule is related to the mass balance of the standard transformation process. Previously, the mass balance was the same for each type of final product, now it will be different. Table 10 shows the mass balances for the production without using by-product and the embodied carbon of the generated by-products. Table 11 presents the mass balances for the production using only by-product.

Table 10 - New mass balances for Scenarios 2 and 2' for production without using by-product

Type of final product produced by the company

\begin{tabular}{lllllll} 
& \multicolumn{7}{c}{ company } \\
\cline { 3 - 7 } & $\mathbf{1}$ & $\mathbf{2}$ & $\mathbf{3}$ & $\mathbf{4}$ & $\mathbf{5}$ \\
\hline \multirow{3}{*}{ Input } & Energy (kWh) & 15000 & 12000 & 1800 & 5000 & 1000 \\
\cline { 2 - 7 } & Virgin raw material (ton) & 2 & 2 & 3 & 4 & 1 \\
\cline { 2 - 7 } & Final product (ton) & 0.3 & 0.5 & 0.6 & 0.4 & 0.2 \\
\hline \multirow{3}{*}{ Output } & $\mathrm{CO}_{2}$ (ton) & 1.2 & 1.4 & 2.5 & 3.3 & 0.1 \\
\cline { 2 - 7 } & Final product (ton) & 1 & 1 & 1 & 1 & 1 \\
\cline { 2 - 7 } & By-product (ton) & 0.1 & 0.1 & 0.1 & 0.1 & 0.1 \\
\hline \multirow{2}{*}{$\begin{array}{l}\text { Embodied carbon of the generated by- } \\
\text { product (kgCO } / \mathrm{kg})\end{array}$} & 8 & 3 & 1 & 1 & 2 \\
\hline
\end{tabular}

Source: the Authors

Table 11. New mass balances for Scenarios 2 and 2' for production using only by-product

\begin{tabular}{lllllll} 
& & \multicolumn{6}{c}{$\begin{array}{l}\text { Type of final product produced by } \\
\text { the company }\end{array}$} \\
\cline { 3 - 7 } & & $\mathbf{1}$ & $\mathbf{2}$ & $\mathbf{3}$ & $\mathbf{4}$ & $\mathbf{5}$ \\
\hline \multirow{3}{*}{ Input } & Energy (kWh) & 800 & 1200 & 6600 & 1000 & 1000 \\
\cline { 2 - 7 } & By-product (ton) & 1.2 & 1.3 & 1.2 & 1.5 & 1.4 \\
\hline \multirow{3}{*}{ Output } & $\mathrm{CO}_{2}$ (ton) & 0.1 & 0.2 & 0.1 & 0.4 & 0.3 \\
\cline { 2 - 7 } & Final product (ton) & 1 & 1 & 1 & 1 & 1 \\
\cline { 2 - 7 } & By-product (ton) & 0.1 & 0.1 & 0.1 & 0.1 & 0.1 \\
\hline
\end{tabular}

Source: the Author 


\section{IDENTIFYING GROUP OF INDICATORS}

Figure 5 shows the simulation results of Scenarios 1 and 1'. Each graph indicates the value of each indicator in each simulation period. Symbiotic Utilization (Figures $5 a$ and $5 b$ ) and Industrial Symbiosis Indicator (Figure 5c) were the only that presented distinct curves, one for each scenario. In other indicators, the curves overlap and there is no need for more than one graph. In the case of Symbiotic Utilization, the curves are presented in different graphs, because of their unequal magnitude, so the Figure 5a (Symbiotic Utilization) is for Scenario 1 and Figure $5 \mathrm{~b}$ (Symbiotic Utilization') if for Scenario 1'. For the Industrial Symbiosis Indicator the two curves are presented in the same graph (Figure $5 \mathrm{c}$ ), and the curves are differentiated by the legend, where ISI (Industrial Symbiosis Indicator) is for Scenario 1 and ISI' (Industrial Symbiosis Indicator') if for Scenario 2'. The graph of Figure 5h is not an indicator; it represents the percentage of reused by-products and was added by the authors. 
Figure 5 - Indicators simulation for Scenarios 1 and 1' Amount of reused by-products indicators
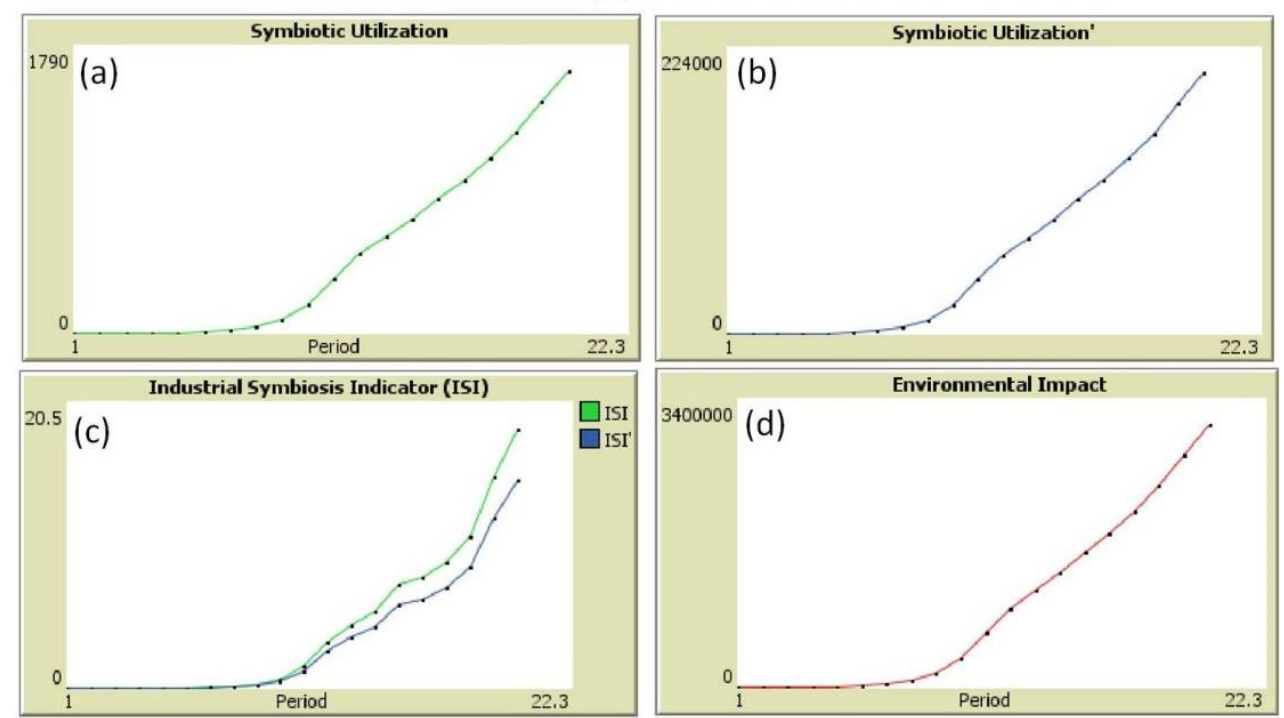

Percentage of reused by-products indicators
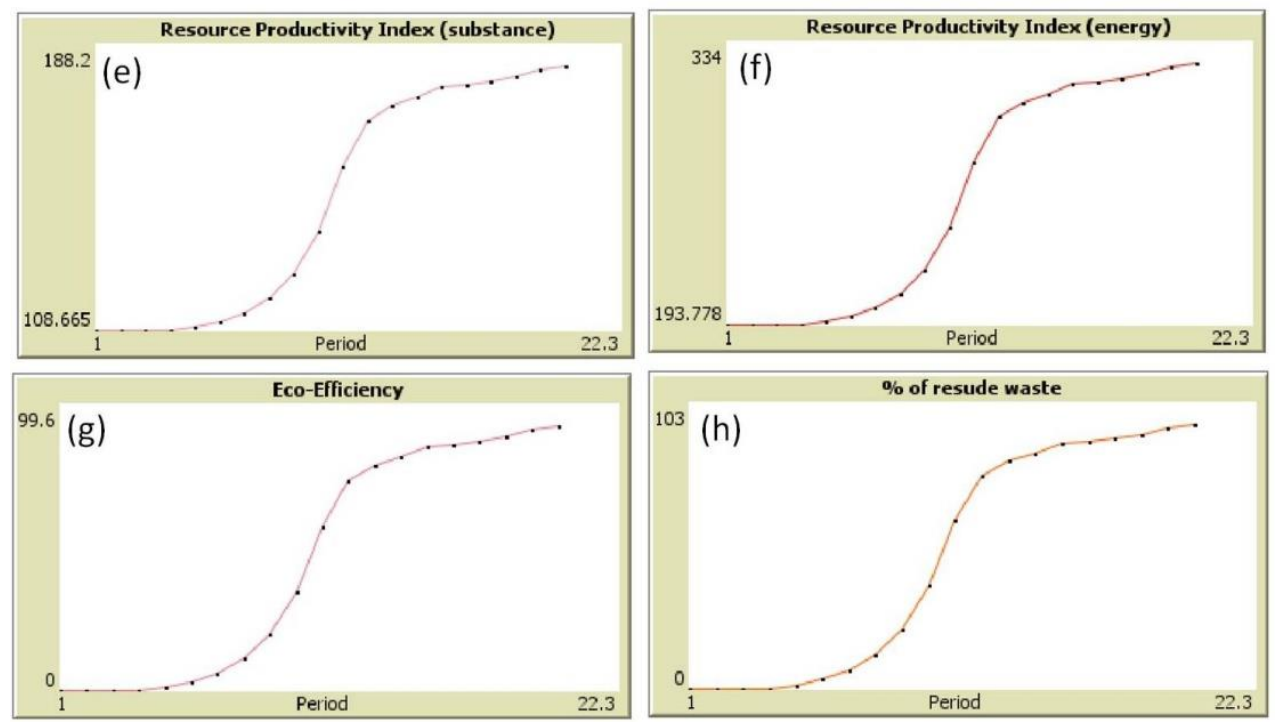

Link indicators
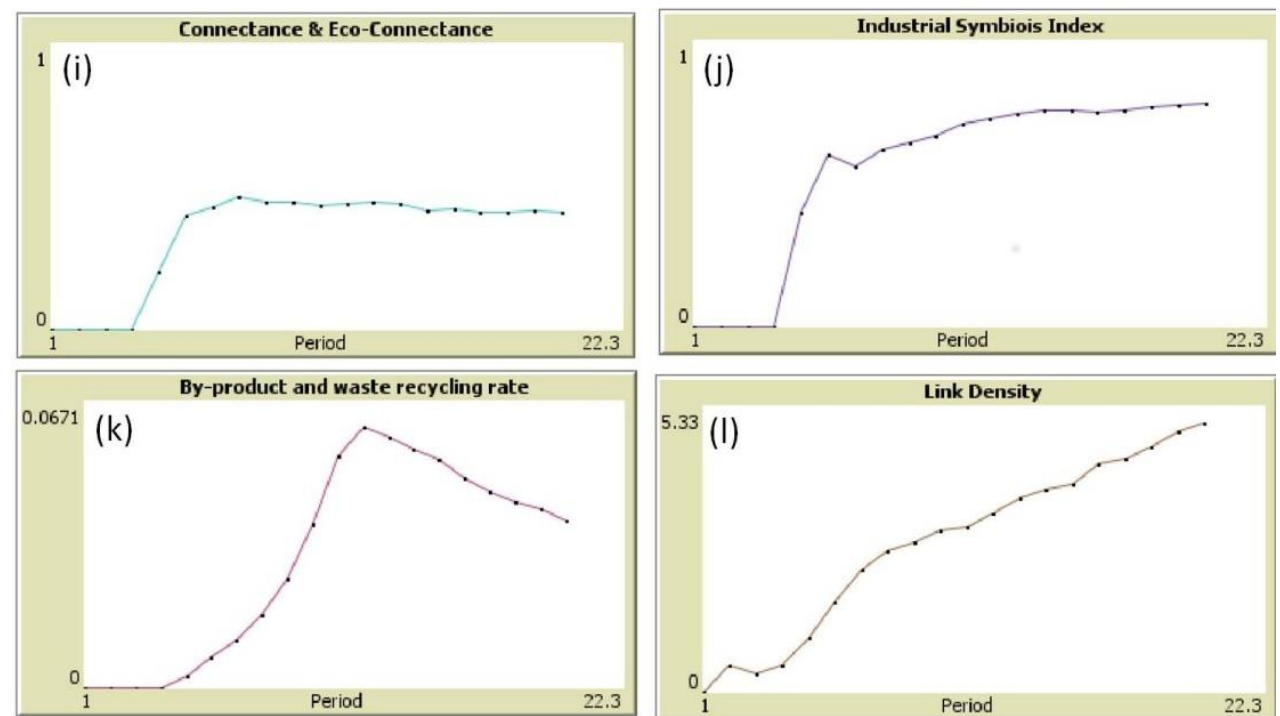

Source: the Authors 
The curves in Figure 5 demonstrate how each indicator registers the industrial symbiosis variation, the fundamental information offered by them. The analysis of the evolution profile allowed to clearly identifying two groups of indicators with a homogeneous pattern and a third group with more varied profiles. The fact that the profiles are close means that they capture the industrial symbiosis evolution in a similar way, demonstrating the same variation.

Figure 5 is already organized according to these groups, which, after the analysis, received a label according to Table 12.

Table 12. Indicators classification according to the profile

\begin{tabular}{lll}
\hline Category & Indicators & Figure 5 \\
\hline \multirow{2}{*}{$\begin{array}{l}\text { Amount of reused } \\
\text { by-products } \\
\text { indicators }\end{array}$} & Symbiotic Utilization & Figures 5a and 5b \\
\cline { 2 - 3 } & Industrial Symbiosis Indicator & Figure 5c \\
\cline { 2 - 3 } $\begin{array}{l}\text { Percentage of } \\
\text { reused by-products } \\
\text { indicators }\end{array}$ & Environmental Impact & Figure 5d \\
\cline { 2 - 3 } & Resource Productivity Index (Substance) & Figure 5e \\
\cline { 2 - 3 } & Resource Productivity Index (Energy) & Figure 5f \\
\hline \multirow{3}{*}{ Link indicators } & Connectance \& Eco-Connectance & Figure 5g \\
\cline { 2 - 3 } & Industrial Symbiosis Index & Figure 5j \\
\cline { 2 - 3 } & By-Product And Waste Recycling Rate & Figure 5k \\
\cline { 2 - 3 } & Link Density & Figure 5l \\
\hline \multicolumn{2}{c}{ Source: the Authors } & \\
\hline
\end{tabular}

\subsection{Amount of reused by-products indicators}

The indicators of this group presented a growing industrial symbiosis profile, close to an exponential curve, indicating a situation compatible with the scenario induced in the simulation.

This group of indicators uses potential impact measures in its formulation, which explains the greater variation at the end of the simulation when there is more reuse of by-products. More intense use of by-products has a greater impact on these indicators in relation to the number of connections. Therefore, this group of indicators was denominated Amount of reused by-products indicators.

The Symbiotic Utilization (Figures $5 \mathrm{a}$ and $5 \mathrm{~b}$ ), and Industrial Symbiosis Indicator (Figure 5c), show differences between Scenario 1 and 1'. In the case of Symbiotic Utilization (Figures $5 a$ and $5 b$ ), this variation is in the value magnitude, but 
the curve profile remains the same. This is because the amount of by-products exchanged is multiplied by its potential hazard.

In the Industrial Symbiosis Indicator (Figure 5c) there is a more subtle variation, since the impact is accounted for each flow, the reuse and the discharge flow. Furthermore, the curves of the two scenarios (1 and $1^{\prime}$ ) remain close while there is little by-product exchange and then separate in the course of the simulation, as it was expected given its formulation.

The Environmental Impact (Figure $5 d$ ) is the only indicator that should have a low numerical value. However, it presented an unexpected behavior. It considers, as input data, the Embodied Carbon Cost (ECC) of the reused by-products, the Virgin Materials Financial Saving (VMFS) due to the symbiotic exchanges, the Landfill Diversion Financial Saving (LDFS), the Transportation Financial Impact (TFI), and the Energy Consumption Financial Impact (ECFI) of the reused by-products. When a larger amount of by-products is exchanged, the ECC increases, causing a negative impact on the indicator (increased value). In this situation, the values of VMFS and LDFS also increase, generating a positive impact on the indicator (decreased value), and a decrease in the value of the ECFI, since using by-products in the manufacturing process consumes less energy, further generating a positive impact on the indicator (decreased value). For simplification, the TFI was considered null in EIPSymb\#2. It can be noticed that only the ECC has a negative impact, while the other input data, except the TFI that is null, have a positive impact on the indicator. The effect generated by the ECC in the simulation is stronger than the effect of the other input data, because of the multiplication between the embodied carbon and the $\mathrm{CO}_{2}$ price selected for the standard transformation process considered in EIPSymb\#2.

Table 13 shows the input variables required to calculate each of the indicators identified in the group Amount of reused by-products indicators. 
Table 13 - Input variables required to calculate the indicators identified in the group Amount of reused by-products indicators

\begin{tabular}{llll}
\hline Input data & $\begin{array}{l}\text { Symbiotic } \\
\text { Utilization (Figure } \\
\text { 5a and Figure 5b) }\end{array}$ & $\begin{array}{l}\text { Industrial } \\
\text { Symbiosis } \\
\text { Indicator (Figure } \\
\text { 5c) }\end{array}$ & $\begin{array}{l}\text { Environmental } \\
\text { Impact (Figure } \\
\text { 5d) }\end{array}$ \\
\hline $\begin{array}{l}\text { Amount of reused by- } \\
\text { products }\end{array}$ & $\mathrm{X}$ & $\mathrm{X}$ & $\mathrm{X}$ \\
\hline $\begin{array}{l}\text { Qualitative classification } \\
\text { of each by-product type }\end{array}$ & $\mathrm{X}$ & $\mathrm{X}$ & $\mathrm{X}$ \\
\hline $\begin{array}{l}\text { Amount of discarded by- } \\
\text { products }\end{array}$ & $\mathrm{X}$ & $\mathrm{X}$ \\
\hline $\begin{array}{l}\text { Quantitative classification } \\
\text { of each by-product type }\end{array}$ & $\mathrm{X}$ \\
\hline $\begin{array}{l}\text { Price of CO } \mathrm{O}_{2} \text { in the carbon } \\
\text { exchange scheme }\end{array}$ & $\mathrm{X}$ \\
\hline $\begin{array}{l}\text { Price of the feedstock that } \\
\text { is replaced }\end{array}$ & $\mathrm{X}$ \\
\hline $\begin{array}{l}\text { Price of by-product } \\
\text { exchanged }\end{array}$ & $\mathrm{X}$ \\
\hline $\begin{array}{l}\text { Disposal cost for by- } \\
\text { product exchanged }\end{array}$ & $\mathrm{X}$ \\
\hline $\begin{array}{l}\text { Landfill tax } \\
\begin{array}{l}\text { Transportation cost for } \\
\text { exchange by-products }\end{array}\end{array}$ & $\begin{array}{l}\text { Carbon content of energy } \\
\text { type }\end{array}$ & & $\mathrm{X}$ \\
\hline
\end{tabular}

Source: the Authors

\subsection{Percentage of reused by-products indicators}

A second group of indicators presented the evolution of industrial symbiosis in the form of an "S curve" with a higher growth rate in the middle of the simulation. The indicators identified in this group resemble the behavior of the percentage of reused waste, which is evident when comparing the three indicators, Resource Productivity Index - Substance (Figure 5e), Resource Productivity Index - Energy (Figure 5f) and Eco-Efficiency (Figure $5 \mathrm{~g}$ ), with a curve created specifically for this analysis, the Percentage of reused waste (Figure $5 \mathrm{~h}$ ). Therefore, this group of indicators was called Percentage of reused by-products indicators.

This means that in order to verify the industrial symbiosis evolution, focused on by-product reuse and less turbulent scenarios, it would make no difference to choose any indicator of this group. The choice could be made, therefore, for 
convenience. If there is an EIP with a preponderant resource, for example, where energy has the greatest impact, the Resource Productivity Index - Energy (Figure 5f) could be used. If there were too many resources, perhaps the Percentage of the reused waste would be enough (Figure $5 \mathrm{~h}$ ). If the available data are monetary, the Eco-Efficiency (Figure $5 \mathrm{~g}$ ) could be used. Table 14 presents the input variables required to calculate each of the indicators identified in the group Percentage of reused by-products indicators.

Table 14 - Input variables required to calculate the indicators identified in the group Percentage of reused by-products indicators

\begin{tabular}{llll}
\hline & $\begin{array}{l}\text { Resource } \\
\text { Productivity } \\
\text { Index - } \\
\text { Substance } \\
\text { (Figure 5e) }\end{array}$ & $\begin{array}{l}\text { Resource } \\
\text { Productivity } \\
\text { Index - Energy } \\
\text { (Figure 5f) }\end{array}$ & $\begin{array}{l}\text { Eco-Efficiency } \\
\text { (Figure 5g) }\end{array}$ \\
\hline $\begin{array}{l}\text { Economic benefit through } \\
\text { the industrial symbiosis }\end{array}$ & $\mathrm{X}$ & $\mathrm{X}$ & $\mathrm{X}$ \\
\hline $\begin{array}{l}\text { Amount of virgin material } \\
\text { used }\end{array}$ & $\mathrm{X}$ & $\mathrm{X}$ \\
\hline Energy consumption & & $\mathrm{X}$ & $\mathrm{X}$ \\
\hline $\mathrm{CO}_{2}$ emission & & $\mathrm{X}$ \\
\hline
\end{tabular}

Source: the Authors

\subsection{Link indicators}

The rest of the indicators did not indicate a similar evolution. Analyzing them, however, it was possible to identify a common characteristic. They use the number of links as the main factor in their input data; therefore, they were denominated Link indicators.

Except for the By-Product And Waste Recycling Rate (Figure 5k), they indicated an increasing industrial symbiosis, as would be expected at the proposed scenario. Their profile, however, was very diverse and a decision maker using them would have different information on the industrial symbiosis evolution throughout the periods.

The problem with these indicators is that the links are influenced by compensation phenomena during the entrance and exit of companies in the park. Connectance \& Eco-Connectance (Figure 5i) and the Industrial Symbiosis Index (Figure $5 \mathrm{j}$ ) indicate a smaller growth than the Link Density (Figure $5 \mathrm{l}$ ). This is because the indicators Connectance \& Eco-Connectance (Figure 5i) and Industrial 
Symbiosis Index (Figure 5j) have a limit in their value that is equal to one. Therefore, they tend to an equilibrium level for the proposed scenarios, while the Link Density (Figure 5l) can always increase as it is calculated by the ratio between the number of total links (symbiotic and due to buying or selling final product) and the number of companies in the park. Moreover, the number of total links grows faster than the number of companies.

Connectance \& Eco-Connectance (Figure 5i) could be used to measure the industrial symbiosis based on the relations between companies in the less turbulent environments. This indicator does not consider the amount of links due to buying or selling final product, as the Industrial Symbiosis Index (Figure 5j) and Link Density (Figure 5l) do, and can provide information on the level of symbiotic relationship between the companies in the park. The By-Product And Waste Recycling Rate (Figure 5k) cannot represent the positive evolution of this scenario. It is optimistic at the beginning of the simulation, showing a rapid positive variation, and then it decreases. This indicator should not be used in stable scenarios to verify the industrial symbiosis evolution. Table 15 presents the input variables required to calculate each of the indicators identified in the group Link indicators.

Table 15 - Input variables required to calculate the indicators identified in the group Link indicators

\begin{tabular}{lllll}
\hline Input data & $\begin{array}{l}\text { Connectance } \\
\text { \& Eco- } \\
\text { Connectance } \\
\text { (Figure 5i) }\end{array}$ & $\begin{array}{l}\text { Industrial } \\
\text { Symbiosis } \\
\text { Index (Figure } \\
\mathbf{5 j}\end{array}$ & $\begin{array}{l}\text { By-Product } \\
\text { And Waste } \\
\text { Recycling } \\
\text { Rate (Figure } \\
\text { 5k) }\end{array}$ & $\begin{array}{l}\text { Link Density } \\
\text { (Figure 5I) }\end{array}$ \\
\hline $\begin{array}{l}\text { Number of symbiotic } \\
\text { links }\end{array}$ & $\mathrm{X}$ & $\mathrm{X}$ & $\mathrm{X}$ & $\mathrm{X}$ \\
\hline $\begin{array}{l}\text { Number of companies } \\
\text { in the EIP }\end{array}$ & $\mathrm{X}$ & $\mathrm{X}$ & $\mathrm{X}$ \\
\hline $\begin{array}{l}\text { Number of buy/sell } \\
\text { final product links }\end{array}$ & & $\mathrm{X}$ & $\mathrm{X}$ & \\
\hline $\begin{array}{l}\text { Amount of reused by- } \\
\text { products }\end{array}$ & & $\mathrm{X}$ & \\
\hline $\begin{array}{l}\text { Amount of discarded } \\
\text { by-products }\end{array}$ & & & & \\
\hline
\end{tabular}

Source: the Authors 


\section{EFFECT OF TURBULENCE}

Scenarios 2 and $2^{\prime}$ were created specifically to verify how indicators behave in environments where there are drastic changes in the number of companies in EIP and in their industrial operations. Figure 6 presents the indicators behavior for the simulation with Scenarios 2 and 2'. Similarly to Scenarios 1 and 1', Figure $6 a$ (Symbiotic Utilization) is for Scenario 2 and Figure 6b (Symbiotic Utilization') if for Scenario 2'. And the Industrial Symbiosis Indicator (Figure 6d) presents a legend where ISI (Industrial Symbiosis Indicator) is for Scenario 2 and ISI' (Industrial Symbiosis Indicator') is for Scenario 2'. 
Figure 6 - Indicators simulation for Scenarios 2 and 2'

Amount of reused by-products

indicators

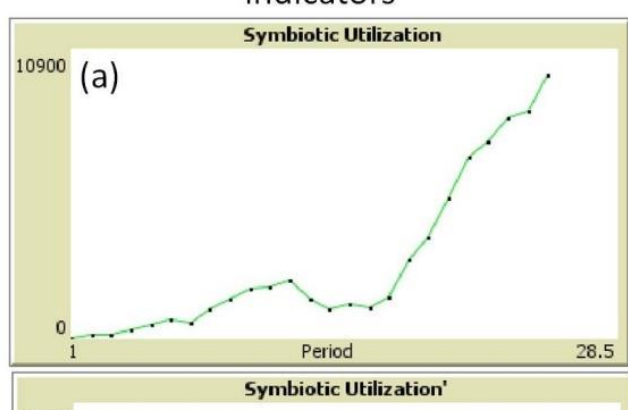

(b)
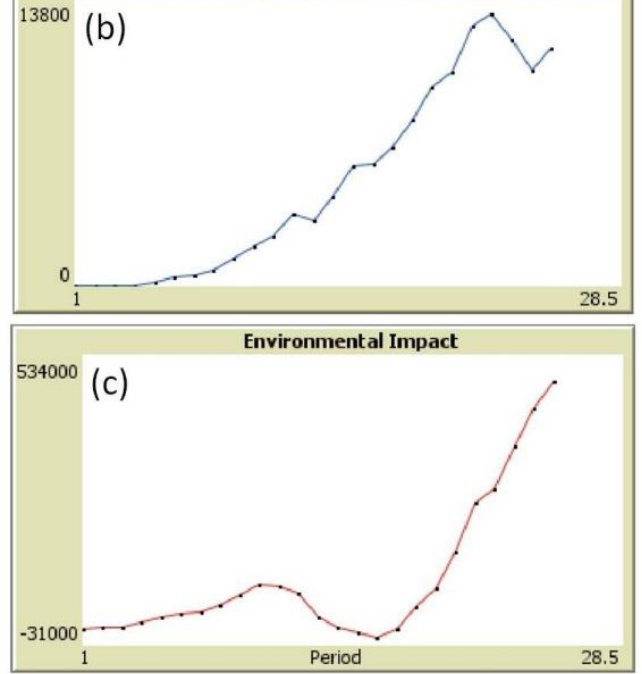

Percentage of reused by-products

indicators
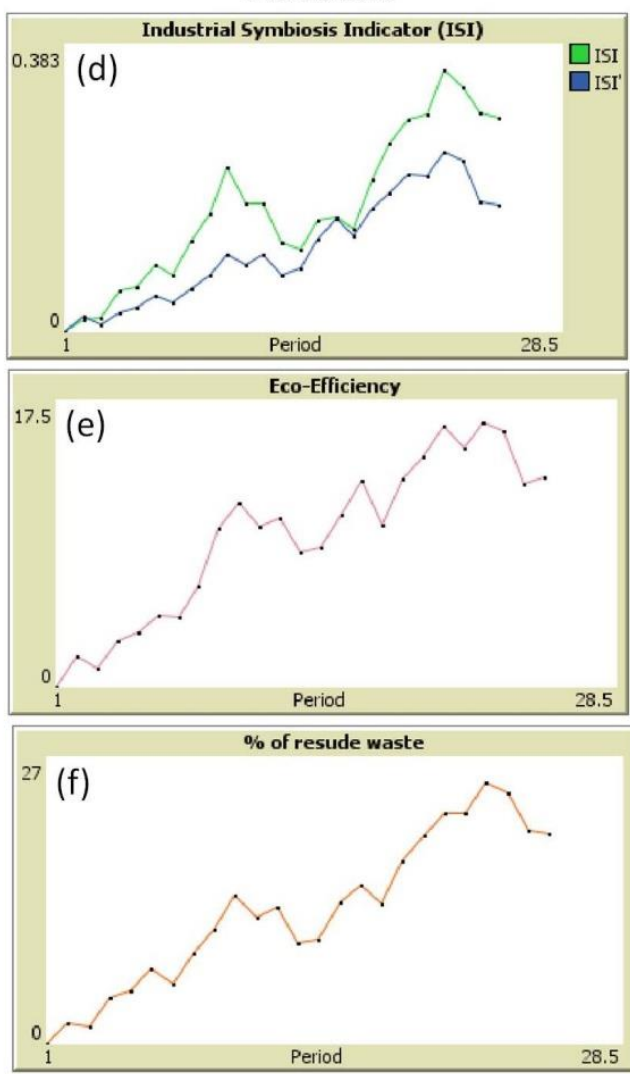

Link indicators

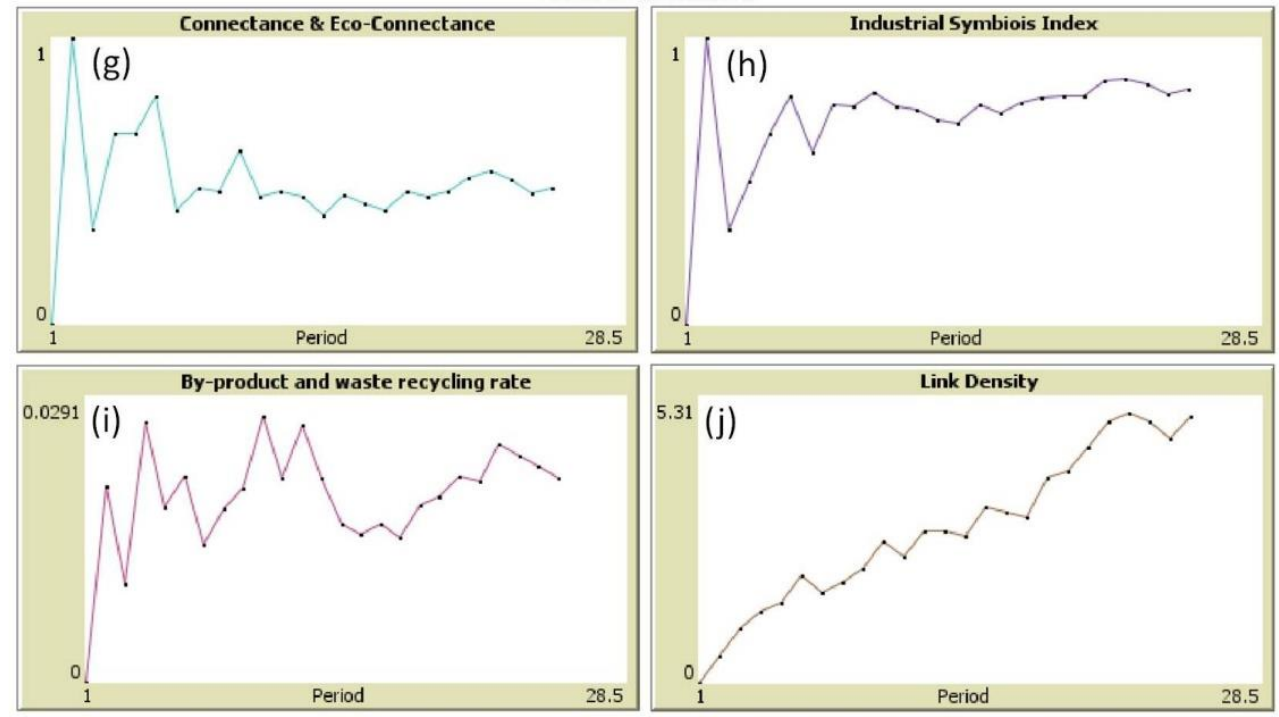

Without classification
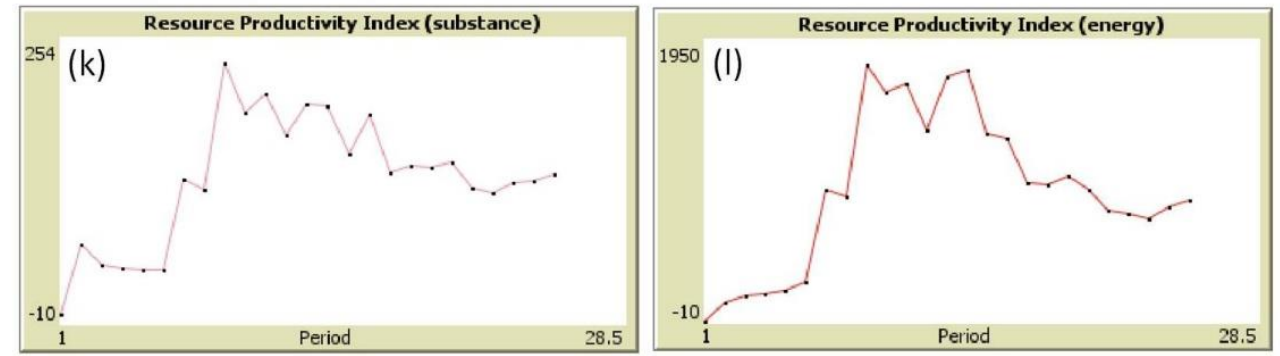

Source: the Authors 
The energy consumption, which now does not always decrease with the use of by-products in production, generates a different influence in these scenarios. In the previous scenarios, the use of by-products always decreases the energy consumption, positively influencing the indicators. In addition, not all final products, when produced through the reuse of by-products as a substitute for other inputs, reduce $\mathrm{CO}_{2}$ emissions, energy and virgin material consumption, and save money at the same time. An example is the production of the final product type 5, where the production through by-product, while decreases the consumption of virgin material and maintains the same energy consumption, increases the $\mathrm{CO}_{2}$ emissions and is not economically advantageous, as can be seen in Tables 10 and 11 .

An interesting effect was observed in the Industrial Symbiosis Indicator (Figure $6 d)$. It presented a profile similar to another indicators group, resembling the performance curve presented by the Percentage of reuse by-product indicators, instead of the Amount of reuse by-product indicators.

Resource Productivity Index, Substance and Energy, (Figures 6k and 6l) also no longer behave according to the group they were classified in Scenarios 1 and 1'. In this case, they received the label Without classification.

Comparing the Amount of reused by-products indicators group with the other groups shown in Figure 6, it is possible to notice that the indicators in this group revealed a constant increase in the industrial symbiosis evolution trend, even in conditions of significant changes. The indicators that remained in this group kept the pattern of industrial symbiosis evolution as it was in the previous scenarios. These indicators seem to be less sensitive to the effects of several simultaneous changes, such as entry and exit of companies and changes in products and relationships.

Again, Symbiotic Utilization (Figures $6 \mathrm{a}$ and $6 \mathrm{~b}$ ) and Industrial Symbiosis Indicator (Figure 6d) presented differences between Scenarios 2 and 2', showing that the by-products classification influences their value and that this measure is important for capturing the evolution.

In Scenarios 1 and 1', Symbiotic Utilization presented a change only in the magnitude between the scenario variation, while in Scenarios 2 and 2 ' there is a significant difference in the profile. As an example, from period 23 to period 24 the total amount of reused by-products increased, the value of Symbiotic Utilization (Figure 6a), referring to Scenario 2, increased but the value of Symbiotic Utilization' (Figure 6b), referring to Scenario 2', decreased. This is due to the different by- 
products classifications within each scenario. In Scenario 2, the by-products $A$ and $B$ have high potential hazard, while the by-products $C, D$, and $E$ have low potential hazard. In Scenario 2', the classifications are the opposite, by-products $A$ and $B$ have low potential hazard and by-products $\mathrm{C}, \mathrm{D}$, and $\mathrm{E}$ have high potential hazard. It can be concluded that the amount of by-products $A$ and $B$, classified as high environmental impact in Scenario 2 and as low environmental impact in Scenario 2', increased, while the amount of by-products C, D, and E, classified as low environmental impact in Scenario 2 and as high environmental impact in Scenario 2', decreased.

The second group, Percentage of reused by-products indicators, did not present the same general pattern as in the previous scenario, where they were the most homogeneous evolution profile. The effect of turbulence significantly influenced these indicators, in particular, the Resource Productivity Index, Substance and Energy (Figures $6 \mathrm{k}$ and $6 \mathrm{l}$ ) that were labeled Without classification. It can be considered that these indicators were not able to express the reality induced in the scenario and that they could not be applied to such types of situation.

This can be explained because they are measures of partial productivity, that is, they reproduce the variation of specific resources. On the contrary, the indicator Eco-Efficiency (Figure 6e), was able to capture the overall trend, being aligned with Percentage of reused waste (Figure 6f). Therefore, in a turbulent situation, the use of Eco-Efficiency or the simple Percentage of reused waste would be more suitable instead of the partial resources indicators.

The indicators from the Link indicators group again did not present a homogeneous pattern within the group, showing great variation among them. However, it is possible to verify that Connectance \& Eco-Connectance (Figure 6g) and Industrial Symbiosis Index (Figure 6h) tend to an equilibrium level for the defined scenarios, as well as Scenarios 1 and 1 '.

It is interesting to note that Industrial Symbiosis Indicator (Figure 6d), in these scenarios, behaves very similarly to the Percentage of reused waste (Figure 6f), a simple calculation proposed in this article during the analysis. However, the Industrial Symbiosis Indicator is a more robust indicator, calculated with many parameters and in stable situations like Scenarios 1 and 1', differs from the Percentage of reused waste. In a more turbulent environment, this metric demonstrated a virtue due to the effect of compensation between the by-products that are being reused and the by- 
products that are being discarded. This may mean that, for the measurement of industrial symbiosis in turbulent environments with data scarcity for the calculation of other indicators, this indicator could be both simple and more robust.

In addition, the Industrial Symbiosis Indicator and the Environmental Impact are the only indicators that consider the calculation of relative weights. The Industrial Symbiosis Indicator considers the weights of the criteria that classify the by-products; and the Environmental Impact considers the weights of the sub indicators that compose it. In the scenarios simulated in this work (Scenarios 1, 1', 2 and 2'), the weights of the criteria for the Industrial Symbiosis Indicator are equal; similarly, the weights of the sub indicators for the Environmental Impact calculation are also considered equal.

In the case of the Industrial Symbiosis Indicator, for Scenarios 1 and 1' these weights, if different, would have no influence on the general behavior of the indicator, since by-products are classified with the same potential environmental impact. For Scenarios 2 and 2', with different weights, the indicator could behave differently between each period, but its overall behavior would still be similar to the group that it was classified in these scenarios, Percentage of reused by-products indicators, because the weights are part of the by-products classification, which in turn have already demonstrated their influence.

About the Environmental Impact, some sub indicators have different influences on the indicator value, that is, there are sub indicators that negatively influence the indicator value and sub indicators that have a positive influence on the indicator value. For Scenarios 1 and 1', if a sub indicator that influences for the Environmental Impact value be smaller has a higher relative weight, the indicator value could regress with the evolution of the periods, however, the behavior would only be reversed to that shown in Figure $5 \mathrm{~d}$, still behaving according to the influence of the amount of reused by-products. For Scenarios 2 and 2', the rules for the transformation process were changed, as can be seen in Tables 10 and 11; this change of rules influences the calculation of the sub indicators, also influencing the indicator value. If the weights of the sub indicators are changed, what happens is that some sub indicators will exert a greater influence on the indicator value and some sub indicators will exert less influence on this value. However, this difference would be in the indicator value, which may change the behavior between periods, but the 
indicator general behavior would still be according to the amount of reused byproducts.

In other words, the weights of the by-product evaluation criteria for the Industrial Symbiosis Indicator and the weights of the sub indicators for the Environmental Impact are important and influence the indicator value, but the behavior of these indicators would still be ruled by the same factors in the simulated scenarios. 


\section{DISCUSSION AND CONLUSIONS}

The results of simulations, according to proposed scenarios, made it possible to identify a set of indicators that need to be used with moderation and care. These are the Environmental Impact, Symbiotic Utilization, By-Product And Waste Recycling Rate, Link Density, Industrial Symbiosis Index, and Resource Productivity Index.

The Environmental Impact, in addition to presenting an unexpected behavior, due to its formulation, requires excessive input data to be calculated. By-Product And Waste Recycling Rate, even in an optimal scenario for the industrial symbiosis development, was not able to report the real situation. Link Density and Industrial Symbiosis Index are easy to calculate, but they use the number of buying or selling final product links as input, which the authors do not believe are capable of influencing the industrial symbiosis level of the park. Symbiotic Utilization is good for scenarios of increasing and unchanging industrial symbiosis. However, it can not show variations when the scenario is turbulent, because it does not consider the amount of by-products discarded. The Resource Productivity Index is a partial measure, making the Eco-Efficiency a better choice.

Industrial Symbiosis Indicator, Eco-Efficiency, Connectance \& EcoConnectance stood out. The Industrial Symbiosis Indicator was able to represent distinct industrial symbiosis profiles for the different Scenarios 1 and 2, demonstrating flexibility. It was able to resemble different groups of indicators for each scenario and in both cases, the group that best represented the reality induced in the scenario. The explanation is its mathematical formulation that is simple enough to adapt to stable situations (such as the initial scenarios), but it contemplates the impact through a simplest system of weights, which makes the indicator respond in an appropriate manner to the turbulences.

The Eco-Efficiency aims to measure the efficiency of industrial symbiosis networks. Therefore, it does not consider as input data the amounts of reused and discarded by-products, but amounts of inputs that come from outside the system (the EIP), $\mathrm{CO}_{2}$ emissions, and the economic benefit reached through the symbiotic networks.

These two indicators were able to indicate the industrial symbiosis evolution, both in stable environments and in scenarios that are more turbulent. However, they 
require a considerable amount of information to be calculated, as shown in Tables 13 and 14.

Connectance \& Eco-Connectance uses as input data the number of symbiotic links between the companies and the number of companies in the park, which is simple to obtain. In addition, it behaved similar in the different scenarios proposed, tending to an equilibrium level, which shows the level of symbiotic relationship between the companies in each scenario.

A plausible option is to use different indicators simultaneously, following the guidelines by Hardy and Graedel (2002), who proposed the use of Connectance \& Eco-Connectance and Symbiotic Utilization indicators together. The results of this simulation indicated that the ideal situation for a holistic evaluation of industrial symbiosis is through the joint analysis of the Industrial Symbiosis Indicator, EcoEfficiency and Connectance \& Eco-Connectance.

It would be possible to follow the industrial symbiosis evolution in the EIP through the Industrial Symbiosis Indicator. Through the Eco-Efficiency, it is possible to verify the efficiency variation, regarding the financial result, the input usage and $\mathrm{CO}_{2}$ emissions of the EIP as a whole. At the same time, using the Connectance \& Eco-Connectance, it is possible to see the level of relationship between the EIP companies and understand the reason for various results, for example, if the industrial symbiosis comes from the exchange of by-products between a few companies or many companies. Table 16 summarizes the recommendations.

Table 16 - Conclusions on the indicators' behavior

\begin{tabular}{ll}
\hline Conclusion & Indicators \\
\hline & Environmental Impact \\
& Symbiotic Utilization \\
By-Product And Waste Recycling Rate \\
$\begin{array}{l}\text { Not recommended as } \\
\text { Link Density } \\
\text { Industrial Symbiosis Index } \\
\text { Resource Productivity Index }\end{array}$ \\
\hline The most complete & $\begin{array}{l}\text { Industrial Symbiosis Indicator } \\
\text { Eco-Efficiency }\end{array}$ \\
\hline The simplest & Connectance \& Eco-Connectance \\
\hline Combination for a & $\begin{array}{l}\text { Industrial Symbiosis Indicator } \\
\text { holistic evaluation }\end{array}$ \\
& $\begin{array}{l}\text { Eco-Efficiency } \\
\text { Connectance \& Eco-Connectance }\end{array}$ \\
\hline
\end{tabular}


After the simulations and the discussion about the indicators, we are now able to answer the four questions proposed in Section 2.2 regarding the industrial symbiosis indicators identified in the literature by Mantese and Amaral (2016), and presented in Table 1.

Are indicators different from each other? The two indicators proposed by Gao et al. (2013) are equal to those proposed by Dai (2010), changing only their names. In addition, the Eco-Connectance of Dai (2010) is equal to Connectance by Hardy and Graedel (2002). The rest of the indicators are different; some have similar behavior or similar input data for their calculation, but this is answer of another question.

Which is the degree of similarity or differentiation between the indicators? Some indicators presented similarity, both in behavior and in the construction and use of input data. The indicators classified as Link indicators in both simulations are similar with respect to the use of input data and construction, because, as can be seen in Table 15, they use similar input data. Still with regard to the use of data and construction, Resource Productivity Index is similar to the EcoEfficiency, because they are measures of efficiency, the first is an efficiency measure of one substance and the second is an efficiency measure of different factors at once. The Industrial Symbiosis Indicator has similarity regarding the input data with the Symbiotic Utilization, since they are the only ones that consider an environmental impact classification of the by-products. There are also similarities of behavior, as can be observed by the indicators classification through the simulation of Scenarios 1 and 1 '.

In which environmental conditions are they advantageous? In a favorable situation for the development of industrial symbiosis, as in Scenarios 1 and 1', most indicators showed a behavior consistent with the environment, with the exception of Environmental Impact and By-Product And Waste Recycling Rate. In turbulent environments, in addition to these two indicators, the Symbiotic Utilization may also not show the real situation.

Which indicator to apply? There is no indicator that stands out from the others, as some indicators are able to inform about different aspects. The best option, which has already been suggested in this section, is the combined use of three indicators for a holistic assessment of the industrial symbiosis networks; they 
are the Industrial Symbiosis Indicator, the Eco-Efficiency and the Connectance \& Eco-Connectance.

Although the scenarios allowed verifying the indicators behavior in extreme conditions, the main limitation of this work is that the data were not extracted from an actual case of an EIP. It is correct to say that using data from an actual situation would be the best alternative, since, in addition to comparing the indicators with each other, we could discuss their real evolutions. However, data from an EIP over time are not trivial to obtain and this may be a future research that would certainly advance the model.

We can also conclude that this new version of the model, EIPSymb\#2, is more complete regarding the representation of the reality of an EIP and its symbiotic interactions, being able to calculate the various industrial symbiosis indicators available in the literature. Furthermore, we believe that it is also able to calculate industrial symbiosis indicators that may be proposed in the future.

As further research it is suggested the application of the industrial symbiosis indicators to monitor the evolution of this phenomenon in actual parks, where it would be possible to analyze the usefulness of these indicators for decision-making, contributing even more to the evolution of this type of indicators, making them more robust. Another front of research may be the adaptation of EIPSymb\#2 to even more complex situations, for example, considering other agents such as prefectures and public authorities, including their policies as a source of influence on the symbiotic connections. 


\section{ACKNOWLEDGMENTS}

The authors thank São Paulo Research Foundation (FAPESP), through the grant \#2015/17192-5, for the funding support. The opinions, assumptions, and conclusions or recommendations expressed in this material are the responsibility of the authors and do not necessarily reflect the view of FAPESP. 


\section{APPENDIX A - DOWNLOADING AND USING THE EIPSYMB\#2}

This new version, the EIPSymb\#2, is now available in the online community Modeling Commons (MODELING COMMONS, 2016). The link to access the EIPSymb\#2 in the Modeling Commons community is: http://modelingcommons.org/browse/one model/4780. There are details about the model function and how to use it. Anyone can download the model for free.

Since the Modeling Commons is also an environment for collaboration on modeling projects (MODELING COMMONS, 2016), it is also possible to upload other versions of the EIPSymb\#2. Therefore, the first version of the model, EIPSymb, can also be found through the same link. 


\section{APPENDIX B - MATHEMATICAL DESCRIPTION OF THE MODEL PARAMETERS}

The EIPSymb\#2 is guided by some parameters, which are defined in Mantese and Amaral (2017) and in this work. However, this appendix presents a more formal mathematical description of them. Table 17 presents the general parameters of the model, Table 18 the parameters of the agent company, Table 19 the parameters of the links, and Table 20 the decision parameters that are influenced by the input data.

Table 17 - EIPSymb\#2 General parameters

\begin{tabular}{lll}
\hline Name (notation) & Description & Range \\
\hline period $(\mathrm{P})$ & Amount of periods simulated & $\mathrm{N}$ (natural numbers) \\
\hline company-amount $(\mathrm{C})$ & Amount of companies in the park & $\mathrm{N}$ \\
\hline link-amount $(\mathrm{L})$ & Amount of symbiotic connections & $\mathrm{N}$ \\
\hline & Source: the Authors &
\end{tabular}

Table 18 - Parameters of the agents company (continue)

\begin{tabular}{|c|c|c|c|}
\hline Name (notation) & Description & Range & Dependency equation \\
\hline who (W) & Identification number & $\begin{array}{l}\mathrm{N} \text { (natural } \\
\text { numbers) }\end{array}$ & N/A (not applicable) \\
\hline time-in-park (T) & $\begin{array}{l}\text { Number of complete } \\
\text { periods in the EIP }\end{array}$ & $\begin{array}{l}\mathrm{N}^{*} \text { (natural } \\
\text { numbers, } \\
\text { excluding } 0 \text { ) }\end{array}$ & $\mathrm{N} / \mathrm{A}$ \\
\hline type-product (TP) & $\begin{array}{l}\text { Type of final product } \\
\text { produced }\end{array}$ & $\{1,2,3,4,5\}$ & $N / A$ \\
\hline $\begin{array}{l}\text { type-residue- } \\
\text { generated (TRG) }\end{array}$ & $\begin{array}{l}\text { Type of by-product } \\
\text { generated }\end{array}$ & $\{A, B, C, D, E\}$ & $\begin{array}{l}\text { If } T P=1, \text { then } T R G=A \\
\text { If } T P=2, \text { then } T R G=B \\
\text { If } T P=3, \text { then } T R G=C \\
\text { If } T P=4, \text { then } T R G=D \\
\text { If } T P=5 \text {, then } T R G=E\end{array}$ \\
\hline $\begin{array}{l}\text { type-residue-used } \\
\text { (TRU) }\end{array}$ & $\begin{array}{l}\text { Type of by-product that } \\
\text { can be used as input }\end{array}$ & $\{A, B, C, D, E\}$ & $\begin{array}{l}\text { If } T P=1, \text { then } T R U=B \\
\text { If } T P=2, \text { then } T R U=C \\
\text { If } T P=3, \text { then } T R U=D \\
\text { If } T P=4, \text { then } T R U=E \\
\text { If } T P=5 \text {, then } T R U=A\end{array}$ \\
\hline $\begin{array}{l}\text { type-product-used } \\
\text { (TPU) }\end{array}$ & $\begin{array}{l}\text { Type of final product } \\
\text { used as input }\end{array}$ & $\{1,2,3,4,5\}$ & $\begin{array}{l}\text { If } T P=1, \text { then } T P U=4 \\
\text { If } T P=2, \text { then } T P U=5 \\
\text { If } T P=3, \text { then } T P U=1 \\
\text { If } T P=4, \text { then } T P U=2 \\
\text { If } T P=5, \text { then } T P U=3\end{array}$ \\
\hline
\end{tabular}


Table 18 - Parameters of the agents company (continuation)

\begin{tabular}{|c|c|c|c|}
\hline Name (notation) & Description & Range & Dependency equation \\
\hline $\begin{array}{l}\text { type-virgin-raw- } \\
\text { material (TVR) }\end{array}$ & $\begin{array}{l}\text { Type of virgin raw } \\
\text { material used as input }\end{array}$ & $\{I, I I, I I I, I V, V\}$ & $\begin{array}{l}\text { If } \mathrm{TP}=1, \text { then } \mathrm{TVR}=\mathrm{I} \\
\text { If } \mathrm{TP}=2, \text { then } \mathrm{TVR}=\mathrm{II} \\
\text { If } \mathrm{TP}=3, \text { then } \mathrm{TVR}=\mathrm{III} \\
\text { If } \mathrm{TP}=4, \text { then } \mathrm{TVR}=\mathrm{IV} \\
\text { If } \mathrm{TP}=5, \text { then } \mathrm{TVR}=\mathrm{V}\end{array}$ \\
\hline $\begin{array}{l}\text { produced-with- } \\
\text { residue (PWR) }\end{array}$ & $\begin{array}{l}\text { Amount of final product } \\
\text { produced using by- } \\
\text { product as input }\end{array}$ & {$[0,+\infty[$} & $\mathrm{N} / \mathrm{A}$ \\
\hline $\begin{array}{l}\text { produced-without- } \\
\text { residue (PWNR) }\end{array}$ & $\begin{array}{l}\text { Amount of final product } \\
\text { produced without using } \\
\text { by-product as input }\end{array}$ & ] $0,+\infty[$ & $\mathrm{N} / \mathrm{A}$ \\
\hline $\begin{array}{l}\text { product-produced } \\
\text { (PP) }\end{array}$ & $\begin{array}{l}\text { Amount of final product } \\
\text { produced }\end{array}$ & ] $0,+\infty[$ & $P P=P W R+P W N R$ \\
\hline $\begin{array}{l}\text { residue-generated } \\
(\mathrm{RG})\end{array}$ & $\begin{array}{l}\text { Amount of by-product } \\
\text { generated }\end{array}$ & ] $0,+\infty[$ & $R G=P P \times 0.1$ \\
\hline $\begin{array}{l}\text { residue-absorption- } \\
\text { capacity (RAC) }\end{array}$ & $\begin{array}{l}\text { Capacity of by-product } \\
\text { that the company is able } \\
\text { to absorb as input }\end{array}$ & ] $0,+\infty[$ & $\mathrm{RAC}=\mathrm{PP} \times 1.2$ \\
\hline $\begin{array}{l}\text { residue-absorbed } \\
\text { (RA) }\end{array}$ & $\begin{array}{l}\text { Amount of by-product } \\
\text { used as input }\end{array}$ & {$[0,+\infty[$} & $\mathrm{RA}=\mathrm{PWR} \times 1.2$ \\
\hline product-input (PI) & $\begin{array}{l}\text { Amount of final product } \\
\text { used as input }\end{array}$ & {$[0,+\infty[$} & $\mathrm{PI}=\mathrm{PWNR} \times 0.3$ \\
\hline $\begin{array}{l}\text { virgin-raw-material } \\
\text { (VR) }\end{array}$ & $\begin{array}{l}\text { Amount of virgin raw } \\
\text { material used as input }\end{array}$ & {$[0,+\infty[$} & $\mathrm{VR}=\mathrm{PWNR} \times 2$ \\
\hline $\operatorname{co2}(\mathrm{CO})$ & Amount of $\mathrm{CO}_{2}$ emission & ] $0,+\infty[$ & $\mathrm{CO}=\mathrm{PWR} \times 0.1+\mathrm{PWNR} \times 1.2$ \\
\hline energy $(E)$ & Amount of energy used & ] $0,+\infty[$ & $E=P W R \times 800+P W N R \times 15000$ \\
\hline cost $(\mathrm{CT})$ & $\begin{array}{l}\text { Monetary value spent } \\
\text { with inputs }\end{array}$ & ] $0,+\infty[$ & $\begin{array}{l}C T=E \times 0.05+V R \times 200+ \\
P I \times 2000+R A \times 1300\end{array}$ \\
\hline revenue $(\mathrm{RV})$ & $\begin{array}{l}\text { Monetary value received } \\
\text { by the sale of final } \\
\text { product and by-product }\end{array}$ & ] $0,+\infty[$ & $\begin{array}{l}R V=P P \times 2000+\left(R G-I_{W}\right) \times 1300 \\
\text { Where, } \\
I_{W_{0}: \text { intensity of the link that sends }} \\
\text { by-product to the landfill }\end{array}$ \\
\hline profit (PT) & $\begin{array}{l}\text { Profit considering the } \\
\text { costs and the revenue }\end{array}$ & ]$-\infty,+\infty[$ & $\mathrm{PT}=\mathrm{RV}-\mathrm{CT}$ \\
\hline
\end{tabular}


Table 19 - Parameters of the links

\begin{tabular}{|c|c|c|c|}
\hline $\begin{array}{l}\text { Name } \\
\text { (notation) }\end{array}$ & Description & Range & Dependency equation \\
\hline end1 (E1) & $\begin{array}{l}\text { Identification number of } \\
\text { the agent that is sending } \\
\text { material }\end{array}$ & $\begin{array}{l}\mathrm{N}^{*} \text { (natural } \\
\text { numbers, } \\
\text { excluding } 0)\end{array}$ & $\begin{array}{l}\mathrm{E} 1=\mathrm{W} \text { of the agent that is sending } \\
\text { material }\end{array}$ \\
\hline end2 (E2) & $\begin{array}{l}\text { Identification number of } \\
\text { the agent that is } \\
\text { receiving material }\end{array}$ & $\mathrm{N}$ & $\begin{array}{l}\mathrm{E} 2=\mathrm{W} \text { of the agent that is receiving } \\
\text { material }\end{array}$ \\
\hline intensity (I) & $\begin{array}{l}\text { Amount of material that } \\
\text { is being send by the link }\end{array}$ & ] $0,+\infty[$ & $\mathrm{N} / \mathrm{A}$ \\
\hline $\begin{array}{l}\text { time- } \\
\text { existence } \\
\text { (TE) }\end{array}$ & $\begin{array}{l}\text { Number of periods that } \\
\text { the link exists }\end{array}$ & $\mathrm{N}^{*}$ & $N / A$ \\
\hline $\begin{array}{l}\text { type-residue } \\
\text { (TR) }\end{array}$ & $\begin{array}{l}\text { Type of material that is } \\
\text { being send by the link }\end{array}$ & $\begin{array}{l}\{A, B, C, D, E \\
1,2,3,4,5\}\end{array}$ & $\begin{array}{l}\text { If the link is sending final product, then TR } \\
=T P \text { of the agent that is sending material. } \\
\text { If the link is sending by-product, then TR = } \\
\text { TRG of the agent that is sending material }\end{array}$ \\
\hline color (CL) & Color of the link & $\begin{array}{l}\text { \{green, red, } \\
\text { blue\} }\end{array}$ & $\begin{array}{l}\text { If the link is sending by-product and the } \\
\text { end } 2 \neq 0 \text {, then } C L=\text { green. } \\
\text { If the link is sending by-product and the } \\
\text { end } 2=0 \text {, then } C L=\text { red. } \\
\text { If the link is sending final product, then } C L \\
=\text { blue. }\end{array}$ \\
\hline
\end{tabular}

Source: the Authors

Table 20 - Decisions parameters that use input data (continue)

\begin{tabular}{|c|c|c|}
\hline Input parameter & $\begin{array}{l}\text { Value } \\
\text { inserted }\end{array}$ & How it works in the model \\
\hline $\begin{array}{l}\text { Probability of entry of } \\
\text { a new company }\end{array}$ & $\mathrm{X} 1$ & $\begin{array}{l}\text { The model draws a number between } 1 \text { and } 100: Y 1 \text {. } \\
\text { If } Y 1 \leq X 1 \text {, then a new company enters the EIP. } \\
\text { If } Y 1>X 1 \text {, then no company enters the EIP. }\end{array}$ \\
\hline $\begin{array}{l}\text { Probability of exit of a } \\
\text { company }\end{array}$ & $\mathrm{X} 2$ & $\begin{array}{l}\text { The model draws a number between } 1 \text { and } 100: Y 2 \text {. } \\
\text { If } Y 2 \leq X 2 \text {, then the company leaves the EIP. } \\
\text { If } Y 2>X 2 \text {, then the company does not leave the EIP. }\end{array}$ \\
\hline $\begin{array}{l}\text { Probability of creating } \\
\text { connection }\end{array}$ & X3 & $\begin{array}{l}\text { The model draws a number between } 1 \text { and } 100: Y 3 \text {. } \\
\text { If } Y 3 \leq X 3 \text {, then it is created a symbiotic link between the two } \\
\text { companies. } \\
\text { If } Y 3>X 3 \text {, then it is not created a symbiotic link between the two } \\
\text { companies. }\end{array}$ \\
\hline
\end{tabular}

Source: the Authors 
Table 20 - Decisions parameters that use input data (continuation)

\begin{tabular}{|c|c|c|}
\hline Input parameter & $\begin{array}{l}\text { Value } \\
\text { inserted }\end{array}$ & How it works in the model \\
\hline \multirow{7}{*}{$\begin{array}{l}\text { Probability of } \\
\text { increasing connection } \\
\text { intensity }\end{array}$} & \multirow{7}{*}{$\mathrm{X} 4$} & $\begin{array}{l}\text { For each symbiotic link, the model draws a number between } 1 \\
\text { and } 100: \text { Y } 4 \text {. }\end{array}$ \\
\hline & & If $\mathrm{Y} 4 \leq \mathrm{X} 4$, then $\mathrm{I}_{\mathrm{E} 1 \mathrm{E} 2}^{\mathrm{P}}=\mathrm{I}_{\mathrm{E} 1 \mathrm{E} 2}^{\mathrm{P}-1} \times \mathrm{Z} 1$ \\
\hline & & If $\mathrm{Y} 4>\mathrm{X} 4$, then $\mathrm{I}_{\mathrm{E} 1 \mathrm{E} 2}^{\mathrm{P}}=\mathrm{I}_{\mathrm{E} 1 \mathrm{E} 2}^{\mathrm{P}-1}$ \\
\hline & & Where, \\
\hline & & $\begin{array}{l}\mathrm{I}_{\mathrm{E} 1 \mathrm{E} 2}^{\mathrm{P}} \text { : Intesity of the link that sends by-product from the company } \\
\mathrm{E} 1 \text { to the company } \mathrm{E} 2 \text { at the period } \mathrm{P} \text {. }\end{array}$ \\
\hline & & $\begin{array}{l}\mathrm{I}_{\mathrm{E} 1 \mathrm{E} 2}^{\mathrm{P}-1} \text { : Intesity of the link that sends by-product from the company } \\
\mathrm{E} 1 \text { to the company } \mathrm{E} 2 \text { at the period } \mathrm{P}-1 \text {. }\end{array}$ \\
\hline & & Z1: Intensity variation step. \\
\hline
\end{tabular}

For each symbiotic link, the model draws a number between 1 and 100: Y5.

If $Y 5 \leq X 5$, then $\mathrm{I}_{\mathrm{E} 1 \mathrm{E} 2}^{\mathrm{P}}=\mathrm{I}_{\mathrm{E} 1 \mathrm{E} 2}^{\mathrm{P}-1} / \mathrm{Z} 1$

If $\mathrm{Y} 5>\mathrm{X} 5$, then $\mathrm{I}_{\mathrm{E} 1 \mathrm{E} 2}^{\mathrm{P}}=\mathrm{I}_{\mathrm{E} 1 \mathrm{E} 2}^{\mathrm{P}-1}$

Probability of Where,

decreasing connection $\quad \mathrm{X} 5$

$\mathrm{I}_{\mathrm{E} 1 \mathrm{E} 2}^{\mathrm{P}}$ : intesity of the link that sends by-product from the company intensity

$\mathrm{E} 1$ to the company $\mathrm{E} 2$ at the period $\mathrm{P}$.

$\mathrm{I}_{\mathrm{E} 1 \mathrm{E} 2}^{\mathrm{P}-1}$ : intesity of the link that sends by-product from the company $\mathrm{E} 1$ to the company $\mathrm{E} 2$ at the period $\mathrm{P}-1$.

$\mathrm{Z1}$ : Intensity variation step.

For each company, the model draws a number between 1 and 100: Y6.

If $\mathrm{Y} 6 \leq \mathrm{X} 6$, then $\mathrm{PP}_{\mathrm{W}}^{\mathrm{P}}=\mathrm{PP}_{\mathrm{W}}^{\mathrm{P}-1} \times \mathrm{Z2}$

Probability of If $\mathrm{Y} 6>\mathrm{X} 6$, then $\mathrm{PP}_{\mathrm{W}}^{\mathrm{P}}=\mathrm{PP}_{\mathrm{W}}^{\mathrm{P}-1}$

increasing production $\mathrm{X} 6$

Where,

$\mathrm{PP}_{\mathrm{W}}^{\mathrm{P}}$ : product-produced of company $\mathrm{W}$ ate the period $\mathrm{P}$.

$\mathrm{PP}_{\mathrm{W}}^{\mathrm{P}-1}$ : product-produced of company $\mathrm{W}$ ate the period $\mathrm{P}-1$.

Z2: Production increment.

For each company, the model draws a number between 1 and 100: Y7.

If $\mathrm{Y} 7 \leq \mathrm{X} 7$, then $\mathrm{PP}_{\mathrm{W}}^{\mathrm{P}}=\mathrm{PP}_{\mathrm{W}}^{\mathrm{P}-1} / \mathrm{Z} 2$
Probability of decreasing production $\mathrm{X} 7$ If $\mathrm{Y} 7>\mathrm{X} 7$, then $\mathrm{PP}_{\mathrm{W}}^{\mathrm{P}}=\mathrm{PP}_{\mathrm{W}}^{\mathrm{P}-1}$ Where, $\mathrm{PP}_{\mathrm{W}}^{\mathrm{P}}$ : product-produced of company $\mathrm{W}$ ate the period $\mathrm{P}$. $\mathrm{PP}_{\mathrm{W}}^{\mathrm{P}-1}$ : product-produced of company $\mathrm{W}$ ate the period $\mathrm{P}-1$. Z2: Production increment.

Value that influences in the "Probability of increasing connection Intensity variation step Z1 intensity" and in the "Probability of decreasing connection intensity".

Production increment Z2
Value that influences in the "Probability of increasing production" and in the "Probability of decreasing production". 
As previously commented, this thesis is presented in the format of a collection of papers; the four previous chapters presented the papers that compose the thesis. However, there are also results that are not published yet; this chapter presents these results. 


\section{APPLICATION OF THE 3S METHODOLOGY USING THE SPECIFIC CRITERIA}

\subsection{Assisted application with an expert}

This assisted application aimed to identify difficulties of interpretation and/or understanding of the criteria proposed by Mantese et al. (2016). To this end, it was selected an expert in the area of environmental performance indicators to answer the questionnaire, while it was being observed. It was selected the Industrial Symbiosis Indicator, proposed by Felicio et al. (2016) for the assisted application. The Industrial Symbiosis Indicator was selected for this application, because it was the indicator that stood out both in the qualitative comparison performed in Mantese and Amaral (2016) and in the simulation performed in Mantese and Amaral (2017).

With the assisted application, it was identified problems of description of some criteria, as well as criteria that contained a lot of information and needed to be separated. The problems were corrected and the new version of the criteria is presented in Table 1. 
Table 1 - Criteria for the evaluation of industrial symbiosis indicators updated after the assisted application

Questionnaire to evaluate the indicators of industrial symbiosis to be validated
Conceptual coherence
1. The indicator is able to measure the exchange of by-products among the companies in
the Eco-Industrial Park

2. The indicator is able to measure the exchange of water and energy among the companies in the Eco-Industrial Park

3. The indicator evaluates the different by-products generated according to their potential of environmental impact

4. The indicator considers amounts of by-products generated by the companies that are reused as raw material by other companies in the Eco-Industrial Park. In a direct way*

5. The indicator considers amounts of by-products generated by the companies that are not shared with other companies in the Eco-Industrial Park, being discarded

Operational coherence

1. The mathematical formulation is suitable for measuring industrial symbiosis, taking into account the aspects that must be quantified

2. The calculation of the indicator does not take into account data that are not relevant to measure the Industrial Symbiosis

3. All the data needed for measuring the Industrial Symbiosis are being considered in the calculation of the indicator

4. The measurement procedures for obtaining the data related to the Industrial Symbiosis are adequate, allowing the reproduction and comparison of the indicator

5. The indicator is able to indicate trends regarding the evolution of the Industrial Symbiosis in the Eco-Industrial Park

6. The numerical result obtained through the calculation of the indicator has no limit, meaning that the Industrial Symbiosis can always be improved

7. The indicator allows the comparison of the level of the Industrial Symbiosis with other Eco-Industrial Parks

Utility

1. The indicator calculation and its procedures are easy to be performed and do not require excessive effort

2. The data considered in the calculation of the indicator are provided by reliable sources

3. The data considered in the calculation of the indicator are provided by sources that are easy to access

4. The indicator can support decision

5. It is acceptable the need of human resources for obtain data and calculate the indicator

6. It is acceptable the need of utilization and acquisition of equipment for obtain data and calculate the indicator

7. It is acceptable the need of knowledge acquisition for obtain data and calculate the indicator

8. The indicator presents an excellent cost-benefit ratio

${ }^{*}$ The indicator is able to record directly the by-products that are reused, rather than, for example, quantify them by the decrease in the use of virgin raw material 
The result was an increase of 5 criteria. And the changes were mainly in the division of some criteria. An example is the Operational coherence criterion: "The data needed to calculate the indicator are relevant, while there are no data that are relevant and are not considered". This criterion was divided into two:

- The calculation of the indicator does not take into account data that are not relevant to measure the Industrial Symbiosis;

- All the data needed for measuring the Industrial Symbiosis are being considered in the calculation of the indicator.

This was done because the initial criterion had two statements and the expert could consider, for example, that the indicator meets the first statement, but not the second, and thus would have difficulty in assigning a grade.

In addition, the other changes were made to a better description of the criteria, as in the case of the Conceptual coherence criterion: "Considers amounts of byproduct reused. In a direct way". Which was best described and now it is: "The indicator considers amounts of by-products generated by the companies that are reused as raw material by other companies in the Eco-Industrial Park. In a direct way". This type of change helps in a better understanding of the criteria and in the consequent minimization of a misinterpretation.

\subsection{Experts selection}

The first expert selected was the expert with whom was conducted the assisted application. In this case there was the need to have access to the expert in order to conduct the assisted application. Therefore, the expert selected was a PhD professor with extensive experience in environmental performance indicators, who works at another university in the same city where the project was developed.

Regarding the strategy to access the other experts, it was first identified professionals from the academic and industrial area who demonstrated acknowledged knowledge on the subject. In this case there was no restriction of location, since the evaluation did not have to be assisted. It was contacted about 20 professionals, but this strategy did not succeed.

So, the second strategy started, which was to contact graduate students in the area of industrial ecology, with whom the access were more easily, since they are from the same university where the project was developed. This strategy proved to 
be efficient and it was identified three students in this area who also demonstrated knowledge about industrial symbiosis and performance indicators.

Finally, adding the three graduate students to the expert with who was conducted the assisted application, it was obtained a group of four experts for the application of the 3S Methodology in the Industrial Symbiosis Indicator using the specific criteria of industrial symbiosis.

\subsection{Application of the 3S Methodology for the validation of the Industrial Symbiosis Indicator}

Concerning 3S Methodology, when the answers of the experts are discrepant, other rounds, according to the Delphi technique, must be performed in order to reach a consensus. That is what happened in this application because, after the evaluation with the 4 experts, the results indicated that some of the criteria showed a high standard deviation between the answers, being unacceptable. After just one more round, the final result were reached. It is presented in Table 2 . 
Table 2 - Evaluation of the Industrial Symbiosis Indicator according to experts

\begin{tabular}{|c|c|c|c|}
\hline Class & Criteria & $\begin{array}{l}\text { Average } \\
\text { grade }\end{array}$ & $\begin{array}{l}\text { Standard } \\
\text { deviation }\end{array}$ \\
\hline \multirow{5}{*}{$\begin{array}{l}\text { Conceptual } \\
\text { coherence }\end{array}$} & $\begin{array}{l}\text { 1. The indicator is able to measure the exchange of by- } \\
\text { products among the companies in the Eco-Industrial Park }\end{array}$ & 4.75 & 0.5 \\
\hline & $\begin{array}{l}\text { 2. The indicator is able to measure the exchange of water and } \\
\text { energy among the companies in the Eco-Industrial Park }\end{array}$ & 3 & 1.41 \\
\hline & $\begin{array}{l}\text { 3. The indicator evaluates the different by-products generated } \\
\text { according to their potential of environmental impact }\end{array}$ & 4 & 0.82 \\
\hline & $\begin{array}{l}\text { 4. The indicator considers amounts of by-products generated } \\
\text { by the companies that are reused as raw material by other } \\
\text { companies in the Eco-Industrial Park. In a direct way }\end{array}$ & 4.5 & 0.58 \\
\hline & $\begin{array}{l}\text { 5. The indicator considers amounts of by-products generated } \\
\text { by the companies that are not shared with other companies in } \\
\text { the Eco-Industrial Park, being discarded }\end{array}$ & 3.25 & 0.5 \\
\hline \multirow{7}{*}{$\begin{array}{l}\text { Operational } \\
\text { coherence }\end{array}$} & $\begin{array}{l}\text { 1. The mathematical formulation is suitable for measuring } \\
\text { industrial symbiosis, taking into account the aspects that must } \\
\text { be quantified }\end{array}$ & 4.5 & 0.58 \\
\hline & $\begin{array}{l}\text { 2. The calculation of the indicator does not take into account } \\
\text { data that are not relevant to measure the Industrial Symbiosis }\end{array}$ & 3 & 0.82 \\
\hline & $\begin{array}{l}\text { 3. All the data needed for measuring the Industrial Symbiosis } \\
\text { are being considered in the calculation of the indicator }\end{array}$ & 2 & 0.82 \\
\hline & $\begin{array}{l}\text { 4. The measurement procedures for obtaining the data related } \\
\text { to the Industrial Symbiosis are adequate, allowing the } \\
\text { reproduction and comparison of the indicator }\end{array}$ & 4 & 0 \\
\hline & $\begin{array}{l}\text { 5. The indicator is able to indicate trends regarding the } \\
\text { evolution of the Industrial Symbiosis in the Eco-Industrial Park }\end{array}$ & 3 & 0.82 \\
\hline & $\begin{array}{l}\text { 6. The numerical result obtained through the calculation of the } \\
\text { indicator has no limit, meaning that the Industrial Symbiosis } \\
\text { can always be improved }\end{array}$ & 4.25 & 0.5 \\
\hline & $\begin{array}{l}\text { 7. The indicator allows the comparison of the level of the } \\
\text { Industrial Symbiosis with other Eco-Industrial Parks }\end{array}$ & 4.5 & 0.58 \\
\hline \multirow{8}{*}{ Utility } & $\begin{array}{l}\text { 1. The indicator calculation and its procedures are easy to be } \\
\text { performed and do not require excessive effort }\end{array}$ & 4 & 0 \\
\hline & $\begin{array}{l}\text { 2. The data considered in the calculation of the indicator are } \\
\text { provided by reliable sources }\end{array}$ & 3.5 & 0.58 \\
\hline & $\begin{array}{l}\text { 3. The data considered in the calculation of the indicator are } \\
\text { provided by sources that are easy to access }\end{array}$ & 2.75 & 0.96 \\
\hline & 4. The indicator can support decision & 4.5 & 0.58 \\
\hline & $\begin{array}{l}\text { 5. It is acceptable the need of human resources for obtain data } \\
\text { and calculate the indicator }\end{array}$ & 4.75 & 0.5 \\
\hline & $\begin{array}{l}\text { 6. It is acceptable the need of utilization and acquisition of } \\
\text { equipment for obtain data and calculate the indicator }\end{array}$ & 4 & 0.82 \\
\hline & $\begin{array}{l}\text { 7. It is acceptable the need of knowledge acquisition for obtain } \\
\text { data and calculate the indicator }\end{array}$ & 4.75 & 0.5 \\
\hline & 8. The indicator presents an excellent cost-benefit ratio & 3.5 & 1 \\
\hline
\end{tabular}


It is possible to observe that only one criterion continued with the standard deviation greater than 1. It was considered unnecessary to carry out another round because it would be tiring and repetitive to the experts. Furthermore, with the evaluation of the criteria, the experts could justify the reason for the grades; and, specifically in this criterion, it was noticed that the reason for this discrepancy was because it considers at the same time both water and energy. As some experts considered that the indicator was able to measure water, but not energy, they had difficulty in answering. It is proposed one more change in this criterion, separating it in two:

- The indicator is able to measure the exchange of water among the companies in the Eco-Industrial Park;

- The indicator is able to measure the exchange of energy among the companies in the Eco-Industrial Park.

Thus, the Conceptual coherence class has now 6 criteria.

Following with the results of the 3S Methodology application with the specific criteria; the weights of the criteria within each class were considered the same, as well as the weight of each index to form the Aggregated Assessment. Table 3 presents the aggregation of the criteria in the three indexes and the indicator final grade.

Table 3 - Grade of each index and of the Aggregated Assessment for the Industrial Symbiosis Indicator

\begin{tabular}{ll}
\hline Index & Grade \\
\hline Conceptual Coherence & 3.90 \\
\hline Operational Coherence & 3.61 \\
\hline Utility & 3.97 \\
\hline Aggregated Assessment & $\mathbf{3 . 8 3}$ \\
\hline \multicolumn{2}{c}{ Source: the Author }
\end{tabular}

According to the proposed by Cloquell-Ballester et al. (2006) the indicator was rated between 3.5 and 4.5 , requiring a brief review. 


\section{FRAMEWORK PROPOSITION}

\subsection{Development of the artifacts for operationalization}

Before presenting the structure of the Framework, the artifacts that are used for its construction are introduced.

\subsubsection{Indicator report template}

The Indicator report provides theoretical and technical information on the indicator. This report follows the suggestion of Cloquell-Ballester et al. (2006), presented in Table 4.

Table 4 - Indicator Report

\section{Guide for indicator report}

\begin{tabular}{ll}
\hline 1. Indicator & Name of the proposed indicator \\
\hline 2. Aspect & $\begin{array}{l}\text { 2.1. Name of the environmental or social aspect (system } \\
\text { component) to be quantified through the indicator } \\
\text { 2.2. Description: description of the environmental or social } \\
\text { characteristic that represents the aspect }\end{array}$ \\
\hline $\begin{array}{l}\text { 3.1. Conceptual definition: definition of the indicator and of the } \\
\text { concepts and characteristics that it is made up of }\end{array}$ \\
$\begin{array}{l}\text { 3.2. Description of data and units: description of the data and } \\
\text { units used to quantify the environmental aspect }\end{array}$ \\
$\begin{array}{l}\text { 3.3. Operational definition: definition of the mathematical } \\
\text { expression used to quantify the environmental aspect } \\
\text { 3.4. Measuring method: details about sampling and/or measuring } \\
\text { procedures followed by the indicator to be obtained. Possibility to } \\
\text { reproduce and compare the measurement }\end{array}$
\end{tabular}

4.1. Interpretation/meaning: Description of its interpretation and meaning through explanation of its operation

4.2. Accuracy: explanation of the indicator's accuracy and

4. Justification sensitivity to changes in the factor and security of both information and data

4.3. Relevancy: explanation of the indicator's relevancy to represent the characteristic that is to be quantified (aspect)

5. Sources

Availability of data sources. Name of the documents and/or files where the data comes from

Source: Adapted from Cloquell-Ballester et al. (2006)

\subsubsection{Simulation report template}

It is used the EIPSymb\#2 simulation model, proposed by Mantese and Amaral (2018) to simulate the indicator in different scenarios and then verify its behavior. 
If the indicator to be validated is new, that is, it is not considered in the simulation model, its calculation must be inserted in the source code. If it is an indicator considered, its calculation is already inserted in the model.

As EIPSymb\#2 already considers the calculation of the industrial symbiosis indicators identified in Mantese and Amaral (2016), the Simulation report should also contain comparisons between the indicators. Table 5 presents the template of the Simulation report with the information it should contain. Likewise the Framework, the information provided by the Simulation report is an evolution of the initial idea of procedure presented in Mantese et al. (2016).

Table 5 - Simulation report

Source: the Author

\subsubsection{Specific criteria}

They are the criteria adapted from the original criteria of Cloquell-Ballester et al. (2006). After the application with the Industrial Symbiosis Indicator the criteria were 
Table 6 - Criteria for evaluation of industrial symbiosis indicators, final version

\section{Questionnaire to evaluate the indicators of industrial symbiosis to be validated}

Conceptual coherence

1. The indicator is able to measure the exchange of by-products among the companies in the EcoIndustrial Park

2. The indicator is able to measure the exchange of water among the companies in the Eco-Industrial Park

3. The indicator is able to measure the exchange of energy among the companies in the Eco-Industrial Park

4. The indicator evaluates the different by-products generated according to their potential of environmental impact

5. The indicator considers amounts of by-products generated by the companies that are reused as raw material by other companies in the Eco-Industrial Park. In a direct way*

6 . The indicator considers amounts of by-products generated by the companies that are not shared with other companies in the Eco-Industrial Park, being discarded

\section{Operational coherence}

1. The mathematical formulation is suitable for measuring industrial symbiosis, taking into account the aspects that must be quantified

2. The calculation of the indicator does not take into account data that are not relevant to measure the Industrial Symbiosis

3. All the data needed for measuring the Industrial Symbiosis are being considered in the calculation of the indicator

4. The measurement procedures for obtaining the data related to the Industrial Symbiosis are adequate, allowing the reproduction and comparison of the indicator

5. The indicator is able to indicate trends regarding the evolution of the Industrial Symbiosis in the Eco-Industrial Park

6. The numerical result obtained through the calculation of the indicator has no limit, meaning that the Industrial Symbiosis can always be improved

7. The indicator allows the comparison of the level of the Industrial Symbiosis with other Eco-Industrial Parks

Utility

1. The indicator calculation and its procedures are easy to be performed and do not require excessive effort

2. The data considered in the calculation of the indicator are provided by reliable sources

3. The data considered in the calculation of the indicator are provided by sources that are easy to access

4. The indicator can support decision

5. It is acceptable the need of human resources for obtain data and calculate the indicator

6. It is acceptable the need of utilization and acquisition of equipment for obtain data and calculate the indicator

7. It is acceptable the need of knowledge acquisition for obtain data and calculate the indicator

8. The indicator presents an excellent cost-benefit ratio

*The indicator is able to record directly the by-products that are reused, rather than, for example, quantify them by the decrease in the use of virgin raw material 


\subsection{Development of the Framework concept}

The Framework was named CE-3S Framework. The name is a reference to the integration of Conceptual validation with Empirical validation, using as base the 3S Methodology. It aims to perform the validation according to the specific criteria for industrial symbiosis indicators, but with the differential of combining empirical simulation data. The CE-3S Framework is shown in Figure 3.

Figure 3 - CE-3S Framework

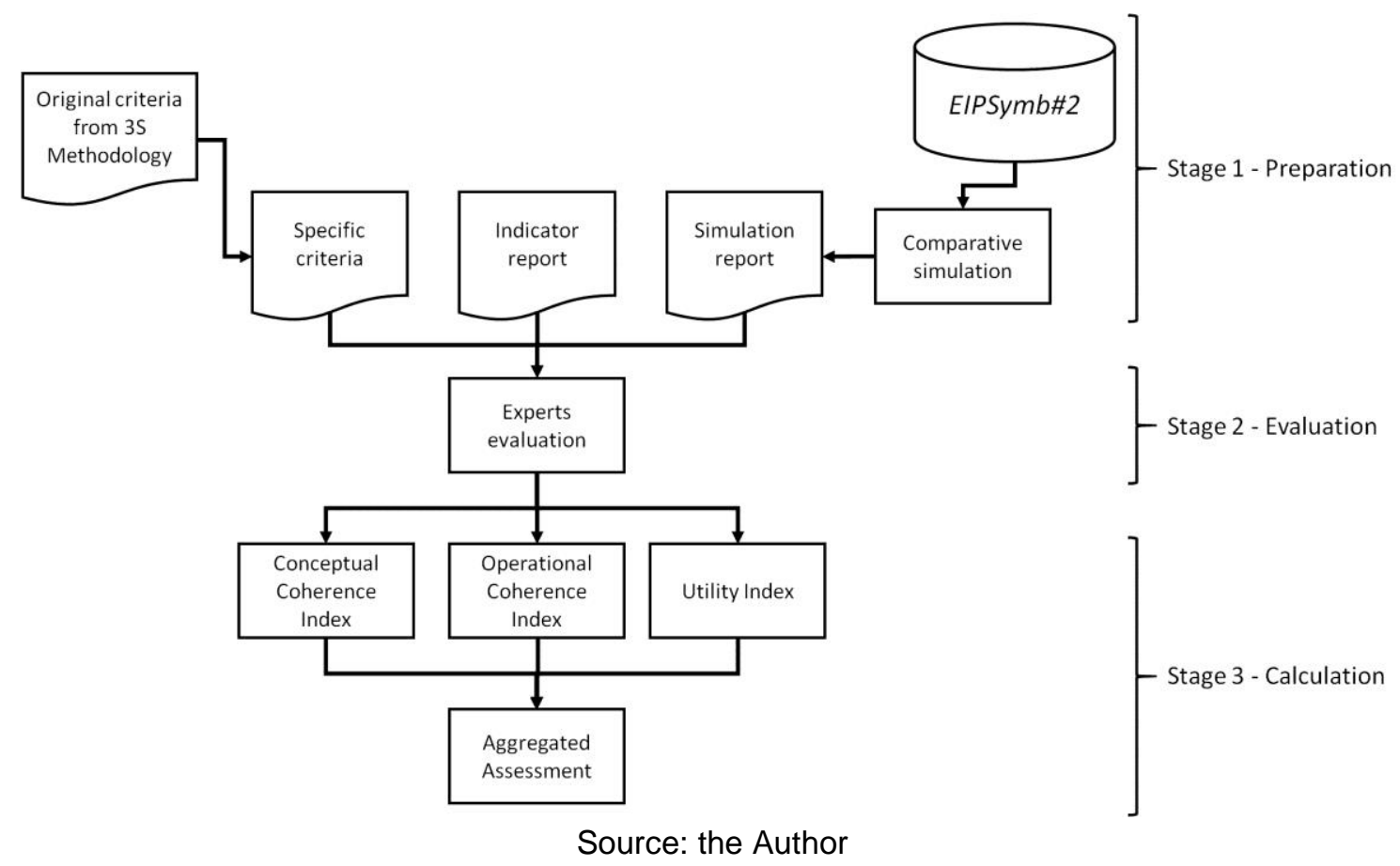

The Framework is divided into 3 stages: Preparation; Evaluation; Calculation.

\subsubsection{Stage 1 - Preparation}

The first stage is devoted to the preparation of the documents that will provide information for the experts, so they can validate the indicator.

\subsubsection{Stage 2 - Evaluation}

In the Evaluation stage the experts evaluate the indicator according to the specific criteria and based on the conceptual information about the indicator, present in the Indicator report, and on the simulation information, available in the Simulation report. This stage is very similar to 35 Methodology. Each criterion must be answered by each expert through a Likert scale of 5 levels: 
- 1: Totally disagree;

- 2: Disagree;

- 3: Neither disagree nor agree;

- 4: Agree;

- 5: Totally agree.

Before moving on to the next stage, the final grade for each criterion is calculated by the average of each expert grade. At this time, the standard deviation of the answers is also calculated to verify if there was no divergence. Here it is followed the suggestion of Cloquell-Ballester et al. (2006) for the standard deviation of the answers, where they consider that if the standard deviation is greater than 1 , then the experts answers diverge, and then the Delphi technique must be used until the answers are convergent, that is, that they have standard deviation less than 1.

\subsubsection{Stage 3 - Calculation}

After ensuring the convergence of the experts answers, the grades of the three indexes in which the criteria are divided are calculated. For this purpose it is used the weighted average of the final grade of each criterion. For the definition of the criteria weights, the Analytic Hierarchy Process is suggested.

With regard to who should assign weights to the criteria, through the first stage of this research (Application of the 3S Methodology using the specific criteria) it was verified that this work should not be in charge of the experts responsible for the indicator validation, as this would result in additional rework to reach a consensus. The suggestion is that the weights should be assigned by the indicator user. A good example is when it is being evaluated an indicator to be used in an EIP, in this case the administrator of the park may be responsible for the weights assignment, since he knows the main characteristics of the industrial symbiosis he wants to measure.

The grades of the three indexes are aggregated in the final grade of the indicator, called Aggregated Assessment. Cloquell-Ballester et al. (2006) suggested the use of the Electre $T R I$ technique for the calculation of this final grade. It can also be used the average of the three indexes.

Finally, a validation threshold, as suggested by Cloquell-Ballester et al. (2006), is not defined. The Framework provides valuable information for the interested in the validation decide whether the indicator is able to measure the phenomenon it is 
proposed to measure, that is, the industrial symbiosis, and which of the existing indicators is most appropriate for its situation. 


\section{DISCUSSION}

\subsection{Industrial Symbiosis Indicator validation}

The research allowed the evaluation of the Industrial Symbiosis Indicator. According to the results, the indicator was considered in the second level, requiring a brief review. However, more than the final grade, the grades of each criterion can inform a lot about the indicator. Thus the grades were separate into three groups: (i) high grades, corresponding to the indicator strengths; (ii) low grades, referring to the indicator weaknesses; (iii) medium grades. Table 7 presents the first group, the criteria that obtained high grades.

Table 7 - Criteria with high grades

\begin{tabular}{|c|c|c|}
\hline Class & Criteria & Grade \\
\hline \multirow{2}{*}{$\begin{array}{l}\text { Conceptual } \\
\text { coherence }\end{array}$} & $\begin{array}{l}\text { 1. The indicator is able to measure the exchange of by-products } \\
\text { among the companies in the Eco-Industrial Park }\end{array}$ & 4.75 \\
\hline & $\begin{array}{l}\text { 4. The indicator considers amounts of by-products generated by the } \\
\text { companies that are reused as raw material by other companies in } \\
\text { the Eco-Industrial Park. In a direct way }\end{array}$ & 4.5 \\
\hline \multirow{3}{*}{$\begin{array}{l}\text { Operational } \\
\text { coherence }\end{array}$} & $\begin{array}{l}\text { 1. The mathematical formulation is suitable for measuring industrial } \\
\text { symbiosis, taking into account the aspects that must be quantified }\end{array}$ & 4.5 \\
\hline & $\begin{array}{l}\text { 6. The numerical result obtained through the calculation of the } \\
\text { indicator has no limit, meaning that the Industrial Symbiosis can } \\
\text { always be improved }\end{array}$ & 4.25 \\
\hline & $\begin{array}{l}\text { 7. The indicator allows the comparison of the level of the Industrial } \\
\text { Symbiosis with other Eco-Industrial Parks }\end{array}$ & 4.5 \\
\hline \multirow{3}{*}{ Utility } & 4. The indicator can support decision & 4.5 \\
\hline & $\begin{array}{l}\text { 5. It is acceptable the need of human resources for obtain data and } \\
\text { calculate the indicator }\end{array}$ & 4.75 \\
\hline & $\begin{array}{l}\text { 7. It is acceptable the need of knowledge acquisition for obtain data } \\
\text { and calculate the indicator }\end{array}$ & 4.75 \\
\hline
\end{tabular}

Source: the Author

According to the evaluation, the Industrial Symbiosis Indicator has several qualities, divided into the three different classes. Some of these qualities are very important for a performance indicator in general, such as: it is able to support the decision; it has the mathematical formulation suitable for measuring the phenomenon to which it is proposed to measure; and it allows comparison. Other qualities are more important specifically for an industrial symbiosis indicator: it can measure by- 
product exchanges among the park companies; and it does not have a limit on its numerical value.

Table 8 presents the criteria that obtained the lowest grades.

Table 8 - Criteria with low grades

\begin{tabular}{lll}
\hline Class & Criteria & Grade \\
\hline $\begin{array}{l}\text { Conceptual } \\
\text { coherence }\end{array}$ & $\begin{array}{l}\text { 2. The indicator is able to measure the exchange of water and } \\
\text { energy among the companies in the Eco-Industrial Park }\end{array}$ & 3 \\
\hline & $\begin{array}{l}\text { 2. The calculation of the indicator does not take into account data } \\
\text { that are not relevant to measure the Industrial Symbiosis }\end{array}$ & 3 \\
\cline { 2 - 3 } $\begin{array}{l}\text { Operational } \\
\text { coherence }\end{array}$ & $\begin{array}{l}\text { 3. All the data needed for measuring the Industrial Symbiosis are } \\
\text { being considered in the calculation of the indicator }\end{array}$ & 2 \\
\cline { 2 - 3 } & $\begin{array}{l}\text { 5. The indicator is able to indicate trends regarding the evolution of } \\
\text { the Industrial Symbiosis in the Eco-Industrial Park }\end{array}$ & 3 \\
\hline Utility & $\begin{array}{l}\text { 3. The data considered in the calculation of the indicator are } \\
\text { provided by sources that are easy to access }\end{array}$ & 2.75 \\
\hline
\end{tabular}

Source: the Author

Similarly, according to the experts, the Industrial Symbiosis Indicator has some weaknesses, also in the three classes. As, for example: data sources are not so easy to access; it considers data that is not so relevant for the industrial symbiosis measurement; and, mainly, it does not consider all the necessary data for the industrial symbiosis measurement.

Table 9 presents the criteria classified with intermediate grades.

Table 9 - Criteria with medium grades

Criteria

Grade

3. The indicator evaluates the different by-products generated according to their potential of environmental impact

4

Conceptual coherence

5 . The indicator considers amounts of by-products generated by the companies that are not shared with other companies in the EcoIndustrial Park, being discarded

Operational

4. The measurement procedures for obtaining the data related to coherence the Industrial Symbiosis are adequate, allowing the reproduction and 4 comparison of the indicator

1. The indicator calculation and its procedures are easy to be performed and do not require excessive effort

4

2. The data considered in the calculation of the indicator are

Utility provided by reliable sources

6. It is acceptable the need of utilization and acquisition of equipment for obtain data and calculate the indicator

8. The indicator presents an excellent cost-benefit ratio 
The criteria presented in Table 9 are qualities that the indicator has, but that are not their core strengths. Among these qualities there is the Conceptual coherence criterion: "The indicator evaluates the different by-products generated according to their potential of environmental impact", which, according to its authors (FELICIO et al., 2016), is one of the differences in relation to the other indicators. There are important criteria for a good indicator, such as: it has adequate procedures to obtain data in order to enable its reproduction; and it has an acceptable costbenefit ratio. It also has important criteria for an industrial symbiosis indicator: it considers the amount of by-products that are being discarded.

Finally, the value of each index (Conceptual coherence, Operational coherence, and Utility) and the Aggregated Assessment, presented in Table 3, are presented. The values of the indexes show in which aspect the indicator was better evaluated. In the case of this evaluation, the values of the three indexes were close, indicating a balance in the Industrial Symbiosis Indicator.

In the Aggregated Assessment the indicator was classified as requiring a brief review. At this point, the 35 Methodology can be criticized. It seems important that, at the end of an indicator validation methodology, it be informed if the indicator is validated or not, but the threshold proposed in the 35 Methodology seems to be chosen arbitrarily. Several other ways of reporting whether the indicator is validated or not can be proposed, such as, for example, considering the indicator validated if its Aggregated Assessment is greater than 4 while no criterion has a grade less than 2. Or just a qualitative verdict, as, for example, the end user considers, after the evaluation of the criteria, that the indicator is able to measure the phenomenon to which it is proposed to measure.

\subsection{Application of the 3S Methodology using the specific criteria}

In a first moment, the criteria needed to be updated and improved, so it was conducted the assisted application. The changes were made mainly to improve the understanding of the experts when they are using the criteria in the evaluation of some industrial symbiosis indicator. During the application of the 35 Methodology another problem was identified and a small change in the criteria was made; one Conceptual coherence criterion was separated into two. Although there were some 
changes, they were not structural changes, but about the presentation of the criteria. Table 6 presents the final set of criteria after all changes.

It was necessary to conduct two rounds for experts to come to a consensus. A rework, but that was not considered an excessive effort, because only 7 criteria, among the 20 applied, needed to be answered again due to its high standard deviation.

The experts did not have considerable problems to answer the validation questionnaire. However, because it is a new type of indicators that are not yet widespread and little is known about them, the more information available to the experts, the better. Therefore, information about the indicator behavior through simulations was also inserted in the CE-3S Framework proposition.

Analyzing the amount of information and conclusions that could be drawn with the numerical result of each criterion, it can be concluded that this type of evaluation with the specific criteria is very useful and it is not difficult to be carried out. The main problem was the low adherence of experts to participate in the evaluation, but this could be overcome.

\subsection{Framework for the validation of industrial symbiosis indicators}

The CE-3S Framework is no longer just an idea, as the procedure proposed in Mantese et al. (2016), since the tools necessary for its application are all developed and more, have been successfully applied. The specific criteria for industrial symbiosis indicators were applied and its usefulness was verified. The simulation model was first proposed in Mantese and Amaral (2017) and now it is in its second version, the EIPSymb\#2 proposed by Mantese and Amaral (2018).

One of the main strengths of the Framework is that the criteria are specific to industrial symbiosis indicators, verifying if the indicator is suitable for both performance indicators in general and industrial symbiosis theories. Another strength that must be emphasized is the use of simulations to provide different types of information to the experts.

As a limitation, since it is a Framework for the validation of indicators, it is expected that at the end of its application it will be possible to inform if the indicator has been validated or not. However, a validation threshold, as defined in $3 S$ Methodology by Cloquell-Ballester et al. (2006), is not proposed, because this would 
be done in an arbitrary way. The solution was to leave it in charge of the interested in the validation to decide if the indicator is able to measure the industrial symbiosis. 


\section{CONCLUSIONS}

The CE-3S Framework combines aspects of conceptual validation and empirical validation to assign greater reliability to industrial symbiosis indicators, so they can be used in real cases. It emerges as a tool able to inform a lot about the qualities and weaknesses of the industrial symbiosis indicators; it is also possible to use the information generated to make improvements in the indicators. It can be used both by researchers who have proposed an industrial symbiosis indicator and are interested in validating it, and by those interested in using an indicator and want to select the best option. Furthermore, it is also capable of directing the development of new industrial symbiosis indicators.

Regarding the Industrial Symbiosis Indicator, more qualities than weaknesses have been identified, however these weaknesses cannot be neglected, they should be understood as limitations of the indicator. On the other hand, industrial symbiosis is a complex phenomenon, which considers a considerable amount of variables and diverse data sources, therefore it is difficult to measure; and measuring using just one performance indicator can be even more challenging. Considering the large number of industrial symbiosis indicators that exist, a good alternative is to combine indicators that have different characteristics in the process of performance measurement. 
This is the final chapter of the thesis, which presents a synthesis of the results achieved through the four published papers (Chapter II to Chapter V) and the unpublished results (Chapter VI), relating then with the research objectives (Chapter I). It also presents the final conclusions on the work. 


\section{SYNTHESIS OF RESULTS}

The results of the research are described in the papers (from Chapter II to Chapter V) and in the unpublished results available in Chapter VI. Figure 1 illustrates the relationship between these results, demonstrating that they report, together, a coherent research path. The parties are integrated, so they can answer to the research problems presented.

Figure 1 - Research results and their relationships

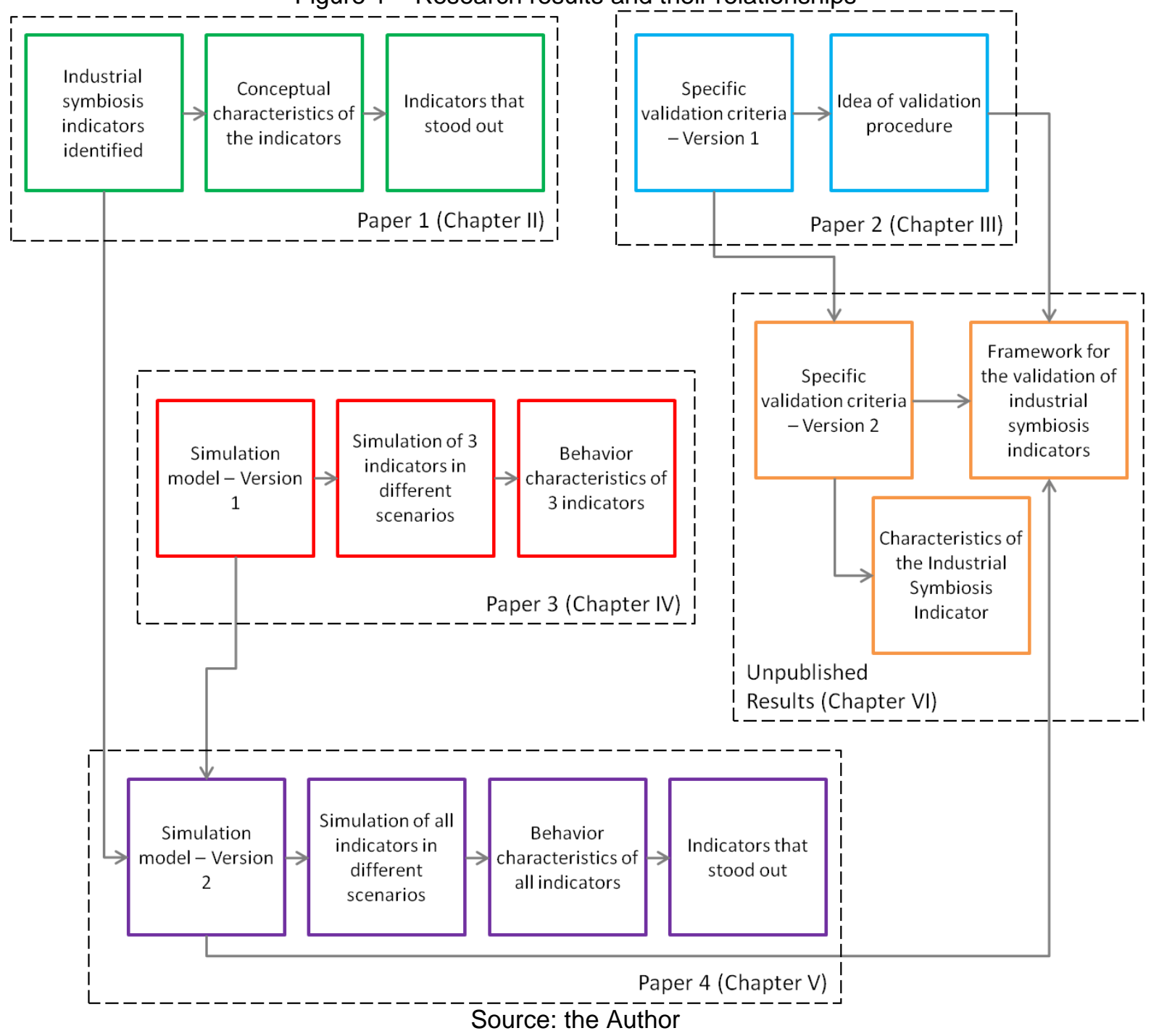

The arrows in Figure 1 mean that the content at the beginning of the arrow served as a basement for the content generated at the arrowhead. An example is the result "Simulation Model - Version 2", which was only possible to be achieved due to the development of the first version of the model and the identification of the industrial symbiosis indicators. 
Also from Figure 1, it can be seen that, although the papers are individual documents, they converge in a way that contributes to the achievement of the specific objectives and especially the central objective of the research, the framework developed and that synthesizes the contributions. 


\section{FINAL CONCLUSIONS}

Specific discussions and conclusions about the results of each paper and about the unpublished results have been provided in their respective chapters. This final section presents final conclusions about the contributions achieved in the research program and possible ways for the continuation of research with the results and conclusions presented here.

The main contributions are (i) the specific validation criteria for industrial symbiosis indicators; (ii) the simulation model for benchmarking of industrial symbiosis indicators; (iii) and the framework for the validation of industrial symbiosis indicators.

The specific criteria were applied in the validation of the Industrial Symbiosis Indicator, demonstrating its usefulness and reliability. The criteria verify important aspects for performance indicators in general and important aspects for the specific measurement of industrial symbiosis. The Industrial Symbiosis Indicator was well evaluated and it was possible to identify its positive characteristics and some of its weaknesses, concluding that the Industrial Symbiosis Indicator is a good tool for measuring and monitoring the industrial symbiosis in industrial parks.

The simulation model was successfully applied in the simulation and comparison of all the industrial symbiosis indicators identified. The results confirm that the use of $A B M$ is appropriate for the simulation of symbiotic relationships in EIPs, since it is a technique simple to be applied, that allows the creation of diverse scenarios and can reproduce the behavior of the indicators in each period. Regarding the industrial symbiosis indicators, it was possible to identify patterns of behavior and separate them into three groups: (i) Amount of reused by-products indicators; (ii) Percentage of reused by-products indicators; (iii) Link indicators. The Industrial Symbiosis Indicator presented an interesting behavior in these simulations, it was classified into different groups depending on the scenario calibrated, demonstrating flexibility. However, it was not possible to identify a single indicator better than the others; so it is suggested the combined use of the Industrial Symbiosis Indicator with the Eco-efficiency, of Park and Behera (2014), and with the Connectance (or Ecoconnectance), proposed in Hardy and Graedel (2002) and in Tiejun (2010).

The previous elements, specific criteria and simulation model, were combined in a framework for the validation of industrial symbiosis indicators that combines 
aspects of conceptual validation and empirical validation in order to provide diverse information to the experts responsible for the validation. The framework can be used both by those who wish to use an industrial symbiosis indicator and want to select the best option, as well as by who proposed an indicator and wish to analyze its validity. In addition, it can be used as a tool to assist in the development of new indicators.

As a limitation, the framework was not completely applied in a real case, but is basically composed of the specific validation criteria and the simulation model that were applied, respectively, in the validation of the Industrial Symbiosis Indicator and in the simulation of all the indicators identified. Despite the limitation, the research was able to deep investigate the area of validation of industrial symbiosis indicators, being until now the only research on this specific topic.

Finally, there is still work that should be done for the development of this area and of this type of indicator. The main outspreads that this research may have are:

- Use of the indicators in cases of real EIPs. In this case, the results and conclusions presented in this research can contribute to guiding the choice of which indicators to apply in a real case. This option can contribute even more to instigate managers of EIPs to use this type of tool to monitor and control industrial symbiosis.

- Apply the framework for the validation of industrial symbiosis indicators. In this case, the proposed framework would be used for the validation of the industrial symbiosis indicators that were identified here and also the indicators not present in this work. If the indicator to be validated is not present in this research, it would be necessary to enter its calculation in EIPSymb\#2 to proceed with the simulation, then select and contact experts to answer the questionnaire composed of the specific validation criteria proposed in this research. This option could contribute to unravel even more the industrial symbiosis indicators.

- Use the simulation model as a platform for decision support in EIPs. In this case, the simulation model proposed in this research, the EIPSymb\#2, would be used as an instrument to support EIP managers in making decisions regarding industrial symbiosis, as, for example, how to promote the development of industrial symbiosis through financial incentives. For this 
option it would be necessary to promote significant developments in the simulation model so that it can consider behavioral aspects of the companies. 


\section{REFERENCES}

This chapter presents the bibliographical references of the whole thesis, that is, of all previous chapters. Another possibility would be to insert a reference section in each of the chapters, which would make the sections repetitive, since the chapters share a considerable amount of references in common. 
AGARWAL, A.; STRACHAN, P. Literature review on eco-industrial development initiatives around the world and the methods employed to evaluate their performance/effectiveness. Consultancy Report prepared for Databuild Ltd. and National Industrial Symbiosis Programme, 2006.

ANEEL. Fatores de Conversão. 2017 Available at: <http://www2.aneel.gov.br/arquivos/pdf/atlas_fatoresdeconversao_indice.pdf>. Accessed on: 15 Aug. 2017.

AVELINE, A.; ROUSSEAU, M. L.; GUICHARD, L.; LAURENT, M.; BOCKSTALLER, C. Evaluating an environmental indicator: Case study of MERLIN, a method for assessing the risk of nitrate leaching. Agricultural Systems, v. 100, n. 1, p. 22-30, 2009.

BAIN, A.; SHENOY, M.; ASHTON, W.; CHERTOW, M. Industrial symbiosis and waste recovery in an Indian industrial area. Resources, Conservation and Recycling, v. 54, n. 12, p. 1278-1287, 2010.

BICHRAOUI, N.; GUILLAUME, B.; HALOG, A. Agent-based modelling simulation for the development of an industrial symbiosis-preliminary results. Procedia Environmental Sciences, v. 17, p. 195-204, 2013.

BOCKSTALLER, C.; GIRARDIN, P. How to validate environmental indicators. Agricultural systems, v. 76, n. 2, p. 639-653, 2003.

BOCKSTALLER, C.; GUICHARD, L.; KEICHINGER, O.; GIRARDIN, P.; GALAN, M. B.; GAILLARD, G. Comparison of methods to assess the sustainability of agricultural systems: a review. In: Sustainable Agriculture. Springer Netherlands, p. 769-784, 2009.

BONAT, D. Metodologia da pesquisa. IESDE BRASIL SA, 2009.

CAMBRIDGE DICTIONARY. By-product. $2017 . \quad$ Available at: <http://dictionary.cambridge.org/dictionary/english/by-product>. Accessed on: 15 Aug. 2017.

CHERTOW, M. R. "Uncovering" industrial symbiosis. Journal of Industrial Ecology, v. 11, n. 1, p. 11-30, 2007.

CHERTOW, M. R. Industrial symbiosis: literature and taxonomy. Annual review of energy and the environment, v. 25, n. 1, p. 313-337, 2000.

CHERTOW, M. R. The eco-industrial park model reconsidered. Journal of Industrial Ecology, v. 2, n. 3, p. 8-10, 1998.

CHERTOW, M.; EHRENFELD, J. Organizing Self-Organizing Systems. Journal of Industrial Ecology, v. 16, n. 1, p. 13-27, 2012.

CHERTOW, M.R.; ASHTON, W.; ESPINOSA, J.C. Industrial symbiosis in Puerto Rico: environmentally e related agglomeration economies. Regional Studies, v. 42, n. 10, p. 1299-1312, 2008.

CLOQUELL-BALLESTER, V-A.; CLOQUELL-BALLESTER, V-A.; MONTERDE-DÍAZ, R. SANTAMARINA-SIRUANA, M-C. Indicators validation for the improvement of environmental and social impact quantitative assessment. Environmental Impact Assessment Review, v. 26, n. 1, p. 79-105, 2006.

CONFORTO, E. C.; AMARAL, D. C.; SILVA, S. L. D. Roteiro para revisão bibliográfica sistemática: aplicação no desenvolvimento de produtos e gerenciamento de projetos. In: Anais do 8 Congresso Brasileiro de Gestão de Desenvolvimento de Produto-CBGDP, Porto Alegre, RS. 2011.

DAI, T. Two quantitative indices for the planning and evaluation of eco-industrial parks. Resources, Conservation and Recycling, v. 54, n. 7, p. 442-448, 2010. 
DALFOVO, M. S.; LANA, R. A.; SILVEIRA, A. Métodos quantitativos e qualitativos: um resgate teórico. Revista Interdisciplinar Científica Aplicada, v. 2, n. 3, p. 1-13, 2008.

EHRENFELD, J. R.; CHERTOW, M. R. Industrial symbiosis: the legacy of Kalundborg. A handbook of industrial ecology, p. 334, 2002.

FELICIO M., AMARAL D., ESPOSTO K., DURANY X. G., Industrial symbiosis indicators to manage eco-industrial parks as dynamic systems. Journal of Cleaner Production, v. 118, p. 54-64, 2016.

FONSECA, J. J. S. Metodologia da pesquisa científica. Apostila, Fortaleza: UEC, 2002.

FRANCESCHINI, F.; GALETTO, M.; MAISANO, D. Classification of performance and quality indicators in manufacturing. International Journal of Services and Operations Management, v. 2 n. 3, p. 294-311, 2006.

GAO, X. L.; LI, R. Q.; LI, R. Study on Byproducts Recycling in Eco-Industrial Parks. Advanced Materials Research, v. 788, p. 288-292, 2013.

GENG, Y.; LIU, Z.; XUE, B.; DONG, H.; FUJITA, T.; CHIU, A. Emergy-based assessment on industrial symbiosis: a case of Shenyang Economic and Technological Development Zone. Environmental Science and Pollution Research, v. 21, n. 23, p. 13572-13587, 2014.

GERHARDT, T. E.; SILVEIRA, D. T. Métodos de pesquisa. Plageder, 2009.

GHALI, M. R.; FRAYRET, J.-M.; AHABCHANE, C. Agent-based model of self-organized industrial symbiosis. Journal of Cleaner Production, v. 161, p. 452-465, 2017.

GILBERT, N. Agent-based models. Sage, 2008.

GRIMM, .V; BERGER, U.; DEANGELIS, D. L.; POLHILL, J. G.; GISKE, J.; RAILSBACK, S. F. The ODD protocol: a review and first update. Ecological modelling, v. 221, n. 23, p. 2760-2768, 2010.

GRIMM, V.; BERGER, U.; BASTIANSEN, F.; ELIASSEN, S.; GINOT, V.; GISKE, J.; GOSSCUSTARD, J.; GRAND, T.; HEINZ, S. K.; HUSE, G.; HUTH, A.; JEPSEN, J. U.; JØRGENSEN, C.; MOOIJ, W. M.; MÜLLER, B.; PE'ER, G.; PIOU, C.; RAILSBACK, S. F.; ROBBINS, A. M.; ROBBINS, M. M.; ROSSMANITH, E.; RÜGER, N.; STRAND, E.; SOUISSI, S.; STILLMAN, R. A.; VABØ, R.; VISSER, U.; DEANGELIS, D. L. A standard protocol for describing individual-based and agent-based models. Ecological modelling, v. 198, n. 1, p. 115-126, 2006.

GRIMM, V.; RAILSBACK, S. F. Individual-based modeling and ecology. Princeton university press, 2013.

HAK, T.; KOVANDA, J.; WEINZETTEL, J. A method to assess the relevance of sustainability indicators: Application to the indicator set of the Czech Republic's Sustainable Development Strategy. Ecological Indicators, v. 17, p. 46-57, 2012.

HAMMOND, G.; JONES, C. Inventory of carbon \& energy Version 2.0 (ICE V2. 0). Department of Mechanical Engineering, University of Bath, Bath, UK, 2011.

HARDY, C.; GRAEDEL, T. E. Industrial ecosystems as food webs. Journal of Industrial Ecology, v. 6, n. 1, p. 29-38, 2002.

INDIGO DEVELOPMENT. Eco-industrial parks (EIP). 2006. Available at: <http://www.indigodev.com/Ecoparks.html>. Accessed on: 24 Oct. 2014.

JACOBSEN, N. B. Industrial symbiosis in Kalundborg, Denmark: a quantitative assessment of economic and environmental aspects. Journal of industrial ecology, v. 10, n. 1-2, p. 239-255, 2006. 
KURTZ, J. C.; JACKSON, L. E.; FISHER, W. S. Strategies for evaluating indicators based on guidelines from the Environmental Protection Agency's Office of Research and Development. Ecological indicators, v. 1, n. 1, p. 49-60, 2001.

LEAL, F. Um diagnóstico do processo de atendimento a clientes em uma agência bancária através de mapeamento do processo e simulação computacional. Dissertação (Mestrado em Eng. de Produção) Programa de Pós-Graduação em Engenharia de Produção, Universidade Federal de Itajubá, Itajubá: UNIFEI, 2003.

LOMBARDI, D. R.; LAYBOURN, P. Redefining industrial symbiosis. Journal of Industrial Ecology, v. 16, n. 1, p. 28-37, 2012.

LOWE, E. A. Eco-industrial park handbook for Asian developing countries. A Report to Asian Development Bank, Environment Department, Indigo Development, Oakland, CA, 2001.

MANTESE, G. C.; AMARAL, D. C. Agent-based simulation to evaluate and categorize industrial symbiosis indicators. Journal of Cleaner Production, v. 186 p. 450-464, 2018.

MANTESE, G. C.; AMARAL, D. C. Comparison of industrial symbiosis indicators through agent-based modeling. Journal of Cleaner Production, v. 140, p. 1652-1671, 2017.

MANTESE, G. C.; AMARAL, D. C. Identification and qualitative comparison of performance indicators of industrial symbiosis. Revista Produção Online, v. 16, n. 4, p. 1329-1348, 2016.

MANTESE, G. C.; DE PIERE, B. A.; AMARAL, D. C. A Procedure to Validate Industrial Symbiosis Indicators Combining Conceptual and Empirical Validation Methods. In: ISPE TE, p. 166-175, 2016.

MARCONI, M. de A.; LAKATOS, E. Maria. Fundamentos de metodologia científica. 5. ed.-São Paulo: Atlas, 2003.

MEUL, M.; NEVENS, F.; REHEUL, D. Validating sustainability indicators: focus on ecological aspects of Flemish dairy farms. Ecological indicators, v. 9, n. 2, p. 284-295, 2009.

MODELING COMMONS. NetLogo Modeling Commons. 2016. Available at: $<$ http://modelingcommons.org>. Accessed on: 07 Oct. 2016.

MOREIRA, C. M. Estratégias de Reposição de Estoques em Supermercados: Avaliação por meio de simulação. Dissertação (Mestrado em Eng. Produção) Programa de Pós-Graduação em Engenharia de Produção, Universidade Federal de Santa Catarina, Florianópolis, SC, 2001.

MOUSSEAU, V.; SLOWINSKI, R.; ZIELNIEWICZ, P. ELECTRE TRI 2.0a. Methodological Guide and user's Manual. LAMSADE, Paris: Université de Paris-Dauphine. 1999.

NEELY, A. D.; GREGORY; M.; PLATTS, K. Performance measurement systems design: a literature review and research agenda. International Journal of Operations \& Production Management, v. 15 n. 4, p. 80-116. 1995.

NEELY, A. D.; RICHARDS, A. H.; MILLS, J. F.; PLATTS, K. W.; BOURNE, M. C. S. Designing performance measures: a structured approach. International journal of operations \& Production management, v. 17, n. 11, p. 1131-1152, 1997.

NETLOGO. NetLogo User Manual: Version 5.2. 2015. Available at: $<$ https://ccl.northwestern.edu/netlogo/docs>. Accessed on: 08 Apr. 2015.

NETLOGO. NetLogo User Manual: version 5.2. 2016. Available at: <http://ccl.northwestern.edu/netlogo/index.shtml>. Accessed on: 20.04.2016.

NETLOGO. NetLogo User Manual: version 6.0.2. 2017. Available at: $<$ https://ccl.northwestern.edu/netlogo/docs/>. Accessed on: 22 Dec. 2017. 
PAGE, S. E. Agent Based Models. The New Palgrave Dictionary of Economics. Palgrave MacMillan, New York. 2005

PARK, H. S. BEHERA, S. K. Methodological aspects of applying eco-efficiency indicators to industrial symbiosis networks. Journal of Cleaner Production, v. 64, p. 478-485, 2014.

RAILSBACK, S. F.; GRIMM, V. Agent-based and individual-based modeling: a practical introduction. Princeton university press, 2011.

RAMOS, T. B.; CAEIRO, S. Meta-performance evaluation of sustainability indicators. Ecological Indicators, v. 10, n. 2, p. 157-166, 2010.

RIGBY, D., WOODHOUSE, P., YOUNG, T., BURTON, M. Constructing a farm level indicator of sustainable agricultural practice. Ecological Economics, v. 39, n. 3, p. 463-478, 2001.

RODRIGUES, A. M.; ZEVIANI, C. H.; REBELATO, M. C.; BORGES, L. Avaliação de desempenho ambiental industrial: elaboração de um referencial metodológico. Revista Produção Online, v. 15, n. 1, p. 101-134, 2015.

ROLLANO, C. R. L.; DE OLIVEIRA FONTES, C. H.; BARBOSA, A. S. Análise da evolução do desenvolvimento sustentável nas indústrias produtoras de biocombustíveis no Brasil. Revista Produção Online, v. 15, n. 2, p. 696-733, 2015.

ROMERO, E.; RUIZ, M. C. Proposal of an agent-based analytical model to convert industrial areas in industrial eco-systems. Science of the Total Environment, v. 468, p. 394-405, 2014.

SOKKA, L.; MELANEN, M.; NISSINEN, A. How can de sustainability of industrial symbioses be measured?. Progress in Industrial Ecology - An International Journal, v. 5, n. 5/6, p. 518-535. 2008. p. 518.

STRACK, J. GPSS: modelagem e simulação de sistemas. Rio de Janeiro: LTC, 1984.

TACHIZAWA, T. Sustentabilidade e responsabilidade social: proposta de modelo de diagnóstico socioambiental baseada em pesquisa empírica. Revista Produção Online, v. 9, n. 4, p. 795-821, 2009.

THOMSON REUTERS. Web of Science. 2015. Available at: <http://apps.webofknowledge.com/UA_GeneralSearch_input.do?product=UA\&search_mode=General Search\&SID=4BQI1LwNdHBiu1hUF9O\&preferencesSaved=>. Access on: 22 dec. 2015.

TIEJUN, D. Two quantitative indices for the planning and evaluation of eco-industrial parks. Resources, Conservation and Recycling, v. 54, n. 7, p. 442-448, 2010.

TROKANAS, N.; CECELJA, F.; RAAFAT, T. Semantic Approach for Pre-assessment of Environmental Indicators in Industrial Symbiosis. Journal of Cleaner Production, v. 96, p. 349-361, 2015.

VALENTINE, S. V. Kalundborg Symbiosis: Fostering progressive innovation in environmental networks. Journal of Cleaner Production, v. 118, p. 65-77, 2016.

VEIGA, L. B. E.; MAGRINI, A. Eco-industrial park development in Rio de Janeiro, Brazil: a tool for sustainable development. Journal of cleaner production, v. 17, n. 7, p. 653-661, 2009.

VIANNA, W. B.; GIFFHORN; E.; FERREIRA, N. A. de; PALADINI, E. P. Alinhamento Estratégico e Indicadores de Desempenho: Um Estudo para a Integração de Processos de Gestão da Qualidade. Revista Produção Online, v. 10, n. 1, 2010.

WANG, G.; FENG, X.; CHU, K. H. A novel approach for stability analysis of industrial symbiosis systems. Journal of Cleaner Production, v. 39, p. 9-16, 2013. 
WEN, Z.; MENG, X. Quantitative assessment of industrial symbiosis for the promotion of circular economy: a case study of the printed circuit boards industry in China's Suzhou New District. Journal of Cleaner Production, v. 90, p. 211-219, 2015.

WILENSKY, U.; RAND, W. An introduction to agent-based modeling: modeling natural, social, and engineered complex systems with NetLogo. MIT Press, 2015.

WU, W.; LI, L. J.; WEI, D. P. Analysis of the regional industrial symbiosis systems in developing countries. In: 13th International conference on industrial engineering and engineering management, p. 2674-2678, 2006.

ZHOU, L.; HU, S.; LI, Y.; JIN, Y.; ZHANG, X. Modeling and Optimization of a Coal-Chemical Ecoindustrial System in China. Journal of Industrial Ecology, v. 16, n. 1, p. 105-118, 2012. 